\title{
NEAR-FIELD EXPLOSION EFFECTS ON THE BEHAVIOUR OF REINFORCED CONCRETE COLUMNS: A NUMERICAL INVESTIGATION
}

\author{
A thesis submitted to \\ the Faculty of Graduate and Postdoctoral Affairs \\ in Partial Fulfillment of the requirements for the degree \\ Masters of Applied Science in Civil Engineering \\ by \\ Lawrence Abladey Abladey \\ Department of Civil and Environmental Engineering \\ Carleton University \\ Ottawa-Carleton Institute of Civil and Environmental Engineering \\ January, 2014 \\ C)2014 Lawrence Abladey Abladey
}




\begin{abstract}
Recent terrorist attacks and accidental explosions involving hazardous materials around the world have increased the need to study the behaviour of structures subjected to blast loadings. Most research work investigating the behaviour of reinforced concrete columns to blast loading have concentrated on their response to planar loading from far-field explosions. Limited amount of work is available on the effects of near-field explosion on the behaviour of reinforced concrete columns.

This thesis presents the results of a numerical study designed to investigate the effects of near-field explosions on the behaviour of reinforced concrete columns. The numerical investigation is a follow up on a project to a live explosion testing of reinforced concrete columns subjected to explosion from scaled distances ranging from 0.25 to $1.0 \mathrm{~m} / \mathrm{kg}^{1 / 3}$. The experimental results are used to validate the numerical models which are then used to conduct parametric studies to evaluate the effects of scaled distance, and concrete properties on the response of reinforced concrete columns.

The numerical analysis showed that for increasing charge masses, the natural period of vibration of reinforced concrete columns increased. Also the effects of tie spacing were markedly noticeable at lower scaled distances. Peak column deflections at higher scaled distances occurred mid-height while peak column deflections at lower scaled distances occurred closer to the column supports.
\end{abstract}




\section{Acknowledgements}

My biggest thanks go to my parents, who without their love and financial support I would not have made it this far. I would also like to thank my brother and sister who encouraged and pushed me to reach this high.

I also express my profound gratitude to my supervisor, Dr. Abass Braimah, for his guidance, patience and constructive criticism towards the completion of this thesis.

I am also grateful to Farouk Siba and George Antwi for their help in the laboratory. Special thanks go to Precious Appiah-Danquah who assisted me and encouraged me throughout the duration of this thesis.

I would also like to acknowledge Carleton University for the financial support, which allowed me to concentrate on my studies.

To everyone else who has been a part of this project, I say God bless you. 


\section{Table of Contents}

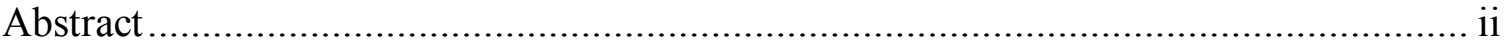

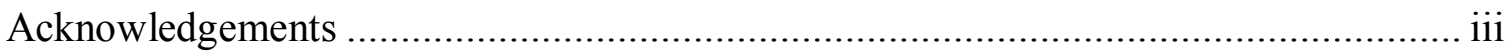

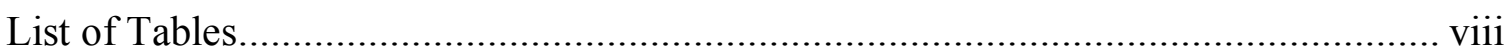

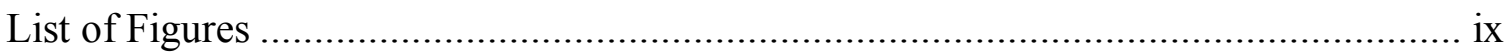

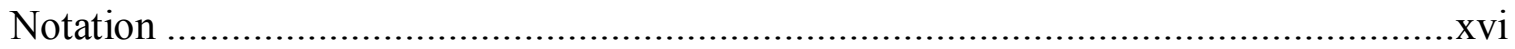

1 Chapter: Introduction .....................................................................

1.1 Background...............................................................................

1.2 Objectives of the Numerical Simulation ..............................................

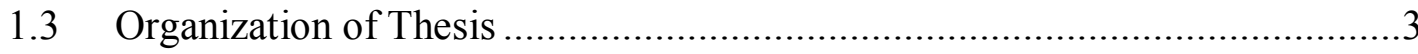

2 Chapter: Literature Review .........................................................................

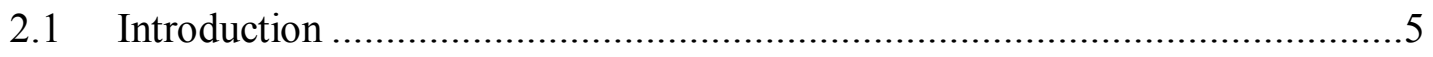

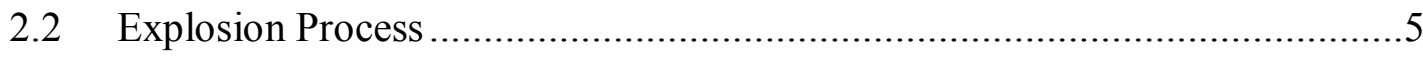

2.3 Blast wave pressure profiles .........................................................

2.4 Classification of Explosions ......................................................

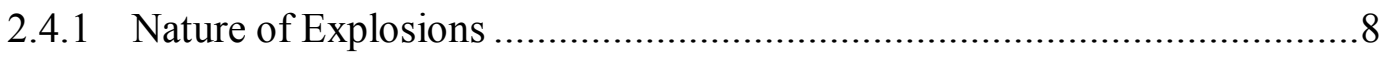

2.4.2 Planned and Accidental Explosions ............................................... 8

2.5 Blast Waves Scaling laws ................................................................ 9

2.6 Evolution of Numerical Modeling ............................................... 10

2.7 Review on Theoretical Bases of Hydrocodes...................................... 11 
2.7.2 Coupling of the Lagrange and Euler Solvers ........................................18

2.8 Review of Concrete Constitutive Models .................................................18

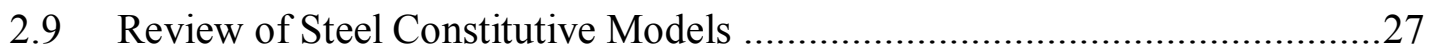

2.10 Effects of High Strain Loading on Concrete and Steel ...........................29

$2.10 .1 \quad$ Concrete

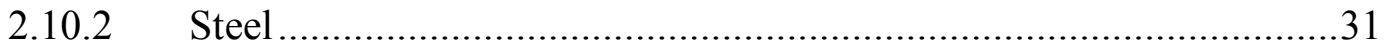

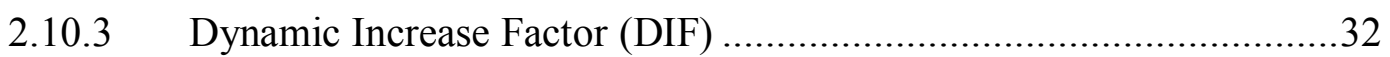

2.11 Review of Research on Blast Loading on RC Members ……...................36

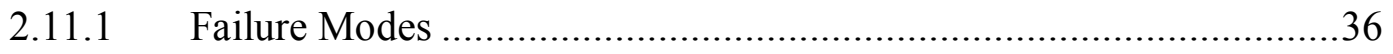

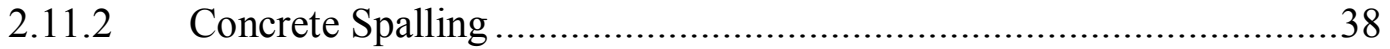

2.11.3 Numerical Simulation on Concrete Spalling …..................................39

2.11.4 Field Experiment on Concrete Spalling ………................................39

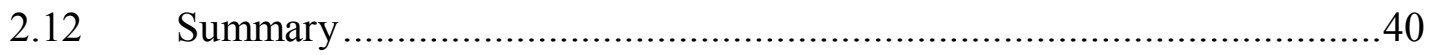

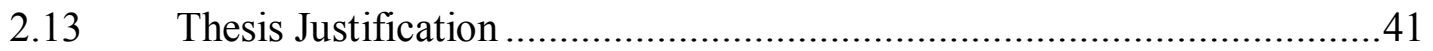

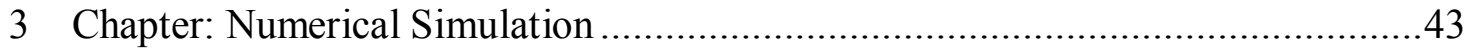

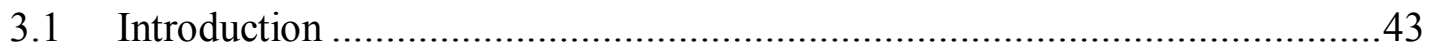

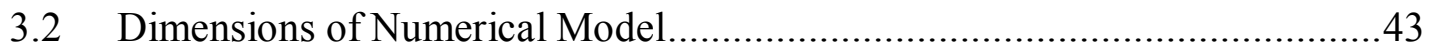

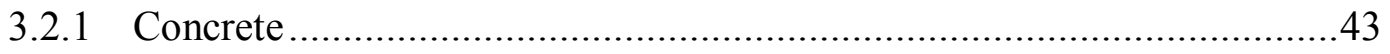

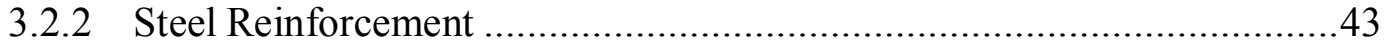


3.3.1 Concrete Constitutive Material Model ................................................46

3.3.2 Steel Constitutive Material Model ..................................................4

3.3.3 Parameters of the Air Model...........................................................48

3.4 Description of Modelling Process........................................................48

3.4.1 Modelling of Concrete ........................................................... 48

3.4.2 Modelling of Steel Reinforcement ...................................................49

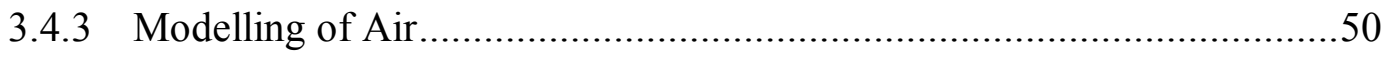

3.4.4 Modelling of ANFO Explosive ........................................................51

3.4.5 Mesh Sensitivity Analysis for 2D Numerical Model ............................55

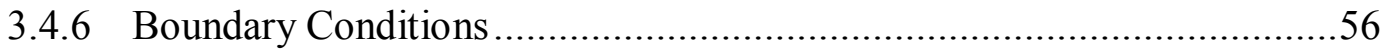

3.4.7 Interactions of Modelled Parts ........................................................58

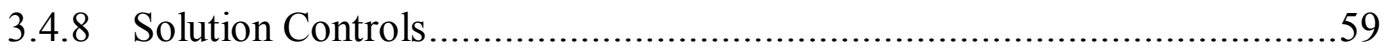

3.4.9 Output data acquisition using gauges .........................................59

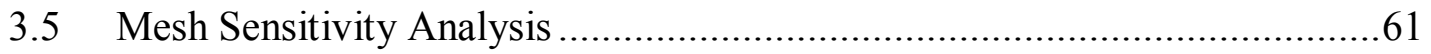

3.6 Effects of Boundary Distance on Column Response ...............................63

3.7 Effect of Tensile Strain Rate Exponent on Column Deflection ...................67

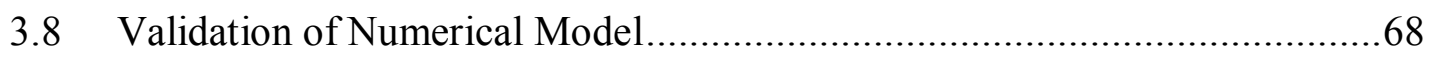

4 Chapter: Numerical Results and Discussions .............................................. 77

4.1 Effects of Charge Mass on the Deflection of RC Columns .........................77 
4.1.1 $\mathrm{Z}=0.6 \mathrm{~m} / \mathrm{kg}^{1 / 3}$

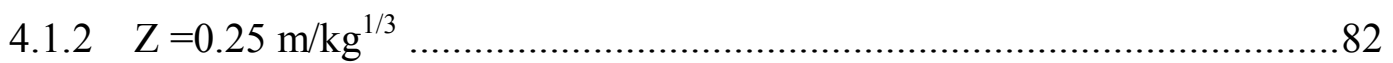

4.2 Comparing Deflections at Different Column Heights ...................................85

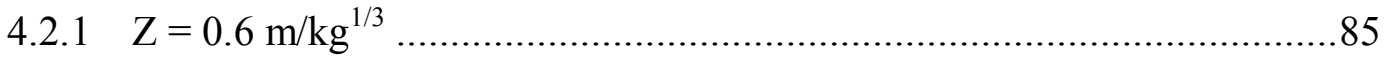

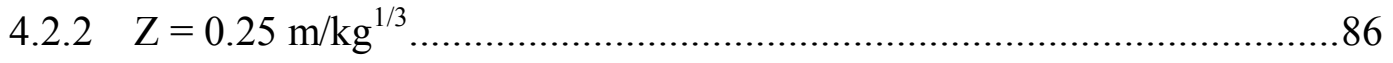

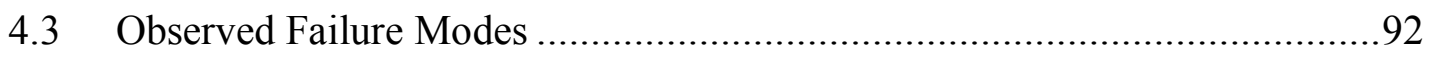

4.4 Effect of concrete compressive strength ……….......................................96

4.5 Strain Development in Reinforcing Bars ................................................99

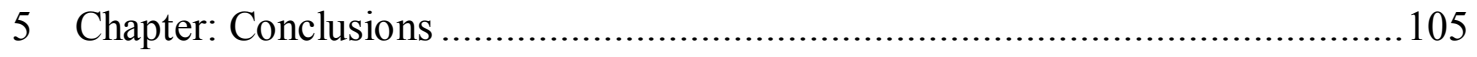

6 Chapter: Recommendation and Future Research ............................................... 106

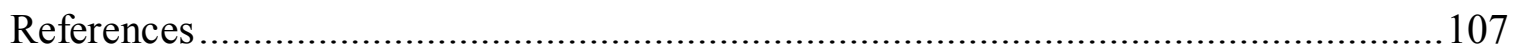




\section{List of Tables}

Table 3-1: RHT Model Parameters for 35-MPa Concrete.............................................46

Table 3-2: 4340 Steel Model Parameters of Steel Reinforcement .................................47

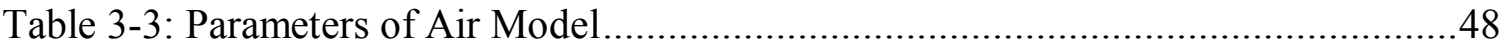

Table 3-4: charges masses with corresponding radii..................................................53

Table 3-5: Peak Incident Pressure values for different mesh sizes .................................56

Table 3-6: Mesh sensitivity analysis Summary .......................................................63

Table 4-1: Maximum Deflections $(\mathrm{mm})$ at $\mathrm{Z}=0.6 \mathrm{~m} / \mathrm{kg}^{1 / 3}$ for $75-\mathrm{mm}$ tie-spacing .........81

Table 4-2: Maximum Deflections $(\mathrm{mm})$ at $\mathrm{Z}=0.6 \mathrm{~m} / \mathrm{kg}^{1 / 3}$ for $150-\mathrm{mm}$ tie-spacing .......81

Table 4-3: Maximum Deflections $(\mathrm{mm})$ at $\mathrm{Z}=0.6 \mathrm{~m} / \mathrm{kg}^{1 / 3}$ for $300-\mathrm{mm}$ tie-spacing .......81

Table 4-4: Maximum Deflections $(\mathrm{mm})$ at $\mathrm{Z}=0.25 \mathrm{~m} / \mathrm{kg}^{1 / 3}$ for $75-\mathrm{mm}$ tie-spacing........84

Table 4-5: Maximum Deflections $(\mathrm{mm})$ at $\mathrm{Z}=0.25 \mathrm{~m} / \mathrm{kg}^{1 / 3}$ for $150-\mathrm{mm}$ tie-spacing......85

Table 4-6: Maximum Deflections ( $\mathrm{mm})$ at $\mathrm{Z}=0.25 \mathrm{~m} / \mathrm{kg}^{1 / 3}$ for 300 -mm tie-spacing......85

Table 4-7: Steel reinforcement strains on front face at $Z=0.6 \mathrm{~m} / \mathrm{kg}^{1 / 3}$ for $50 \mathrm{~kg} \ldots \ldots \ldots . .102$

Table 4-8: Steel reinforcement strains on back face at $Z=0.6 \mathrm{~m} / \mathrm{kg}^{1 / 3}$ for $50 \mathrm{~kg}$.......... 103

Table 4-9: Steel reinforcement strains on front face at $Z=0.25 \mathrm{~m} / \mathrm{kg}^{1 / 3}$ for $50 \mathrm{~kg} \ldots \ldots \ldots 103$

Table 4-10: Steel reinforcement strains on back face at $Z=0.25 \mathrm{~m} / \mathrm{kg}^{1 / 3}$ for $50 \mathrm{~kg}$.......104 


\section{List of Figures}

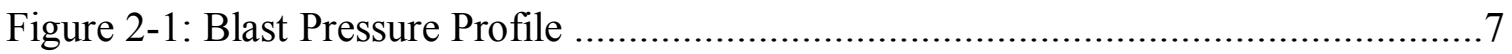

Figure 2-2: structured IJK index (AUTODYN 2009) ……………….......................17

Figure 2-3: Distortion of a Lagrange Grid (Birnbaum et al. 1999) ..................................17

Figure 2-4: An Example of an Euler Grid (Birnbaum et al. 1999) ..................................17

Figure 2-5: An Example of an ALE Grid (Birnbaum et al. 1999) ………………..........18

Figure 2-6: Concept of three limit surfaces (Riedel et al. 1999) .....................................23

Figure 2-7: Illustrations of strain hardening, RHT model (Brannon and Leelavanichkul

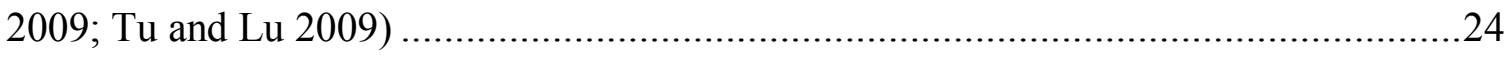

Figure 2-8: Failure Surface, RHT model (Brannon and Leelavanichkul 2009) ...............27

Figure 2-9: Effect of strain rate on concrete compressive strength (ASCE 2010) ............30

Figure 2-10: Magnitude of strain rates Reproduced from (Bischoff and Perry 1991),.....31

Figure 2-11: Strain rate for concrete in compression (Wu et al. 2011) ............................33

Figure 2-12: Strain rate for concrete in tension (Leppänen 2006) ...................................35

Figure 2-13: Shear failure on a circular column (Fujikura 2011) ..................................38

Figure 3-1: Cross-sectional plan of concrete columns .................................................44

Figure 3-2: Tie spacing in RC columns: (a) 75-mm spacing, (b) 150-mm tie spacing, and

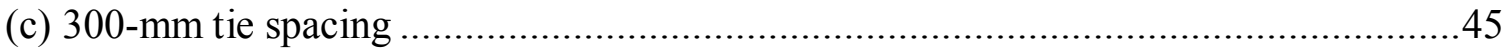

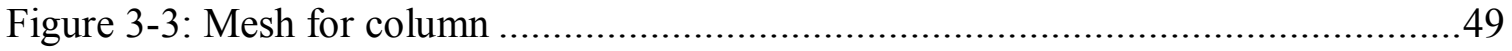

Figure 3-4: Reinforcement cage showing longitudinal and transverse sections ...............50

Figure 3-5: Air space around column ......................................................................51

Figure 3-6: A 2D model showing the ANFO and Air ................................................53

Figure 3-7: Blast wave propagation in the 2D model....................................................54 
Figure 3-8: 3D remap of the blast pressure wave ..............................................54

Figure 3-9: Pressure profiles of mesh sensitivity analysis for $2 \mathrm{D}$ model ........................55

Figure 3-10: Fixed supports condition of RC column .......................................57

Figure 3-11: Outflow and reflective boundaries in the region of air............................58

Figure 3-12: Joints at nodes between column and beam elements..............................59

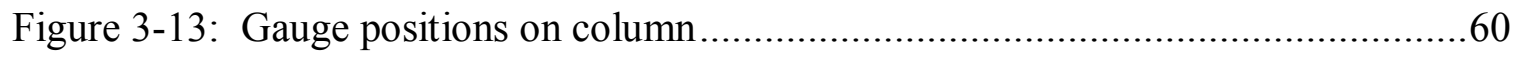

Figure 3-14: Gauge positions on steel reinforcement (a) front face (b) back face..........61

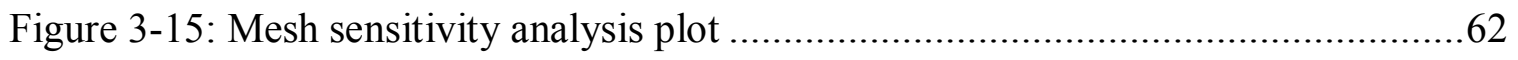

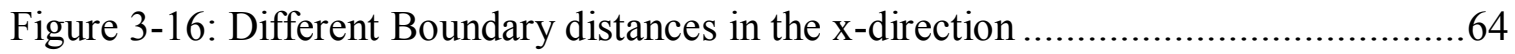

Figure 3-17: Different Boundary distances in the $\mathrm{z}$-direction ................................65

Figure 3-18: Column Deflection at height $1.5 \mathrm{~m}$ for different distances in the $\mathrm{x}$-direction

Figure 3-19: Column Deflection at height $1.5 \mathrm{~m}$ for different distances in the z-direction

Figure 3-20: Effect of Tensile Strain Rate Exponent on Column Deflection ..................68

Figure 3-21: Blast Test setup for Validation........................................................ 71

Figure 3-22: Graph plots comparing deflections at standoff distance of $2.6 \mathrm{~m} \ldots \ldots \ldots \ldots \ldots . . .72$

Figure 3-23: Graph plots comparing deflections at standoff distance of $2.7 \mathrm{~m} \ldots \ldots \ldots \ldots \ldots . . . . .73$

Figure 3-24: Visual display of the failed columns at standoff distance of $1.3 \mathrm{~m}$...........74

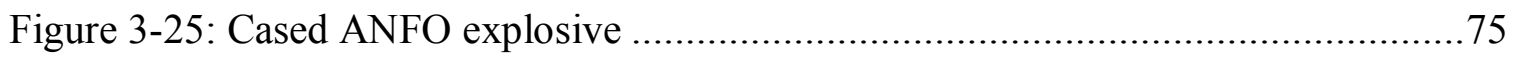

Figure 3-26: RC Colum on Site prior to testing .................................................. 76

Figure 4-1: Column deflections at height $1.5 \mathrm{~m}$ for $75-\mathrm{mm}$ tie spacing at $\mathrm{Z}=0.6 \mathrm{~m} / \mathrm{kg}^{1 / 3}$ 
Figure 4-2: Column deflections at mid-height $1.5 \mathrm{~m}$ for $150 \mathrm{~mm}$ tie spacing at $\mathrm{Z}=0.6$

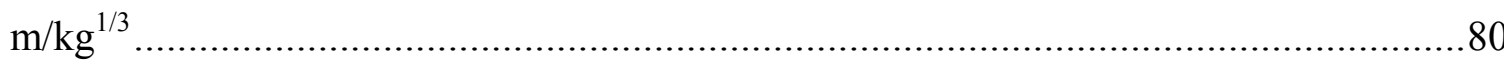

Figure 4-3: Column deflections at height $1.5 \mathrm{~m}$ for $300-\mathrm{mm}$ tie spacing at $\mathrm{Z}=0.6 \mathrm{~m} / \mathrm{kg}^{1 / 3}$

Figure 4-4: Column deflections at height $1.5 \mathrm{~m}$ for $75-\mathrm{mm}$ tie spacing at $\mathrm{Z}=0.25 \mathrm{~m} / \mathrm{kg}^{1 / 3}$

Figure 4-5: Column deflections at height $1.5 \mathrm{~m}$ for $150-\mathrm{mm}$ tie spacing at $\mathrm{Z}=0.25$

$\mathrm{m} / \mathrm{kg}^{1 / 3}$

Figure 4-6: Column deflections at height $1.5 \mathrm{~m}$ for $300-\mathrm{mm}$ tie spacing at $\mathrm{Z}=0.25$

$\mathrm{m} / \mathrm{kg}^{1 / 3}$

Figure 4-7: Column deflections for $75-\mathrm{mm}$ tie spacing at $\mathrm{Z}=0.6 \mathrm{~m} / \mathrm{kg}^{1 / 3}$ for $25 \mathrm{~kg}$ charge

mass

Figure 4-8: Column deflections for $150-\mathrm{mm}$ tie spacing at $\mathrm{Z}=0.6 \mathrm{~m} / \mathrm{kg}^{1 / 3}$ for $25 \mathrm{~kg}$ charge mass .88

Figure 4-9: Column deflections for $300-\mathrm{mm}$ tie spacing at $\mathrm{Z}=0.6 \mathrm{~m} / \mathrm{kg}^{1 / 3}$ for $25 \mathrm{~kg}$ charge mass 88

Figure 4-10: Column deflections for $75-\mathrm{mm}$ tie spacing at $\mathrm{Z}=0.25 \mathrm{~m} / \mathrm{kg}^{1 / 3}$ for $50 \mathrm{~kg}$ charge. .89

Figure 4-11: Column deflections for $300-\mathrm{mm}$ tie spacing at $Z=0.25 \mathrm{~m} / \mathrm{kg}^{1 / 3}$ for $50 \mathrm{~kg}$ charge. .89

Figure 4-12: Column deflections for $300-\mathrm{mm}$ tie spacing at $Z=0.25 \mathrm{~m} / \mathrm{kg}^{1 / 3}$ for $50 \mathrm{~kg}$ charge. .90 
Figure 4-13: Column deflections for 75-mm tie spacing at $Z=0.25 \mathrm{~m} / \mathrm{kg}^{1 / 3}$ for $25 \mathrm{~kg}$ charge.

Figure 4-14: Column deflections for $150-\mathrm{mm}$ tie spacing at $Z=0.25 \mathrm{~m} / \mathrm{kg}^{1 / 3}$ for $25 \mathrm{~kg}$ charge.

Figure 4-15: Column deflections for 300-mm tie spacing at $Z=0.25 \mathrm{~m} / \mathrm{kg}^{1 / 3}$ for $25 \mathrm{~kg}$ charge.

Figure 4-16: Shear failure along a $75 \mathrm{~mm}$ tie spacing $\mathrm{RC}$ column for $150 \mathrm{~kg}$ .93

Figure 4-17: Shear failure along a 150-mm tie spacing RC column for $150 \mathrm{~kg}$..... .93

Figure 4-18: Shear failure along a 300-mm tie spacing RC column for $150 \mathrm{~kg}$ .94

Figure 4-19: Shear failure along a 75-mm tie spacing RC column for $100 \mathrm{~kg}$ .94

Figure 4-20: Shear failure along a 150-mm tie spacing RC column for $100 \mathrm{~kg}$ .95

Figure 4-21: Shear failure along a 300-mm tie spacing RC column for $100 \mathrm{~kg} \ldots \ldots \ldots \ldots . . . .95$

Figure 4-22: Mid-Height Column Deflections at $\mathrm{Z}=0.25 \mathrm{~m} / \mathrm{kg}^{1 / 3}$ .97

Figure 4-23: Mid-Height Column Deflections at $Z=0.6 \mathrm{~m} / \mathrm{kg}^{1 / 3}$ .97

Figure 4-24: Failure modes for each concrete strength at $Z=0.25 \mathrm{~m} / \mathrm{kg}^{1 / 3}$ for $100 \mathrm{~kg} \ldots . .98$

Figure 4-25: Failure modes for each concrete strength at $Z=0.25 \mathrm{~m} / \mathrm{kg}^{1 / 3}$ for $150 \mathrm{~kg} \ldots . .98$

Figure 4-26: Steel reinforcement strains on front face at $Z=0.6 \mathrm{~m} / \mathrm{kg}^{1 / 3}$ for $50 \mathrm{~kg} \ldots \ldots . .100$

Figure 4-27: Steel reinforcement strains on back face at $Z=0.6 \mathrm{~m} / \mathrm{kg}^{1 / 3}$ for $50 \mathrm{~kg} \ldots \ldots . .101$

Figure 4-28: Steel reinforcement strains on front face at $Z=0.25 \mathrm{~m} / \mathrm{kg}^{1 / 3}$ for $50 \mathrm{~kg} \ldots \ldots .101$

Figure 4-29: Steel reinforcement strains on back face at $Z=0.25 \mathrm{~m} / \mathrm{kg}^{1 / 3}$ for $50 \mathrm{~kg} \ldots \ldots 102$

Figure 6-1: Column deflections at height $1 \mathrm{~m}$ for $75-\mathrm{mm}$ tie spacing at $\mathrm{Z}=0.6 \mathrm{~m} / \mathrm{kg}^{1 / 3} 114$

Figure 6-2: Column deflections at height $2 \mathrm{~m}$ for $75-\mathrm{mm}$ tie spacing at $\mathrm{Z}=0.6 \mathrm{~m} / \mathrm{kg}^{1 / 3} 114$ 
Figure 6-3: Column deflections at height $1 \mathrm{~m}$ for $150-\mathrm{mm}$ tie spacing at $Z=0.6 \mathrm{~m} / \mathrm{kg}^{1 / 3}$

Figure 6-4: Column deflections at height $2 \mathrm{~m}$ for $150-\mathrm{mm}$ tie spacing at $Z=0.6 \mathrm{~m} / \mathrm{kg}^{1 / 3}$

Figure 6-5: Column deflections at height $1 \mathrm{~m}$ for $300-\mathrm{mm}$ tie spacing at $Z=0.6 \mathrm{~m} / \mathrm{kg}^{1 / 3}$

Figure 6-6: Column deflections at height $2 \mathrm{~m}$ for $300-\mathrm{mm}$ tie spacing at $Z=0.6 \mathrm{~m} / \mathrm{kg}^{1 / 3}$

Figure 6-7: Column deflections at height $1 \mathrm{~m}$ for $75-\mathrm{mm}$ tie spacing at $Z=0.25 \mathrm{~m} / \mathrm{kg}^{1 / 3}$

Figure 6-8: Column deflections at height $2 \mathrm{~m}$ for $75-\mathrm{mm}$ tie spacing at $\mathrm{Z}=0.25 \mathrm{~m} / \mathrm{kg}^{1 / 3}$

Figure 6-9: Column deflections at height $1 \mathrm{~m}$ for $150-\mathrm{mm}$ tie spacing at $Z=0.25 \mathrm{~m} / \mathrm{kg}^{1 / 3}$

Figure 6-10: Column deflections at height $2 \mathrm{~m}$ for $150-\mathrm{mm}$ tie spacing at $\mathrm{Z}=0.25 \mathrm{~m} / \mathrm{kg}^{1 / 3}$

Figure 6-11: Column deflections at height $1 \mathrm{~m}$ for $300-\mathrm{mm}$ tie spacing at $\mathrm{Z}=0.25 \mathrm{~m} / \mathrm{kg}^{1 / 3}$

Figure 6-12: Column deflections at height $2 \mathrm{~m}$ for $300-\mathrm{mm}$ tie spacing at $\mathrm{Z}=0.25 \mathrm{~m} / \mathrm{kg}^{1 / 3}$

Figure 6-13: Column deflections for $75-\mathrm{mm}$ tie spacing at $Z=0.6 \mathrm{~m} / \mathrm{kg}^{1 / 3}$ for $50 \mathrm{~kg}$ charge mass 120 
Figure 6-14: Column deflections for $75-\mathrm{mm}$ tie spacing at $Z=0.6 \mathrm{~m} / \mathrm{kg}^{1 / 3}$ for $75 \mathrm{~kg}$ charge mass

Figure 6-15: Column deflections for $75-\mathrm{mm}$ tie spacing at $\mathrm{Z}=0.6$ for $\mathrm{m} / \mathrm{kg}^{1 / 3} 100 \mathrm{~kg}$ charge mass

Figure 6-16: Column deflections for $75-\mathrm{mm}$ tie spacing at $Z=0.6 \mathrm{~m} / \mathrm{kg}^{1 / 3}$ for $150 \mathrm{~kg}$ charge mass

Figure 6-17: Column deflections for $150-\mathrm{mm}$ tie spacing at $\mathrm{Z}=0.6 \mathrm{~m} / \mathrm{kg}^{1 / 3}$ for $50 \mathrm{~kg}$ charge mass

Figure 6-18 Column deflections for $150-\mathrm{mm}$ tie spacing at $\mathrm{Z}=0.6 \mathrm{~m} / \mathrm{kg}^{1 / 3}$ for $75 \mathrm{~kg}$ charge mass

Figure 6-19: Column deflections for $150-\mathrm{mm}$ tie spacing at $\mathrm{Z}=0.6 \mathrm{~m} / \mathrm{kg}^{1 / 3}$ for $100 \mathrm{~kg}$ charge mass

Figure 6-20: Column deflections for $150-\mathrm{mm}$ tie spacing at $Z=0.6 \mathrm{~m} / \mathrm{kg}^{1 / 3}$ for $150 \mathrm{~kg}$ charge mass

Figure 6-21: Column deflections for $300-\mathrm{mm}$ tie spacing at $\mathrm{Z}=0.6 \mathrm{~m} / \mathrm{kg}^{1 / 3}$ for $50 \mathrm{~kg}$ charge mass

Figure 6-22: Column deflections for $300-\mathrm{mm}$ tie spacing at $Z=0.6 \mathrm{~m} / \mathrm{kg}^{1 / 3}$ for $75 \mathrm{~kg}$ charge mass

Figure 6-23: Column deflections for $300-\mathrm{mm}$ tie spacing at $Z=0.6 \mathrm{~m} / \mathrm{kg}^{1 / 3}$ for $100 \mathrm{~kg}$ charge mass

Figure 6-24: Column deflections for $300-\mathrm{mm}$ tie spacing at $Z=0.6 \mathrm{~m} / \mathrm{kg}^{1 / 3}$ for $150 \mathrm{~kg}$ charge mass 125 
Figure 6-25: Column deflections for $75-\mathrm{mm}$ tie spacing at $Z=0.25 \mathrm{~m} / \mathrm{kg}^{1 / 3}$ for $75 \mathrm{~kg}$ charge mass

Figure 6-26: Column deflections for $75-\mathrm{mm}$ tie spacing at $\mathrm{Z}=0.25 \mathrm{~m} / \mathrm{kg}^{1 / 3}$ for $100 \mathrm{~kg}$ charge mass 126

Figure 6-27: Column deflections for $75-\mathrm{mm}$ tie spacing at $\mathrm{Z}=0.25 \mathrm{~m} / \mathrm{kg}^{1 / 3}$ for $150 \mathrm{~kg}$ charge mass

Figure 6-28: Column deflections for $150-\mathrm{mm}$ tie spacing at $Z=0.25 \mathrm{~m} / \mathrm{kg}^{1 / 3}$ for $75 \mathrm{~kg}$ charge mass

Figure 6-29: Column deflections for $150-\mathrm{mm}$ tie spacing at $\mathrm{Z}=0.25 \mathrm{~m} / \mathrm{kg}^{1 / 3}$ for $100 \mathrm{~kg}$ charge mass 128

Figure 6-30: Column deflections for $150-\mathrm{mm}$ tie spacing at $\mathrm{Z}=0.25 \mathrm{~m} / \mathrm{kg}^{1 / 3}$ for $150 \mathrm{~kg}$ charge mass 128

Figure 6-31: Column deflections for 300-mm tie spacing at $Z=0.25 \mathrm{~m} / \mathrm{kg}^{1 / 3}$ for $75 \mathrm{~kg}$ charge mass

Figure 6-32: Column deflections for $300-\mathrm{mm}$ tie spacing at $\mathrm{Z}=0.25 \mathrm{~m} / \mathrm{kg}^{1 / 3}$ for $100 \mathrm{~kg}$ charge mass .129

Figure 6-33: Column deflections for $300-\mathrm{mm}$ tie spacing at $\mathrm{Z}=0.25 \mathrm{~m} / \mathrm{kg}^{1 / 3}$ for $150 \mathrm{~kg}$ charge mass 130 


\section{Notation}

\begin{tabular}{|c|c|}
\hline A & Material constant for the Johnson and Holmquist concrete model \\
\hline A & porosity parameter of concrete \\
\hline$a_{\text {init }}$ & initial porosity of concrete \\
\hline B & Material constant for the Johnson and Holmquist concrete model \\
\hline$C$ & The velocity of a sound single in the Courant-Friedrich-Levy criterion \\
\hline$C$ & Material constant for the Johnson and Holmquist concrete model \\
\hline$D$ & Accumulated material damage \\
\hline$\varepsilon_{\mathrm{pl}}$ & Plastic strain \\
\hline$\varepsilon_{\mathrm{pl}(\text { presoftening) }}$ & $\begin{array}{l}\text { Difference between the strain at the failure surface and the strain at the } \\
\text { elastic strength surface }\end{array}$ \\
\hline$\dot{\varepsilon_{\mathrm{s}}}$ & Static strain rate \\
\hline$f_{c}$ & dynamic compressive strength \\
\hline$f_{c}^{\prime}$ & Static compressive strength \\
\hline$f_{t}$ & Tensile strength of concrete \\
\hline$f_{i}$ & External force \\
\hline $\mathrm{F}_{\text {rate }}(\dot{\varepsilon})$ & The dynamic increase factor in the RHT model \\
\hline $\mathrm{G}$ & Shear modulus \\
\hline $\mathrm{I}_{\mathrm{so}}$ & Incident impulse \\
\hline $\mathrm{I}_{\mathrm{r}}$ & Reflected impulse \\
\hline $\mathrm{J}_{2}$ & Second deviatoric stress invariant \\
\hline$J_{3}$ & Third deviatoric stress invariant \\
\hline
\end{tabular}


$\mathrm{p}_{\mathrm{u}}$

$\mathrm{P}_{\text {crush }}$

$\mathrm{P}_{\text {lock }}$

$\mathrm{P}_{\mathrm{o}}$

$\mathrm{P}_{\mathrm{r}}$

$\mathrm{P}_{\text {so }}$

$\mathrm{P}^{*}$

$\mathrm{p}_{\text {spall }}^{*}$

$\mathrm{R}$

$S_{i j}$

SMAX

$\mathrm{t}_{\mathrm{d}}{ }^{-}$

$\mathrm{t}_{\mathrm{d}}{ }^{+}$

$Y_{\text {fail }}$
Material constant for the Johnson and Holmquist concrete model

Upper cap pressure, the pressure at which the elastic limit surface intercepts the hydrostatic axis.

Lower cap pressure, the pressure where the uniaxial compression path intercepts the elastic limit surface

initial pore core pressure

Pressure at total compaction

Atmospheric Pressure

Reflected overpressure

Incident Overpressure

normalized pressure with respect to $f_{c}{ }^{\prime}$

Ratio of the material tensile strength to the compressive strenth

Standoff distance measured from the centre of explosion to a given

point of interest

Deviatoric stress

Maximum strength obtained for the concrete material

Negative phase duration, the time during which the pressure is below

the atmospheric pressure

Positive phase duration, the time during which the incident pressure or

the reflected pressure is above atmospheric pressure

The failure surface 

the cube root of the charge mass

$\rho$

$e$

$\omega$
Density

the specific energy

tensile strain rate exponent

Lode angle, function of the second and third deviatoric stress invariant 


\section{Chapter: Introduction}

\subsection{Background}

Recent terrorist attacks and accidental explosions involving hazardous materials around the world have increased the need to study the behaviour of structures subjected to blast loading. Although most of the explosions occurring in the past have been mainly due to accidents, recently there has been an increase in the number of planned explosion attacks against infrastructure systems designed to inflict injury and fatality to the population and damage to the infrastructure systems. The Oklahoma City bombing (Bangash and Bangash 2006), London Subway and Bus attacks (Drury et al. 2009), foiled Via Rail terrorist plot (Weston 2013), and the British Columbia Legislature building bomb plots (Hughes 2013) as well as accidental industrial explosions such as the Flixborough disaster in England (Sadee et al. 1977), the ammonium nitrate factory explosion in Texas (Meyers and Shanley 1990) and the Lac Megantic train explosion in Quebec (Blatchford 2013) have increased awareness of the vulnerability of structures to blast loading.

Concrete is a widely used material in the construction industry. Although concrete members have excellent compression resistance, they have limited tensile stress resistance and are augmented with reinforcement to increase tensile resistance and durability under static loading. Explosions, however, cause high amplitude and short duration dynamic loading on the concrete members. The behaviour of concrete members under static loading is different from that under dynamic loading. Hence, there is a need to investigate the effects of high amplitude and short duration dynamic loading on the strength, durability, and, ductility of concrete members. 
Many research works have been published in the literature studying the effects of blast loading on reinforced concrete elements. Most of the research is aimed at the response of elements such as columns to far-field blast loading. A few research works have investigated the response and behaviour of reinforced concrete columns, in particular, to near-field explosions. The probability of terrorists' attack increases with a decrease in amount of explosives. Thus, it is much more plausible for reinforced concrete columns to be attacked with small amounts of explosives at near-field distances than a larger amount of explosive at a larger standoff distance (Gebbeken et al. 2003; Braimah and Contestabile 2007).

The study of structural elements subjected to blast loading can be accomplished through either field testing or numerical simulations. Field testing requires access to a remote site where it is acceptable to detonate a large quantity of explosives. In Canada, military bases such as Canadian Forces Bases at Petawawa, Ontario or Suffield, Alberta are commonly used. However, access to these sites can be challenging. Also the fabrication and transport of test specimen and a substantial support structure capable of surviving multiple explosions makes field testing cost prohibitive. The alternative is to use high fidelity physics based computational methods to simulate the explosion process, the interaction of blast wave and structural element, and the behaviour of structural elements under blast loading. 


\subsection{Objectives of the Numerical Simulation}

The research reported in this thesis presents an investigation of the behaviour of reinforced concrete columns under near-field blast loading using AUTODYN® software to support field testing of similar reinforced concrete columns. The reinforced concrete columns were designed and detailed in accordance with CSA A23.3-04 and exposed to explosions from different explosive masses detonated at close-range (with scaled distance less than $\left.1.0 \mathrm{~m} / \mathrm{kg}^{1 / 3}\right)$.

The cardinal objectives of the research work reported in this thesis are:

- Validation of the numerical models with experimental test results

- To determine the effects of increasing charge mass on the response of reinforced concrete columns

- To investigate differences in deflections along the height of columns

- To determine the effects of increasing concrete compressive strength on the response behaviour of RC columns

- To observe failure modes

- To investigate strains in reinforcing bars

\subsection{Organization of Thesis}

The thesis is organized into five main chapters. Chapter 1 presents an introduction to the research project, explains the objectives of the study and outlines the scope of the study. Chapter 2 presents comprehensive literature review on subjects pertinent to the research project. These include a review of explosion process, evolution of the blast wave and its interaction with structural objects, and definition of the basic parameters of a blast wave. 
A literature review of numerical modelling techniques and the theoretical bases of hydrocodes is also presented as well as a review of constitutive models for concrete and reinforcing steels. Finally, a review of the effects of high strain loading on concrete and reinforcing steel is presented.

Chapter 3 describes the numerical modelling of the reinforced concrete columns studied in this thesis. A description of the concrete columns (dimensions and material properties) is presented together with the material models chosen for the numerical simulations. The numerical modelling process is explained and their validation with experimental test results presented.

Chapter 4 of the thesis presents the numerical analyses results followed by a discussions and comparison of the behaviour of the column types modelled. The effects of scaled distance, reinforcement detailing, and concrete compressive strength are discussed. Major failure modes of reinforced concrete columns under near-field explosions are also presented and discussed.

Chapter 5 outlines conclusions drawn from the numerical analyses results and their discussions while Chapter 6 presents recommendations for future work. 


\section{Chapter: Literature Review}

\subsection{Introduction}

This chapter presents a literature review on the explosion reaction and process, blast wave scaling laws, and pressure profiles. The chapter also includes a literature review on the theoretical bases of hyrdocodes; the governing equations and their application. The constitutive material models of concrete, steel and TNT explosive are reviewed in addition to research works by other researchers on the response and behaviour of reinforced concrete columns under blast loading.

\subsection{Explosion Process}

An explosion is a term used to describe the sudden release of potential energy and the rapid expansion of gases during the explosion reaction. The released potential energy is accompanied by heat, light, sound and high pressures (Bangash and Bangash 2006; Cormie et al. 2009; Beshara 1994). The expanded hot gas pushes out the surrounding air. As a result, a layer of compressed air is formed in front of the hot expanding gases. This layer of compressed air is termed as the shock front of the blast wave and produces instantaneous increase in pressure, much higher than the atmospheric pressure, in the surrounding area (Cormie et al. 2009; Beshara 1994; Bangash and Bangash 2006). Over time, the high pressure decays and falls below the atmospheric pressure creating a region of underpressure known as negative phase of the blast wave (Bangash and Bangash 2006; Cormie et al. 2009). Conversely, the period during which the pressure is higher than atmospheric pressure is known as the positive phase. After the negative phase, equilibrium occurs and the pressure returns to the atmospheric pressure. The blast wave usually last for a few tens of milliseconds. Figure 2-1 shows the positive and negative 
phase of the blast pressure profile. The pressure generated during the explosion reaction is about $30 \mathrm{GPa}$ with temperature ranging between 3000 to $4000{ }^{\circ} \mathrm{C}$ (Cormie et al. 2009). The blast wave from an explosive detonation is omnidirectional, reflecting off objects it encounters with a density higher than that of the medium it is traveling in. The reflected blast wave has higher pressure than the pressure of the incident wave. The time it takes for the incident wave to travel from the centre of detonation to a point of interest is termed the blast wave arrival time. The pressure instantaneously increases at time of arrival to the incident overpressure $\left(\mathrm{P}_{\mathrm{so}}\right)$ value, where there is no reflecting surface, or the reflected pressure $\left(\mathrm{P}_{\mathrm{r}}\right)$ value in the presence of a reflecting surface. The positive phase duration, the time during which the incident pressure or the reflected pressure is above atmospheric pressure $\left(\mathrm{P}_{\mathrm{o}}\right)$, is denoted as $\mathrm{t}_{\mathrm{d}}{ }^{+}$, while the negative phase duration, the time during which the pressure is under the atmospheric pressure, is denoted, $t_{d}{ }^{-}$, as shown in Figure 2-1. The area under the pressure-time history curve indicates the impulse of the blast wave. 


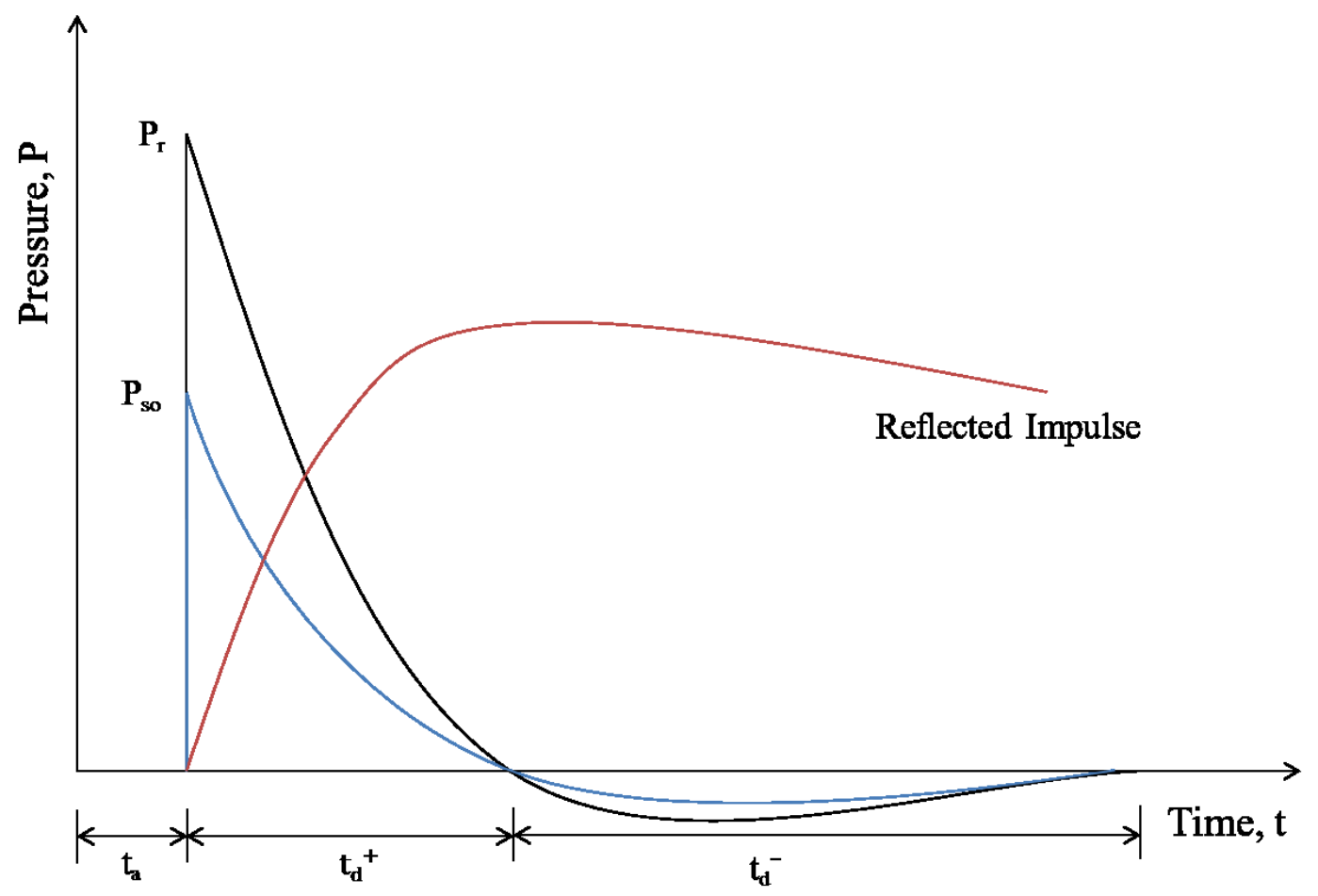

Figure 2-1: Blast Pressure Profile

\subsection{Blast wave pressure profiles}

The blast pressure decays from the peak pressure (incident or reflected) value exponentially to the atmospheric pressure value. The Friedlander equation is the most commonly used exponential function to describe the time variation of blast pressure and is presented in equation 2-1.

$$
P(t)=P\left[1-\frac{t}{t_{d}^{+}}\right]^{-\frac{b t}{t_{d}^{+}}}
$$

where $\mathrm{P}(\mathrm{t})$ is the pressure at time $t$ is, $P$ is the peak overpressure (incident or reflected), $b$ is the waveform parameter, and $\mathrm{t}_{\mathrm{d}}{ }^{+}$is the positive phase duration of the blast pressure as shown in Figure 2-1. The impulse (I) of the blast wave is also defined in equation 2-2 (Zhao et al. 2012; Bangash and Bangash 2006) 


$$
\mathrm{I}(\mathrm{t})=\int_{\mathrm{t}_{\mathrm{d}}}^{\mathrm{t}_{\mathrm{a}}+\mathrm{t}_{\mathrm{d}}^{+}}[\mathrm{P}(\mathrm{t})] d t=\mathrm{P} \int_{\mathrm{t}_{\mathrm{d}}}^{\mathrm{t}_{\mathrm{a}}+\mathrm{t}_{\mathrm{d}}^{+}} \mathrm{e}^{-\frac{\mathrm{bt}}{\mathrm{t}_{\mathrm{d}}^{+}}} d t=\mathrm{P} \cdot \mathrm{t}_{\mathrm{d}}^{+}\left[\frac{1}{\mathrm{~b}}-\frac{1}{\mathrm{~b}^{2}}\left(1-\mathrm{e}^{-\mathrm{b}}\right)\right]
$$

Where the impulse $(\mathrm{I})$ can be the incident impulse $\left(\mathrm{I}_{\mathrm{so}}\right)$ or the reflected impulse $\left(\mathrm{I}_{\mathrm{r}}\right)$

The pressure decay from the peak can also be idealised as a linear function by maintaining same impulse, area under the curve, as in the case of exponential function. This conservative approach gives satisfactory load functions in design (Cormie et al. 2009).

\subsection{Classification of Explosions}

\subsubsection{Nature of Explosions}

Explosions can be classified as physical, nuclear, or chemical explosions based on their nature. Physical explosions include the rapid expansion and rupture of compressed gas containers, volcanic eruptions and violent mixing of liquids. Nuclear explosions on the

other hand are caused by the sudden release of energy through the fusion or the fission of atomic nuclei. The energy from nuclear explosions is derived from the protons and neutrons within the atomic nuclei (Smith et al. 1994). Chemical explosions derive energy from the oxidation of fuel elements such as carbon and hydrogen atoms. The oxidation leads to the production of enormous amounts of energy as compared to physical explosions.

\subsubsection{Planned and Accidental Explosions}

Planned and controlled explosions are used safely to enhance life in mining, combustion engine and controlled explosive demolition of structures. However, some planned explosions such as terrorist attacks lead to loss of lives and the destruction of property. 
Examples of these attacks include the attacks on the World Trade Center Building New York in 1992, The Oklahoma City Bombing in 1995 (Bangash and Bangash 2006), and the Islamabad Marriot Bombing in 2008 (Gunaratna 2008). Most accidental explosions occur during manufacture, storage or transport of explosives. The Texas City explosion in April 16, 1947 disaster was due to the explosions of ammonium nitrate fertilizer on two ships: the Grandcamp and the High Flyer (Katayama et al. 2007; Meyers and Shanley 1990; Stephens 1997). Recent accidental explosions include the Lac Megantic train explosion in Quebec (Blatchford 2013) and the West, Texas fertilizer company explosion in 2013 (Mungin 2013). These explosions resulted in severe damage to property and loss of lives.

\subsection{Blast Waves Scaling laws}

The nature of blast waves is dependent on the energy released and the medium through which the blast waves propagate. The characteristics of the blast waves measured in controlled explosion experiments become the reference explosions based on which other data on other explosions are derived. The data are derived using scaling laws such as Sachs' law and the cube root scaling law (Baker et al. 1983). The Sachs scaling law is used for predicting the characteristics of blast waves at higher altitudes, while the cube root scaling law is used for explosions at sea level atmospheric conditions. In addition, the Sachs' scaling law compares the dimensionless impulse and pressure of the blast wave while the cube root scaling law compares the weight and diameter of an explosive. 
The cube root scaling law states that explosives of different weights and sizes but similar geometry and material detonating at the same scaled distance will produce blast waves with similar characteristics (Bangash and Bangash 2006; Cormie et al. 2009). The cube root scaling law is denoted mathematically in equation 2-3 as;

$$
\frac{\mathrm{d}_{1}}{\mathrm{~d}_{2}}=\left(\frac{\mathrm{W}_{1}}{\mathrm{~W}_{2}}\right)^{1 / 3} \stackrel{\text { yields }}{\longrightarrow} \frac{\mathrm{d}_{1}}{\left(\mathrm{~W}_{1}\right)^{1 / 3}}=\frac{\mathrm{d}_{2}}{\left(\mathrm{~W}_{2}\right)^{1 / 3}}
$$

where $\mathrm{W}_{1}$ and $\mathrm{W}_{2}$ are two explosive charge masses with corresponding diameters $\mathrm{d}_{1}$ and $\mathrm{d}_{2}$. The scaled distance $(Z)$ is defined as shown in equation 2-4 as;

$$
\mathrm{Z}=\left(\frac{\mathrm{R}}{\mathrm{W}^{1 / 3}}\right)
$$

where $R$ is the distance measured from the centre of explosion to a given point of interest. The scaling laws are usually applied to predict the nature of larger explosions using data from small explosions (Bangash and Bangash 2006; Cormie et al. 2009; Baker et al. 1983).

\subsection{Evolution of Numerical Modeling}

The dynamic behaviour of reinforced concrete columns subjected to blast loading can be very complicated involving many phenomena not considered or encountered in static testing. The study of the response of reinforced concrete elements has traditionally been accomplished through live explosive field testing or analytical/numerical simulations. Field testing using substantial amounts of explosives can, however, be expensive and thus limits the amount of research works involving field explosive testing.

The global response of RC columns have been studied by using single-degree-of-freedom (SDOF) techniques (Zhou et al. 2008) while localized response such as spalling and cratering is analyzed with semi-empirical methods (O'Grady et al. 1996). 
Numerical methods are used for simulating reinforced concrete column response to blast loads where the SDOF techniques or semi-empirical methods are not appropriate or give inaccurate results. An example includes the dynamic interaction between explosives, concrete columns and reinforcing steel bars. Numerical methods are capable of modelling a wider range of problems but require specialized expertise and huge computer resources. The specialised expertise requires significant knowledge in modelling of blast wave structure interaction, the explosions process, and material modelling techniques. The blast wave - structure interaction is modelled by loading the front face of reinforced concrete columns with the pressure load profile. This type of modelling process uses either the exponential or much simple triangular load profile. In other simulations, the explosion modelling is achieved by modelling the explosive and detonation in the air medium. The blast wave from detonated explosive propagates through the medium and interacts with all faces of reinforced concrete columns. Many researchers using numerical methods to simulate the response and behaviour of structural elements have reported accurate results in comparison with experimental results from explosive field testing (O'Grady et al. 1996; Fairlie 1998; Birnbaum et al. 1996).

\subsection{Review on Theoretical Bases of Hydrocodes}

The lack of experimental test data due to cost involved in explosive field testing and inaccessibility of test sites, has led to increasing use of theoretical approaches to solving nonlinear dynamic problems involving fluid-structure interactions. The development of theoretical computer codes known as hydrocodes based on computational fluid dynamics principles has led to increased accuracy in predicting the behaviour of structural members. 
Hydrocodes require governing equations of continuity, momentum and energy to model dynamic problems which are based on three fundamental principles (Anderson 2001; Gebbeken and Ruppert 2000):

- Conservation of mass

- Conservation of momentum

- Conservation of energy

The governing equations of mass, momentum and energy are presented in equations 2-5, 2-6 and 2-7 respectively.

Conservation of mass: $\frac{\partial \rho}{\partial t}+\rho \frac{\partial v_{i}}{\partial x_{i}}=0$

Conservation of momentum: $\rho \frac{\partial v_{i}}{\partial t}+\rho v_{i} \frac{\partial v_{i}}{\partial x_{i}}=\frac{\partial s_{i j}}{\partial x_{i}}+\rho f_{i}$

Conservation of energy: $\rho \frac{\partial \mathrm{e}}{\partial \mathrm{t}}+\rho \mathrm{v}_{\mathrm{i}} \frac{\partial \mathrm{e}}{\partial \mathrm{x}_{\mathrm{i}}}=\frac{\mathrm{P}}{\rho}\left(\frac{\partial \rho}{\partial \mathrm{t}}+\mathrm{v}_{\mathrm{i}} \frac{\partial \rho}{\partial \mathrm{x}_{\mathrm{i}}}\right)+\mathrm{s}_{\mathrm{ij}} \varepsilon_{\mathrm{ij}}$

where $\rho$ is the density, $P$ is the pressure, $e$ is the specific energy $S_{i j}$ is the deviatoric stress, $\varepsilon_{i j}$ is the strain rate, $f_{i}$ is the external force, $t$ is the time, $x_{i}$ and $v_{i}$ are the coordinates and the velocities in the computational grid. Although equations 2-5, 2-6 and 2-7 are one dimensional, they can also be extended to two and three dimensions by introducing the $y$ and $\mathrm{z}$ coordinates (Anderson 2001; Tham 2005; Gebbeken and Ruppert 2000).

The governing equations need appropriate boundary conditions such as inflow and outflow boundary conditions to solve problems accurately. The governing equations are discretized for numerical analysis. Discretization techniques employed include the finite difference, finite volume and the finite element techniques. The techniques are 
approached using either implicit or explicit methods. While the explicit method requires only one unknown variable to be solved for, the implicit method has more than one unknown variable and requires the use of simultaneous equations to find the unknown variables. Although the explicit method has a simple setup, stability constraints can lead to longer computer simulation times for a given scenario. However, the implicit method is unconditionally stable over large time steps. Unstable solutions in the implicit method arise from the growth of errors such as the discretization error and round-off error (Anderson 2001). Computer programs such as AUTODYN use the finite difference technique in solving nonlinear problems.

AUTODYN (AUTODYN 2009) is a hydrocode-based explicit analysis tool for modelling nonlinear dynamics of solids, fluids, gases and their interactions. AUTODYN analyses the stress, strains and deformations of bodies (Hayhurst et al. 1996; Fairlie 1998; Birnbaum et al. 1996; Luccioni et al. 2004).

AUTODYN has built-in material constitutive models and material equations of state (EOS) needed for simulating blast wave propagation and interaction with bodies. The equations of state employed in AUTODYN include Linear, Polynomial, Shock, Ideal gas, Jones-Wilkins-Lee (JWL), and the Puff models. Some examples of the material constitutive models used in AUTODYN include Hydrodynamic, Elastic, Brittle, Von Misses, Johnson Cook and the Piecewise hardening models (AUTODYN 2009). The material constitutive models link the stresses developed to deformation and internal energy while the equations of state express the relationships between the pressure, density, specific volume, and specific energy. The mass, momentum and energy equations are coupled with material descriptions to solve problems, involving projectile 
penetration, impacts and blast events (Robertson et al. 1994; Fairlie 1997; Riedel et al. 1999; Riedel et al. 2009).

In addition to using the equations of mass, momentum, and energy, AUTODYN also incorporates the decomposition of stress and the equations of state as shown in equations 2-8 and 2-9 (Tham 2005).

Decomposition of stresses: $\sigma_{i j}=S_{i j}-\varepsilon_{i j} P$

Equation of state: $P=P(\rho, e)$

AUTODYN uses the finite difference, finite volume and finite element methods to analyse problems. The finite element methods are used in modelling computational structural dynamics problems while the finite volume methods are used in modelling fast transient computational fluid dynamics problems. The governing equations under the finite methods are discretized into second order central difference schemes which are based on a conditionally stable explicit time integration method (Anderson 2001). The stability condition is met by using the Courant-Friedrich-Levy criterion to control the time step. The Courant-Friedrich-Levy criterion states that the time step, $\Delta t$ is defined in accordance with equation 2-10 which should be less than the time taken for a sound signal of velocity $c$ to travel through the grid spacing $\Delta x$ (Tham 2005).

$$
\Delta \mathrm{t}<\frac{\Delta \mathrm{x}}{\mathrm{c}}
$$




\subsubsection{AUTODYN Solvers}

AUTODYN uses the Lagrange, Euler, Arbitrary Lagrange Euler (ALE) and the Smooth Particle Hydrodynamics (SPH) solvers to solve dynamic problems. While the Lagrange solvers are used for modelling solid materials and structures, the Euler solvers are used in modelling fluids and large distortions of solids where the application of the Lagrange solvers is limited. In extremely deformed regions, the numerical grid of a Lagrange solver can become severely distorted leading to computational inaccuracies and adverse effects on the integration time step. The issues of excessive distortions can also be addressed by using erosion techniques (Fairlie 1997) in which severely deformed or distorted element are eliminated from the analysis. A structured three-dimensional IJK mesh (Figure 2-2) is used for both Lagrange and Euler grids. For Lagrange solvers, the grid moves with the solid material, while for Euler solvers, the fluid material moves through a fixed grid. Also, there is no transport of solid material between elements in a Lagrangian grid. Based on the nature of the grids, the Lagrange solver is computationally more efficient and it is easier to incorporate complex constitutive models into the solver. The Euler solvers use either the Godunov-type or Flux Corrected Transport (FCT) solvers (Katayama et al. 2007). While the FCT allows for a single material in the solver, the Godunov-type solver is used for computing problems with different materials. This makes the Godunov-type solver suitable for blast related problems with deformable structures.

The ALE solver is a hybrid of the Lagrange and Euler solvers and is used in modelling both solids and fluids. The ALE solver facilitates automatic rezoning of the ALE grid and is used for specialized problems such as internal explosions (Birnbaum et al. 1999). 
The ALE solver also reduces the problems caused by the severe mesh distortions, as encountered by the Lagrange solver. However, an additional computational step is required by the ALE to move the grid and remap the solution onto the new grid (Katayama et al. 2007).

While the Lagrange, Euler and ALE are mesh-based solvers, the SPH solver is mesh-free. The SPH, implemented in 1995 (Quan et al. 2003), is a relatively new method in comparison with the Lagrange and Euler solvers and is used for problems with high velocities, large deformations, and fragmentation. The SPH method eliminates the need for numerical grids in solving spatial derivatives. However, the SPH method requires relatively higher number of particles to locate new particles using interpolation. This makes the SPH method computationally time expensive relative to the Euler and Lagrange solvers (Hayhurst et al. 1996).

Figure 2-3, Figure 2-4 and Figure 2-5 show representative grids for the Lagrange, Euler and ALE solvers, respectively where the velocity (u), coordinate (x), force (F) and mass (m) are defined at corner nodes while stress $(\sigma)$, strain $(\varepsilon)$, pressure $(p)$, density $(\rho)$ and energy (e) are defined in the centres (Birnbaum et al. 1999). 


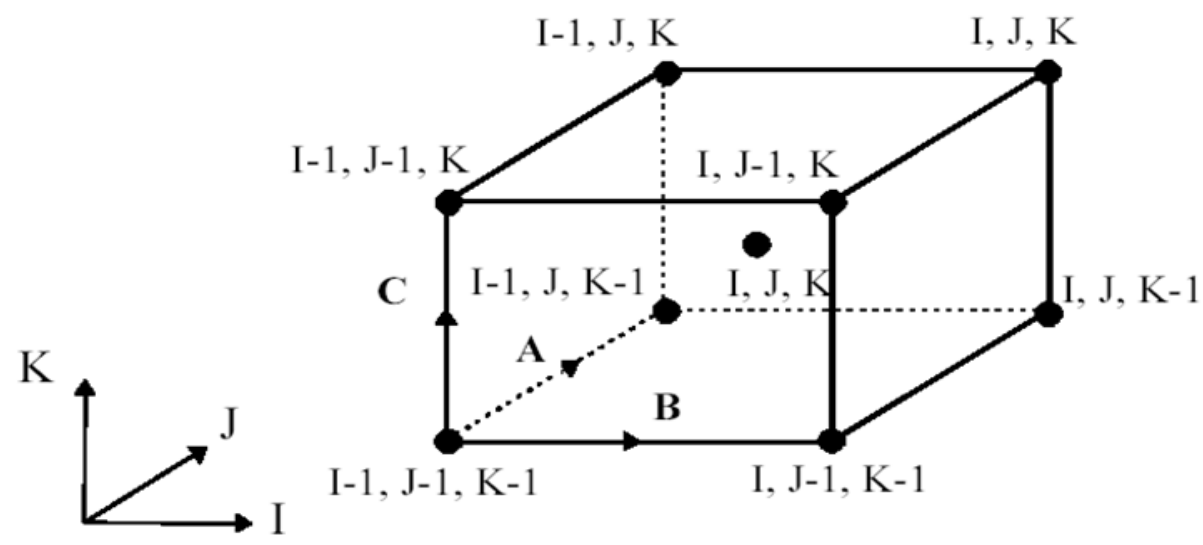

Figure 2-2: structured IJK index (AUTODYN 2009)

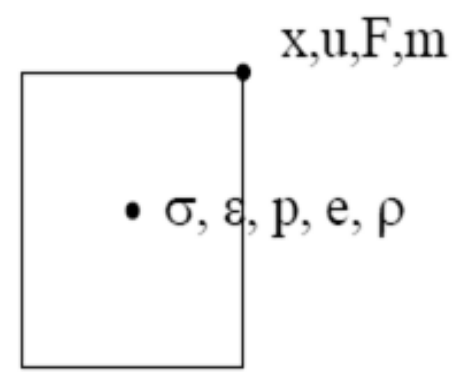

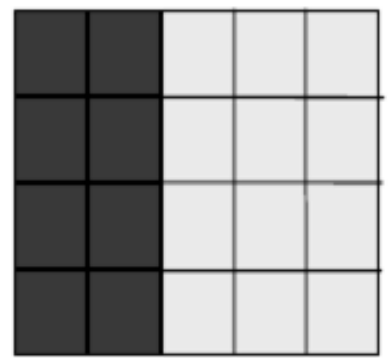

$t=0.0$

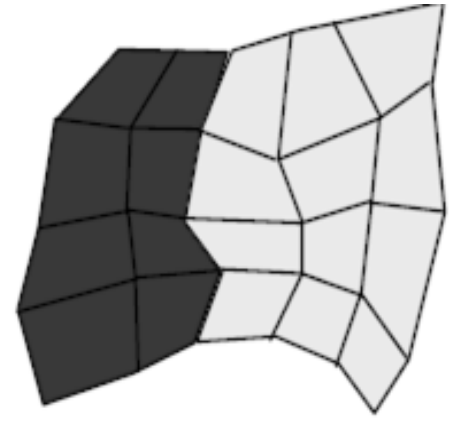

$t=t_{1}$

\section{variables}

Figure 2-3: Distortion of a Lagrange Grid (Birnbaum et al. 1999)

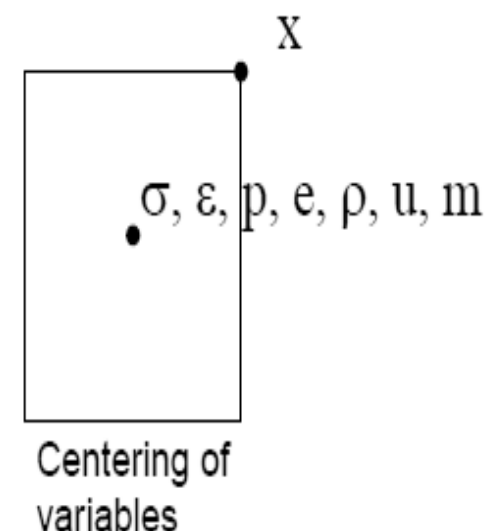

(for coupling)

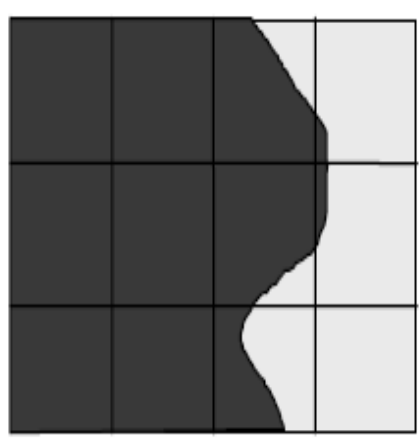

$$
t=t_{1}
$$

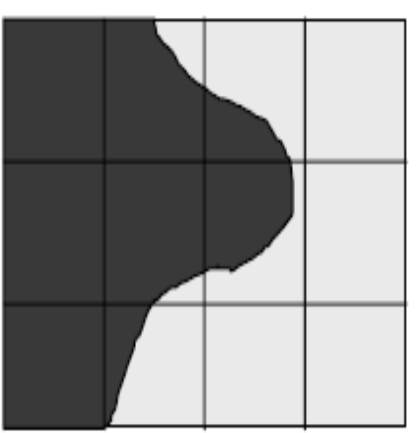

$t=t_{2}$

Figure 2-4: An Example of an Euler Grid (Birnbaum et al. 1999) 


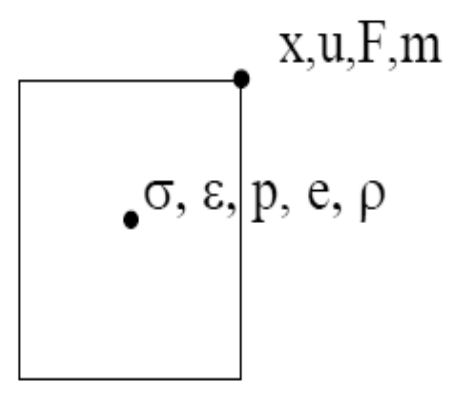

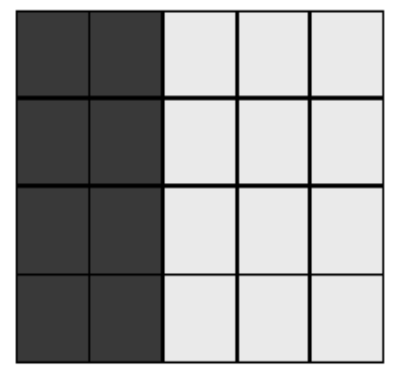

$t=t_{1}$

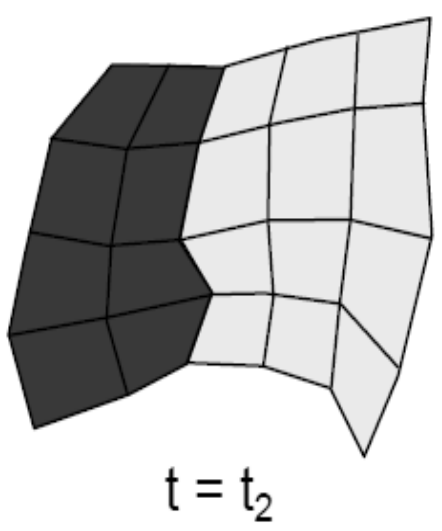

Figure 2-5: An Example of an ALE Grid (Birnbaum et al. 1999)

\subsubsection{Coupling of the Lagrange and Euler Solvers}

Fluid-structure interaction requires the use of both Euler and Lagrange solvers to optimise solutions (Quan et al. 2003). In this interaction, the Euler region acts as a pressure boundary on the Lagrange at the Euler-Lagrange interface while the Lagrange body provides a geometric constraint to the Euler region. The fluid-structure interaction helps in accurately simulating real life blast loading on structures (Birnbaum et al. 1999).

\subsection{Review of Concrete Constitutive Models}

Numerical analyses require constitutive models to describe the behaviour of structural members. Interest in this subject has led to the formulation of different models as attempts are being made to understand the behaviour of structural members. Commercial numerical hydrocodes require sound constitutive models to accurately predict the behaviour of structures. The constitutive models should be able to represent the mechanical process of the material under different loading conditions and rates. Although concrete is a heterogeneous material, it is impractical to formulate the constitutive models based on its heterogeneity, because this will require the modelling of the constituent materials of concrete; especially the aggregates and cementing materials (Riedel et al. 
1999). Concrete is therefore modelled as a homogeneous material to overcome this limitation. Recent studies are aimed at improving homogeneous concrete models, although the complexities of the models have varied over the years. Most of the concrete models in AUTODYN share similar features with some underlying differences as presented in this section. Some similarities of the models are pressure hardening, strain hardening and strain rate dependency. Stresses and strains are treated separately by hydrocodes in volumetric $(\rho, \mu)$ and deviatoric portions $\left(S_{\mathrm{ij}}, \varepsilon_{\mathrm{ij}}\right)$ (Riedel et al. 1999; Kraus et al. 1994).

Most hardened concrete elements have up to $10 \%$ porosity; a property which was originally not accounted for in the EOS (equation 2-9). However in 1969 Herman et al. (Herrmann 1969) proposed the inclusion of the porosity parameter $(\alpha)$ of concrete in the EOS. The introduction of the effects of porosity on compaction of concrete enabled the inclusion of thermal expansion due to shock heating during blast loading (Riedel et al. 1999; Herrmann 1969) as shown in equation 2-11.

$$
\mathrm{P}=\mathrm{P}(\rho \alpha, \mathrm{e})
$$

where,

$$
\alpha=1+\left(\alpha_{\text {init }}-1\right)\left[\frac{\mathrm{P}_{\text {lock }}-\mathrm{P}}{\mathrm{P}_{\text {lock }}-\mathrm{P}_{\text {crush }}}\right]^{\mathrm{n}}
$$

and $\mathrm{P}_{\text {lock }}$ is the pressure at total compaction, $\mathrm{P}_{\text {crush }}$ is the initial pore core pressure and $\alpha_{\text {init }}$ is the initial porosity of the concrete material (Riedel et al. 2009; Tu and Lu 2009). Some concrete constitutive models developed to incorporate the porous EOS of concrete include the Johnson and Holmquist (JH) (Johnson and Holmquist 1994), the Gebbeken 
and Ruppert (GR) (Gebbeken and Ruppert 2000) and the Riedel-Hiermaier-Thoma (RHT) (Riedel et al. 1999) models. The JH model developed in 1993 gives a comprehensive description of the concrete material under general loading conditions (Tu and $\mathrm{Lu}$ 2009). In developing the concrete constitutive model, Johnson and Holmquist (1994) considered concrete to have a linear elastic behaviour until failure. Also the JH model assumes damage of concrete accumulates with increase in dynamic loading. Equations for the failure and post failure surfaces of the concrete were formulated as shown in equations 2-13 and 2-16 respectively. The concrete material maintains a residual state beyond total failure.

$$
\begin{aligned}
& \sigma^{*}=\left[\mathrm{A}+\mathrm{BP}{ }^{* \mathrm{~N}}\right] \times\left(1+\mathrm{CIn}^{*}\right) \text { for } \sigma^{*} \leq \mathrm{SMAX} \\
& \sigma^{*}=\operatorname{SMAX} \text { for } \sigma^{*}>\operatorname{SMAX} \\
& \sigma^{*}=\frac{\sqrt{3 \mathrm{~J}_{2}}}{\mathrm{f}_{\mathrm{c}}{ }^{\prime}}
\end{aligned}
$$

Where ${ }^{*}$ denotes normalized quantities, $\mathrm{P}^{*}$ is the normalized pressure with respect to $\mathrm{f}_{\mathrm{c}}$, $\varepsilon^{*}$ denotes the normalised equivalent plastic strain rate. The equivalent plastic strain is normalized with respect to a unit strain rate, while $A, B, N$ and $C$ are constants. The constant SMAX is the maximum strength obtained for the concrete material, $\mathrm{J}_{2}$ is the second deviatoric stress invariant and $f_{c}$ ' is the uniaxial compressive strength of concrete (Riedel et al. 1999; Tu and Lu 2009).

$\sigma_{\mathrm{Pf}}^{*}=\left[\mathrm{A}(1-\mathrm{D})+\mathrm{BP}^{* \mathrm{~N}}\right] \times\left(1+\mathrm{CIn} \varepsilon^{*}\right)$

where $D$, accumulated by inelastic deformations describes the material damage, ranging from 0 to 1 . The inclusion of the damage parameter reduces the cohesion strength value 
of the initial failure surface. The yield surface is not smooth over the pressure range for the JH model; rather the yield surface has a sharp cut-off plane. The normalised parameters and stress variables make it easier to implement the $\mathrm{JH}$ model in other strength models. However, the JH model is incapable of solving every static and dynamic event. Although experimental results show inelastic deformations with hardening before peak load and reduced failure strength on meridians of triaxial compressions, they are not exhibited by the JH model (Riedel et al. 1999; Tu and Lu 2009). The JH model does not consider the third deviatoric stress invariant, $J_{3}$. However, both the RHT (Riedel et al. 1999) and the GR models, enhanced forms of the JH model, considered the third invariant $J_{3}$ in defining the strength surfaces (Gebbeken and Ruppert 2000). While the RHT model considers the strain hardening effects, both the JH and GR models do not. Also, the RHT model considers an independent fracture surface and a rate dependent hydrostatic strength for concrete as shown in equations 2-17 and 2-18.

The failure surface is defined as:

$$
\begin{aligned}
& \mathrm{Y}_{\text {fail }}\left(\mathrm{p}^{*}, \theta, \dot{\varepsilon}\right)=\mathrm{Y}_{\mathrm{c}}\left(\mathrm{p}^{*}\right) \times \mathrm{r}_{3}(\theta) \times \mathrm{F}_{\text {rate }}(\dot{\varepsilon}) \\
& \mathrm{Y}_{\mathrm{c}}\left(\mathrm{p}^{*}\right)=\mathrm{f}^{\prime}{ }_{\mathrm{c}} \times\left[\mathrm{A} \times\left(\mathrm{p}^{*}-\mathrm{p}_{\text {spall }}^{*} \times \mathrm{F}_{\text {rate }}(\dot{\varepsilon})\right)^{\mathrm{N}}\right] \\
& \mathrm{p}^{*}=\frac{\mathrm{p}}{\mathrm{f}^{\prime}{ }_{\mathrm{c}}} \\
& \mathrm{p}_{\text {spall }}^{*}=\frac{\mathrm{f}_{\mathrm{t}}}{\mathrm{f}^{\prime}{ }_{\mathrm{c}}}
\end{aligned}
$$

Where $f_{c}$ and $f_{t}$ are the uniaxial compressive and tensile strength of concrete respectively, and the constants $A$ and $N$ are the model parameters. The rate factor 
$\mathrm{F}_{\text {rate }}(\dot{\varepsilon})$ denotes the dynamic increase factor (DIF) of the tensile strength as a function of the strain rate (Riedel et al. 1999; Brannon and Leelavanichkul 2009; Riedel et al. 2009). The dynamic increase factor is defined in accordance with equation 2-21 as:

$$
\begin{aligned}
& \mathrm{F}_{\text {rate }}(\dot{\varepsilon})=\left\{\begin{array}{llll}
\left(\frac{\dot{\varepsilon}}{\dot{\varepsilon_{0}}}\right)^{\alpha}: & \mathrm{p}>\mathrm{f}_{\mathrm{c}}^{\prime}, & \text { for } \dot{\varepsilon} \leq 30 \times \mathrm{s}^{-1} \\
\left(\frac{\dot{\varepsilon}}{\dot{\varepsilon_{0}}}\right)^{\beta}: \mathrm{p}^{\beta} \mathrm{f}_{\mathrm{c}}^{\prime}, & \text { for } \dot{\varepsilon}>30 \times \mathrm{s}^{-1}
\end{array}\right\} \\
& \alpha=\frac{1}{5+\frac{3}{4} f_{c}^{\prime}} \\
& \beta=\frac{1}{10+\frac{1}{2} f_{c}^{\prime}} \\
& \mathrm{Y}_{\text {elastic }}=\mathrm{Y}_{\text {fail }}\left(\frac{\mathrm{p}^{*}}{\mathrm{~F}_{\text {elastic }}}\right) \mathrm{F}_{\text {elastic }} \times \mathrm{F}_{\text {cap }}(\mathrm{p}) \\
& F_{\text {cap }}(p)=\left\{\begin{array}{cc}
1 & \text { for } p \leq p_{u}={f^{\prime}}^{\prime} / 3 \\
\sqrt{1-\left(\frac{p-p_{u}}{p_{o}-p_{u}}\right)^{2}} & \text { for } p_{u}<p<p_{o} \\
0 & \text { for } p \geq p_{o}=p_{e l}
\end{array}\right\}
\end{aligned}
$$

where $\dot{\varepsilon}_{\mathrm{o}}=3 \times 10^{-6} \mathrm{~S}^{-1}$ and $\mathrm{p}_{\mathrm{o}}$ is the upper cap pressure, the pressure at which the elastic limit surface intercepts the hydrostatic axis.

$\mathrm{p}_{\mathrm{u}}$ is the lower cap pressure, the pressure where the uniaxial compression path intercepts the elastic limit surface as shown in Figure 2-6 (Riedel et al. 1999; Riedel et al. 2009; Brannon and Leelavanichkul 2009; Tu and Lu 2009). 


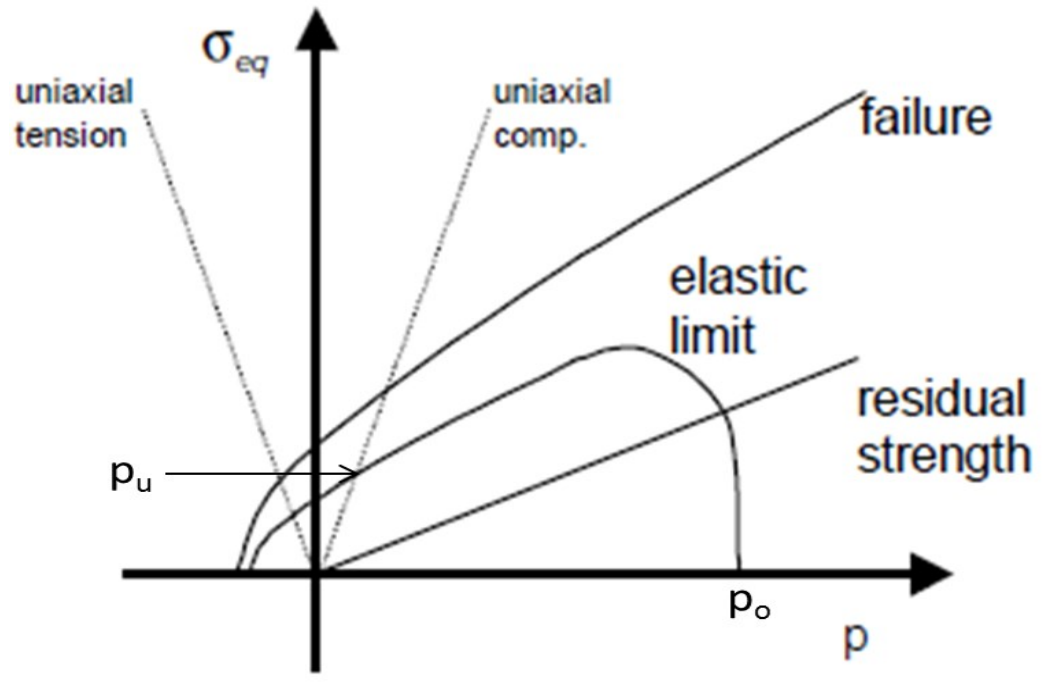

Figure 2-6: Concept of three limit surfaces (Riedel et al. 1999)

The RHT model also introduced an independently defined residual strength to describe the strength of the crushed material ( $\mathrm{Tu}$ and $\mathrm{Lu} 2009$ ).

$$
\mathrm{Y}_{\text {residual }}=\mathrm{B} \times\left(\mathrm{p}^{*}\right)^{\mathrm{M}} \times \frac{\left[\operatorname{sgn}\left(\mathrm{p}^{*}\right)+1\right]}{2}
$$

where the sign function $\operatorname{sgn}\left(\mathrm{p}^{*}\right)$ is defined as:

$$
\operatorname{sgn}\left(\mathrm{p}^{*}\right)=\left\{\begin{array}{ll}
1 & \mathrm{p}^{*}>0 \\
0 & \mathrm{p}^{*}=0 \\
-1 & \mathrm{p}^{*}<0
\end{array}\right\}
$$

The loading and post loading surfaces are defined as

$$
\begin{aligned}
& Y_{\text {loading }}=Y_{\text {elastic }}+\frac{\varepsilon_{\text {pl }}}{\varepsilon_{\text {pl(presoftening })}} \times\left(Y_{\text {fail }}-Y_{\text {elastic }}\right) \\
& Y_{\text {fracture }}=D+Y_{\text {residual }}+(1-D) \times Y_{\text {fail }}
\end{aligned}
$$

The definition of the damage parameter, $\mathrm{D}$ is shown in equation 2-38.

The parameters $\varepsilon_{\mathrm{pl}}$ is the plastic strain and $\varepsilon_{\mathrm{pl} \text { (presoftening) }}$ is the difference between the strain at the failure surface and the strain at the elastic strength surface (equation 2-30) are shown in Figure 2-7. 


$$
\varepsilon_{\text {pl }(\text { presoftening })}=\frac{Y_{\text {fail }}-Y_{\text {elastic }}}{3 G} \times\left(\frac{G_{\text {elastic }}}{G_{\text {elastic }}-G_{\text {plastic }}}\right)
$$

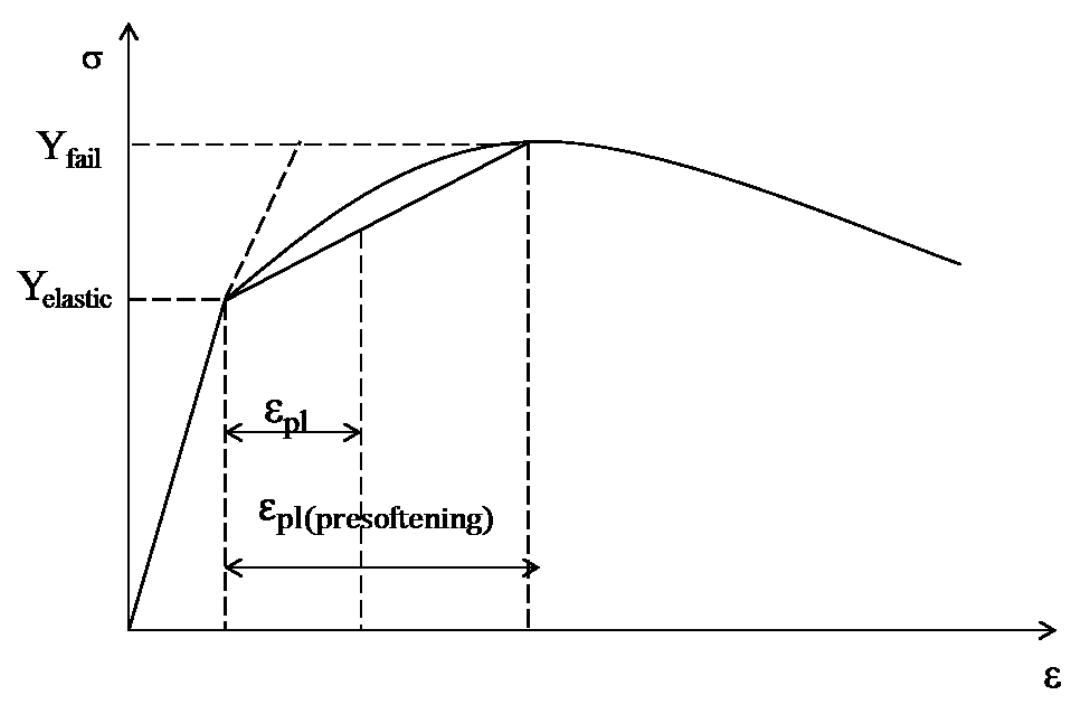

Figure 2-7: Illustrations of strain hardening, RHT model (Brannon and Leelavanichkul 2009; Tu and Lu 2009)

Also, the yield surface of the concrete material in the GR model is smooth over the pressure range as compared to the $\mathrm{JH}$ model. The yield surface in the GR model is defined by equation 2-31.

$$
\tau_{0}=a \times\left(\frac{b-\sigma_{0}}{c-\sigma_{0}}\right)^{d}
$$

where $\tau_{0}$ and $\sigma_{0}$ are the normalized octahedral shear stress and normal stress with respect to $\mathrm{f}_{\mathrm{c}}, b$ is the normalized hydrostatic tensile limit, the variable $a$ also denotes the upper limit for $\tau_{0}$ as $\sigma_{0}$ approaches positive infinity. The exponent $d$ is a parameter that controls the shape of the yield surface ( $\mathrm{Tu}$ and $\mathrm{Lu}$ 2009; Gebbeken and Ruppert 2000). The 
variable $c$ reflects the third stress invariant's influence and is defined as given in equation $2-32$ as;

$$
\mathrm{c}=\mathrm{c}_{\mathrm{t}} \times(\cos 1.5 \theta)^{1.5}+\mathrm{c}_{\mathrm{C}} \times(\sin 1.5 \theta)^{2.0}
$$

where the parameters $c_{t}$ and $c_{c}$ are associated with the tensile and compressive meridians. The material damage is taken into account during the strain rate enhancement. The GR model introduced a hyperbolic function to cap the magnitude of the enhancement factor for very high strain rates as shown in equation $2-33$ below:

$$
\frac{\mathrm{f}_{\mathrm{c}}^{\mathrm{dyn}}}{\mathrm{f}_{\mathrm{c}}}=\left\{\tanh \left[\left(\log \varepsilon^{*}-2.0\right) \times 0.4\right] \times\left(\frac{\mathrm{F}_{\mathrm{m}}}{\mathrm{W}_{\mathrm{y}}}-1.0\right)+1.0\right\} \times \mathrm{W}_{\mathrm{y}}
$$

$F_{m}$ is the limiting value of the rate enhancement factor when the strain rate approaches infinity. $\mathrm{F}_{\mathrm{m}}$ and $\mathrm{W}_{\mathrm{y}}$ are both functions of the damage index ( $\mathrm{Tu}$ and $\mathrm{Lu} 2009$; Gebbeken and Ruppert 2000).

All three concrete constitutive models included a damage parameter. The JH model defined the damage in accordance with equation 2-34 (Tu and Lu 2009). However, this definition was not able to fully capture the behaviour of the concrete. Gebbeken and Ruppert (Gebbeken and Ruppert 2000) introduced another damage parameter that used the average to define the damage of the concrete material as shown in equations $2-35$, 2-36 and 2-37. However, the RHT model introduced a damage parameter similar to that of the $\mathrm{JH}$ model as shown in equation 2-38.

$$
\mathrm{D}=\int_{0}^{\varepsilon_{\mathrm{P}}} \frac{\mathrm{d} \varepsilon_{\mathrm{P}}}{\mathrm{FS}\left(\mathrm{P}^{*}\right)}
$$


Where $d \varepsilon_{P}=d \bar{\varepsilon}_{P}+d \mu_{P}, d \bar{\varepsilon}_{P}$ is the equivalent plastic increment and $d \mu_{P}$ is the plastic volumetric strain increment. $D_{2}$ is defined in equation 2-35 as the concrete damage due to the volumetric compaction.

$$
\begin{aligned}
& \mathrm{D}_{2}=\int_{0}^{\mu_{\text {por }}(\mathrm{t})} \gamma \times\left(\frac{\mu_{\text {por }}(\mathrm{t})}{\mu_{\text {gran }}}\right)^{\gamma-1} \times \frac{\mathrm{d} \mu_{\text {por }}(\mathrm{t})}{\mu_{\text {gran }}} \\
& \mathrm{D}_{1}=\int_{0}^{\varepsilon_{\mathrm{P}}} \frac{\mathrm{d} \varepsilon_{\mathrm{P}}}{\mathrm{FS}\left(\mathrm{P}^{*}\right)}
\end{aligned}
$$

Where $d \varepsilon_{\mathrm{P}}=\mathrm{d} \bar{\varepsilon}_{\mathrm{P}}$

Both $D_{1}$ and $D_{2}$ are combined to determine the overall damage as shown in equation 2-37

as;

$$
\begin{aligned}
& \mathrm{D}=\sqrt{\mathrm{D}_{1}^{2}+\mathrm{D}_{2}^{2}} \leq 1.0 \\
& \mathrm{D}=\sum \frac{\Delta \varepsilon_{\mathrm{P}}}{\mathrm{FS}\left(\mathrm{P}^{*}\right)}
\end{aligned}
$$

$\Delta \varepsilon_{\mathrm{p}}$ is the accumulated plastic strain

$$
\text { FS }\left(\mathrm{P}^{*}\right)=\mathrm{D}_{1}\left(\mathrm{P}^{*}-\mathrm{p}_{\text {spall }}^{*}\right)^{\mathrm{D}_{2}}
$$

$D_{1}$ and $D_{2}$ are input parameters (Riedel et al. 2009; Tu and Lu 2009). 


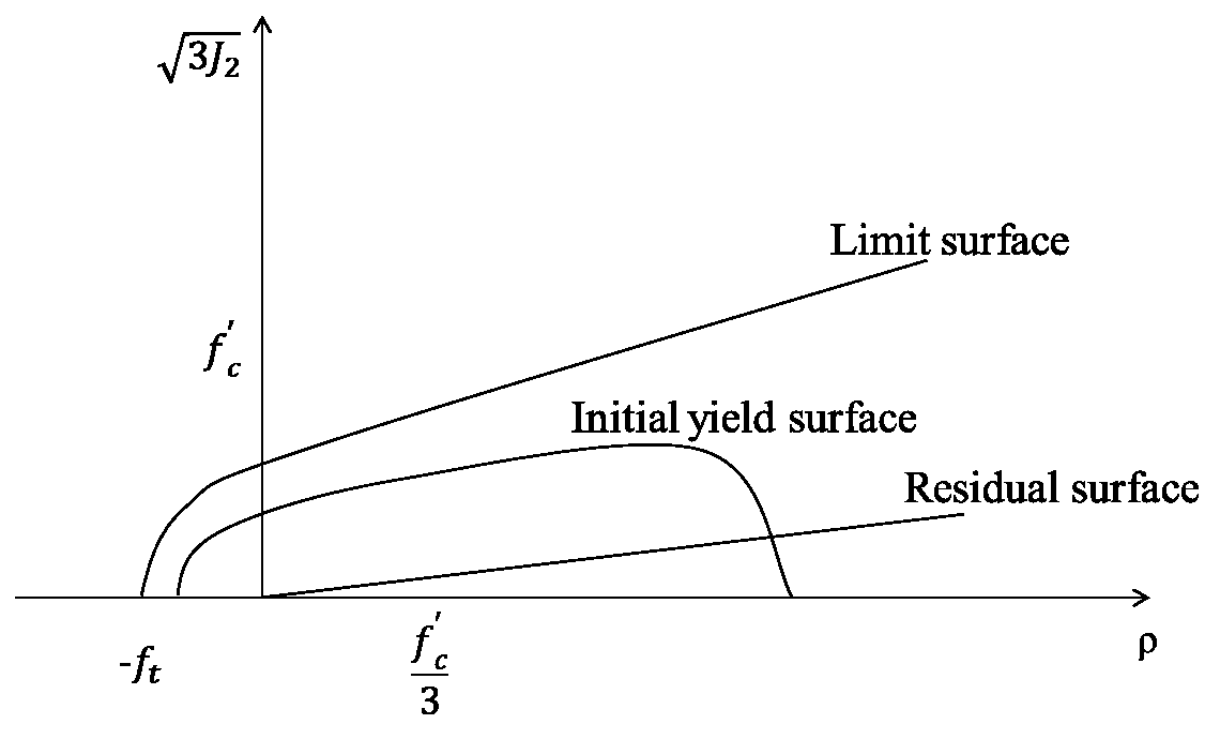

Figure 2-8: Failure Surface, RHT model (Brannon and Leelavanichkul 2009)

\subsection{Review of Steel Constitutive Models}

Research activities in the development of steel constitutive models have increased in recent times. Johnson and Cook developed an AUTODYN constitutive model for 4340 steel (Johnson and Cook 1985), an alloy of Nickel, Chromium and Molybdenum. Johnson and Cook (1985) used torsion test data to determine the parameters needed to formulate the constitutive model. The strength model used in the Johnson Cook (JC) model is formulated using Von Misses tensile stress (Johnson and Cook 1985).

$$
\sigma=\left(\mathrm{C}_{1}+\mathrm{C}_{2} \varepsilon^{\mathrm{n}}\right)\left(1+\mathrm{C}_{3} \operatorname{In} \varepsilon^{*}\right)\left(1-\mathrm{T}^{* \mathrm{~m}}\right)
$$

Where $\varepsilon$ is the equivalent plastic strain, $\varepsilon^{*}$ is a dimensionless plastic strain, and $\mathrm{T}^{*}$ is the homologous temperature. $C_{1}, C_{2}, C_{3}, n$, and $m$ are steel material constants. The expression $\left[\mathrm{C}_{1}+\mathrm{C}_{2} \varepsilon^{\mathrm{n}}\right]$ represents the stress function when $\varepsilon^{*}=1$ and $\mathrm{T}^{*}=0$. The second and third terms of equation 2-40 represent the effects of strain rate and temperature on 4340 steel, respectively. The fracture model developed by Johnson and Cook is 
dependent on the strain rate, temperature and pressure (Johnson and Cook 1985) and is presented in equation 2-42. Fracture of 4340 steel occurs when $D=1$.

$$
\begin{aligned}
& \mathrm{D}=\sum \frac{\Delta \varepsilon}{\varepsilon^{\mathrm{f}}} \\
& \varepsilon^{\mathrm{f}}=\left[\mathrm{D}_{1}+\mathrm{D}_{2}{ }^{\mathrm{D}_{2} \sigma^{\mathrm{m}}}\right]\left[1+\mathrm{D}_{4} \operatorname{In} \varepsilon^{*}\right]\left[1+\mathrm{D}_{5} \mathrm{~T}^{*}\right] \text { for } \sigma^{*} \leq 1.5 \\
& \sigma^{*}=\frac{\sigma^{\mathrm{m}}}{\sigma^{-}}
\end{aligned}
$$

$\sigma^{*}$ is a dimensionless pressure-stress ratio, $\sigma^{\mathrm{m}}$ is average of the three normal stresses, $\sigma$ is Von Misses equivalent stress, and $\mathrm{D}_{1}, \mathrm{D}_{2}, \mathrm{D}_{3}, \mathrm{D}_{4}, \mathrm{D}_{5}$ are material constants. Also, the fracture strain decreases as the hydrostatic stress increases (Johnson and Cook 1985). The JC model is incapable of accurately predicting the strength of steel with strains exceeding $10^{3} \mathrm{~s}^{-1}$. This is because at high strain rates, the yield stress increases tremendously. This limitation of the JC model resulted in development of the modified JC model to include an upper bound for the yield strength (Rule and Jones 1998). The yield strength varied with the logarithm of the dimensionless strain. The strength model in the modified JC models is presented in equation 2-44.

$$
\sigma=\left[C_{1}+C_{2} \varepsilon^{n}\right] \times\left[1+C_{3} \ln \varepsilon^{*}+C_{4}\left(\frac{1}{C_{5}-\ln \varepsilon^{*}}-\frac{1}{C_{5}}\right)\right]\left(1-T^{* m}\right)
$$

where $\mathrm{C}_{4}$ and $\mathrm{C}_{5}$ are empirical coefficients. Strain rate sensitivity of the material is enhanced by the introduction of the expression $1 /\left(\mathrm{C}_{5}-\ln \varepsilon^{*}\right) . \mathrm{C}_{5}$ is the natural logarithm of the critical strain rate level. The contribution of the strain rate sensitivity enhancement term becomes zero at low strain rates. Hence the modified JC model tends towards the JC model. The deviation of the modified model from the original JC model is controlled by the coefficient $\mathrm{C}_{4}$. Also, a peak strain rate sensitivity factor is introduced to prevent 
unrealistic occurrence of an infinite yield strength as $\ln \varepsilon^{*}$ approaches $C_{5}$. The peak strain rate sensitivity factor is defined as

$$
\left[1+C_{3} \operatorname{In} \varepsilon^{*}+C_{4}\left(\frac{1}{C_{5}-\operatorname{In} \varepsilon^{*}}-\frac{1}{C_{5}}\right)\right] \leq C_{6}
$$

with a maximum value set to $\mathrm{C}_{6}$; an assumed constant value for the peak strain rate sensitivity factor (Rule and Jones 1998).

\subsection{Effects of High Strain Loading on Concrete and Steel}

\subsubsection{Concrete}

Research has shown that both the tensile and compressive strength of concrete increase significantly under high strain rates (Figure 2-9) (Malvar and Ross 1998; Schuler et al. 2006; Fu et al. 1991; Yan and Lin 2006; Le Nard and Bailly 2000; Lu and Xu 2004; Van Amelsfort and Weerheijm 1988; Razaqpur et al. 2009; Ožbolt and Sharma 2011). Other properties of concrete such as modulus of elasticity and strain at ultimate strength are also affected by increased strain rate (Krauthammer 1994; Low and Hao 2001; Fu et al. 1991; Bischoff and Perry 1991; Razaqpur et al. 2009). At high strain rates of the order $10 \mathrm{~s}^{-1}$ (Figure 2-10), Malvar and Ross (1998) observed about a 100\% increase in the concrete compressive strength while Van Amelsfort and Weerheijm (1988) observed about 80\% increase in the concrete compressive strength. Also $\mathrm{Lu}$ and $\mathrm{Xu}$ (2004) observed a $150 \%$ increase in the compressive strength at strain rate of order $10^{2} \mathrm{~s}^{-1}$.

Although, there has been documented increase in the compressive strength, at higher static compressive strength, concrete becomes less sensitive to increase in strain rates (Fu et al. 1991). Zech and Wittmann (1980) conducted tests on two concrete beams of 23 MPa and 55 MPa static compressive strength. Zech and Wittmann (1980) observed that 
the strength increase for the $55 \mathrm{MPa}$ concrete beam was less than that of the $23 \mathrm{MPa}$ concrete beam. Also research conducted by Yan and Lin (2006) documented the effects of water on the concrete response to increased strain rate. Yan and Lin (2006) observed a higher increased concrete tensile and compressive strength for saturated concrete than for unsaturated concrete.

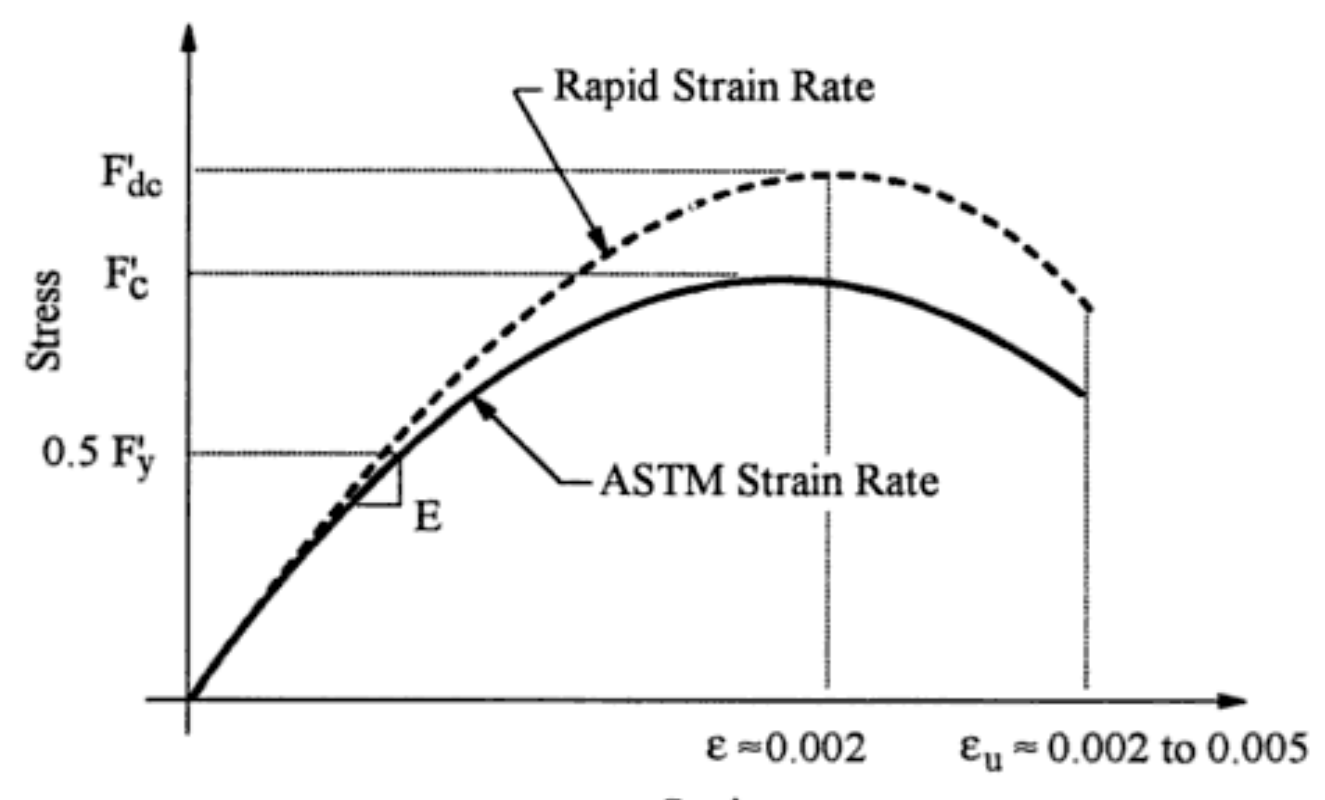

Strain

Figure 2-9: Effect of strain rate on concrete compressive strength (ASCE 2010)

Strain rate effects on the tensile strength of concrete are much more significant than on the compressive strength (Malvar and Ross 1998; Lu and Xu 2004). While Malvar and Ross (1998) observed about 600\% increase in the tensile strength of concrete under high strain rates, Schuler et al. (2006) observed between 400 and 550\% increase at strain rate of the order $10^{2} \mathrm{~s}^{-1}$. Lu and $\mathrm{Xu}(2004)$ also stated increases between $400 \%$ and $700 \%$ in the concrete tensile strength at strain rates of $10 \mathrm{~s}^{-1}$ and $10^{2} \mathrm{~s}^{-1}$ respectively. 


\subsubsection{Steel}

Steel reinforcement also exhibit increased in strength with increased strain rates. Testing on steel reinforcement has shown that the yield strength, ultimate strength and ultimate strain of steel are affected under high strain rates (Flathau 1971; Asprone et al. 2009; Soroushian and Choi 1987; Fu et al. 1991). Malvar and Ross (1998) stated that the yield strength of steel increased was about 50\%, while Fu et al. (1991) observed about 25 to $53 \%$ increases in the yield strength. Flauthau (1971) reported that the yield strength of Grade 60 steel increases to $175 \%$ of the static yield strength under high strain rates.

Similar to concrete, high steel strength is also less sensitive to strain rates (Flathau 1971; Soroushian and Choi 1987). Fu et al. (1991) compared the increase in yield strength of two steel members with static yield strength of $278 \mathrm{MPa}$ and $330 \mathrm{MPa}$. Fu et al. (1991) observed that the $278 \mathrm{MPa}$ steel member showed a 14\% increase in strength while the $330 \mathrm{MPa}$ steel member showed a 12\% increase in strength. Flathau (1971) also observed $17 \%$ and $75 \%$ increase in the yield strength when $520 \mathrm{MPa}$ and $420 \mathrm{MPa}$ steel members were compared.

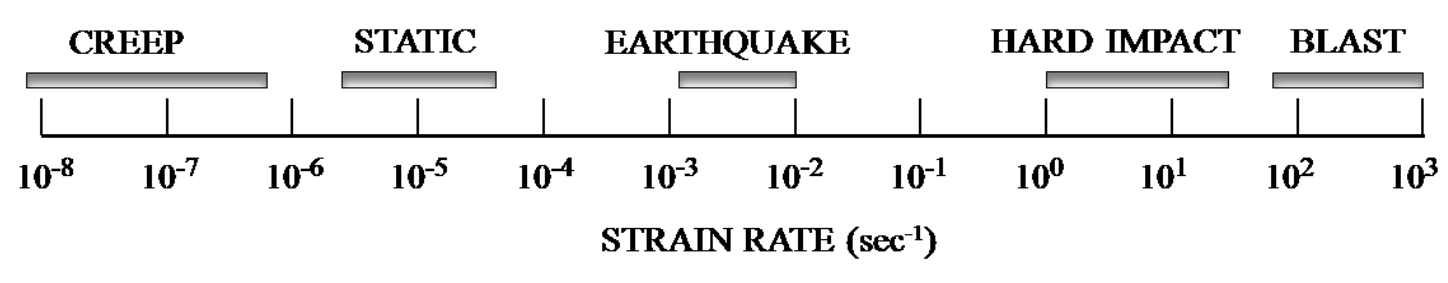

Figure 2-10: Magnitude of strain rates Reproduced from (Bischoff and Perry 1991). 


\subsubsection{Dynamic Increase Factor (DIF)}

Although research has shown an increase in the strength of concrete and steel under high rates of strain, there are some differences in the magnitude of strength increase. Formulating models to account for the effect of strain rate on all the properties of structural materials is very complex. The complexity increases with material nonlinearity. The strain rate effect on concrete properties is dependent on conditions such as moisture content, aggregate type and curing conditions (Fu et al. 1991; Yan and Lin 2006). However using constant strain rate has produced accurate results (Watstein 1953; Bischoff and Perry 1991; Low and Hao 2001). A dynamic increase factor (DIF) defined as the ratio of the dynamic to static material strength is used in modelling to account for the increase in strength for both concrete and steel (Malvar and Ross 1998; Lu and Xu 2004). Watstein et al. (1953) used DIF of 1.4 and 1.2 for the strength and young's modulus respectively for a $30 \mathrm{MPa}$ concrete. In order cases, the DIF was formulated using equations which represented both the tensile and compressive strength increase.

DIF formulation for compressive strength of concrete is shown in Figure 2-11 together with equations 2-46 to 2-49. Malvar and Ross (1998) studies of the behavioour of concrete members under increased strain rates agreed with the Comité Euro-International du Béton (CEB) formulation (1993) for concrete in compression. Malvar and Rose obsverved that the CEB curves in Figure 2-11 were in good agreement with experimental data. 


$$
\begin{gathered}
\mathrm{f}_{c} / \mathrm{f}_{\mathrm{cs}}=\left(\frac{\dot{\varepsilon}}{\dot{\varepsilon_{\mathrm{s}}}}\right)^{1.026 \alpha} \text { for } \dot{\varepsilon} \leq 30 \mathrm{~s}^{-1} \\
\mathrm{f}_{\mathrm{c}} / \mathrm{f}_{\mathrm{cs}}=\gamma\left(\dot{\varepsilon}^{\prime}\right)^{1 / 3} \text { for } \dot{\varepsilon}>30 \mathrm{~s}^{-1} \\
\delta=\frac{1}{5+\frac{3 \mathrm{f}_{\mathrm{c}}^{\prime}}{4}} \\
\log \gamma=6.15 \alpha-0.492
\end{gathered}
$$

Where $\mathrm{f}_{\mathrm{c}}$ is the dynamic compressive strength at $\dot{\varepsilon}$ and $\mathrm{f}_{\mathrm{cs}}$ is the static compressive strength of concrete. The static strain rate $\dot{\varepsilon}_{\mathrm{s}}$ is equal to $30 \times 10^{-6} \mathrm{~s}^{-1}$.

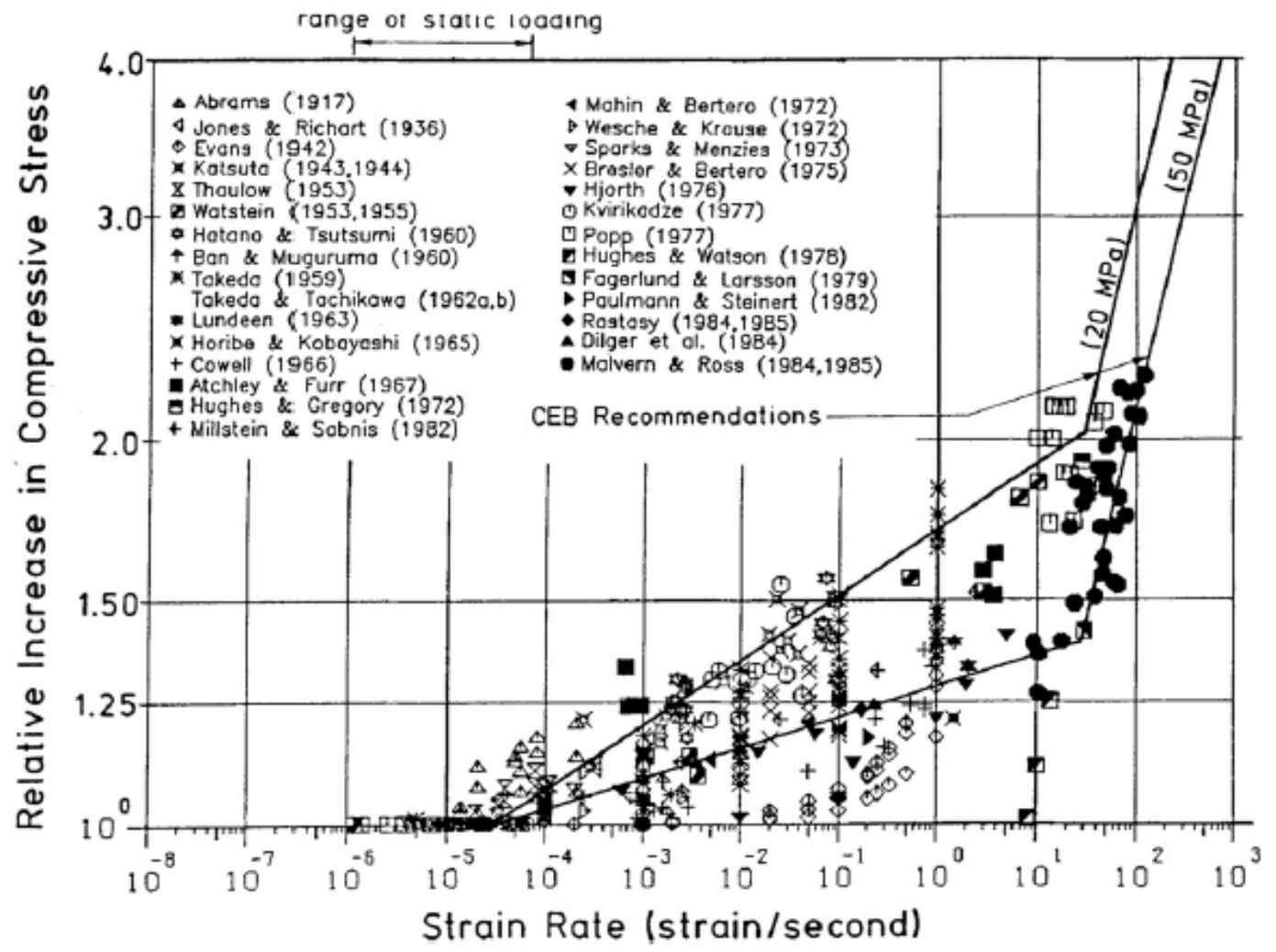

Figure 2-11: Strain rate for concrete in compression (Wu et al. 2011) 
DIF formulation for tensile strength is presented in Figure 2-12 with curve fitting for equations 2-50 to 2-53.

$$
\begin{gathered}
\mathrm{f}_{\mathrm{t}} / \mathrm{f}_{\mathrm{ts}}=\left(\frac{\dot{\varepsilon}}{\dot{\varepsilon_{\mathrm{s}}}}\right)^{1.016 \delta} \text { for } \dot{\varepsilon} \leq 30 \mathrm{~s}^{-1} \\
\mathrm{f}_{\mathrm{t}} / \mathrm{f}_{\mathrm{ts}}=\beta\left(\frac{\dot{\varepsilon}}{\dot{\varepsilon_{\mathrm{s}}}}\right)^{\omega} \text { for } \dot{\varepsilon}>30 \mathrm{~s}^{-1} \\
\delta=\frac{1}{10+\frac{6 \mathrm{f}_{\mathrm{c}}^{\prime}}{\mathrm{f}_{\mathrm{co}}^{\prime}}} \\
\log \beta=7.11 \delta-2.33
\end{gathered}
$$

Where $\mathrm{f}_{\mathrm{t}}$ is the dynamic tensile strength at $\dot{\varepsilon}$ and $\mathrm{f}_{\mathrm{ts}}$ is the static tensile strength of concrete. The static strain rate $\dot{\varepsilon}_{\mathrm{s}}$ is equal to $3 \times 10^{-6} \mathrm{~s}^{-1}, \mathrm{f}_{\mathrm{co}}$ is $10 \mathrm{MPa}$, and $\omega$ is the tensile strain rate exponent equal to $1 / 3$.

From Figure 2-12 for a $30 \mathrm{MPa}$ concrete, the maximum DIF was observed to be 3.9 at $300 \mathrm{~s}^{-1}$. However, Malvar and Rose (1998) reported from a literature review that much larger DIF for concrete in tension could be achieved in testing. Also Asprone et al. (2009) stated that the CEB formulation for DIF in tension underestimated the dynamic tensile strength of concrete. The CEB formulation of the DIF for tension, as shown in Figure 2-12, has a change in the slope at $30 \mathrm{~s}^{-1}$ and valid for upto $300 \mathrm{~s}^{-1}$. Malvar and Rose (1998) also proposed a quasi-static strain rate of $1 \times 10^{-6} \mathrm{~s}^{-1}$ as opposed to the CEB formulation of $3 \times 10^{-6} \mathrm{~s}^{-1}$. This resulted in the modfication of the CEB DIF for tension as 
shown in Figure 2-12. The proposed modified CEB tensile DIF was presented in equations $2-54$ to $2-57$.

$$
\begin{gathered}
\mathrm{f}_{\mathrm{t}} / \mathrm{f}_{\mathrm{ts}}=\left(\frac{\dot{\varepsilon}}{\dot{\varepsilon_{\mathrm{s}}}}\right)^{\delta} \text { for } \dot{\varepsilon} \leq 1 \mathrm{~s}^{-1} \\
\mathrm{f}_{\mathrm{t}} / \mathrm{f}_{\mathrm{ts}}=\beta\left(\frac{\dot{\varepsilon}}{\dot{\dot{\varepsilon}_{\mathrm{s}}}}\right)^{\omega} \text { for } \dot{\varepsilon}>1 \mathrm{~s}^{-1} \\
\delta=\frac{1}{10+\frac{8 \mathrm{f}_{\mathrm{c}}^{\prime}}{\mathrm{f}_{\mathrm{co}}^{\prime}}} \\
\log \beta=6 \delta-2
\end{gathered}
$$

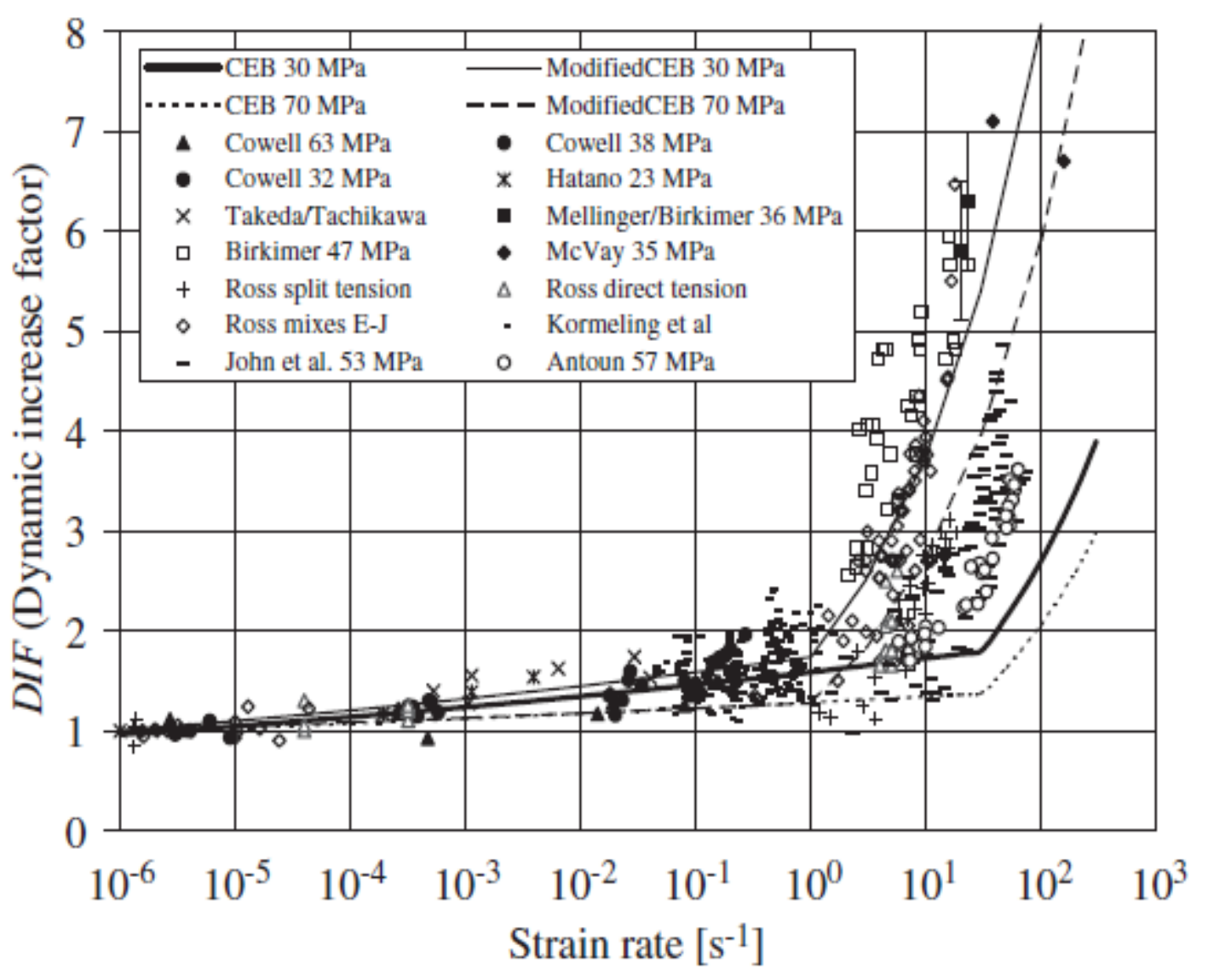

Figure 2-12: Strain rate for concrete in tension (Leppänen 2006) 
The stress-strain behaviour of concrete under dynamic loadings varies with increase in strain rate and knowledge of the behaviour of concrete under such high rate dynamic loading would better predict the response of concrete.

\subsection{Review of Research on Blast Loading on RC Members}

Many research works on the effects of blast loading on reinforced concrete elements have been published (Gebbeken et al. 2001; Weerheijm et al. 1984; Van Amelsfort and Weerheijm 1988; Leppänen 2006; Zhou et al. 2008; Kraus et al. 1994).

Computer related study on behaviour of reinforced concrete members has evolved in recent years from analytical studies to numerical analysis. Although SDOF analysis has been at the fore front of dynamic analysis, its inherent ability of only analysing general structural response has resulted in increased study into more advanced modes of analysis (Razaqpur et al. 2009). The development of hydrocodes to augment experimental testing has witnessed increased interest in recent years. Earlier numerical analysis techniques

consisted of one-dimensional modelling. Nash et al. (1995) investigated the response of unreinforced concrete walls using a one-dimensional numerical modelling technique which gave conservative estimates of spalling of concrete walls. Recent works on the behaviour of RC members have been three-dimensional numerical simulations (Zhou et al. 2008; $\mathrm{Xu}$ and $\mathrm{Lu}$ 2006). Research into concrete member behaviour has evolved from general structural response to studies on localised behaviour of structural members.

\subsubsection{Failure Modes}

In most of the analysis of reinforced concrete members under blast loading, reinforced concrete members experience both global and local failure (Zineddin and Krauthammer 
2007). While global failure results in the collapse of the entire structure, localised failure occurs on only some reinforced concrete members such as beams, slabs and columns. Global failure usually occurs under static and quasi-static loading (Sorensen and McGill 2011). While global failure of the entire structure can also result from large explosives at long distances, according to Braimah and Contestabile (2007) and Gebbeken et al. (2003), the probability of a successful terrorists' attack on infrastructure systems increases with a decrease in amount of explosives used as the probability of acquisition of the explosive is higher as well as the easy concealment of small explosive masses. As such detonation of small explosives in contact with reinforced concrete elements can result in localised failure of the elements. Shear (Figure 2-13) and flexural failure modes are dominant in reinforced concrete members experiencing both global and localised failures (Low and Hao 2002; Gebbeken et al. 2003; Sorensen and McGill 2011). Low and Hao (2002) stated that for some reinforced concrete members, flexural failure modes can be dominant at midspan under long duration and lower blast load amplitudes. Under short duration and high dynamic loads, however, shear failure can occur close to the supports of the reinforced concrete members. Localised failure modes such as concrete spalling, cratering, breaching, and fragmentation may not result in the collapse of the entire structure (Sorensen and McGill 2011; Gebbeken et al. 2003). 


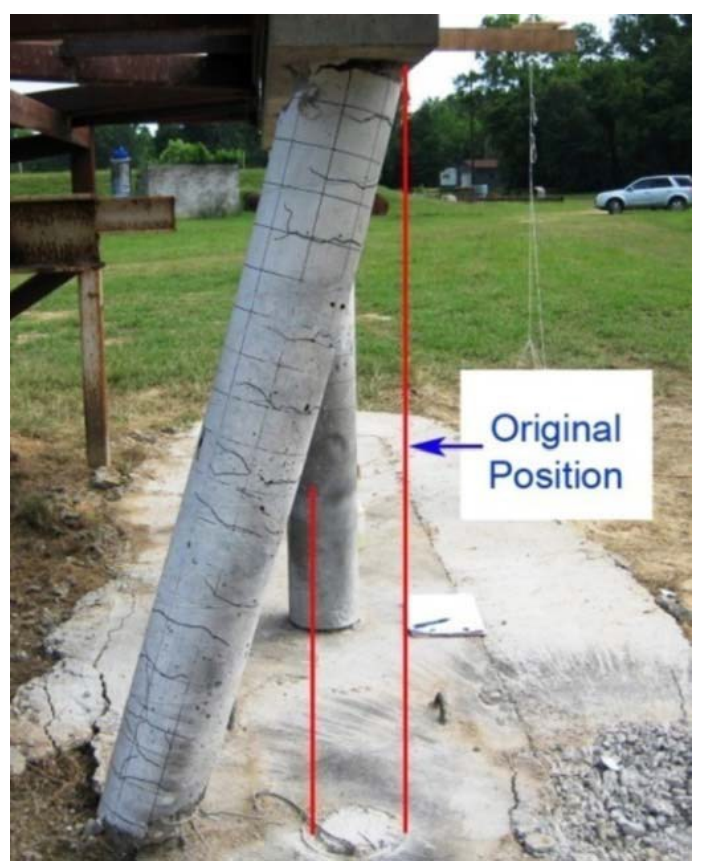

Figure 2-13: Shear failure on a circular column (Fujikura 2011)

\subsubsection{Concrete Spalling}

Concrete spalling, the ejection of concrete from the back face of a structural member, is a dominant failure mode in near-field explosions. Spalling is as a result of tension failure of the concrete member (Tai et al. 2011; Nash et al. 1995; Xu and Lu 2006; Yamaguchi et al. 2011). The magnitude of the reflected tensile waves from dynamic loading can exceed that of the tensile strength of concrete, thus forming cracks on the free surface of the concrete element subjected to explosion effects. As the magnitude of the blast load is increased, the cracks connect causing the ejection of fragments known as spall (Yuan et al. 2008; Birkimer and Lindemann 1971). Initial spalling tests were first conducted using the Split Hopkinson Pressure bar (Nash et al. 1995; Zielinski and Reinhardt 1982; Lee 2003; Gama and Gama 2004). 


\subsubsection{Numerical Simulation on Concrete Spalling}

As stated earlier, numerical simulation has evolved from 1-D to 3-D as the computer hardware evolved. Nash et al. (1995) modelled and studied the behaviour of 1-D unreinforced concrete wall under dynamic loading, assuming planar waves in the spalling process. Xu and Lu (2006) and Zhou et al. (2008) on the other hand considered the effects of non-planarity of the blast waves in the 3-D simulations. Also, Zhou et al. (2008) noted that concrete spalling is rare under low strain rates as is common in far-field explosion. Nash et al. (1995) assumed that there was no attenuation of stress wave as it propagates through concrete material whereas $\mathrm{Xu}$ and $\mathrm{Lu}$ (2006) reported that planar stress waves propagating through concrete can be altered to non-planar due to divergence and spatial distribution of the waves through the concrete.

In order to differentiate between the different stages of spalling, McVay (1988) and Xu and $\mathrm{Lu}$ (2006) categorised concrete spalling into three main categories: no damage, threshold for spall and medium spall. The "no damage" category was defined as the initial stages to barely visible cracking while the threshold for spall was defined as beginning from few cracks to hollow sounding and the onset of spalling. The moderate spall category was defined as damage up to a third of the thickness of a reinforced concrete member (McVay 1988).

\subsubsection{Field Experiment on Concrete Spalling}

Ohtsu et al. (2007), researching the effects of spalling on concrete slabs observed that the volume of concrete spall depends on the flexural toughness of the reinforced concrete slabs. The authors made this observation when they conducted field experiments on 16 slabs with different types of concrete. Namely, reinforced concrete, polyvinyl alcoholic 
fibre-reinforced concrete (PVAFRC), polyethylene fibre-reinforced concrete (PEFRC), and polypropylene fibre-reinforced concrete (PPFRC). The PEFRC had the highest flexural toughness resulting in the smallest spall volume while reinforced concrete had the lowest flexural toughness causing increased spall volume (Yamaguchi et al. 2011; Ohtsu et al. 2007). Yusof et al. (2011) also conducted field experiments on normal reinforced concrete and steel fibre reinforced concrete with varying steel fibre volume percentage. The authors observed that increasing steel fibre percentage volume decreased the damage in steel fibre reinforced concrete elements while increasing the flexural toughness. Tanapornraweekit et al. (2011) investigated the effects of multiple explosions on normal, single-sided fibre reinforced polymer (FRP), a single layered FRP sandwich, and double-layered FRP sandwich RC slabs. Tanapornraweekit et al. (2011) observed that the amount of spalling decreased when normal reinforced concrete slab behaviour was compared to that of a double-layered sandwich reinforced concrete slab.

\subsection{Summary}

The concrete constitutive models reviewed included the JH model, the GR model and the RHT model. The literature showed that the RHT model is well adapted for predicting the response and behaviour of reinforced concrete elements to nonlinear dynamic loading. The 4340 steel model which is based on the Johnson Cook strength model was also reviewed.

The effects of high strain loading on concrete and steel were also reviewed. There has been documentation on increase in both compressive and tensile strength of concrete under high strain rates although varying degrees of increase have been reported. The 
yield and ultimate strength of steel increased significantly under high strain rates. The literature showed that high strength concrete and steel are less sensitive to strain rate increases.

The increased strength of both concrete and steel under high strain rates is quantified with the dynamic increase factors (DIF); defined as the ratio of dynamic to static strength. Also the stress-strain behaviour of concrete under dynamic loadings varied with increase in strain rate.

The numerical study of the response of structural members under dynamic loading has evolved from one-dimensional to three-dimensional problems. The evolution has made the study of localised behaviour of reinforced concrete columns much more plausible. With this, the study of failure modes has also evolved from global failure modes to more localised failure modes. While global failure is primarily the collapse of an entire structure, localised failure occurs on reinforced concrete members such as slabs and columns. Some of the observed localised failure modes include concrete spalling, cratering, breaching, and fragmentation.

\subsection{Thesis Justification}

Due to recent increase in explosions attacks on infrastructural systems, many research works have been published in the literature studying the effects of blast loading on reinforced concrete elements. However most of the research is aimed at the response of elements such as columns to far-field blast loading. A few research works have investigated the response and behaviour of reinforced concrete columns, in particular, to 
near-field explosions. While large amount of explosives at far distances can cause extensive damage to infrastructure systems, small amount of explosives at closer distances can also cause significant damage to infrastructure systems. Also, the probability of terrorists' attack increases with a decrease in amount of explosives. Thus, it is much more plausible for reinforced concrete columns to be attacked with small amounts of explosives at near-field distances than a larger amount of explosive at a larger standoff distance. At near-field detonations it is difficult to conduct full scale experimental parametric study on reinforced concrete columns. This has been largely due to the destruction of instrumentation due to the effects of the blast effects such as the fire ball. Hence numerical simulations have proven to be the best alternative in the parametric analysis of columns under near-field and detonations. 


\section{Chapter: Numerical Simulation}

\subsection{Introduction}

Reinforced concrete columns were modelled in AUTODYN to investigate their behaviour when subjected to blast loads. The numerical investigation forms part of a comprehensive research program which includes an experimental program to determine the response of reinforced concrete columns under live explosive loading. This chapter outlines the dimensions of the numerical model, constitutive models used in the numerical analyses, and the interactions between blast wave and reinforced concrete column. Also, the validation of the numerical model is presented in this chapter.

\subsection{Dimensions of Numerical Model}

\subsubsection{Concrete}

Reinforced concrete columns were modelled using the numerical modelling softwareAUTODYN ${ }^{\circledR}$. The dimensions of the columns were the same as those of the columns in the experimental test program and had a $300 \times 300 \mathrm{~mm}$ cross section and a vertical height of $3000 \mathrm{~mm}$. The concrete strength was specified at $35 \mathrm{MPa}$; however, the concrete compressive test in the experimental program yielded a concrete strength of $40 \mathrm{MPa}$. All columns had a clear concrete cover of $40 \mathrm{~mm}$. Figure 3-1 shows the cross-section plan of the columns.

\subsubsection{Steel Reinforcement}

The same longitudinal reinforcement, $4-25 \mathrm{M}$, was used for the numerical model as for the experimental specimens. Also $10 \mathrm{M}$ ties were modelled for all the columns but with varying tie spacing. The tie spacing was in accordance with detailing for seismic and 
conventional design in the Canadian reinforced concrete design code (A23.3-04). The columns detailed for seismic zones were modelled with $75-\mathrm{mm}$ tie spacing in the plastic hinge zone while conventionally designed columns were modelled with both $150-\mathrm{mm}$ and 300-mm tie spacing. Figure 3-2 shows the longitudinal view of the columns with the three different tie spacing.

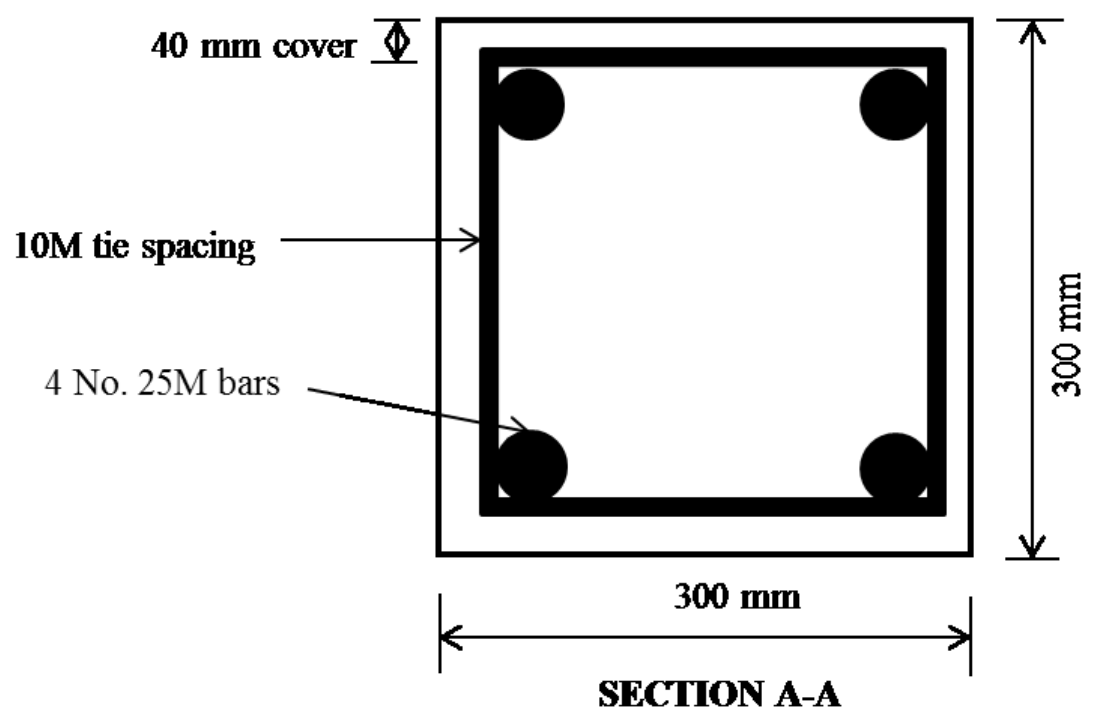

Figure 3-1: Cross-sectional plan of concrete columns 


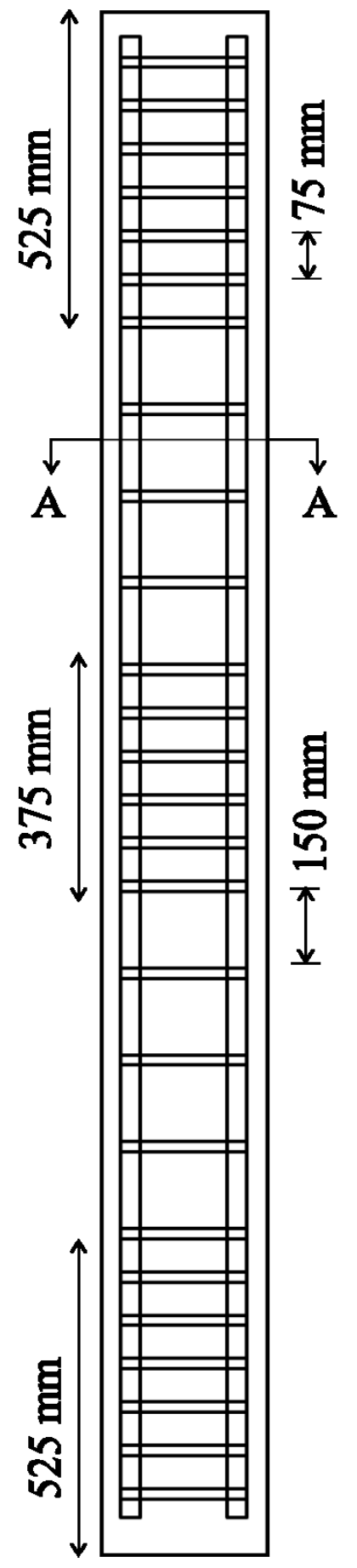

(a)

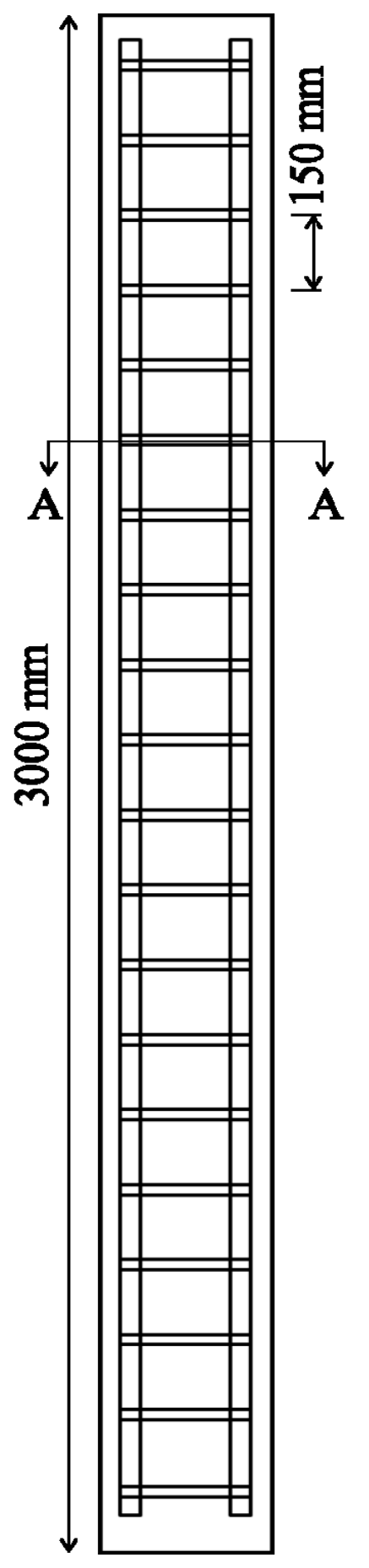

(b)

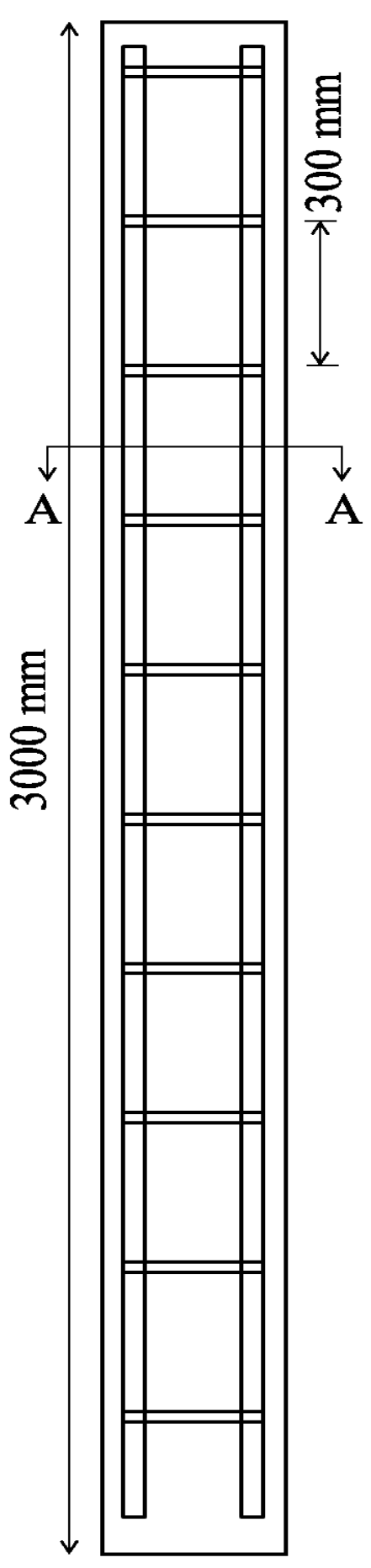

(c)

Figure 3-2: Tie spacing in RC columns: (a) 75-mm spacing, (b) 150-mm tie spacing, and (c) 300-mm tie spacing 


\subsection{Material Models Used in Numerical Simulations}

\subsubsection{Concrete Constitutive Material Model}

The RHT (Riedel et al. 1999) concrete material model was used in modelling the behaviour of the concrete columns. The RHT model predicts the behaviour of the concrete under blast loadings. However, modifications to the general RHT model in AUTODYN were required. While the default compressive strength value of $35 \mathrm{MPa}$ was used for the actual simulations, the strength was changed to $40 \mathrm{MPa}$, the experimental concrete compressive strength, when comparing with the experimental test results. The parameters for the concrete are presented in Table 3-1:.

Table 3-1: RHT Model Parameters for 35-MPa Concrete

\begin{tabular}{|l|l|l|l|}
\hline Parameter & Value & Parameter & Value \\
\hline Equation of State & P alpha & Shear Strength $(\mathrm{fs} / \mathrm{fc})$ & 0.18 \\
\hline Reference density $\left(\mathrm{g} / \mathrm{cm}^{3}\right)$ & 2.75 & Intact Failure Surface Constant A & 1.60 \\
\hline Porous density $\left(\mathrm{g} / \mathrm{cm}^{3}\right)$ & 2.31 & Intact Failure Surface Exp. N & 0.61 \\
\hline Porous soundspeed $(\mathrm{m} / \mathrm{s})$ & 2920.00 & Tens./Comp. Meridian Ratio $(\mathrm{Q})$ & 0.68 \\
\hline $\begin{array}{l}\text { Initial compaction pressure } \\
(\mathrm{MPa})\end{array}$ & 23.30 & Brittle to Ductile Transition & 0.01 \\
\hline $\begin{array}{l}\text { Solid compaction pressure } \\
(\mathrm{GPa})\end{array}$ & 6.00 & G (elastic)/ (elastic-plastic) & 2.00 \\
\hline Compaction exponent & 3.00 & Elastic Strength / ft & 0.70 \\
\hline Solid EOS & Polynomial & Elastic Strength / fc & 0.53 \\
\hline Bulk Modulus A1 $(\mathrm{GPa})$ & 35.27 & Fractured Strength Constant B & 1.60 \\
\hline Parameter A2 $(\mathrm{GPa})$ & 39.58 & Fractured Strength Exponent M & 0.61 \\
\hline Parameter A3 $(\mathrm{GPa})$ & 9.04 & $\begin{array}{l}\text { Compressive Strain Rate Exp. } \\
\text { Alpha }\end{array}$ & 0.03 \\
\hline Parameter B0 & 1.22 & Tensile Strain Rate Exp. Delta & 0.07 \\
\hline Parameter B1 & 1.22 & Use CAP on Elastic Surface? & Yes \\
\hline Parameter T1 $(\mathrm{GPa})$ & 35.27 & Failure & $\begin{array}{l}\text { RHT } \\
\text { Concrete }\end{array}$ \\
\hline Parameter T2 $(\mathrm{kPa})$ & 0.00 & Damage Constant, D1 & 0.04 \\
\hline Reference Temperature $(\mathrm{K})$ & 300.00 & Damage Constant, D2 & 1.00 \\
\hline Specific Heat $(\mathrm{J} / \mathrm{kgK})$ & 654.00 & Minimum Strain to Failure & 0.01 \\
\hline
\end{tabular}




\begin{tabular}{|l|l|l|l|}
\hline Compaction Curve & Standard & Residual Shear Modulus Fraction & 0.13 \\
\hline Strength & $\begin{array}{l}\text { RHT } \\
\text { Concrete }\end{array}$ & Tensile Failure & $\begin{array}{l}\text { Hydro } \\
\text { (Pmin) }\end{array}$ \\
\hline Shear Modulus $(\mathrm{GPa})$ & 16.70 & Erosion & $\begin{array}{l}\text { Geometric } \\
\text { Strain }\end{array}$ \\
\hline $\begin{array}{l}\text { Compressive Strength }(\mathrm{fc}) \\
(\mathrm{MPa})\end{array}$ & 35.00 & Erosion Strain & 2.00 \\
\hline Tensile Strength $(\mathrm{ft} / \mathrm{fc})$ & 0.10 & Type of Geometric Strain & Instantaneous \\
\hline
\end{tabular}

\subsubsection{Steel Constitutive Material Model}

The steel material model used for reinforcing steel (longitudinal and transverse) in the reinforced concrete column simulation was the 4340 Steel model developed by Johnson and Cook (1985). 4340 Steel model accurately predicts the interactions of reinforcing steel with the concrete under blast loading. The reinforcing steel used for the simulation had a yield stress of $400 \mathrm{MPa}$. Table 3-2 presents the parameters of the reinforcing bars of the 4340 Steel model used for the simulation.

Table 3-2: 4340 Steel Model Parameters of Steel Reinforcement

\begin{tabular}{|l|l|l|l|}
\hline Parameter & Value & Parameter & Value \\
\hline Equation of State & Linear & Strain Rate Constant & 0.01 \\
\hline Reference density $\left(\mathrm{g} / \mathrm{cm}^{3}\right)$ & 7.83 & $\begin{array}{l}\text { Thermal Softening } \\
\text { Exponent }\end{array}$ & 1.03 \\
\hline Bulk Modulus $(\mathrm{GPa})$ & 159.00 & Melting Temperature $(\mathrm{K})$ & 1793.00 \\
\hline Reference Temperature $(\mathrm{K})$ & 300.00 & Ref. Strain Rate $(/ \mathrm{s})$ & 1.00 \\
\hline Specific Heat $(\mathrm{J} / \mathrm{kgK})$ & 477.00 & Strain Rate Correction & 1st Order \\
\hline Strength Model & Johnson Cook & Failure & Principal Stress \\
\hline Shear Modulus (GPa) & 81.80 & $\begin{array}{l}\text { Principal Tensile Failure } \\
\text { Stress (MPa) }\end{array}$ & 600.00 \\
\hline Yield Stress (MPa) & 400.00 & Crack Softening & No \\
\hline Hardening Constant (MPa) & 510.00 & Stochastic failure & No \\
\hline Hardening Exponent & 0.26 & Erosion & None \\
\hline
\end{tabular}




\subsubsection{Parameters of the Air Model}

The air medium was modelled using ideal gas equation. The internal energy of the air model was entered as $2.068 \mathrm{e} 5 \mathrm{~kJ} / \mathrm{kg}$. The internal energy initialised the air medium to an atmospheric pressure of $101.3 \mathrm{kPa}$.

Table 3-3: Parameters of Air Model

\begin{tabular}{|l|l|}
\hline Parameter & Value \\
\hline Equation of State & Ideal Gas \\
\hline Reference density $\left(\mathrm{kg} / \mathrm{m}^{3}\right)$ & 1.225 \\
\hline Gamma, $\gamma$ & 1.40 \\
\hline Adiabatic constant & 0.00 \\
\hline Pressure shift $(\mathrm{kPa})$ & 0.00 \\
\hline Reference Temperature $(\mathrm{K})$ & 288.20 \\
\hline Specific Heat $(\mathrm{J} / \mathrm{kgK})$ & 717.60 \\
\hline
\end{tabular}

\subsection{Description of Modelling Process}

\subsubsection{Modelling of Concrete}

The concrete part of the column was modelled using Lagrangian elements. The columns were defined by using a structured mesh. The number of cells in the $\mathrm{X}, \mathrm{Y}$, and $\mathrm{Z}$ directions were 10, 100 and 10 respectively as shown in Figure 3-3. The cell divisions corresponded to a 30-mm mesh size and the total number of nodes was 10000 . 


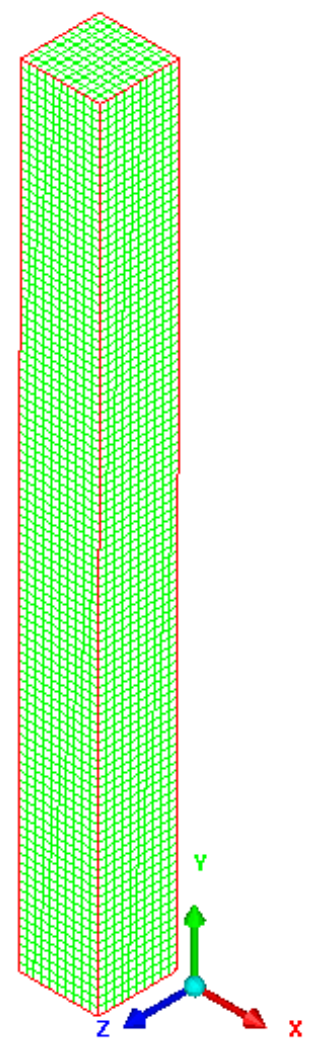

Figure 3-3: Mesh for column

\subsubsection{Modelling of Steel Reinforcement}

Both the longitudinal and transverse reinforcing steel bars were modelled using beam elements. Beam groups were created for the three different reinforcement cages. The radius of $12.5 \mathrm{~mm}$ and $5 \mathrm{~mm}$ of the longitudinal and transverse reinforcements respectively were then applied to the beam groups to represent the proper configuration as shown in Figure 3-4. 


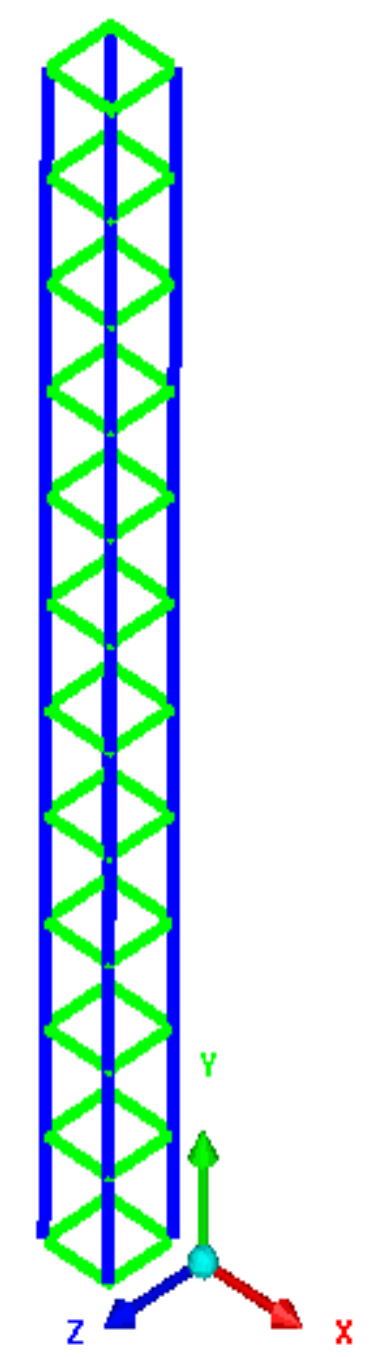

Figure 3-4: Reinforcement cage showing longitudinal and transverse sections

\subsubsection{Modelling of Air}

A region of air was modelled around the concrete column which provided the space needed for the blast waves to propagate and interact with the column. From Figure 3-5, it is observed that the air modelling started at the base of the column and extended beyond the top of the column. The width of the air region was varied $i$ for each numerical simulation while the height and length remained constant at $3600 \mathrm{~mm}$ and $900 \mathrm{~mm}$ respectively (Figure 3-5). A 30-mm mesh size was used in all directions for the region of 
air modelled. An initial condition was also created for the internal energy of the air which was applied to all the air models in the numerical simulation.

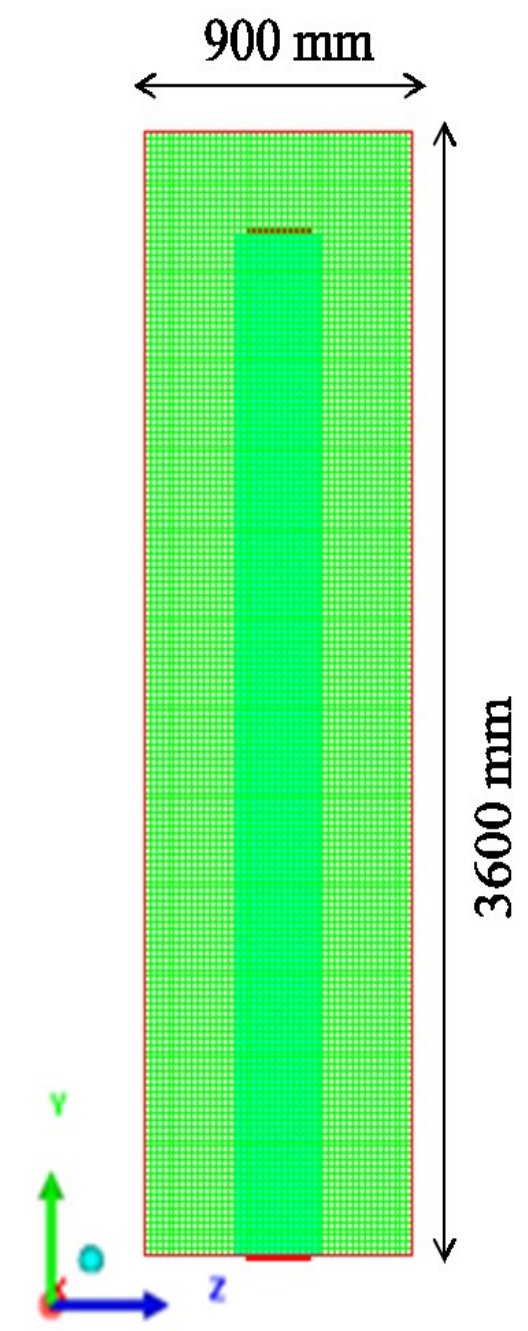

Figure 3-5: Air space around column

\subsubsection{Modelling of ANFO Explosive}

Five different charge masses of ANFO were modelled in a 2D axially symmetric box and remapped onto the 3D numerical model as initial conditions. The charge masses used were $25,50,75,100$ and $150 \mathrm{~kg}$. Using the $2 \mathrm{D}$ axi-symmetric model and remapping to the 3D model saved run time and also allowed for a very fine mesh for the 2D model. 
The procedure also increased the accuracy of the numerical model. Different 2D models were created for each charge mass and distance. The ANFO charge masses were converted to equivalent spherical charge radii using the relation in equation 3-1. The ANFO charge masses could only be modelled by using the equivalent spherical charge radii as presented in Table 3-4. The 2D model of air was created and filled with ANFO as shown in Figure 3-6. A detonation point (Figure 3-6) which determined the initiation time was also placed in the $2 \mathrm{D}$ model. The initiation time was set at $0.00 \mathrm{~s}$. Figure 3-7 also shows the propagation of the blast waves through the $2 \mathrm{D}$ axi-symmetric model while Figure 3-8 shows a remapped model of the blast wave propagation. During the remapping, the origin for the remapped 2D model was entered for each scaled distances. The remapping was done for a height of burst of $1.3 \mathrm{~m}$ from the base of the column footing and represented the test condition in the experimental program.

Pressures generated in the explosions are described with the Jones-Wilkins-Lee (JWL) equation 3-2.

$$
R=\sqrt[3]{\frac{3 \times W}{4 \times \pi \times \rho}}
$$




$$
p=A_{j}\left(1-\frac{w_{j}}{R_{1 j} v_{j}}\right)^{-R_{1 j} v_{j}}+B_{j}\left(1-\frac{w_{j}}{R_{2 j} v_{j}}\right)^{-R_{2 j} v_{j}}+\frac{w_{j} E_{j}}{v_{j}}
$$

where $p$ is the hydrostatic pressure, $v_{j}$ the specific volume, $E_{j}$ the specific internal energy, $A_{j}, B_{j}, R_{1 j}, R_{2 j}$ and $w_{j}$ are material parameters

Table 3-4: charges masses with corresponding radii

\begin{tabular}{|l|l|}
\hline Charge mass, W (kg) & Radius, R (mm) \\
\hline 25 & 195.40 \\
\hline 50 & 246.19 \\
\hline 75 & 281.84 \\
\hline 100 & 310.17 \\
\hline 150 & 355.06 \\
\hline
\end{tabular}
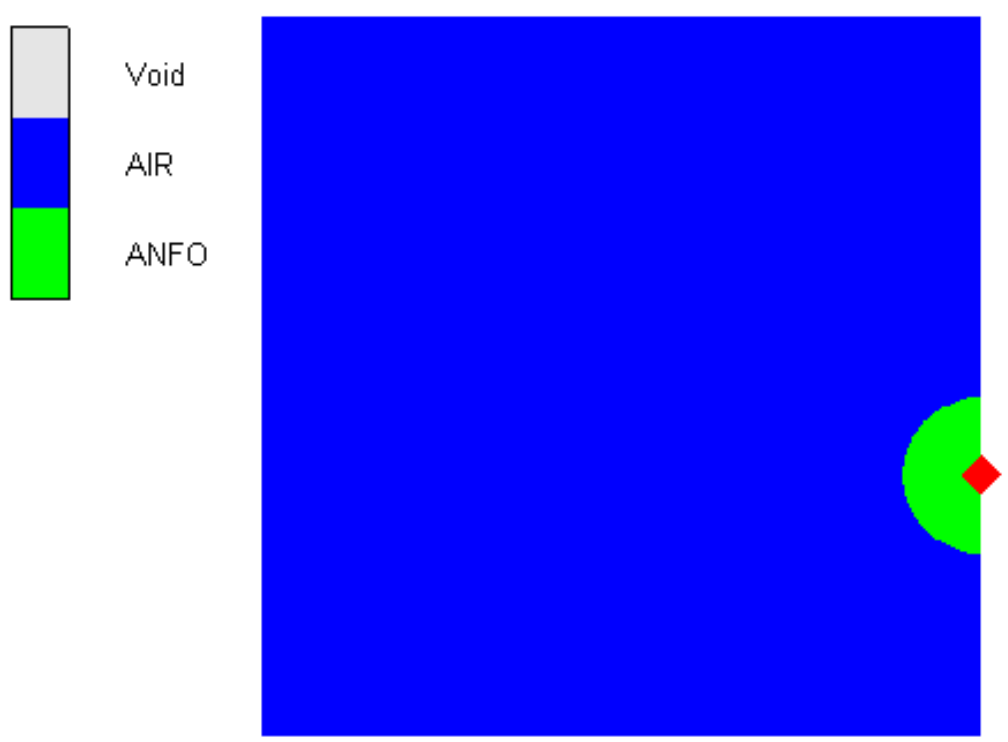

Figure 3-6: A 2D model showing the ANFO and Air 


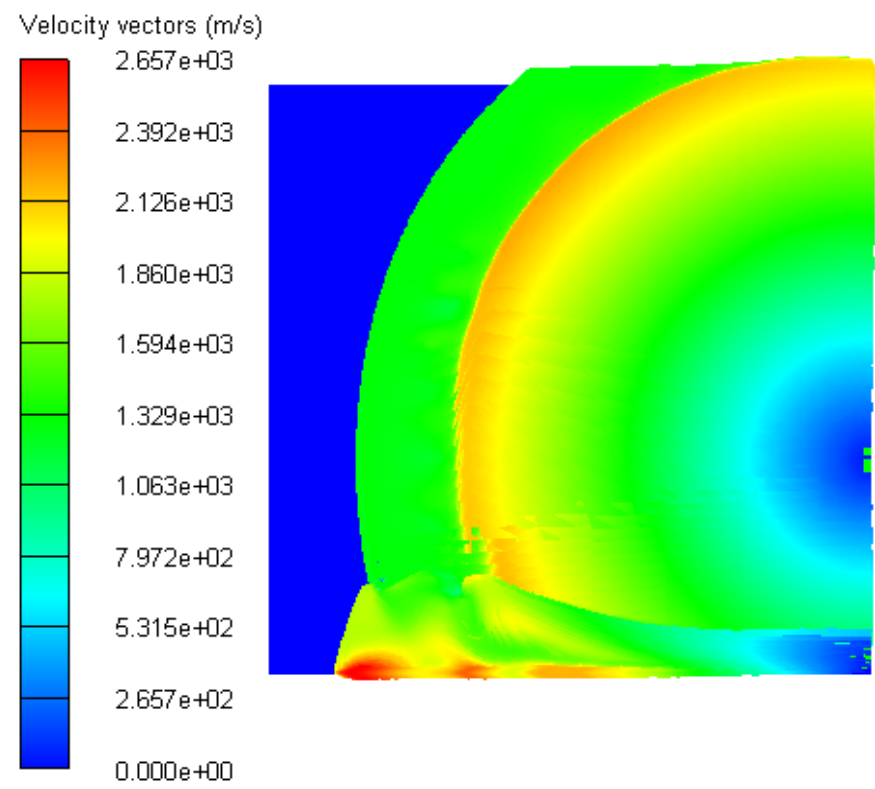

Figure 3-7: Blast wave propagation in the 2D model

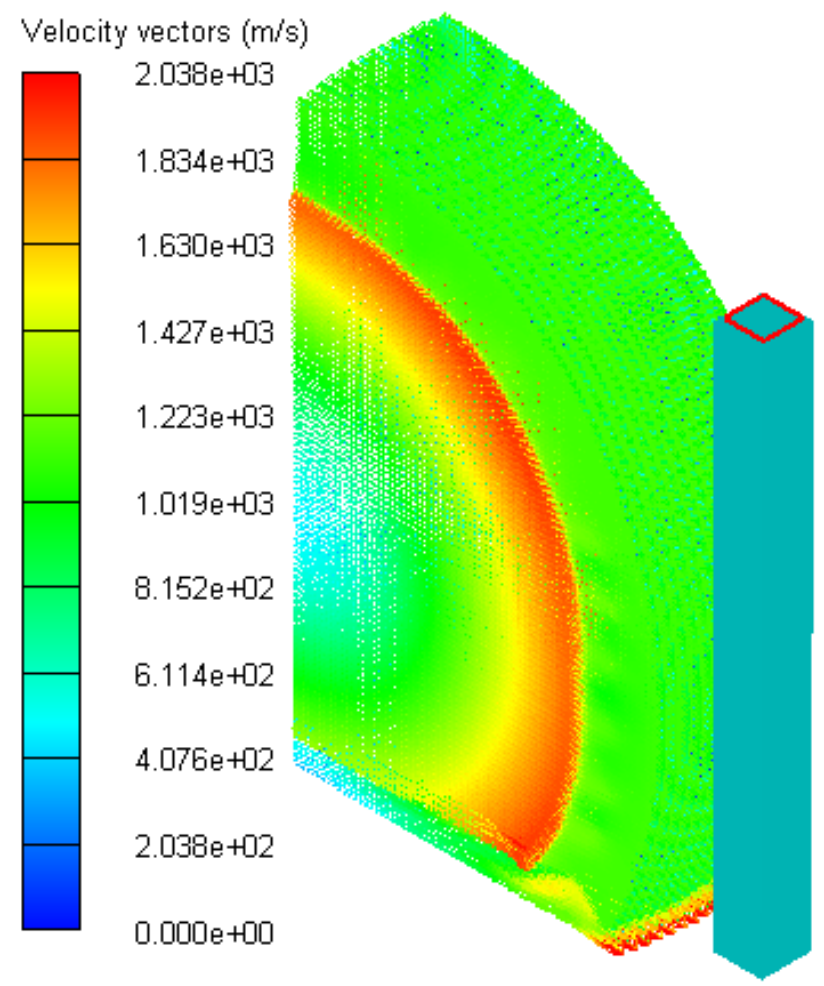

Figure 3-8: 3D remap of the blast pressure wave 


\subsubsection{Mesh Sensitivity Analysis for 2D Numerical Model}

A mesh sensitivity analysis was conducted for the 2D model using $150 \mathrm{~kg}$ TNT charge mass at a standoff distance of $3 \mathrm{~m}$. The pressure profiles were plotted for the mesh sizes of $5 \mathrm{~mm}, 10 \mathrm{~mm}, 20 \mathrm{~mm}$ and $30 \mathrm{~mm}$. The pressure plots of the different mesh sizes were also compared to pressure plot from CONWEP. A mesh size of $10 \mathrm{~mm}$ was used for all 2D models as this reduced computational cost while maintaining a high degree of accuracy (Figure 3-9 and Table 3-5).

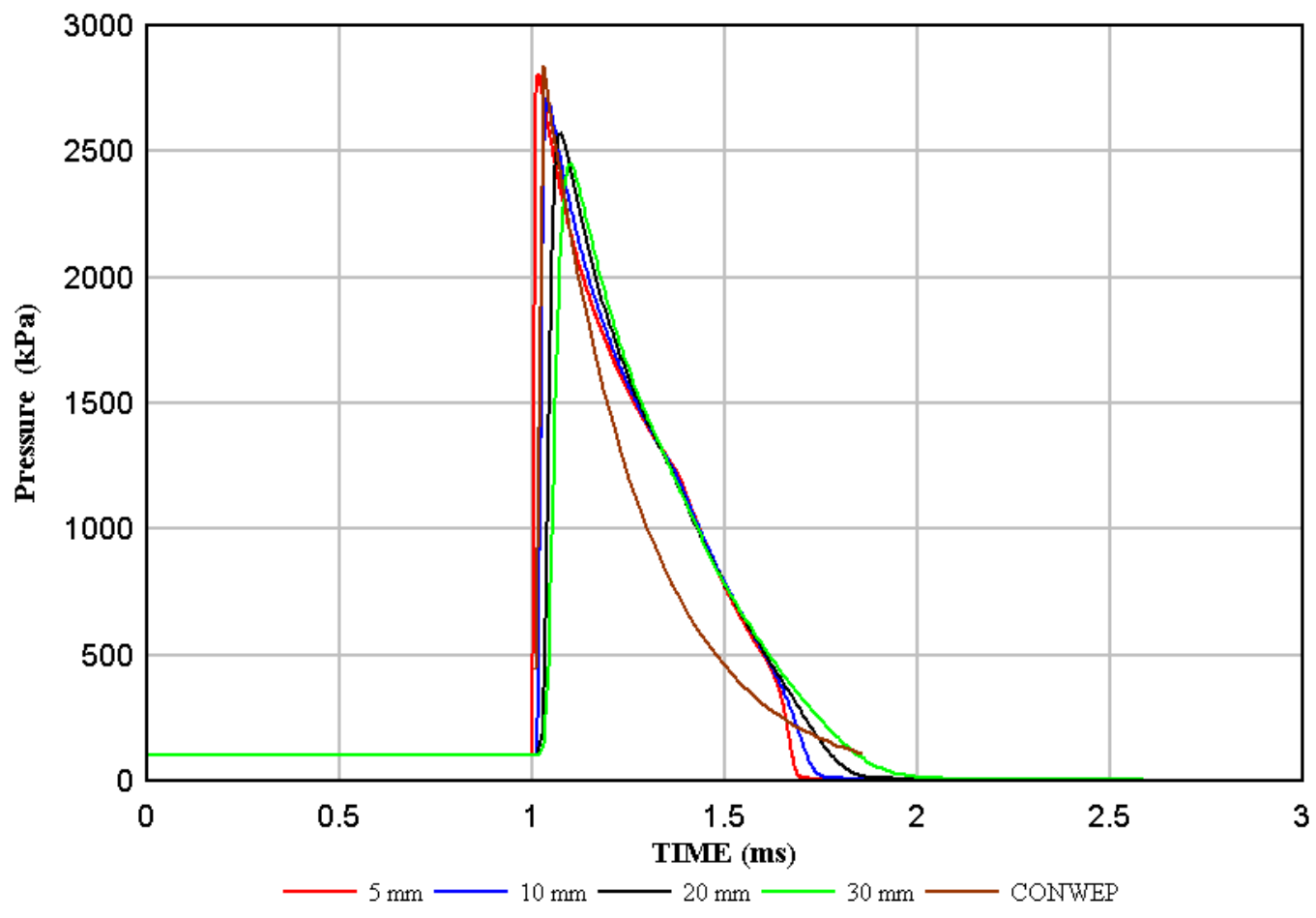

Figure 3-9: Pressure profiles of mesh sensitivity analysis for 2D model 
Table 3-5: Peak Incident Pressure values for different mesh sizes

\begin{tabular}{|l|l|l|}
\hline & Peak Incident Pressure (kPa) & Computer Run Time (mins) \\
\hline CONWEP & 2838 & \\
\hline $\mathbf{5} \mathbf{~ m m}$ & 2808 & 411 \\
\hline $\mathbf{1 0} \mathbf{~} \mathbf{m}$ & 2711 & 30 \\
\hline $\mathbf{2 0} \mathbf{~ m m}$ & 2572 & 4 \\
\hline $\mathbf{3 0} \mathbf{~ m m}$ & 2454 & 2 \\
\hline
\end{tabular}

\subsubsection{Boundary Conditions}

Different boundary conditions were used on different parts of the numerical model to represent boundary conditions in the experimental program. Both the top and bottom supports of the columns were designed for fixed support condition as in the experimental program. The same boundary conditions were modelled by setting the translational and rotational velocities of the nodes to zero as shown in Figure 3-10. 


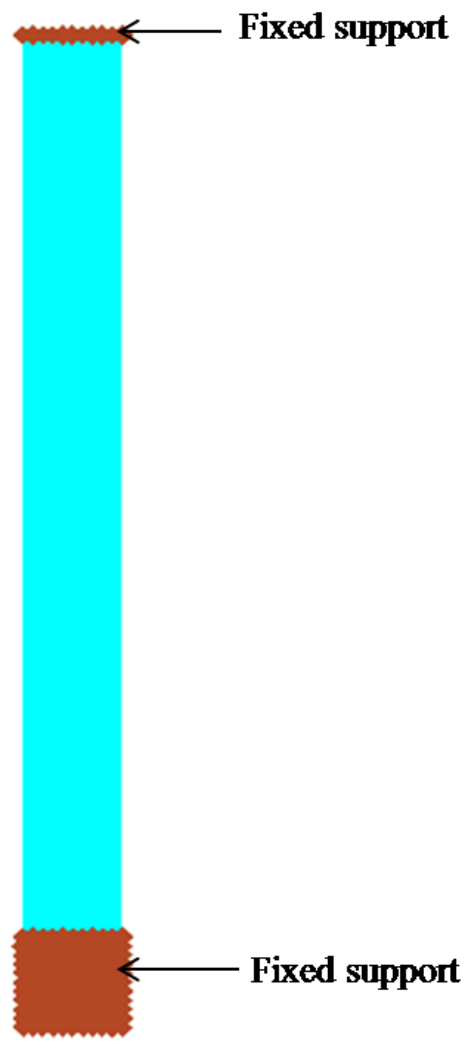

Figure 3-10: Fixed supports condition of RC column

An outflow boundary condition was also used on all four sides of the region of air modelled. The outflow boundary condition allowed the blast waves to exit the region of air without reflecting back to the column. However reflective boundary condition was applied for the ground surface at the bottom of the air region. The outflow boundary condition is presented in Figure 3-11. 


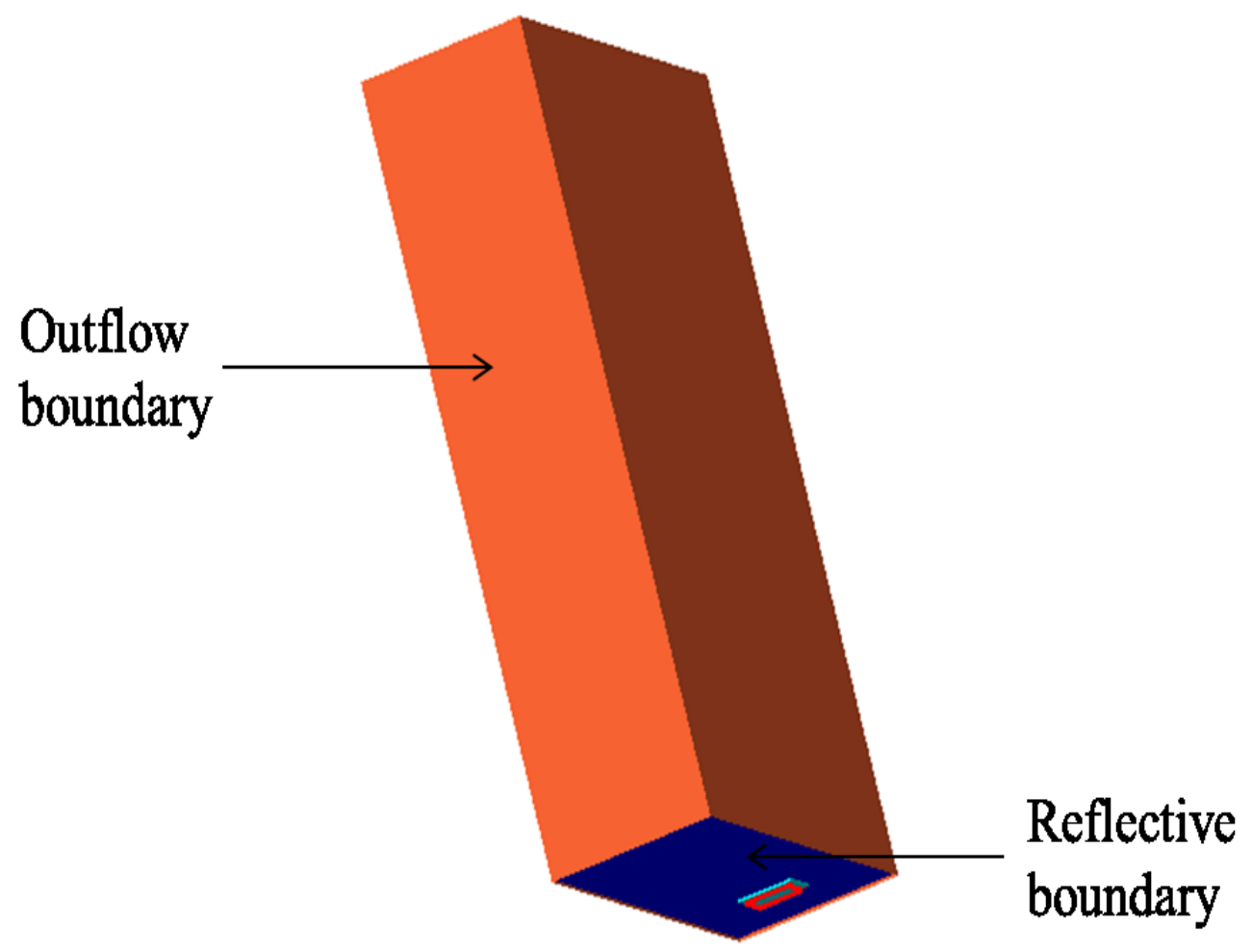

Figure 3-11: Outflow and reflective boundaries in the region of air

\subsubsection{Interactions of Modelled Parts}

The interaction between the columns and the region of air is important in achieving desired results. Based on this, a fully coupled interaction was used for both Eulerian and Lagrangian parts. The fully coupled interaction allowed the air to transfer the explosion energy to the concrete column at the interface between the columns and air.

Also, the beam (reinforcing bars) elements and the concrete elements were rigidly joined at the nodes to ensure perfect bond with no slippage (strain compatibility). Figure 3-12 shows the joints at the nodes for both the beam elements (steel reinforcement) and concrete column. 


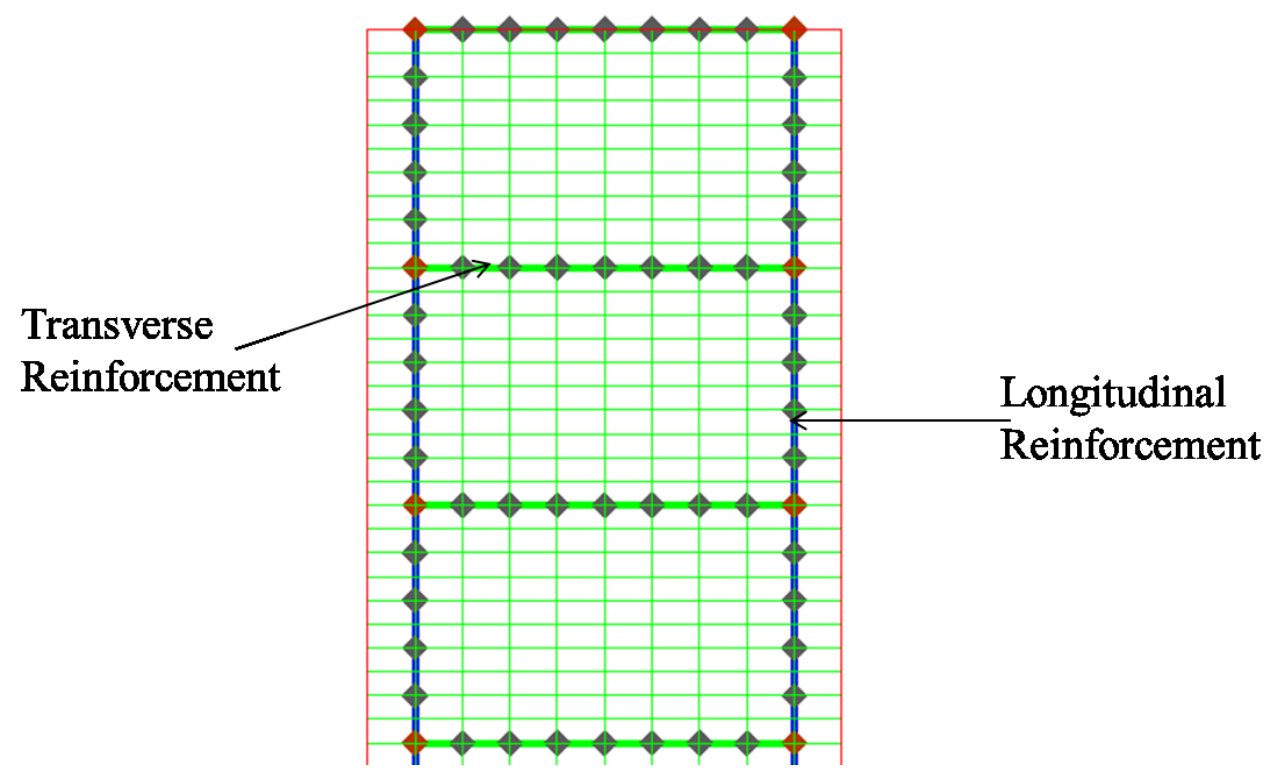

Figure 3-12: Joints at nodes between column and beam elements

\subsubsection{Solution Controls}

The solution controls were defined using run wrap-up criteria and time step options. Although the wrap-up criteria consisted of cycle limit, time limit, energy fraction and energy reference cycle, only the time limit wrap-up criteria was used. A run time limit of $50 \mathrm{~ms}$ was used in all the simulations. The time step was also calculated using the Courant-Friedrich-Levy criterion with a safety factor of 0.6667.

\subsubsection{Output data acquisition using gauges}

Data acquisition is vital in the analysis of numerical analysis. In order to obtain displacement and strain results, monitoring points (gauges) were placed at requisite locations on the columns. Figure 3-13 shows location of gauges and height above the ground where column displacements were monitored, i.e., lower third ( $1 \mathrm{~m}$ from base of column), mid-height (1.5 $\mathrm{m}$ from base of column) and upper third ( $2 \mathrm{~m}$ from base of 
column) points. Figure 3-14 shows the position of the strain gauges on steel reinforcing bars.

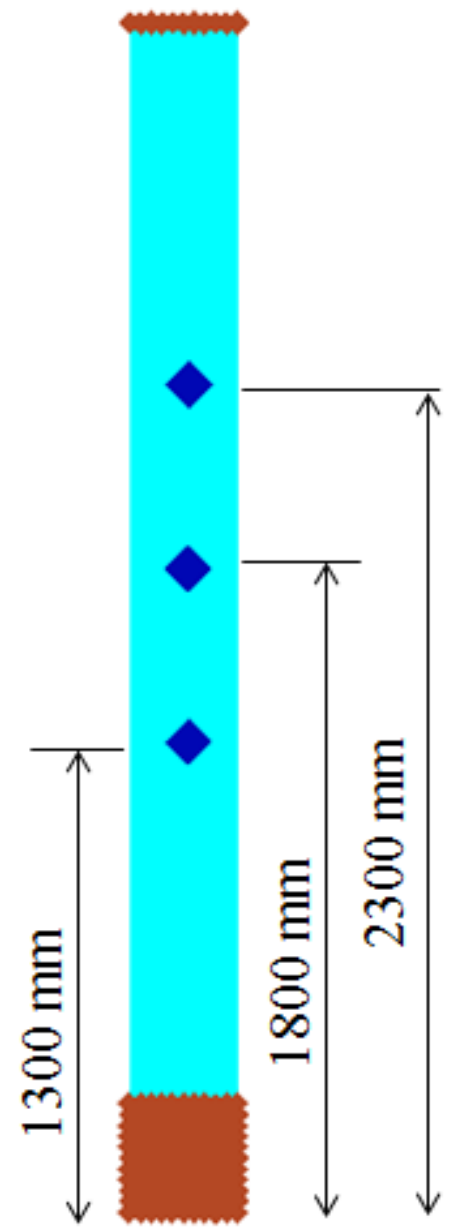

Figure 3-13: Gauge positions on column 


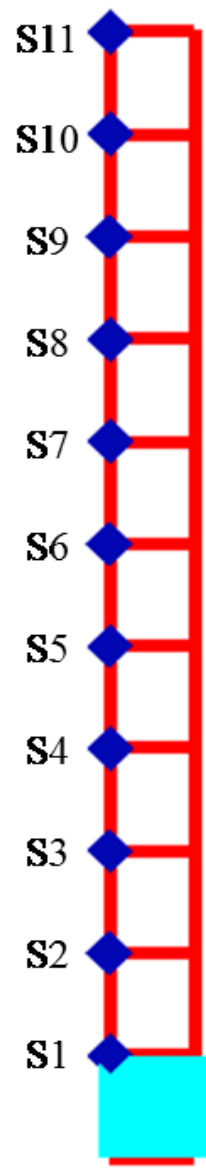

(a)

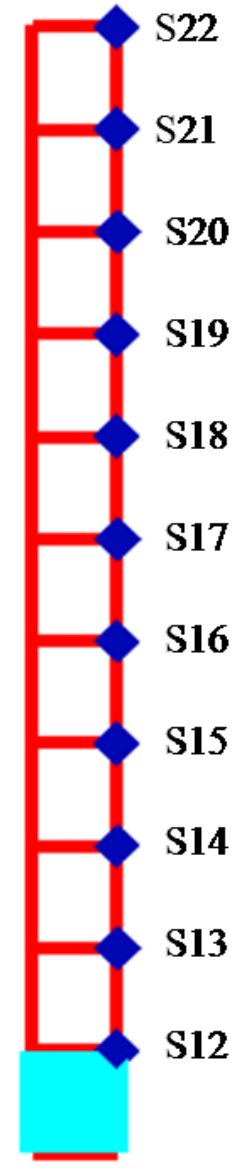

(b)

Figure 3-14: Gauge positions on steel reinforcement (a) front face (b) back face

\subsection{Mesh Sensitivity Analysis}

Different mesh sizes were created and the deflections at mid-height of the RC column was monitored and compared. Three mesh sizes of $15 \mathrm{~mm}, 30 \mathrm{~mm}$ and $60 \mathrm{~mm}$ were used to determine the mesh sensitivity of the numerical simulation to mesh size and to determine the best mesh size that would maximise accuracy and at the least computational cost. The mesh sensitivity analysis was run using the reinforced concrete 
column as shown in Figure 3-1 and Figure 3-2c with a 150-kg ANFO charge mass at standoff distance of $2610 \mathrm{~mm}$. The total run time for the simulation was $20 \mathrm{~ms}$.

Figure 3-15 presents the mid-height deflection of the column using the different mesh sizes and compared to the experimental mid-height displacement profile while Table 3-6 presents summary of the deflections and the computational times to $20 \mathrm{~ms}$. Although the 15-mm mesh size gave a higher degree of deflection accuracy, the computational cost was too high (Table 3-6). Mesh size of $30 \mathrm{~mm}$ was used for the numerical simulation because it gave a reasonable degree of accuracy in terms of deflection without significantly increasing computational cost.

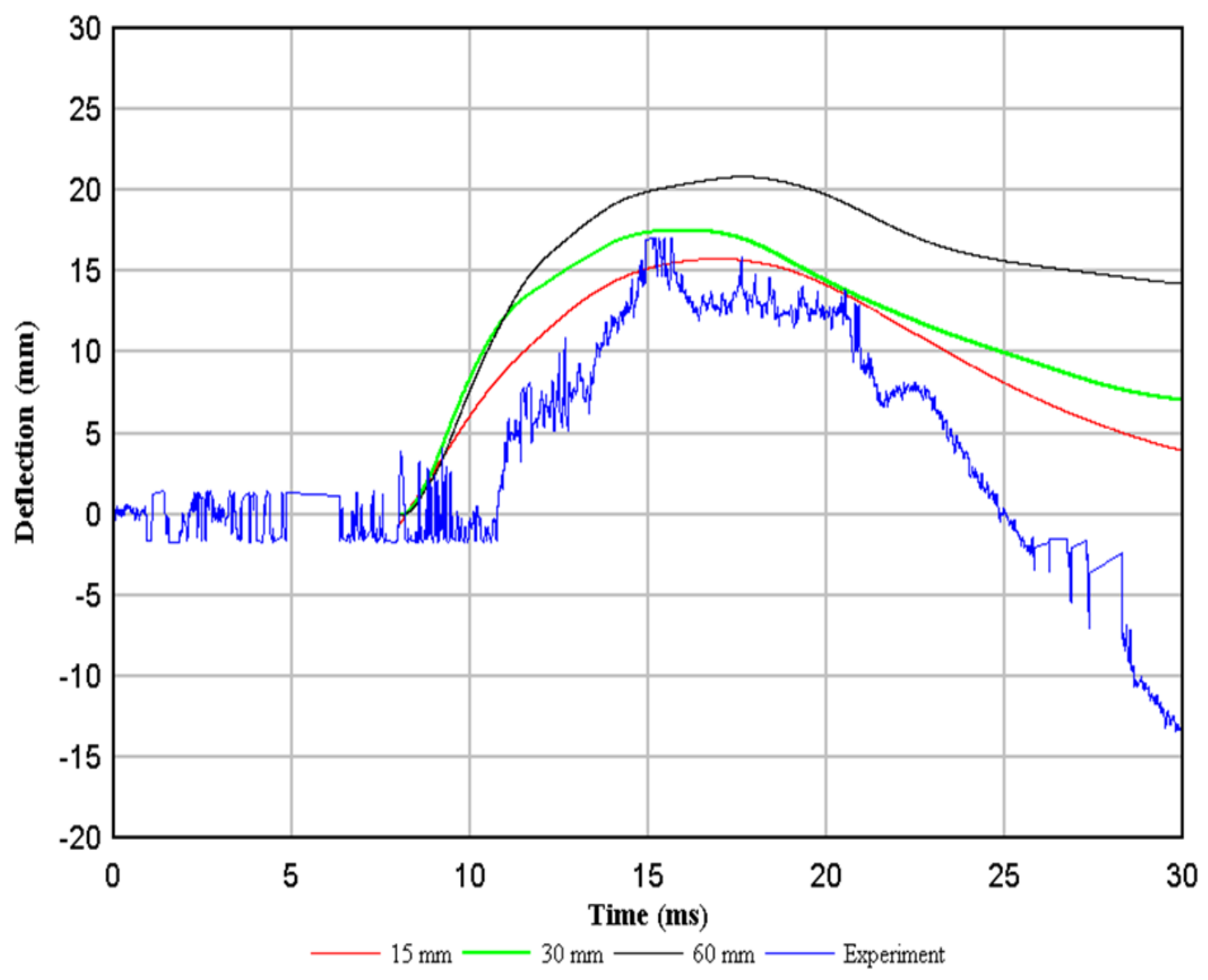

Figure 3-15: Mesh sensitivity analysis plot 
Table 3-6: Mesh sensitivity analysis Summary

\begin{tabular}{|l|l|l|}
\hline mesh size (mm) & Deflection (mm) & Computational Run time (minutes) \\
\hline 60 & 20.84 & 70 \\
\hline 30 & 17.55 & 548 \\
\hline 15 & 15.78 & 12000 \\
\hline Experimental & 16.06 & \\
\hline
\end{tabular}

\subsection{Effects of Boundary Distance on Column Response}

The effect of increasing the distance between the column and the air boundary in the $\mathrm{x}$ direction (behind concrete column) was investigated. Three distances of 300, 600 and $1000 \mathrm{~mm}$ were compared and the effect on the deflection of the column at mid-height was monitored. Figure 3-16 shows the concrete column and region of air modelled to the three distances behind the column. The comparison was achieved using a $30 \mathrm{~mm}$ mesh size for both the column and the region of air. The dimensions of the reinforced concrete column in Figure 3-1 and Figure 3-2c were used with a 50-kg ANFO charge mass at a standoff distance of $2210 \mathrm{~mm}$. Figure 3-18 shows that the distance modelled past the column did not have any effect on the peak deflection of the first cycle of response. However, a slight variation was observed with subsequent amplitudes. From the comparison shown in Figure 3-18, the distance $600 \mathrm{~mm}$ was used because that allowed deflections of the column without the columns exiting the air medium. 
Similarly, the effect of the distance of the air boundary perpendicular to the direction of travel of the blast wave, in the z-direction, was also investigated. The distances 450, 900 and $1800 \mathrm{~mm}$ were randomly selected and the deflections were compared. Again the concrete column shown in Figure 3-1 and in Figure 3-2 was loaded with a 50-kg ANFO charge mass at a scaled distance of $2210 \mathrm{~mm}$. Figure 3-17 shows the boundary distance in the z-direction. Also from Figure 3-19, there was no difference in the deflections for the first cycle when comparing the $900 \mathrm{~mm}$ and $1800 \mathrm{~mm}$. As such $900 \mathrm{~mm}$ was used for the simulation while reducing computational cost.
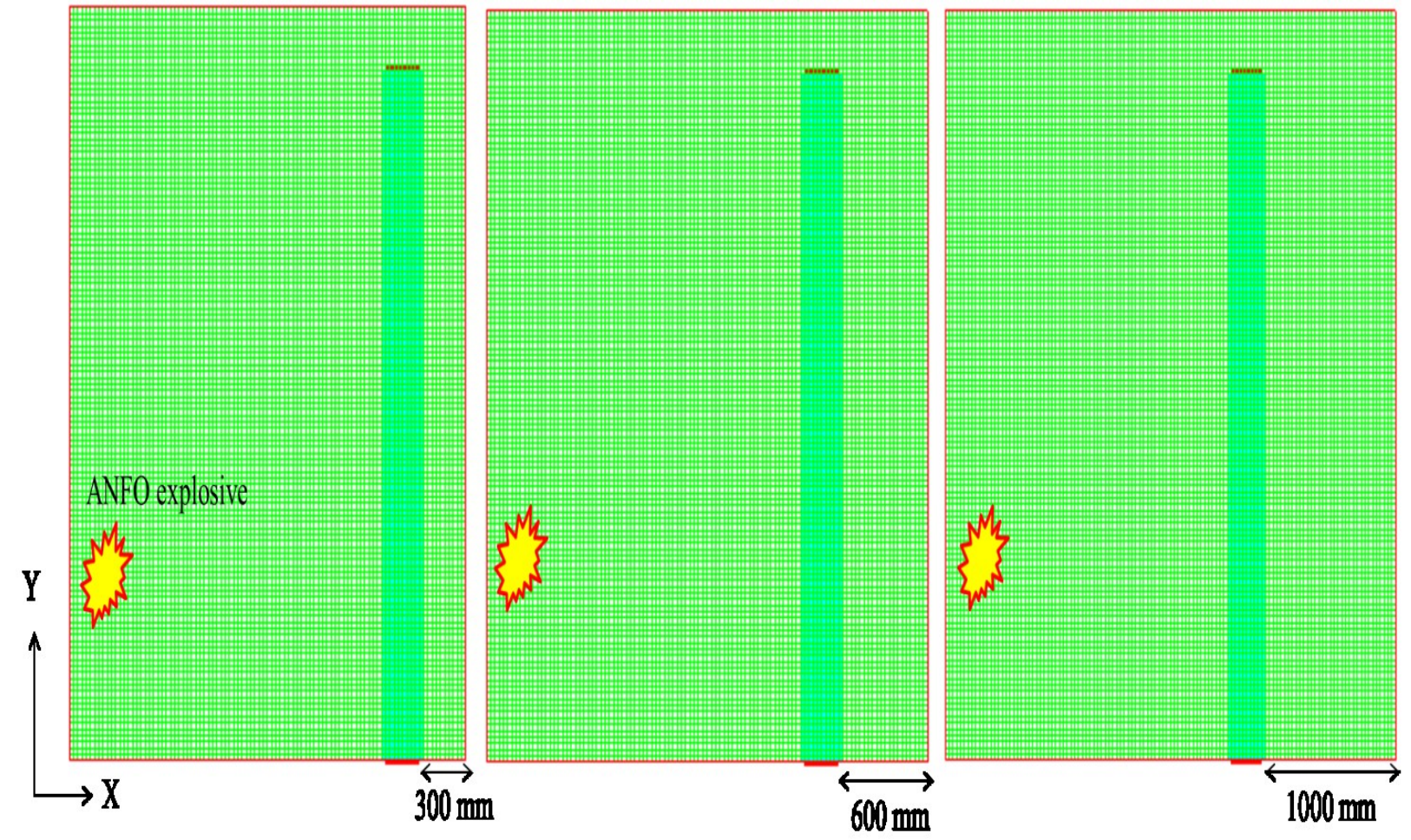

Figure 3-16: Different Boundary distances in the $\mathrm{x}$-direction 

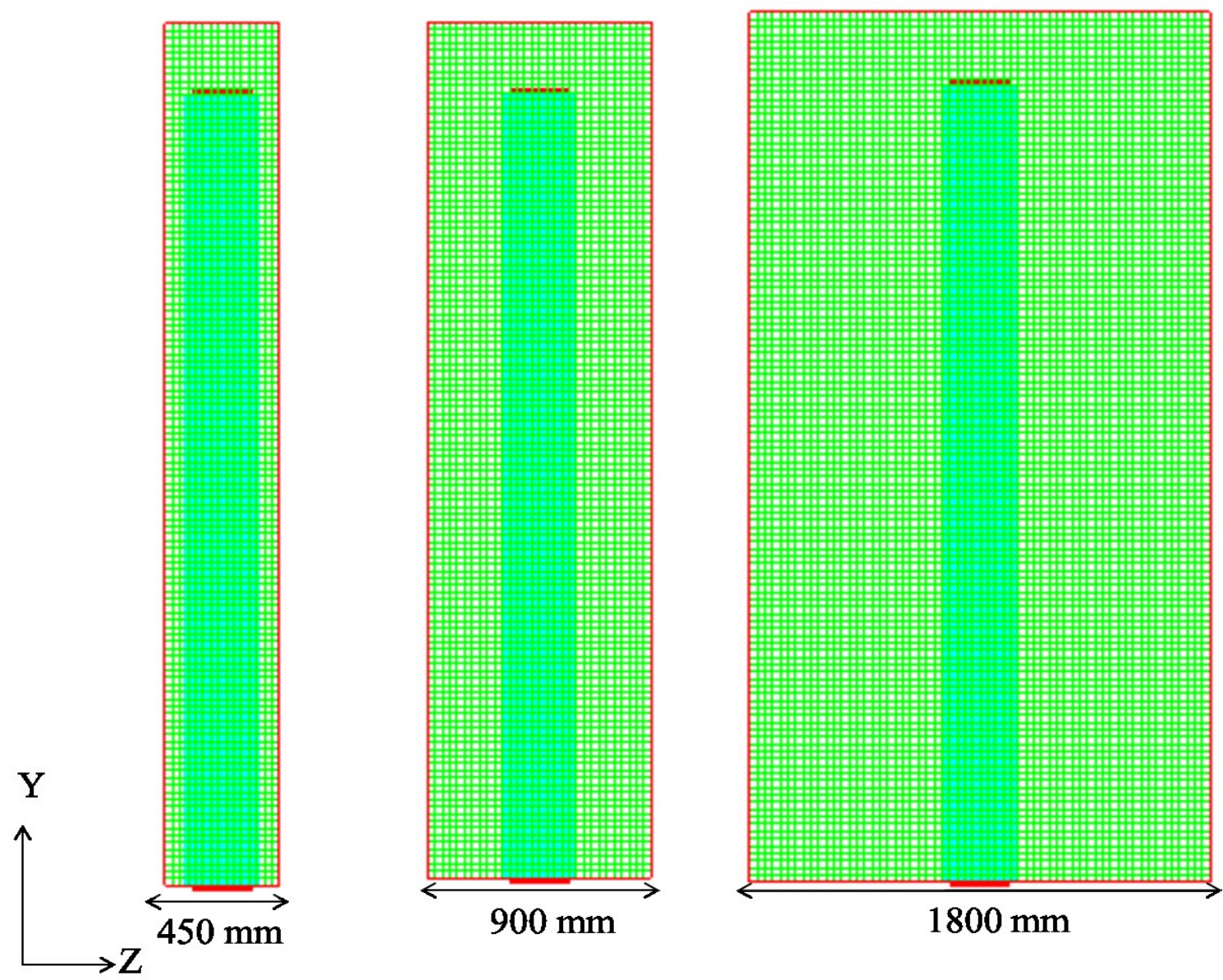

Figure 3-17: Different Boundary distances in the z-direction 


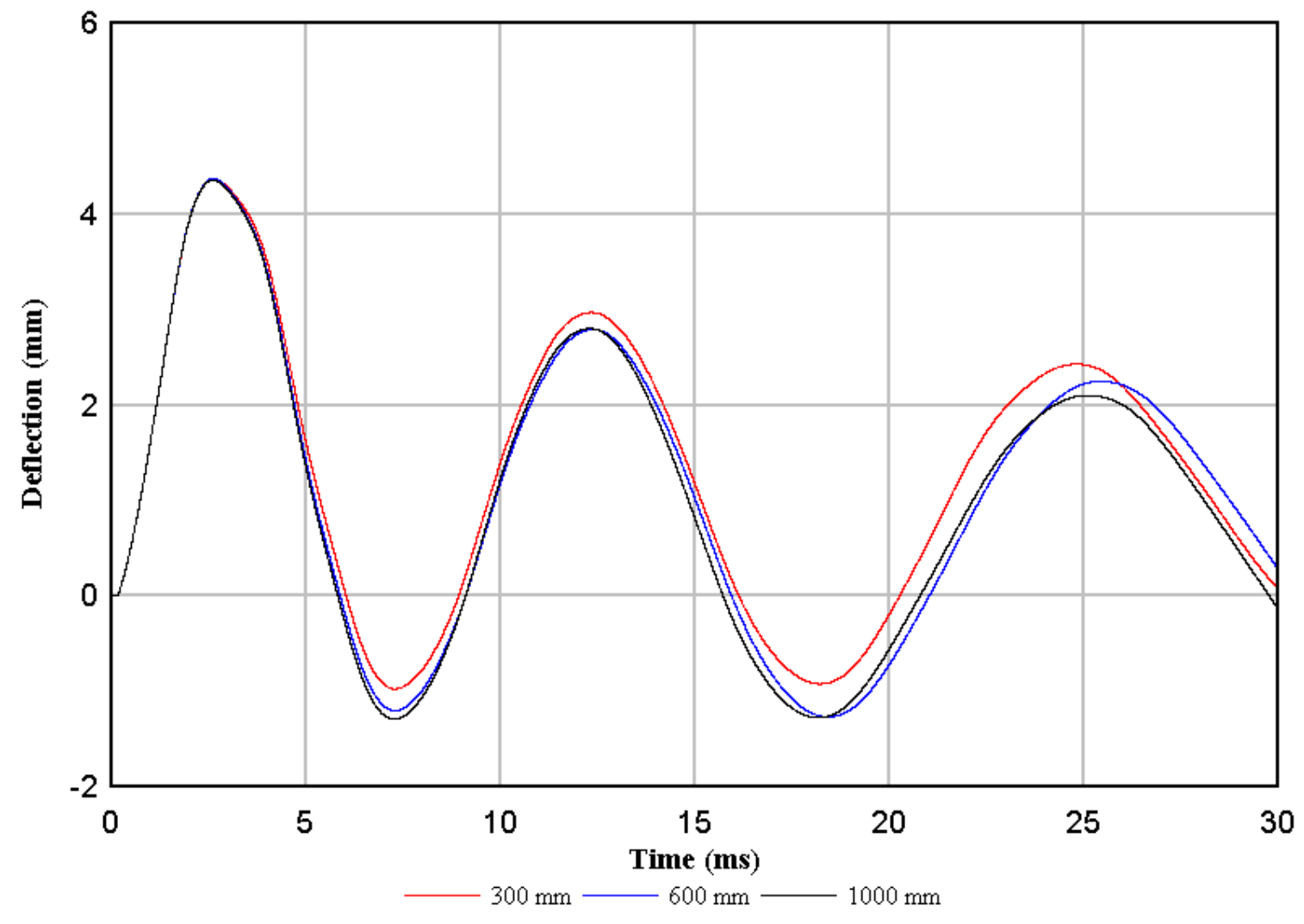

Figure 3-18: Column Deflection at height $1.5 \mathrm{~m}$ for different distances in the $\mathrm{x}$-direction 


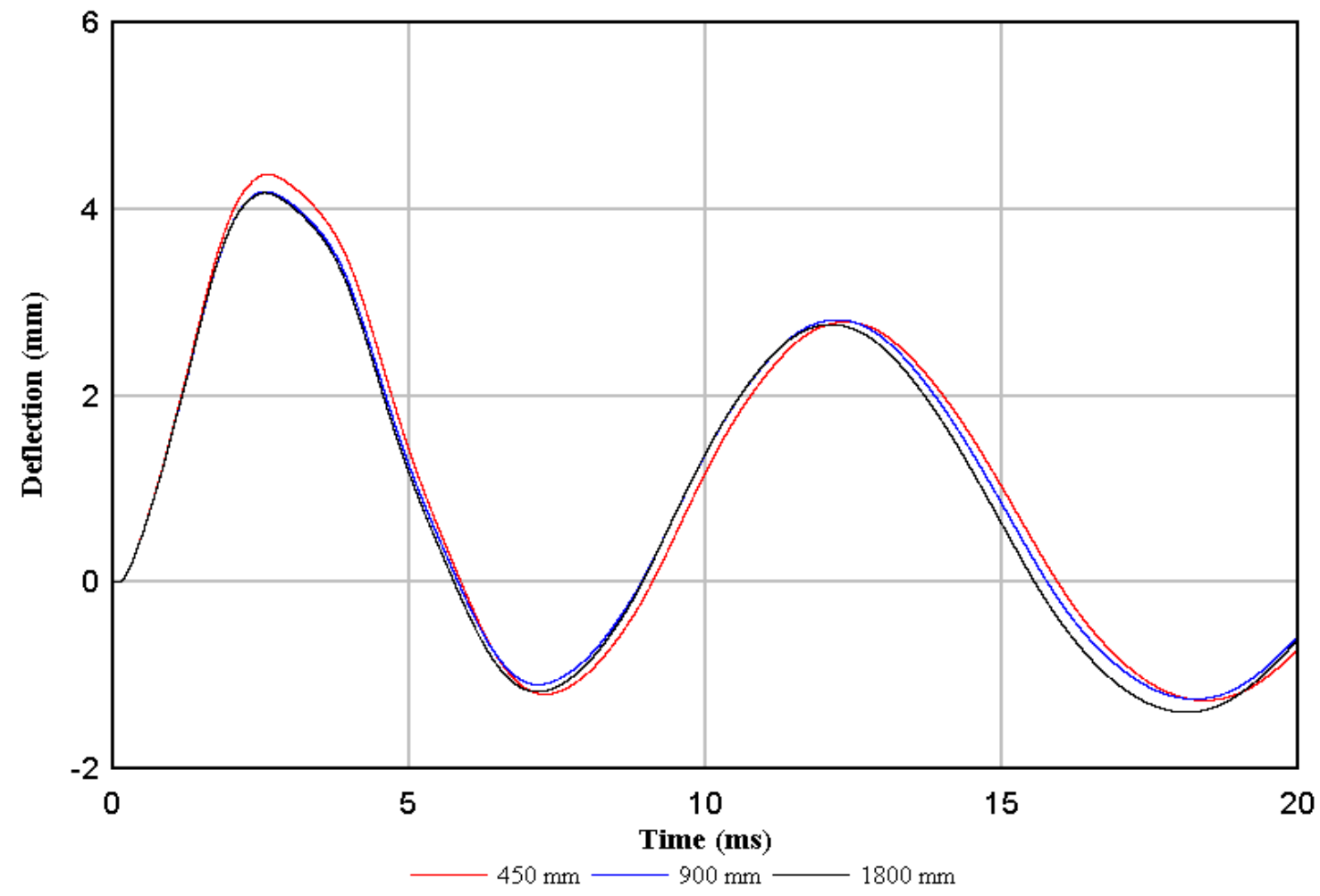

Figure 3-19: Column Deflection at height $1.5 \mathrm{~m}$ for different distances in the z-direction

\subsection{Effect of Tensile Strain Rate Exponent on Column Deflection}

Using default values of the RHT model in AUTODYN could not accurately predict the behaviour of the reinforced concrete column when compared to the experimental results. In lieu of this, the effect of the tensile strain rate exponent, $\omega$ in equation $(2-51)$ was varied until the $\mathrm{RC}$ column response was close to the experimental results. The default tensile strain rate exponent value of 0.032 and two other values, 0.05 and 0.07 were compared. The comparison is shown in Figure 3-20 in which the deflection of the column decreased with increasing tensile strain rate exponent values. The comparison was made using a reinforced concrete column with $300-\mathrm{mm}$ tie spacing at a standoff distance of $2610 \mathrm{~mm}$. The deflection using tensile strain rate exponent value of 0.07 showed agreement with the experimental results. Also while the strain rate exponent was used in 
matching the results of the experimental testing, other sources of error such as imperfect fixity of supports and reflection off the support structure could have affected the column deflections

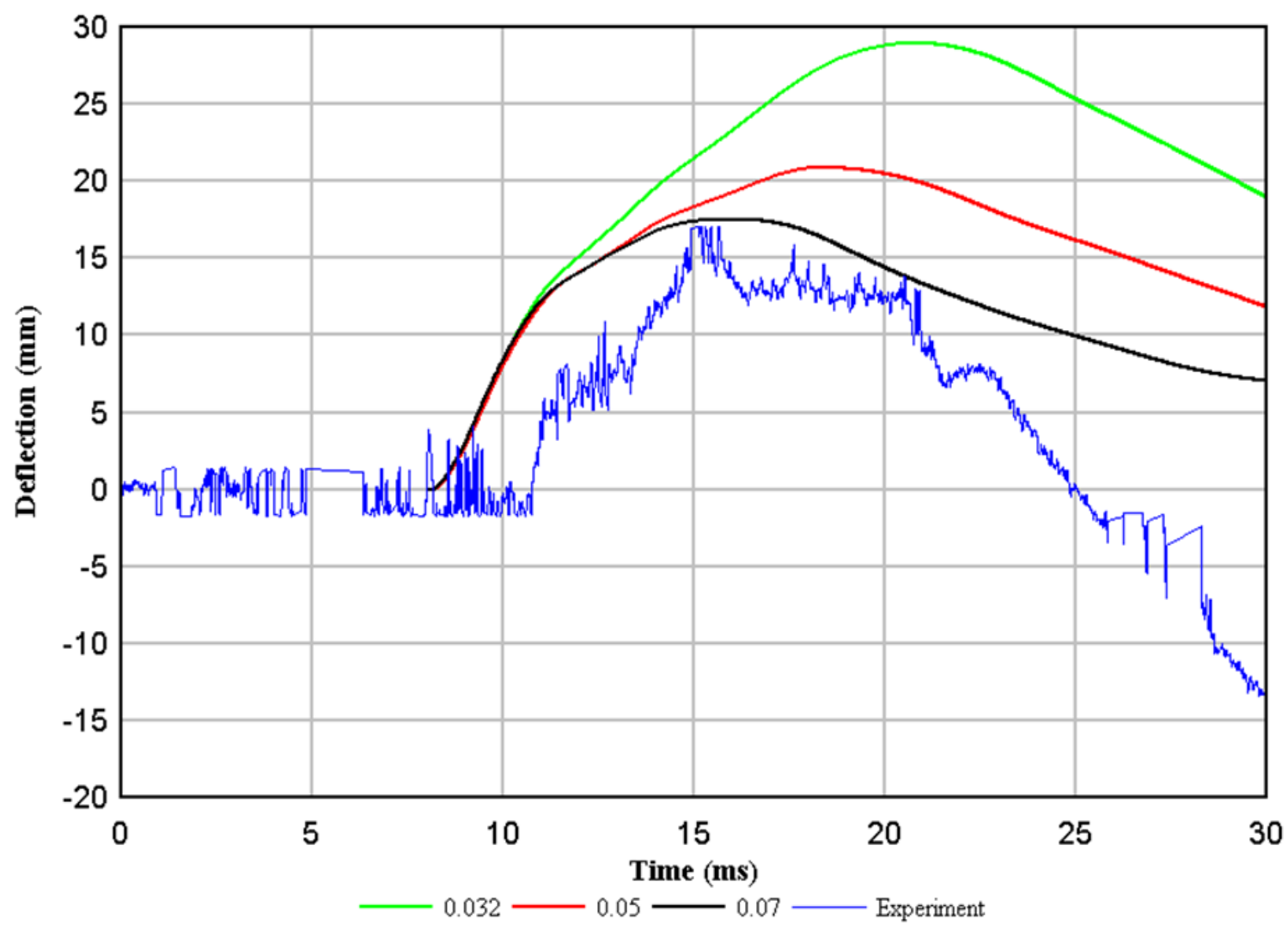

Figure 3-20: Effect of Tensile Strain Rate Exponent on Column Deflection

\subsection{Validation of Numerical Model}

Solutions from numerical simulations, although are often accurate need to be consistent with results from experimental testing. In lieu of this, the numerical simulation reported in this thesis was validated against experimental work conducted in the overall research program. The conventional RC column of height $3000 \mathrm{~mm}$ and cross section of $300 \times$ $300 \mathrm{~mm}$ was designed and detailed in accordance with CSA A23.3-04 as shown in Figure 
3-1 and Figure 3-2. Concrete compressive strength of $40 \mathrm{MPa}$ was used in the numerical simulation for the validation. The 150-kg ANFO explosive charge mass was placed at a height of $1300 \mathrm{~mm}$ above the ground and at a distance of $2610 \mathrm{~mm}$ from the front face of the column as shown in Figure 3-21. The mid-height (1.5 $\mathrm{m}$ from the base of the column) deflection was compared for both the numerical simulation and the experimental test. The comparison showed that the maximum deflection was estimated at $16 \mathrm{~mm}$ for the experimental testing and $18 \mathrm{~mm}$ for the numerical simulation as shown in Figure 3-22. Also the mid-height deflection at standoff distance of $2700 \mathrm{~mm}$ was also compared with the numerical model as shown in Figure 3-23. Figure 3-24 shows the damaged columns for both the numerical and experimental testing under 150-kg ANFO explosive at a standoff distance of $1300 \mathrm{~mm}$. The column in the experimental test was totally disintegrated in comparison with the numerical simulation because the longitudinal reinforcement was lapped at mid-height while they were modelled to be continuous in the numerical simulation.

String potentiometers (string pots) were used to measure the deflection in the experimental test. The string potentiometer was engulfed by the fireball from the explosion causing the string to fail and the string potentiometer retracted. Also, the string potentiometer has been reported to lag in response to the column. The $11 \%$ difference between maximum deflection in the experimental test and numerical simulation is attributable to inaccuracies in the string pot measurements and the support condition used in the experimental test (Figure 3-26).

Other sources contributing to the error in simulating the deflection include ANFO explosive charge shape. The explosive charge was modelled as perfectly spherical while 
in the experimental testing, the explosive charge was cylindrical in shape with a diameter to height ratio of 1 (Figure 3-25). Eventhough the diameter to height ratio of 1 was chosen to minimize charge shape effects it still could have affected the shockfront of the explosion at the very close range. The blast waves from the explosion reflected off the support structure, about $1.5 \mathrm{~m}$ from the column and traveled back to exert loading on the back face of the column. This potentially created a very different loading condition for the column in comparison to the numerical simulation where the blast wave is assumed to flow out of the modelled space at the back. The support system used for the reinforced concrete column in the experimental testing would have allowed some movement of the column, while in the numerical modelling the column was perfectly fixed to the supports. Although, there was a difference in the deflections profiles, the deflections of the numerical model reasonably agree with the experimental testing. 


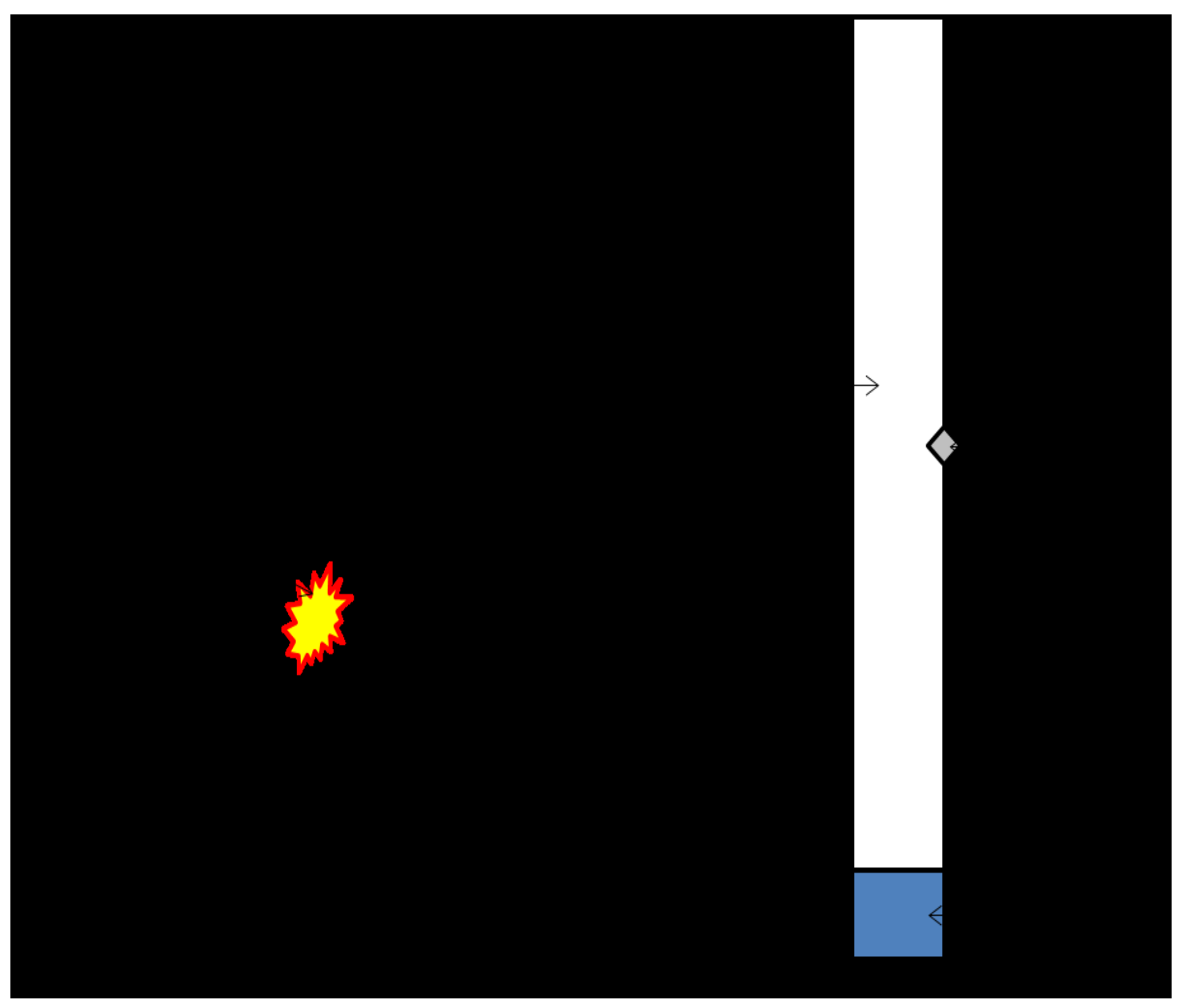

Figure 3-21: Blast Test setup for Validation 


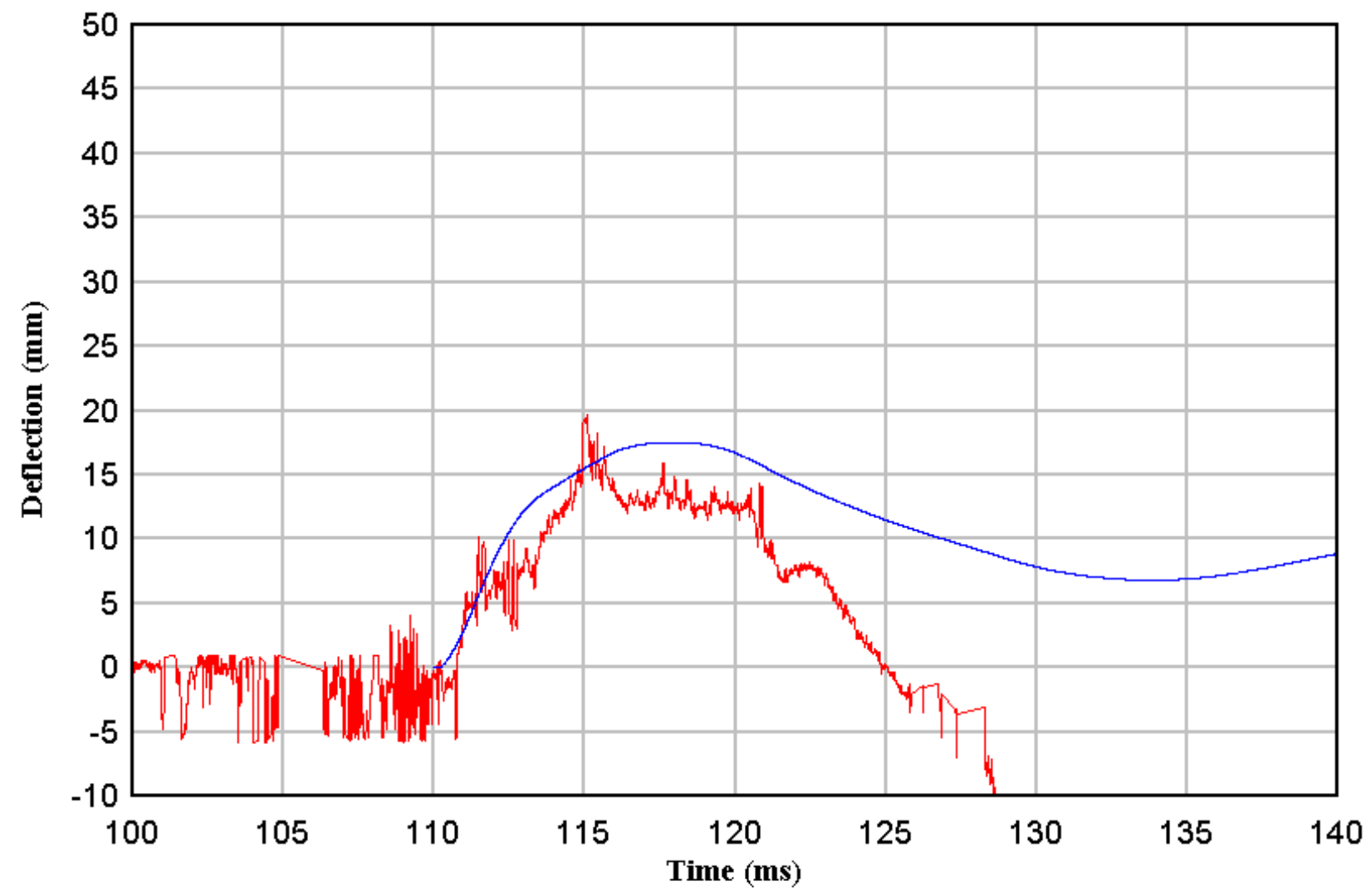

Experiment — Numerical Simulation

Figure 3-22: Graph plots comparing deflections at standoff distance of $2.6 \mathrm{~m}$ 


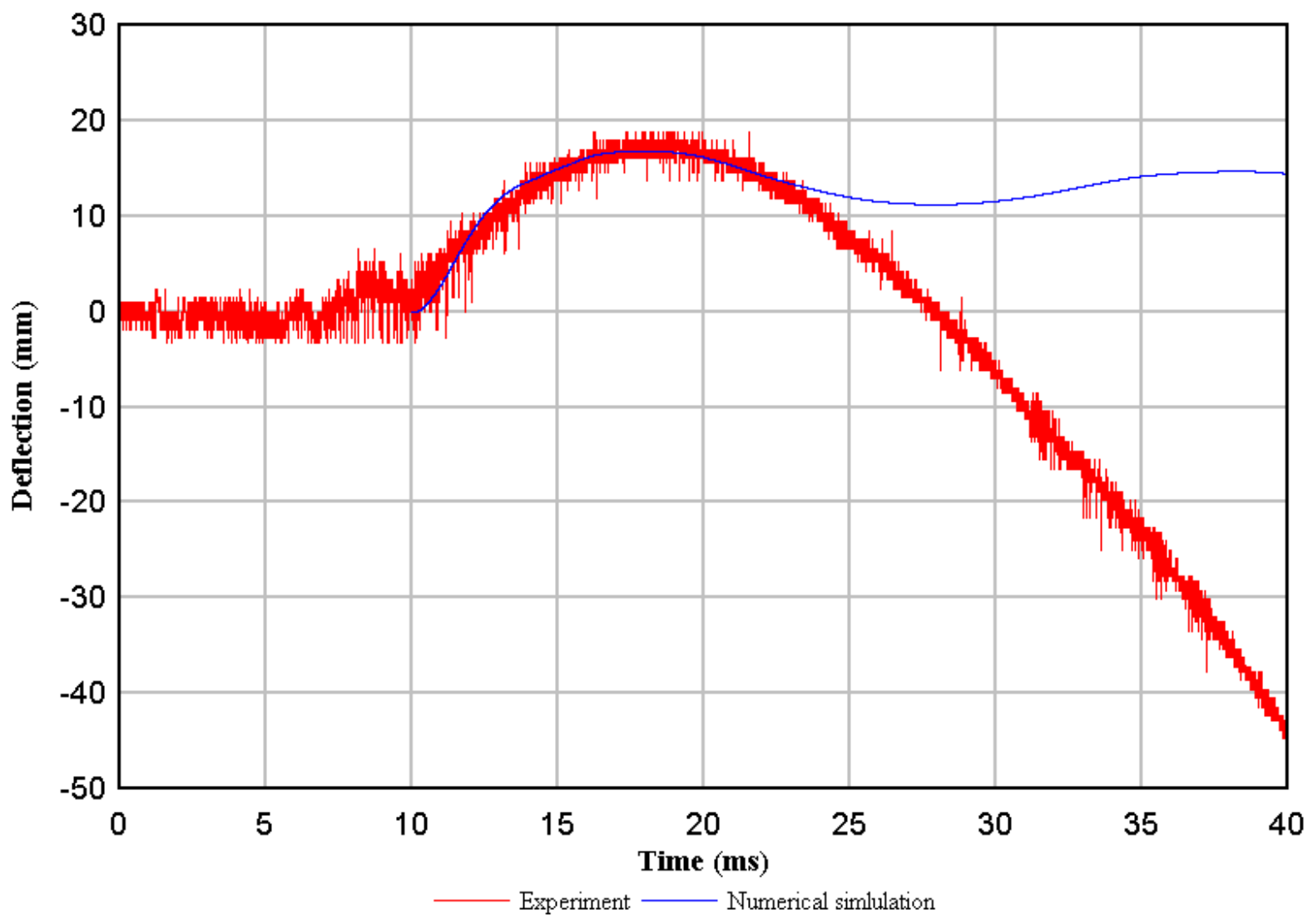

Figure 3-23: Graph plots comparing deflections at standoff distance of $2.7 \mathrm{~m}$ 

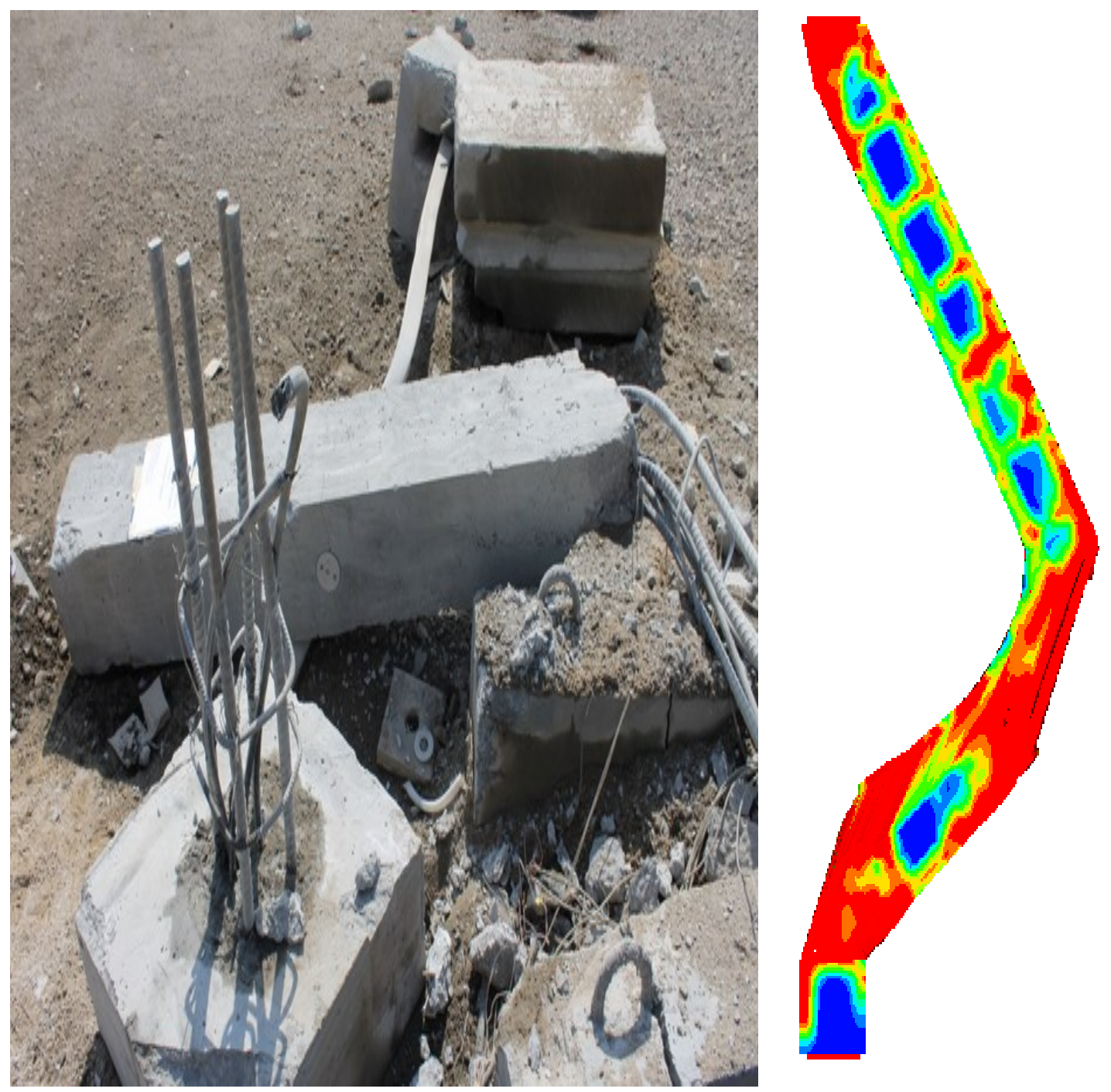

Figure 3-24: Visual display of the failed columns at standoff distance of $1.3 \mathrm{~m}$ 


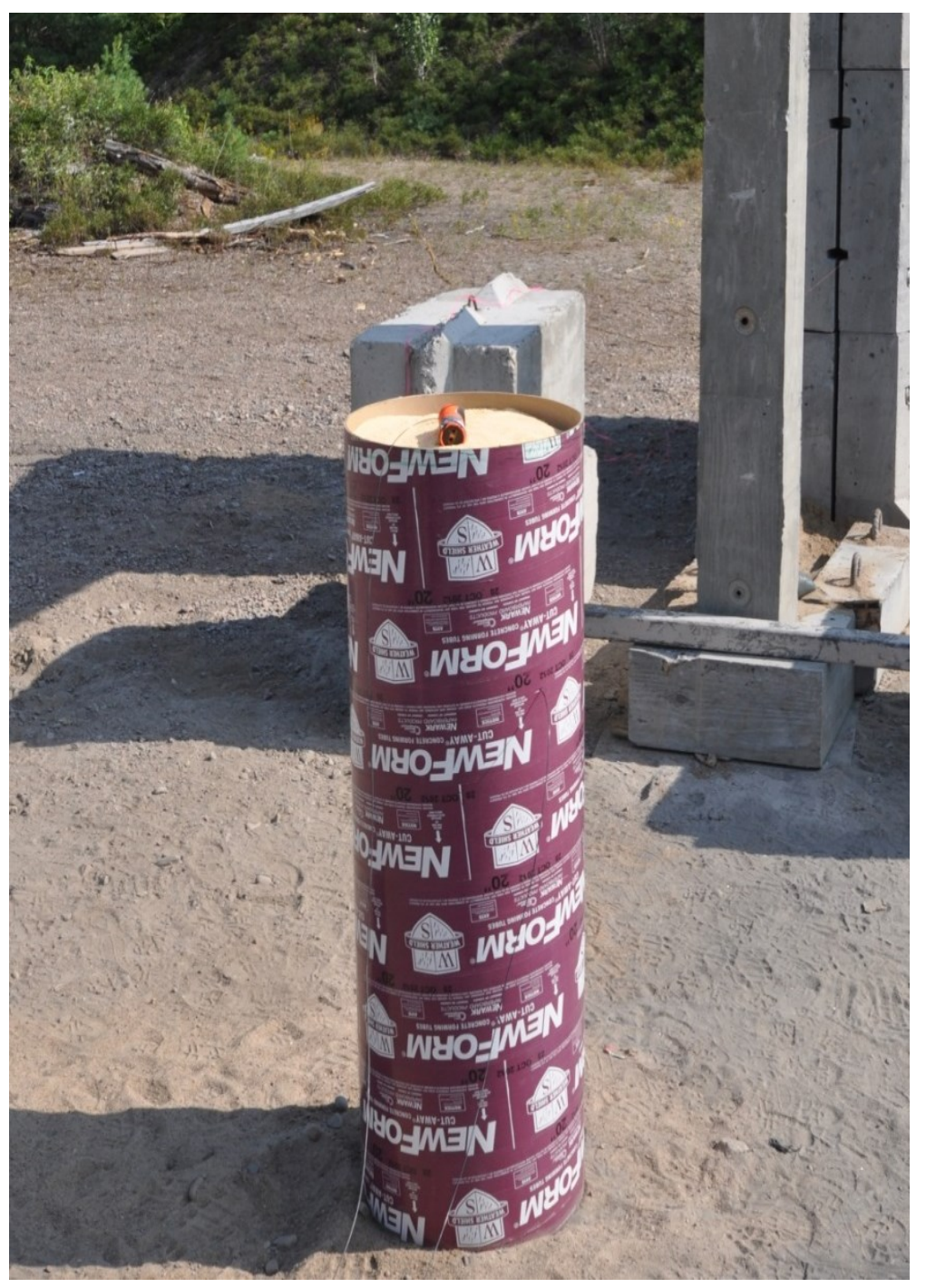

Figure 3-25: Cased ANFO explosive 


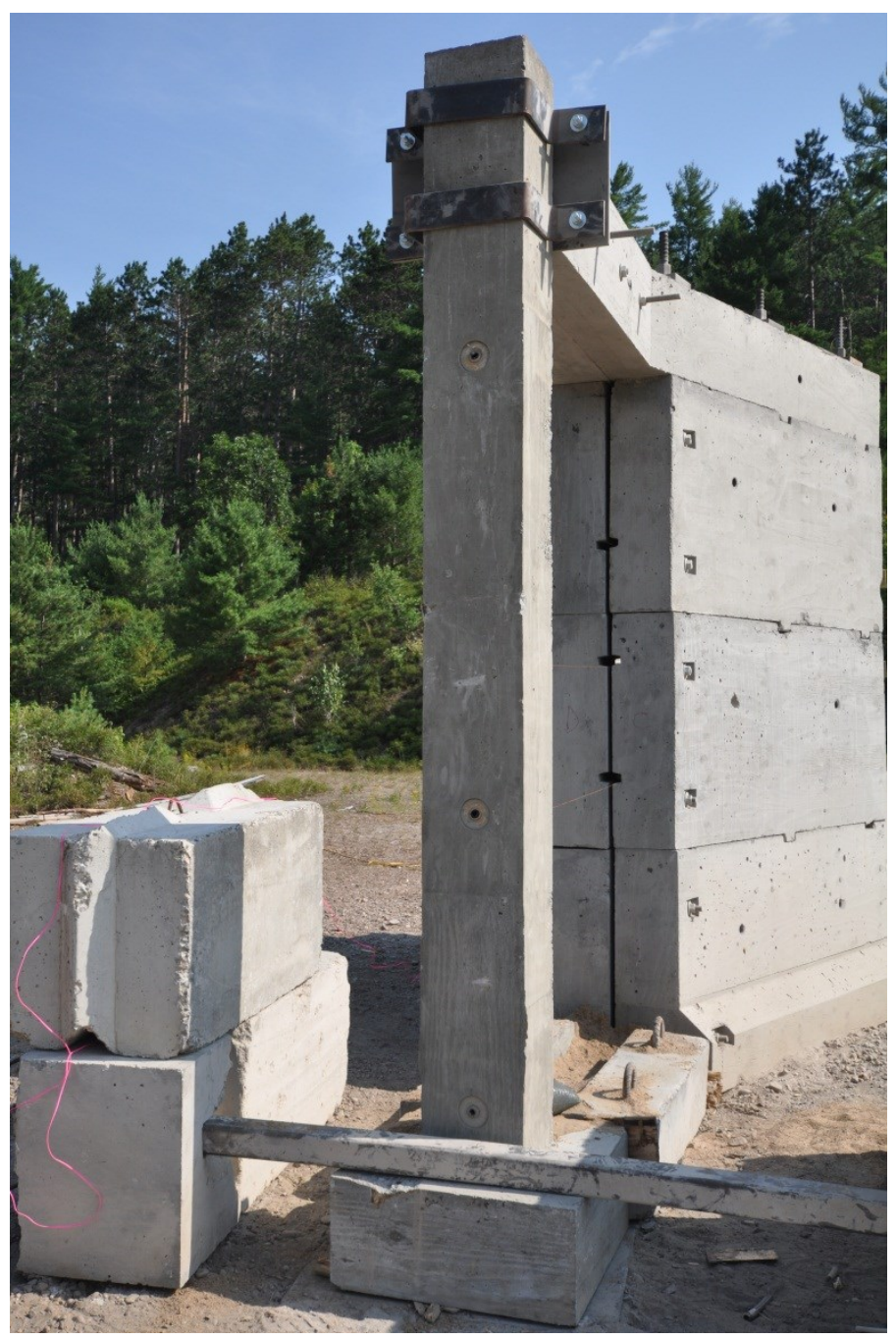

Figure 3-26: RC Colum on Site prior to testing 


\section{Chapter: Numerical Results and Discussions}

The previous chapter presented the modelling and validation of the numerical model of the reinforced concrete columns under blast loading. The experimental program was limited in scope due to the cost and time involved in investigating the effects of various design parameters on the behaviour and response of reinforced concrete columns. This chapter presents the results of a parametric study of the effects of design parameters on the behaviour of RC columns.

\subsection{Effects of Charge Mass on the Deflection of RC Columns}

In the foregoing, reinforced concrete columns were modelled with different tie spacing: $75 \mathrm{~mm}, 150 \mathrm{~mm}$ and $300 \mathrm{~mm}$, and subjected to blast loading from five explosive charge masses. The charge masses used in the simulations were $25 \mathrm{~kg}, 50 \mathrm{~kg}, 75 \mathrm{~kg}, 100 \mathrm{~kg}$, and $150 \mathrm{~kg}$ of ANFO. Results from comparison of the deflections at different elevations on the reinforced concrete column for the five charge masses were analysed. This section discusses results of the mid-height (1.5-m height) deflection of the reinforced concrete columns. The graphs of the mid-height deflection are presented and discussed in this section while the graphs of the third-point deflections are presented in the appendix.

\subsection{1 $Z=0.6 \mathrm{~m} / \mathrm{kg}^{1 / 3}$}

Figure 4-1 presents the deflection of the columns at the mid-height (1.5-m height) of the reinforced concrete column with tie spacing of $75 \mathrm{~mm}$ and under blast loading from a scaled distance of $0.6 \mathrm{~m} / \mathrm{kg}^{1 / 3}$. The deflections from various explosive charge masses at corresponding standoff distances to give a scaled distance of $0.6 \mathrm{~m} / \mathrm{kg}^{1 / 3}$ were investigated. Figure 4-1 shows that the mid-height deflections increased with increasing charge mass; even though the scaled distance remained constant at $0.6 \mathrm{~m} / \mathrm{kg}^{1 / 3}$. Similar 
trends were observed for the lower third-point (1-m height) and the upper third-point (2.0-m height). Table 4-1 shows that for each charge mass the maximum deflection was recorded at mid-height; with the 150-kg charge mass yielding the highest mid-height deflection of $10.57 \mathrm{~mm}$. The behaviour shows that even though different explosive threats, charge mass and standoff distance combination, can have the same scaled distance and thus same peak reflected pressure, their effect on reinforced concrete columns is markedly different. The reason for this could be attributed to the higher impulse of the blast load from the larger charge mass. For instance, the 150-kg charge mass gives a peak reflected pressure of $16.90 \times 10^{3} \mathrm{kPa}$ and associated reflected impulse of $5089 \mathrm{kPa}-\mathrm{ms}$ while the $25-\mathrm{kg}$ charge mass gives a peak reflected pressure of 16.80 $\times 10^{3} \mathrm{kPa}$ and an associated reflected impulse of $2792 \mathrm{kPa}-\mathrm{ms}$ at the same scaled distance of $0.6 \mathrm{~m} / \mathrm{kg}^{1 / 3}$. Also, the duration of blast loading will also be dependent on charge mass leading to higher deflections.

Figure 4-2 and Figure 4-3 present the mid-height deflection profiles for reinforced concrete columns with $150-\mathrm{mm}$ and $300-\mathrm{mm}$ tie spacing, respectively. The behaviour of these columns is similar to that with the $75-\mathrm{mm}$ tie spacing with maximum deflections occurring at mid-height (Table 4-2 and Table 4-3). The highest mid-height deflections were observed with the $150-\mathrm{kg}$ charge mass: $10.86 \mathrm{~mm}$ for the column with $150-\mathrm{mm}$ tie spacing and $10.91 \mathrm{~mm}$ for the column with 300-mm tie spacing.

The deflection profiles from the numerical simulations (Figure 4-1 to 4-3) show that as the charge mass increased, the natural period of vibration also increased, especially under $150-\mathrm{kg}$ charge response. Also the natural period increased with the run time. This is 
likely due to damage to the concrete column, cracking and spalling, reducing the moment of inertia and stiffness of the columns.

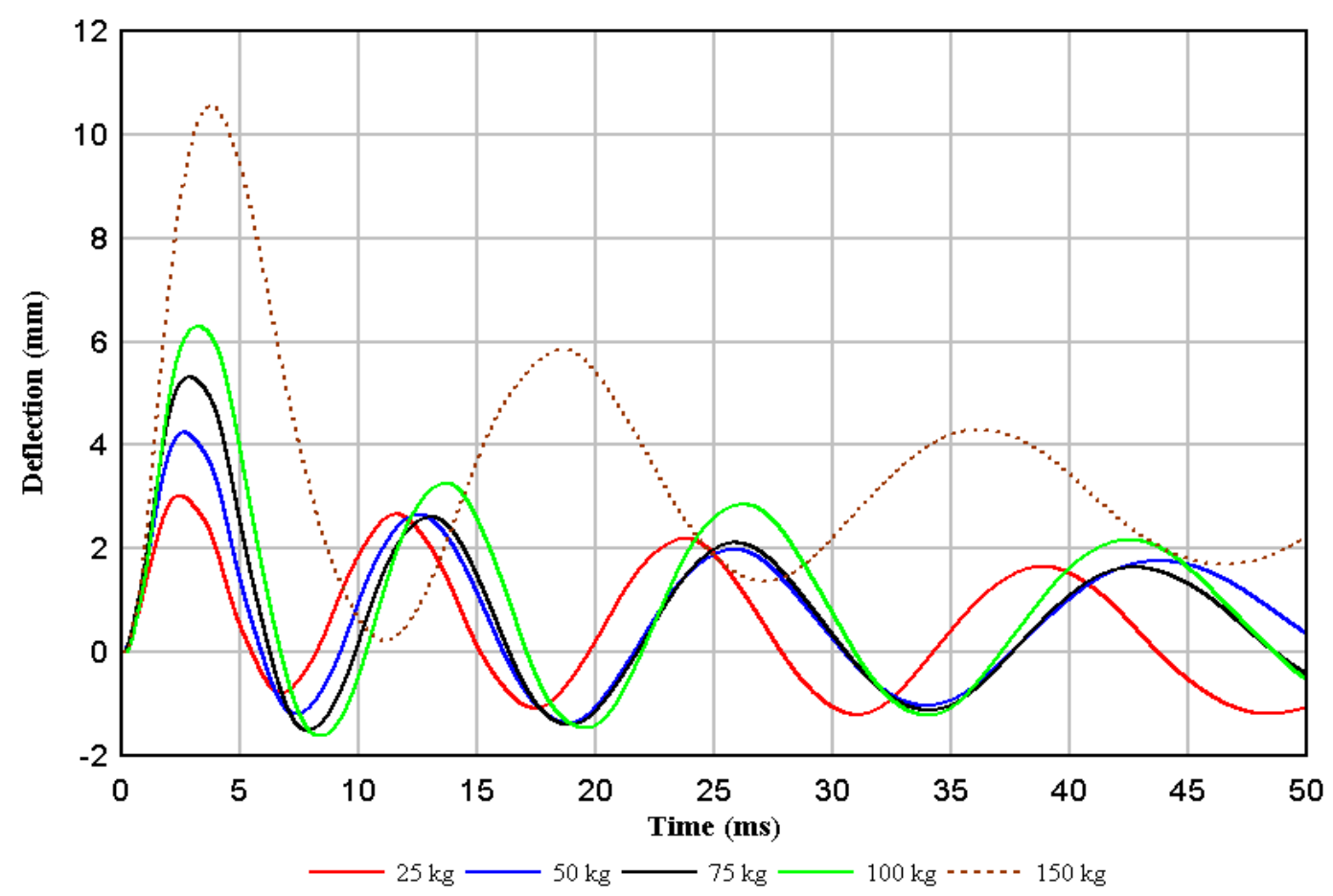

Figure 4-1: Column deflections at height $1.5 \mathrm{~m}$ for $75-\mathrm{mm}$ tie spacing at $\mathrm{Z}=0.6 \mathrm{~m} / \mathrm{kg}^{1 / 3}$ 


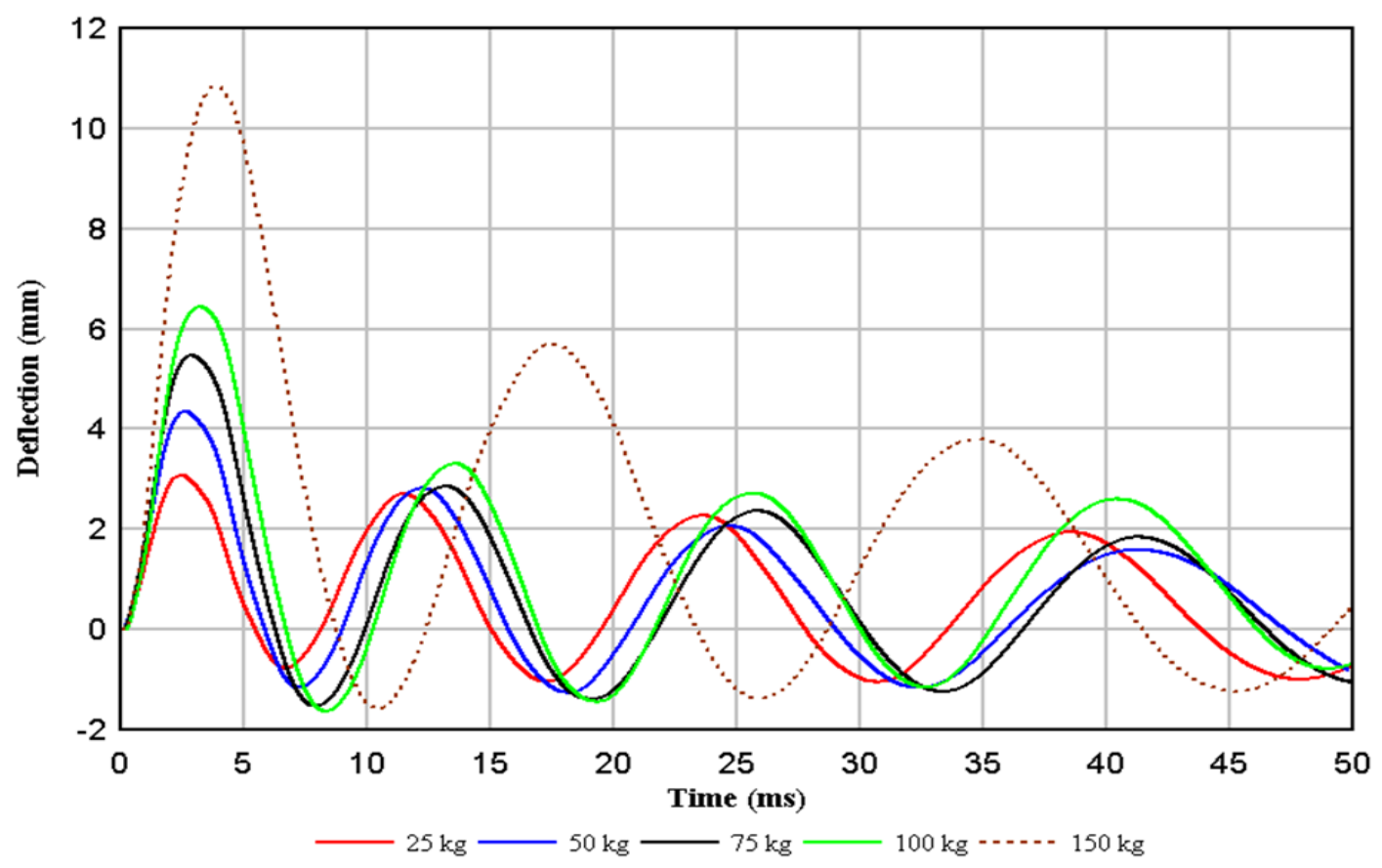

Figure 4-2: Column deflections at mid-height $1.5 \mathrm{~m}$ for $150 \mathrm{~mm}$ tie spacing at $\mathrm{Z}=0.6$ $\mathrm{m} / \mathrm{kg}^{1 / 3}$

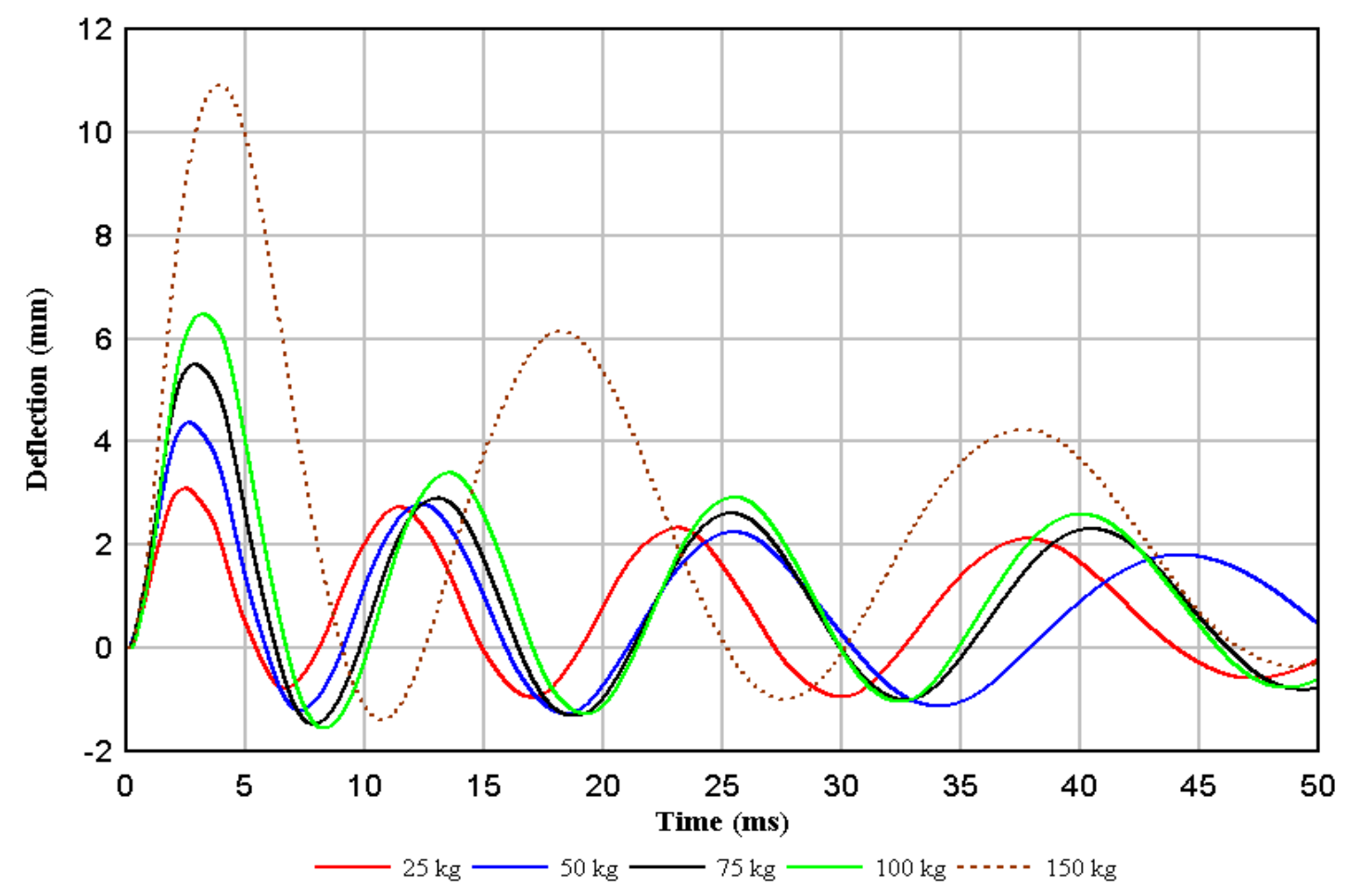

Figure 4-3: Column deflections at height $1.5 \mathrm{~m}$ for $300-\mathrm{mm}$ tie spacing at $\mathrm{Z}=0.6 \mathrm{~m} / \mathrm{kg}^{1 / 3}$ 
Table 4-1: Maximum Deflections (mm) at $\mathrm{Z}=0.6 \mathrm{~m} / \mathrm{kg}^{1 / 3}$ for $75-\mathrm{mm}$ tie-spacing

\begin{tabular}{|l|l|l|l|l|l|}
\hline \multicolumn{2}{|l|}{ Maximum Deflections (mm) } \\
\hline column Height (m) & $\mathbf{2 5} \mathbf{~ k g}$ & $\mathbf{5 0} \mathbf{~ k g}$ & $\mathbf{7 5} \mathbf{~ k g}$ & $\mathbf{1 0 0} \mathbf{~ k g}$ & $\mathbf{1 5 0} \mathbf{~ k g}$ \\
\hline 1 & 2.43 & 3.62 & 4.69 & 5.55 & 10.00 \\
\hline 1.5 & 3.01 & 4.25 & 5.31 & 6.29 & 10.57 \\
\hline 2 & & & & & 8.12 \\
\hline
\end{tabular}

Table 4-2: Maximum Deflections (mm) at $\mathrm{Z}=0.6 \mathrm{~m} / \mathrm{kg}^{1 / 3}$ for $150-\mathrm{mm}$ tie-spacing

\begin{tabular}{|l|l|l|l|l|l|}
\hline \multicolumn{2}{|l|}{ Maximum Deflections (mm) } \\
\hline column Height (m) & $\mathbf{2 5} \mathbf{~ k g}$ & $\mathbf{5 0} \mathbf{~ k g}$ & $\mathbf{7 5} \mathbf{~ k g}$ & $\mathbf{1 0 0} \mathbf{~ k g}$ & $\mathbf{1 5 0} \mathbf{~ k g}$ \\
\hline 1 & 2.47 & 3.69 & 4.83 & 5.70 & 10.25 \\
\hline 1.5 & 3.07 & 4.36 & 5.47 & 6.44 & 10.86 \\
\hline 2 & 2.48 & 3.37 & 4.23 & 5.07 & 8.46 \\
\hline
\end{tabular}

Table 4-3: Maximum Deflections $(\mathrm{mm})$ at $\mathrm{Z}=0.6 \mathrm{~m} / \mathrm{kg}^{1 / 3}$ for $300-\mathrm{mm}$ tie-spacing Maximum Deflections (mm) at $\mathrm{Z}=\mathbf{0 . 6}$ for 300-mm tie-spacing

\begin{tabular}{|l|l|l|l|l|l|}
\hline column Height (m) & $\mathbf{2 5} \mathbf{~ k g}$ & $\mathbf{5 0} \mathbf{~ k g}$ & $\mathbf{7 5} \mathbf{~ k g}$ & $\mathbf{1 0 0} \mathbf{~ k g}$ & $\mathbf{1 5 0} \mathbf{~ k g}$ \\
\hline 1 & 2.49 & 3.70 & 4.87 & 5.73 & 10.34 \\
\hline 1.5 & 3.08 & 4.37 & 5.50 & 6.47 & 10.91 \\
\hline 2 & 2.49 & 3.37 & 4.26 & 5.10 & 8.62 \\
\hline
\end{tabular}




\subsection{2 $\mathrm{Z}=0.25 \mathrm{~m} / \mathrm{kg}^{1 / 3}$}

The reinforced concrete columns with different column tie spacing were modelled under blast loading from the five charge masses used in the previous models. However the standoff distances were changed to yield a constant scaled distance of $0.25 \mathrm{~m} / \mathrm{kg}^{1 / 3}$. Figure 4-4, Figure 4-5 and Figure 4-6 present the mid-height deflection profiles of the columns with 75-mm, 150-mm, and 300-mm tie spacing respectively.

The deflection profiles and the summary of maximum deflections in Table 4-4 to Table 4-6 show that the maximum mid-height deflection increases with increasing charge mass. For the charge mass of $150 \mathrm{~kg}$, the deflection of the column with $75-\mathrm{mm}, 150-\mathrm{mm}$, and $300-\mathrm{mm}$ tie spacing exceeded $500 \mathrm{~mm}$ at the end of the run time of $50 \mathrm{~ms}$, a support rotation in excess of $18^{\circ}$. These columns were considered failed at this support rotation. For charge masses ranging from 25 to $100 \mathrm{~kg}$, the columns attained various maximum deflections without experiencing total failure as shown in the deflection profile plots, except for the column with 300-mm tie spacing which experience excessive deflection of about $313 \mathrm{~mm}$ (Figure 4-6) translating to a support rotation of about $12^{\circ}$.

Similar trends in third-point deflection were observed from Figure 6-9 to Figure 6-10 (Appendix) for the RC column with 150-mm tie spacing under blast loading from scaled distance of 0.25 . The deflections increased with increasing charge masses while under blast loading from $150 \mathrm{~kg}$ explosive charge mass, the columns experienced shear failure. 


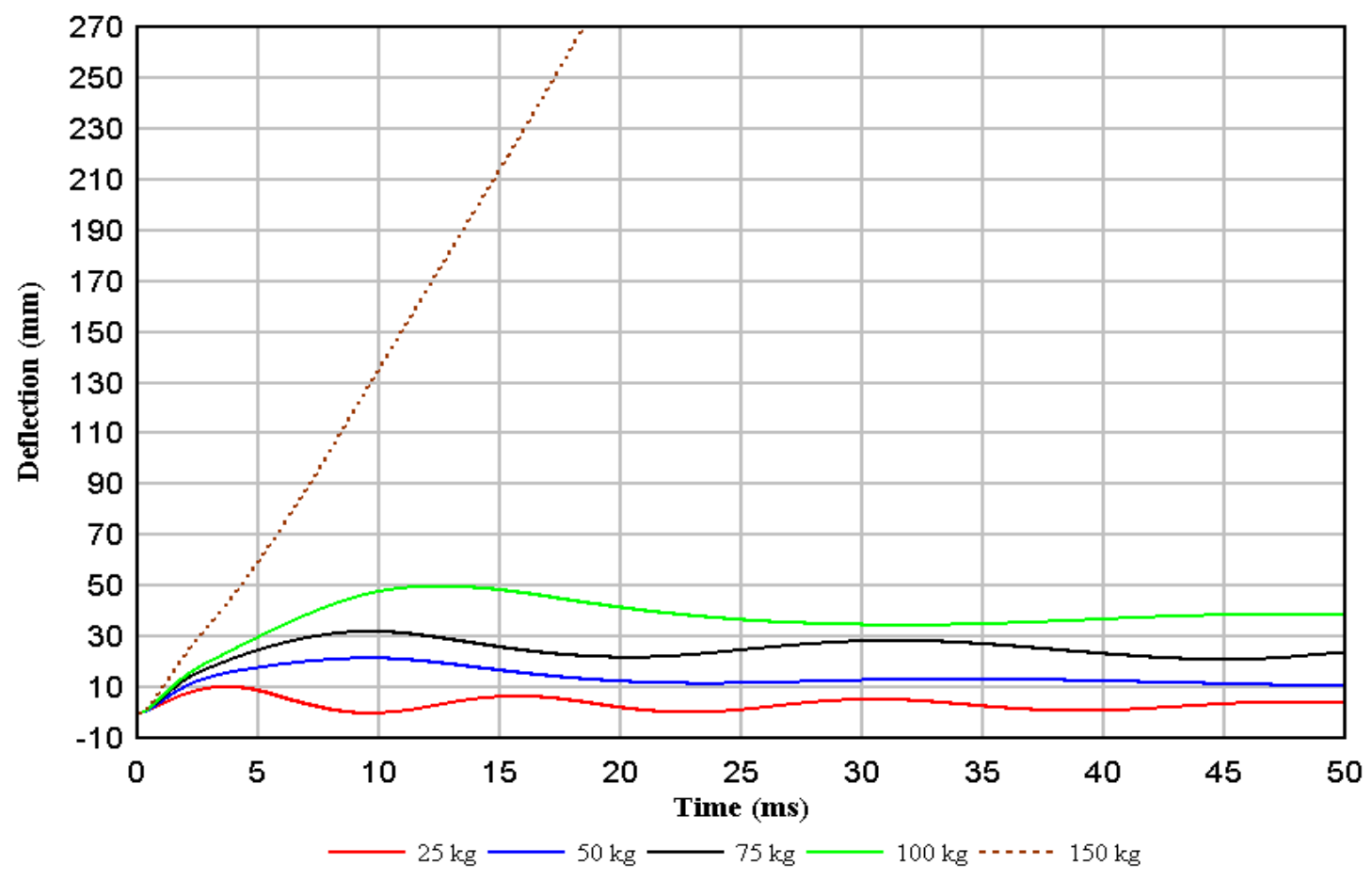

Figure 4-4: Column deflections at height $1.5 \mathrm{~m}$ for $75-\mathrm{mm}$ tie spacing at $\mathrm{Z}=0.25 \mathrm{~m} / \mathrm{kg}^{1 / 3}$

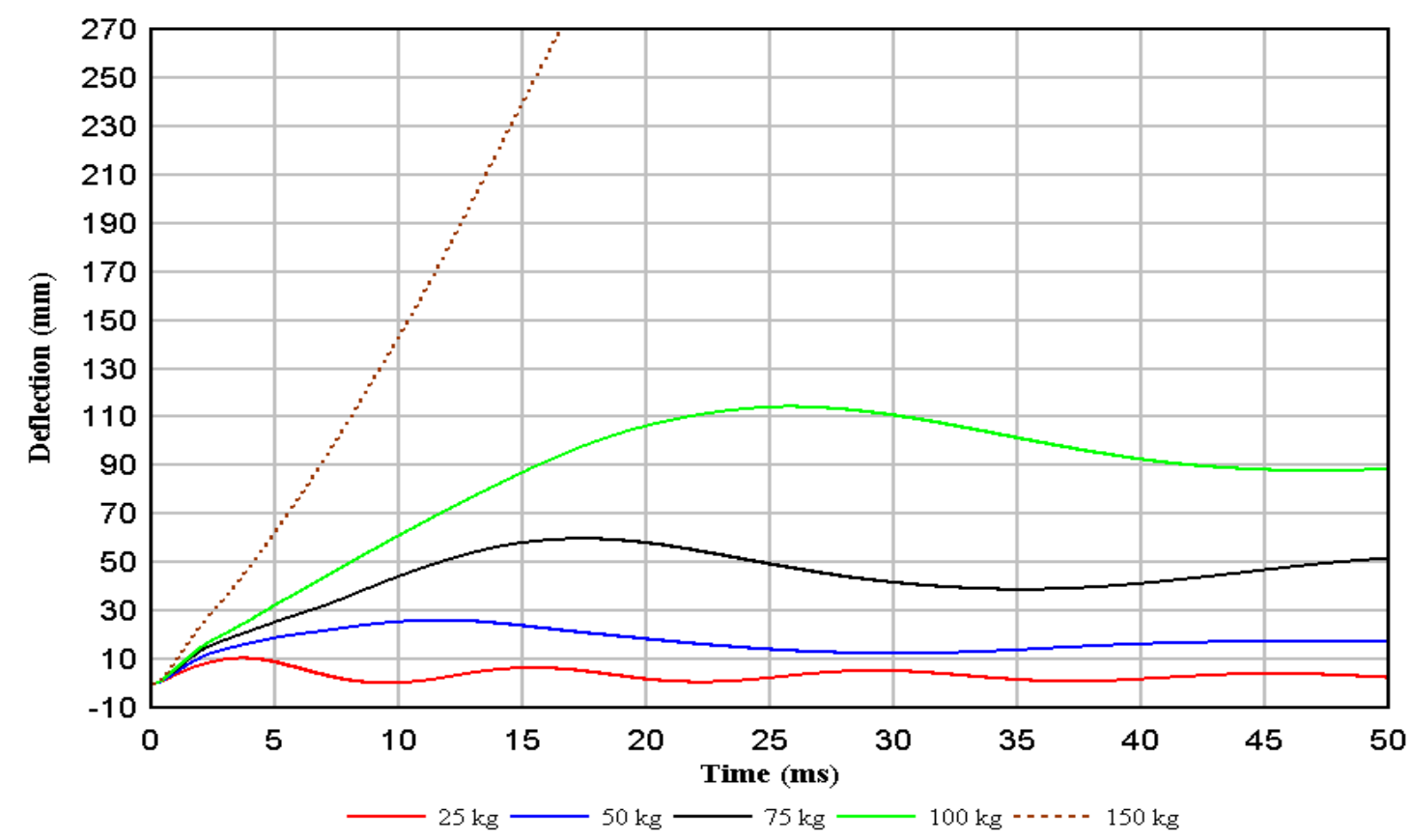

Figure 4-5: Column deflections at height $1.5 \mathrm{~m}$ for $150-\mathrm{mm}$ tie spacing at $\mathrm{Z}=0.25$ $\mathrm{m} / \mathrm{kg}^{1 / 3}$ 


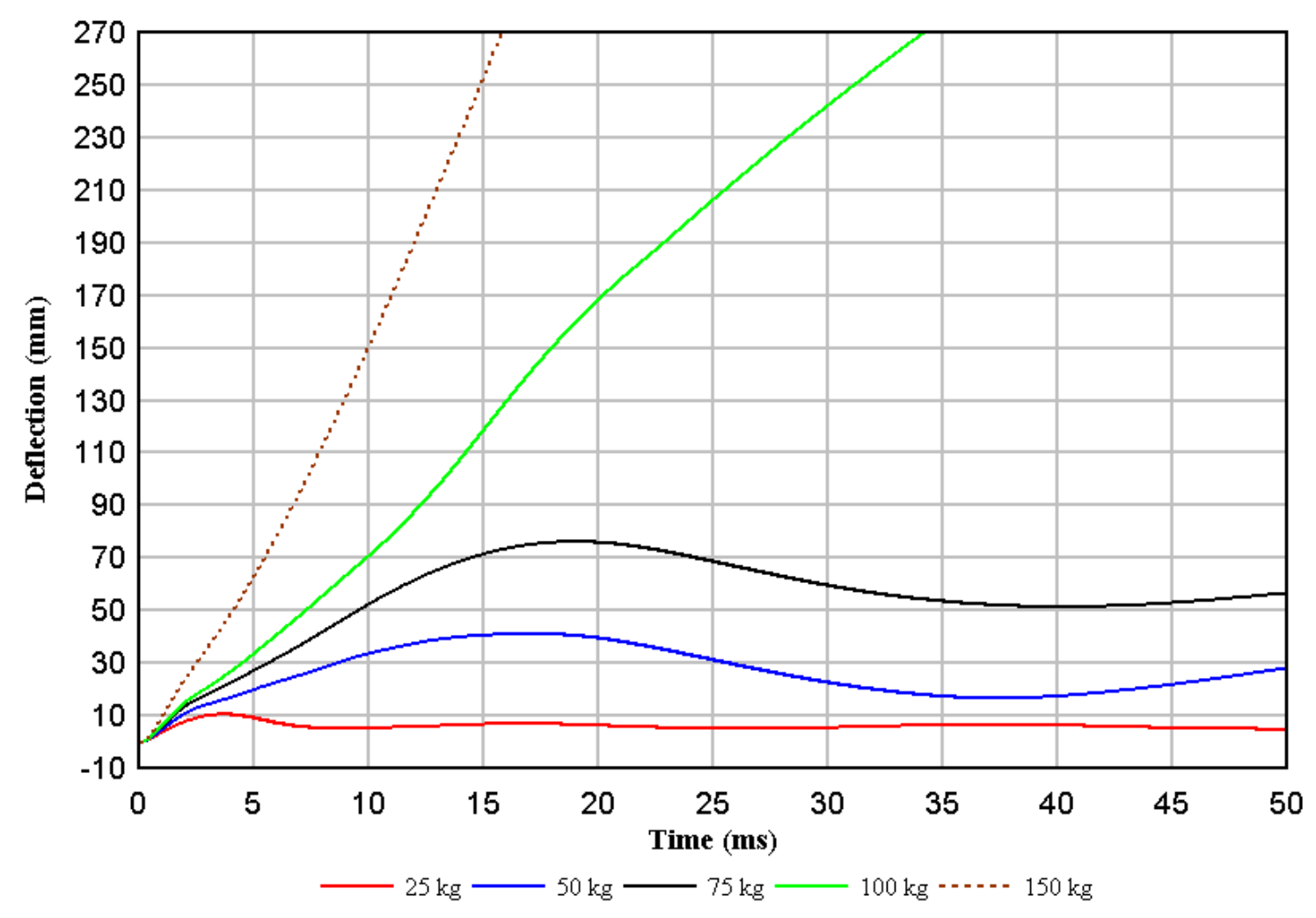

Figure 4-6: Column deflections at height $1.5 \mathrm{~m}$ for $300-\mathrm{mm}$ tie spacing at $\mathrm{Z}=0.25$ $\mathrm{m} / \mathrm{kg}^{1 / 3}$

Table 4-4: Maximum Deflections $(\mathrm{mm})$ at $\mathrm{Z}=0.25 \mathrm{~m} / \mathrm{kg}^{1 / 3}$ for $75-\mathrm{mm}$ tie-spacing

\begin{tabular}{|l|l|l|l|l|l|}
\hline \multicolumn{5}{|l|}{ Maximum Deflections (mm) } \\
\hline column Height (m) & $\mathbf{2 5} \mathbf{~ k g}$ & $\mathbf{5 0} \mathbf{~ k g}$ & $\mathbf{7 5} \mathbf{~ k g}$ & $\mathbf{1 0 0} \mathbf{~ k g}$ & $\mathbf{1 5 0} \mathbf{~ k g}$ \\
\hline 1 & 9.57 & 24.49 & 36.11 & 57.36 & $>543$ \\
\hline 1.5 & 10.21 & 21.45 & 32.81 & 49.73 & $>606$ \\
\hline 2 & 7.82 & 15.45 & 25.75 & 37.21 & $>398$ \\
\hline
\end{tabular}


Table 4-5: Maximum Deflections (mm) at $\mathrm{Z}=0.25 \mathrm{~m} / \mathrm{kg}^{1 / 3}$ for $150-\mathrm{mm}$ tie-spacing Maximum Deflections (mm)

\begin{tabular}{|l|l|l|l|l|l|}
\hline column Height (m) & $\mathbf{2 5} \mathbf{~ k g}$ & $\mathbf{5 0} \mathbf{~ k g}$ & $\mathbf{7 5} \mathbf{~ k g}$ & $\mathbf{1 0 0} \mathbf{~ k g}$ & $\mathbf{1 5 0} \mathbf{~ k g}$ \\
\hline 1 & 9.79 & 30.77 & 70.91 & 125.95 & $>570$ \\
\hline 1.5 & 10.38 & 26.09 & 59.70 & 114.24 & $>585$ \\
\hline 2 & 7.95 & 18.47 & 42.34 & 88.10 & $>520$ \\
\hline
\end{tabular}

Table 4-6: Maximum Deflections (mm) at $Z=0.25 \mathrm{~m} / \mathrm{kg}^{1 / 3}$ for $300-\mathrm{mm}$ tie-spacing

\begin{tabular}{|l|l|l|l|l|l|}
\hline \multicolumn{2}{|l|}{ Maximum Deflections (mm) } \\
\hline column Height (m) & $\mathbf{2 5} \mathbf{~ k g}$ & $\mathbf{5 0} \mathbf{~ k g}$ & $\mathbf{7 5} \mathbf{~ k g}$ & $\mathbf{1 0 0} \mathbf{~ k g}$ & $\mathbf{1 5 0} \mathbf{~ k g}$ \\
\hline 1 & 9.94 & 49.63 & 87.20 & $>275$ & $>851$ \\
\hline 1.5 & 10.46 & 41.09 & 76.16 & $>313$ & $>878$ \\
\hline 2 & 7.99 & 28.64 & 53.79 & $>267$ & $>578$ \\
\hline
\end{tabular}

\subsection{Comparing Deflections at Different Column Heights}

\subsection{1 $\mathrm{Z}=0.6 \mathrm{~m} / \mathrm{kg}^{1 / 3}$}

Figure 4-7, Figure 4-8 and Figure 4-9 present typical responses of reinforced concrete columns with $75-\mathrm{mm}, 150-\mathrm{mm}$, and $300-\mathrm{mm}$ tie spacing respectively for a $25 \mathrm{~kg}$ charge mass. The figures show comparison of the column deflection at the lower third-point, mid-height, and upper third-point under blast loading from a scaled distance of 0.6 $\mathrm{m} / \mathrm{kg}^{1 / 3}$. The general trend observed is that the maximum deflections occurred at the mid- 
height (column height of $1.5 \mathrm{~m}$ ) and that the deflections at lower third-point ( $1 \mathrm{~m}$ from base of column) were consistently higher than deflections at upper third-point ( $2 \mathrm{~m}$ from base of column).

The distance from mid-height point to the lower and upper third-points of the column (1 $\mathrm{m}$ and $2 \mathrm{~m}$ respectively from column base) were the same and would have resulted in similar deflections. However, the higher deflections at lower third-point in comparison to the deflections at upper third-points is attributed to the Mach stem formed from the elevated ANFO explosive charge mass, at a height of burst of $1.3 \mathrm{~m} \mathrm{(1} \mathrm{m} \mathrm{from} \mathrm{base} \mathrm{of}$ column). Also the centre of detonation coincided with the lower third point of the column resulting in a shorter distance from the centre of detonation to this point in comparison to the upper third-point. Thus, the Mach stem and the shorter distance to the centre of detonation resulted in the asymmetric deflected shape along the height of the columns.

\subsection{2 $\mathrm{Z}=0.25 \mathrm{~m} / \mathrm{kg}^{1 / 3}$}

When the deflections at the lower third-point, mid-height, and upper third-point were compared for columns under blast loading from a scaled distance of $0.25 \mathrm{~m} / \mathrm{kg}^{1 / 3}$, the observed trend was different from that at a scaled distance was $0.6 \mathrm{~m} / \mathrm{kg}^{1 / 3}$. Under blast loading from a $25-\mathrm{kg}$ ANFO charge and a scaled distance of $0.25 \mathrm{~m} / \mathrm{kg}^{1 / 3}$, the maximum deflections occurred at mid-height (Figure 4-13, Figure 4-14, and Figure 4-15), while for a $50-\mathrm{kg}$ ANFO charge and a scaled distance of $0.25 \mathrm{~m} / \mathrm{kg}^{1 / 3}$, the maximum deflections occurred at lower third-point ( $1 \mathrm{~m}$ from base of column), as opposed to mid-height (Figure 4-10, Figure 4-11, and Figure 4-12). The deflection profiles for the other charge masses are presented in the Appendix. 
In general, as the scaled distance decreased, the nonlinearity of the blast load distribution along the height of the RC columns increased. However for the $25 \mathrm{~kg}$ charge mass at scaled distance of $0.25 \mathrm{~m} / \mathrm{kg}^{1 / 3}$, the maximum deflections were recorded at the mid-height point of the columns (Figure 4-13, Figure 4-14 and Figure 4-15). Thus, at smaller scaled distances, for smaller charge masses, the shock front is likely to be planar resulting in simultaneous and uniform loading of the column face.

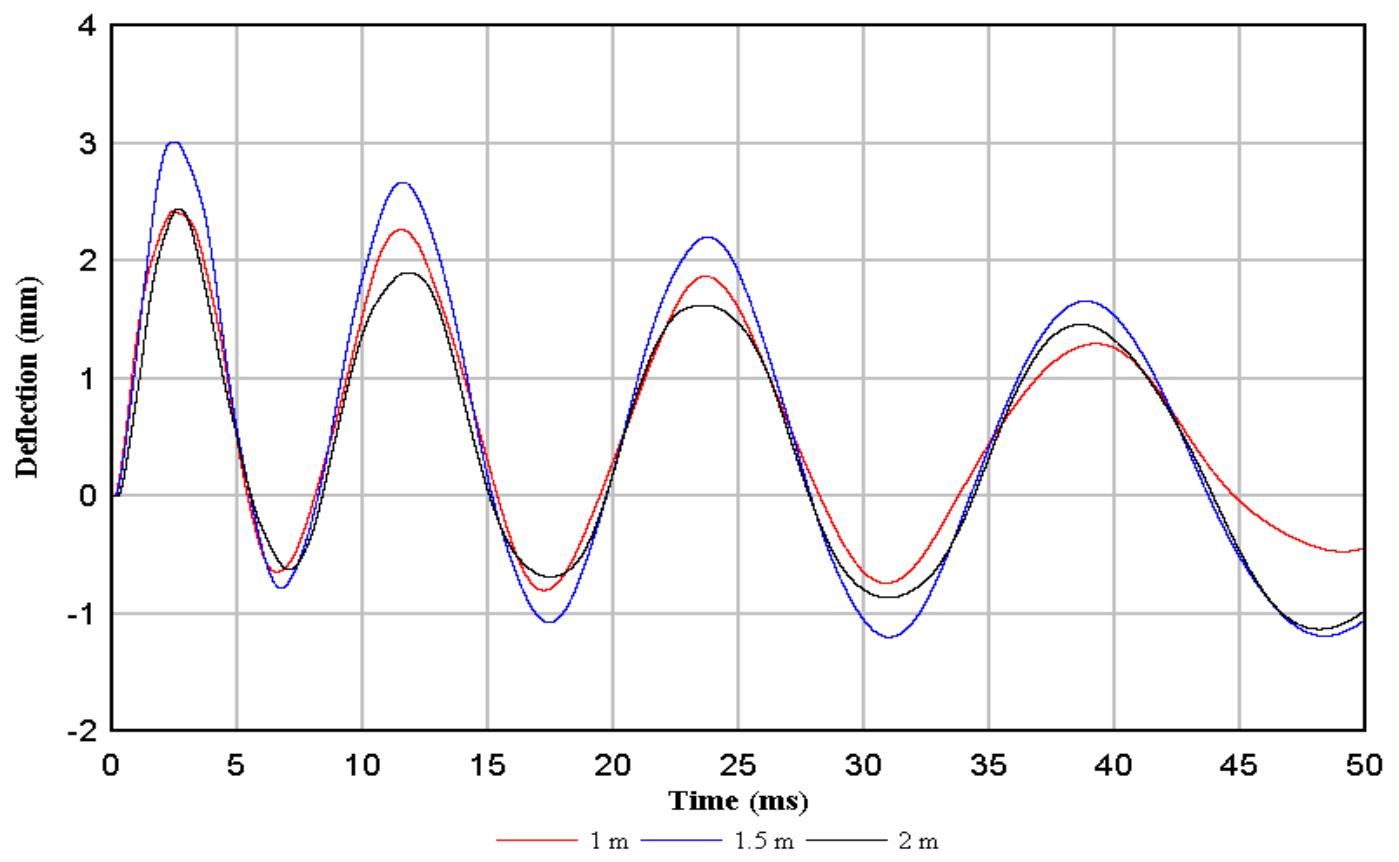

Figure 4-7: Column deflections for $75-\mathrm{mm}$ tie spacing at $Z=0.6 \mathrm{~m} / \mathrm{kg}^{1 / 3}$ for $25 \mathrm{~kg}$ charge mass 


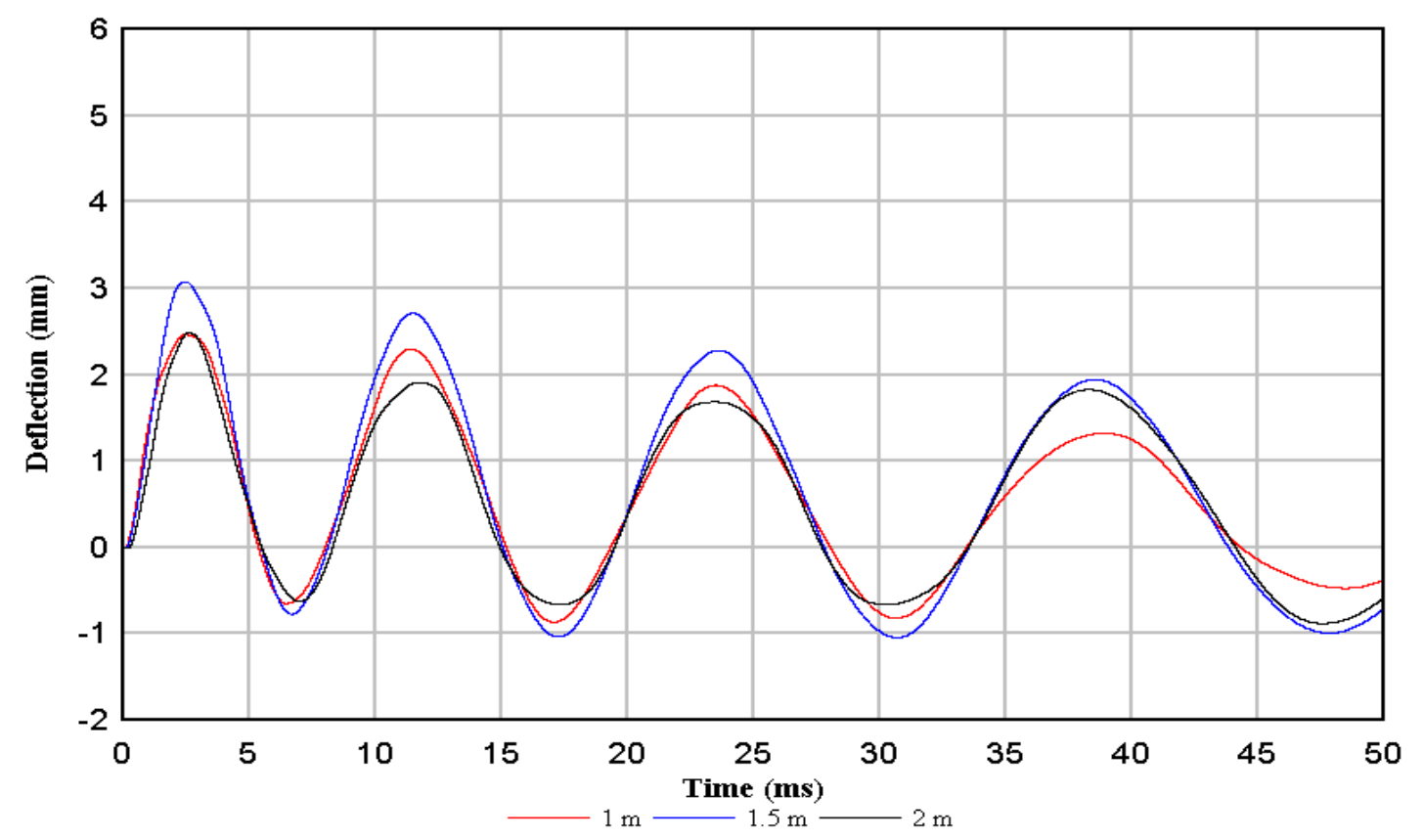

Figure 4-8: Column deflections for $150-\mathrm{mm}$ tie spacing at $\mathrm{Z}=0.6 \mathrm{~m} / \mathrm{kg}^{1 / 3}$ for $25 \mathrm{~kg}$ charge mass

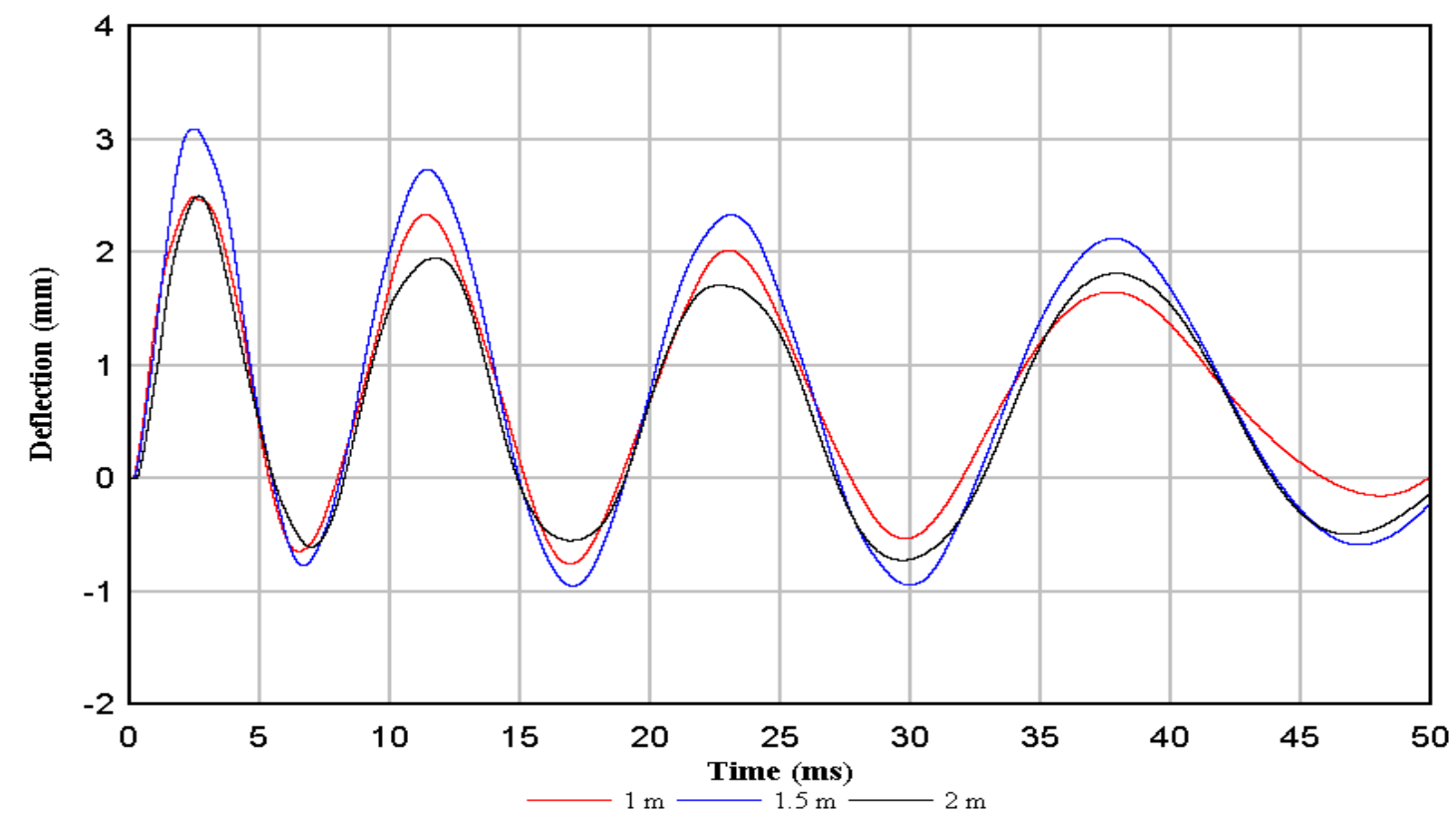

Figure 4-9: Column deflections for $300-\mathrm{mm}$ tie spacing at $\mathrm{Z}=0.6 \mathrm{~m} / \mathrm{kg}^{1 / 3}$ for $25 \mathrm{~kg}$ charge mass 


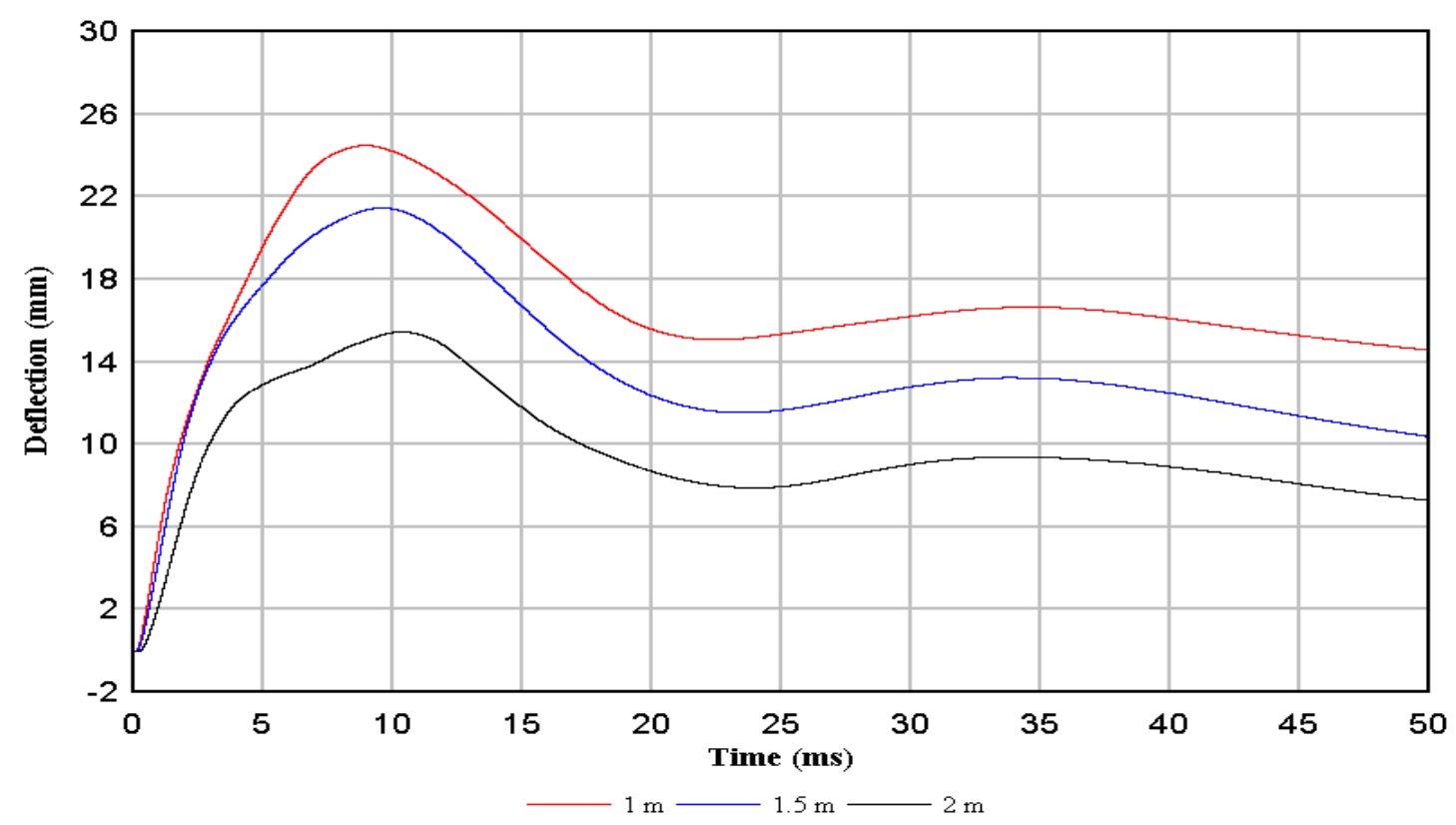

Figure 4-10: Column deflections for $75-\mathrm{mm}$ tie spacing at $Z=0.25 \mathrm{~m} / \mathrm{kg}^{1 / 3}$ for $50 \mathrm{~kg}$ charge

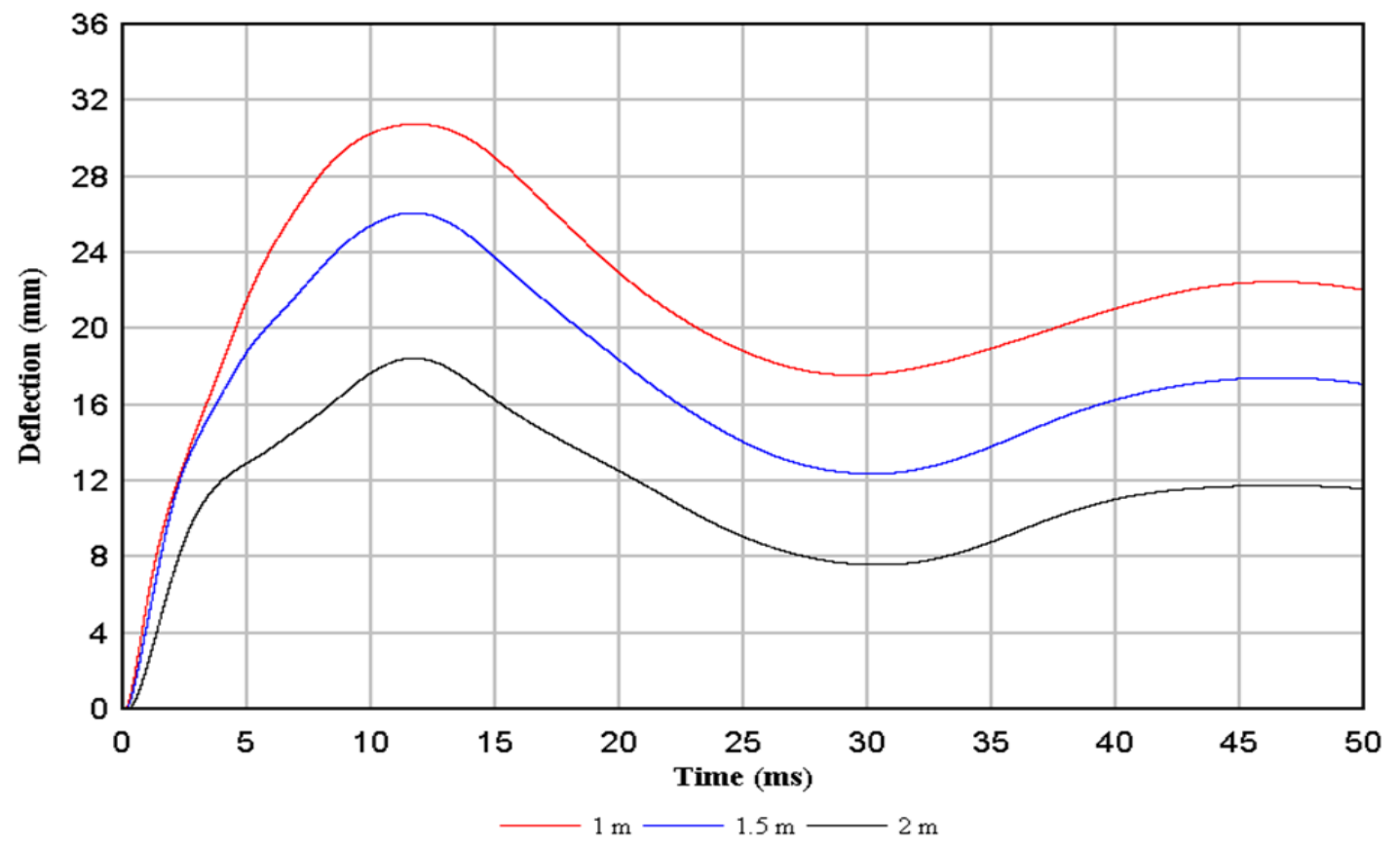

Figure 4-11: Column deflections for 300-mm tie spacing at $Z=0.25 \mathrm{~m} / \mathrm{kg}^{1 / 3}$ for $50 \mathrm{~kg}$ charge 


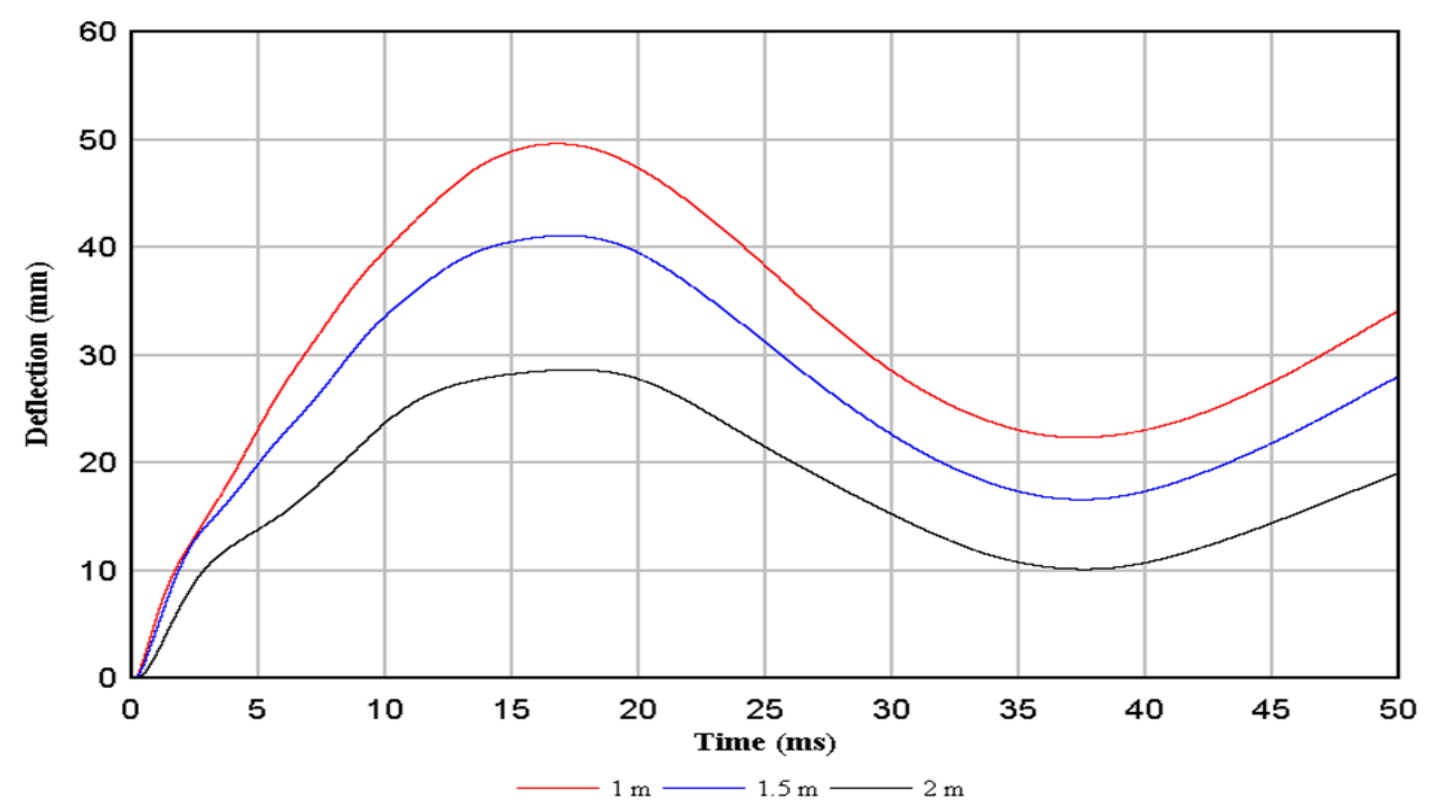

Figure 4-12: Column deflections for 300-mm tie spacing at $Z=0.25 \mathrm{~m} / \mathrm{kg}^{1 / 3}$ for $50 \mathrm{~kg}$ charge

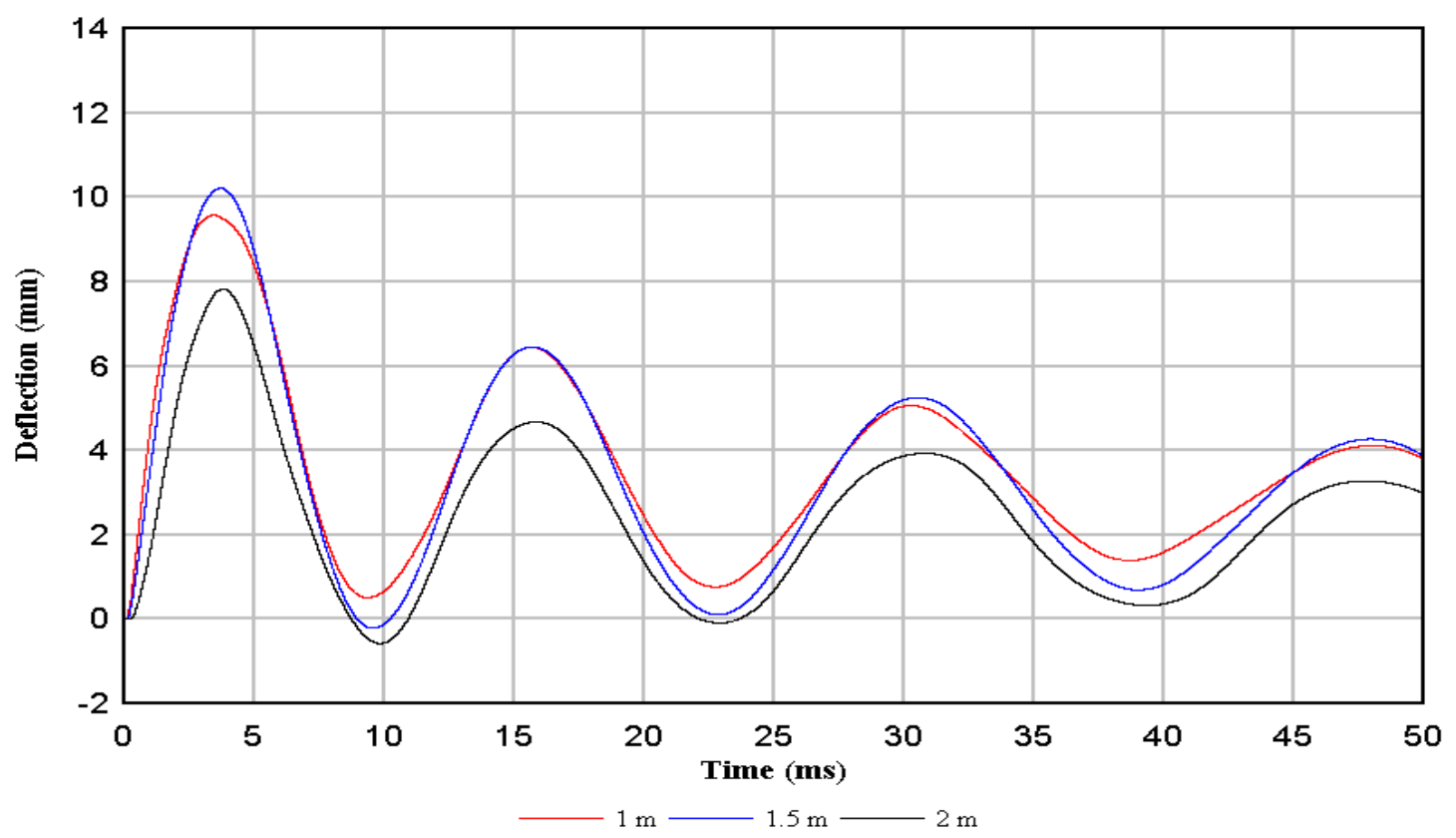

Figure 4-13: Column deflections for $75-\mathrm{mm}$ tie spacing at $Z=0.25 \mathrm{~m} / \mathrm{kg}^{1 / 3}$ for $25 \mathrm{~kg}$ charge 


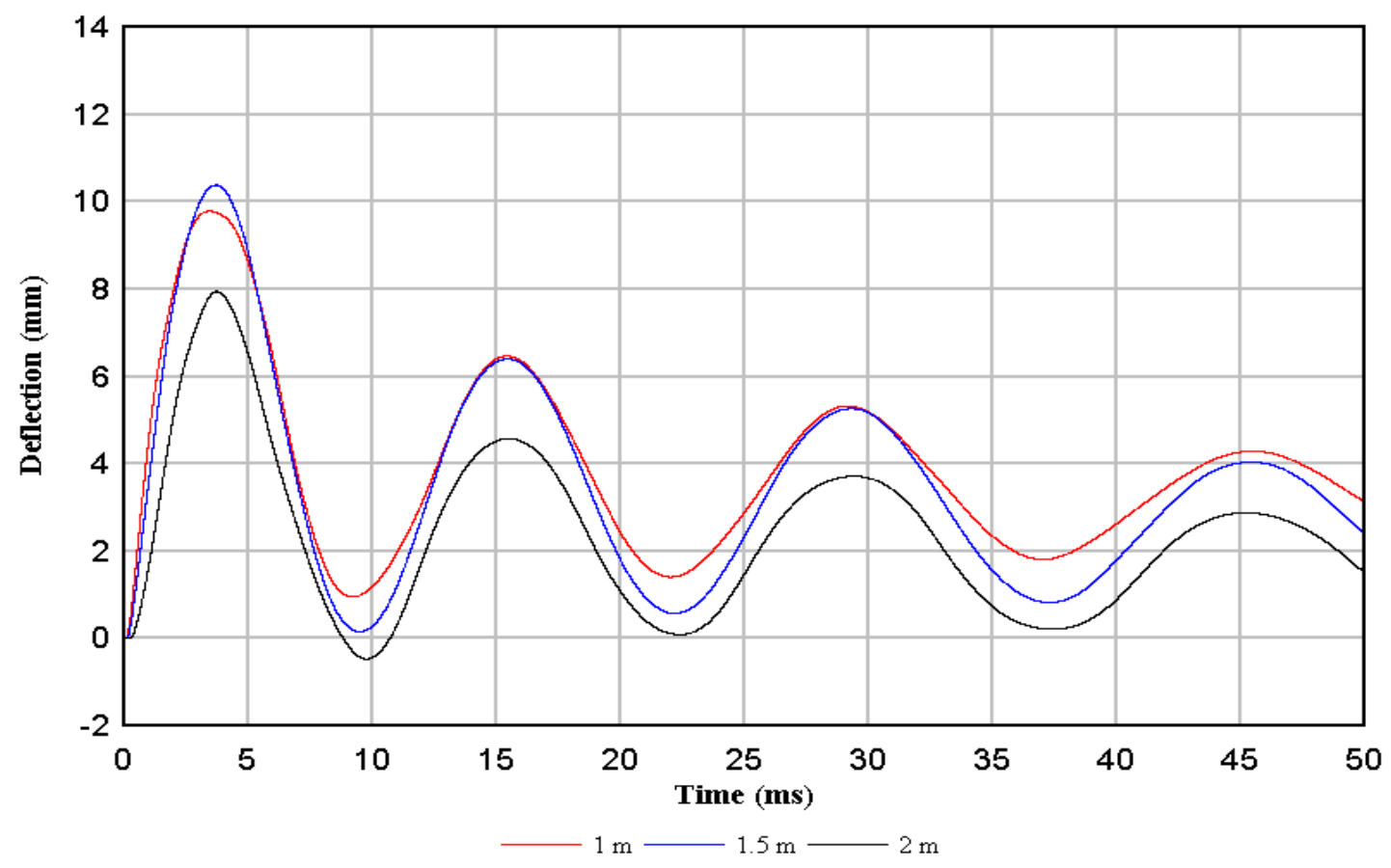

Figure 4-14: Column deflections for 150 - $\mathrm{mm}$ tie spacing at $Z=0.25 \mathrm{~m} / \mathrm{kg}^{1 / 3}$ for $25 \mathrm{~kg}$ charge

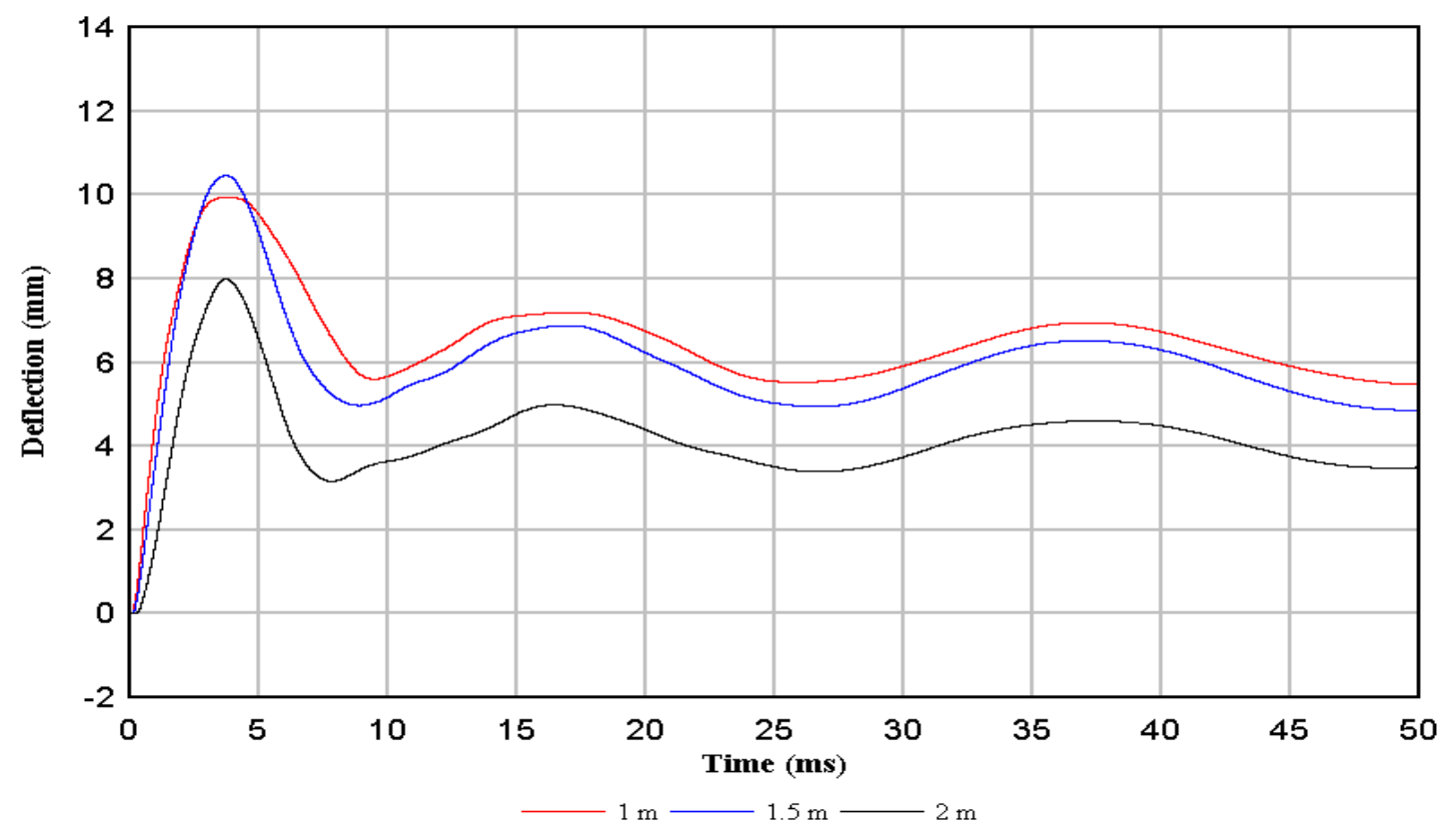

Figure 4-15: Column deflections for 300-mm tie spacing at $Z=0.25 \mathrm{~m} / \mathrm{kg}^{1 / 3}$ for $25 \mathrm{~kg}$ charge 


\subsection{Observed Failure Modes}

Figure 4-16 to Figure 4-18 present failure progression and failure modes observed for the three column types (based on tie spacing) under blast loading from 150-kg charge mass explosion. Figure 4-16 shows failure progression and failure mode of the reinforced concrete column with 75-mm tie spacing while Figure 4-17 and Figure 4-18 show the failure progression and failure modes of the columns with $150-\mathrm{mm}$ and $300-\mathrm{mm}$ tie spacing respectively. In all column types, failure is initiated at the column supports and increases as the magnitude of load increases. At the later stages of loading, flexural cracking and failure is initiated at mid-height. The shear failure appears to be dominant in the column behaviour. The shear failure observed can be attributed to the position of the column relative to the charge mass above the ground. Also the scaled distance of 0.25

$\mathrm{m} / \mathrm{kg}^{1 / 3}$ resulted in nonlinearity of the blast pressure with higher magnitudes at the base of the column.

The effect of tie spacing is noticeable when comparing Figure 4-19, Figure 4-20, and Figure 4-21. The failure progression and failure mode for reinforced concrete column with $75-\mathrm{mm}, 150-\mathrm{mm}$, and $300-\mathrm{mm}$ tie spacing is presented in Figure 4-19, Figure 4-20, and Figure 4-21 respectively. In Figure 4-21, the column was considered failed. However as the tie spacing decreased the extent of failure also decreased. Increase in concrete confinement resulted in a decrease in concrete failure. 


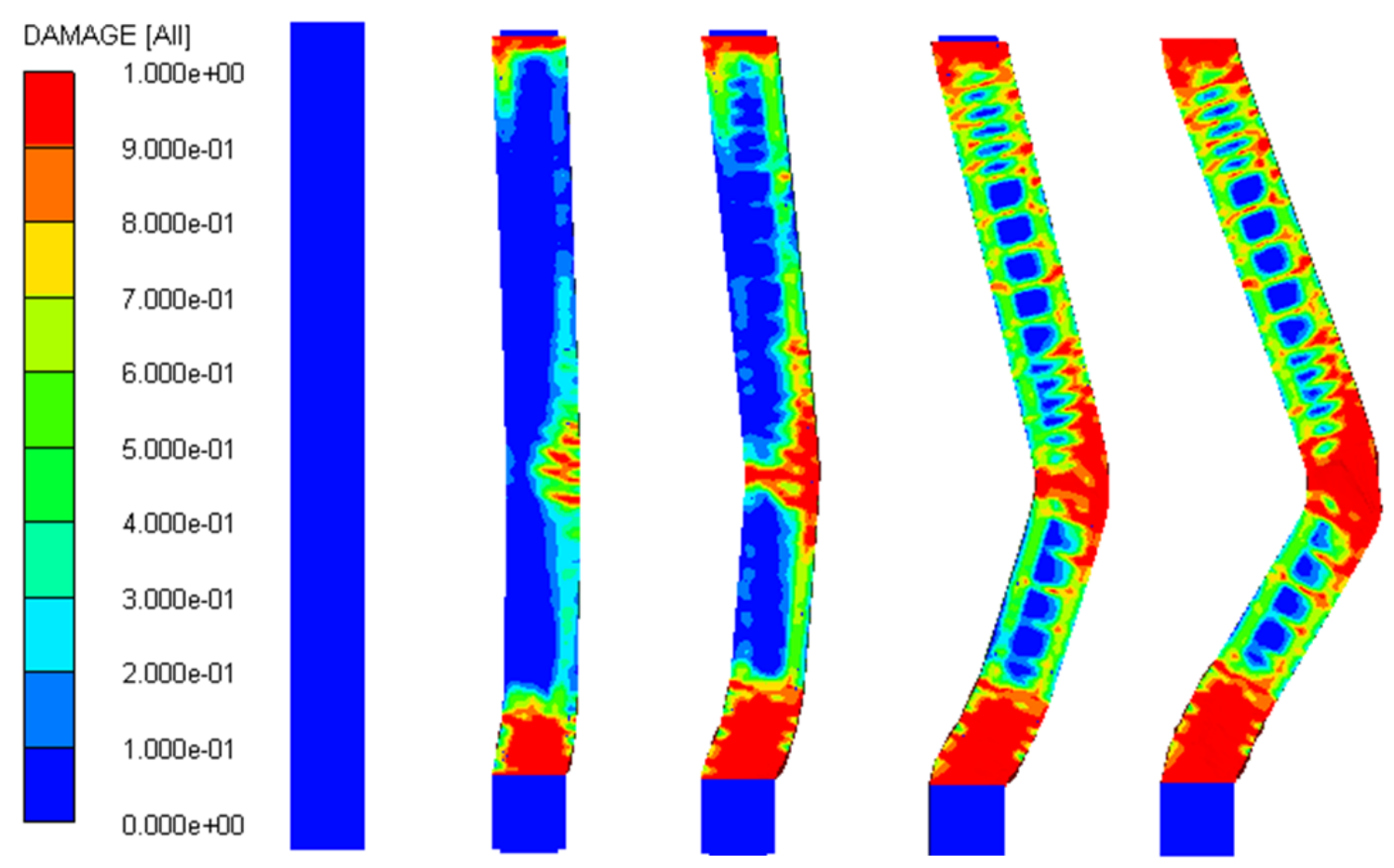

Figure 4-16: Shear failure along a $75 \mathrm{~mm}$ tie spacing RC column for $150 \mathrm{~kg}$
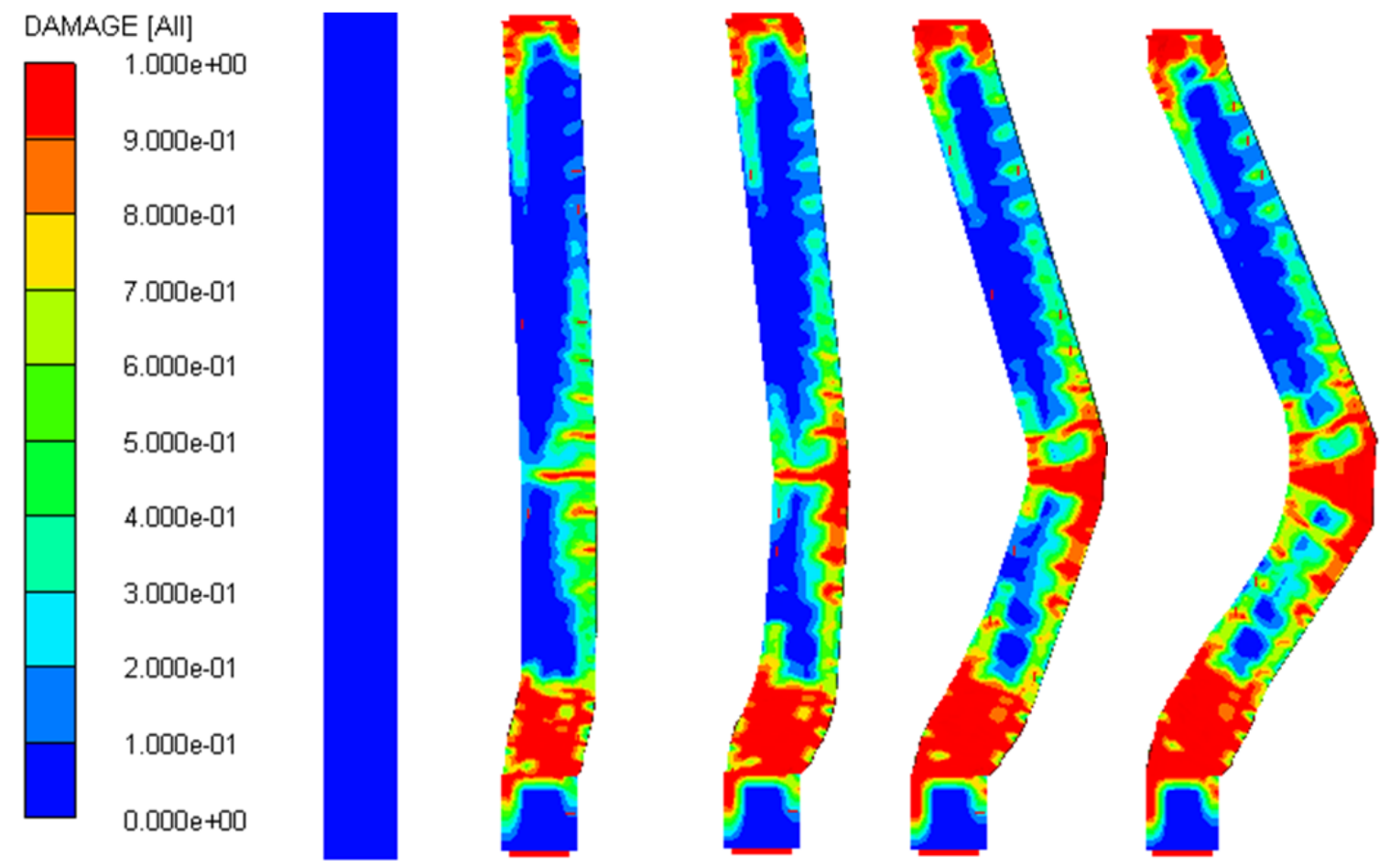

Figure 4-17: Shear failure along a 150-mm tie spacing RC column for $150 \mathrm{~kg}$ 

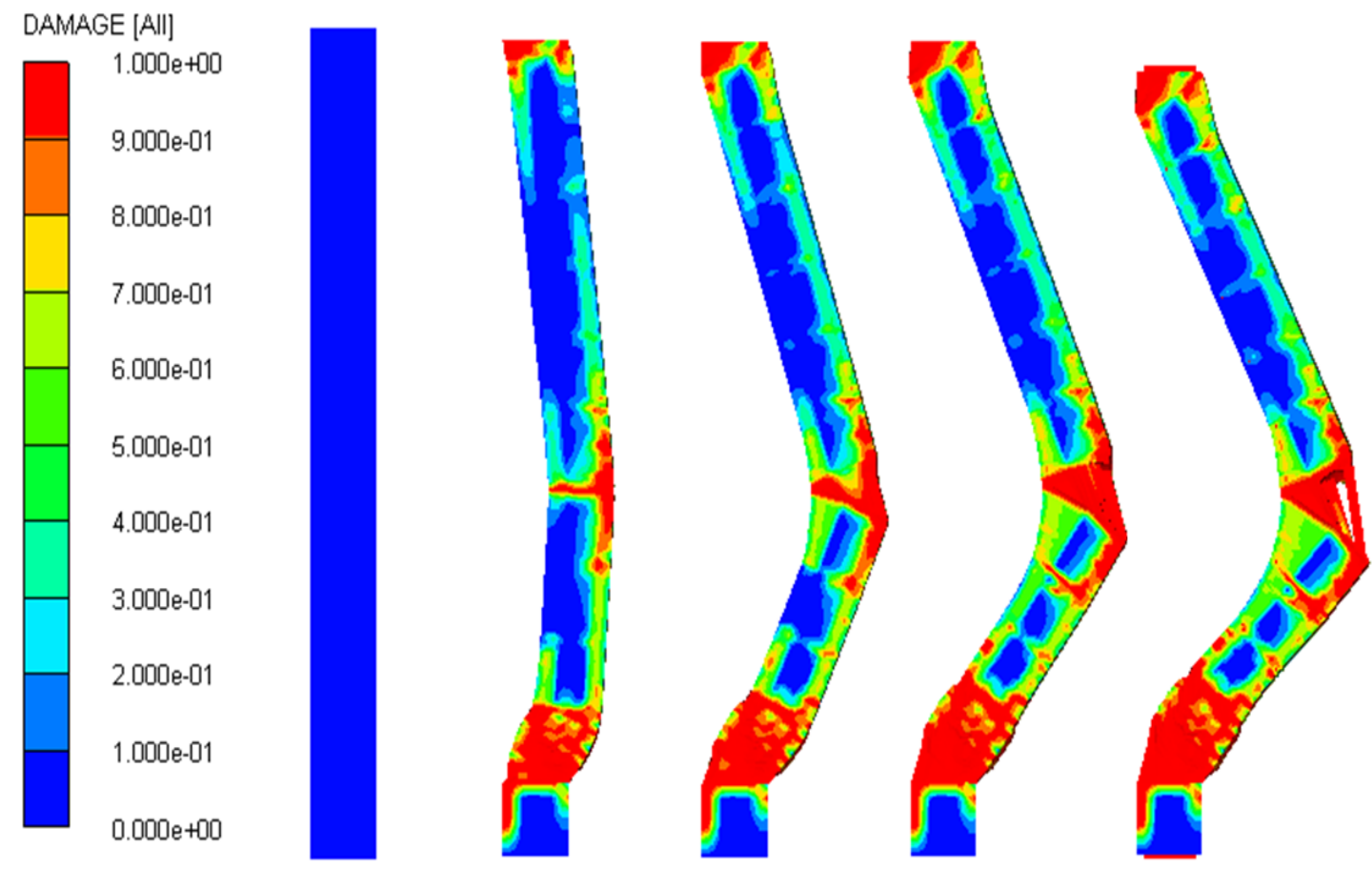

Figure 4-18: Shear failure along a 300-mm tie spacing RC column for $150 \mathrm{~kg}$
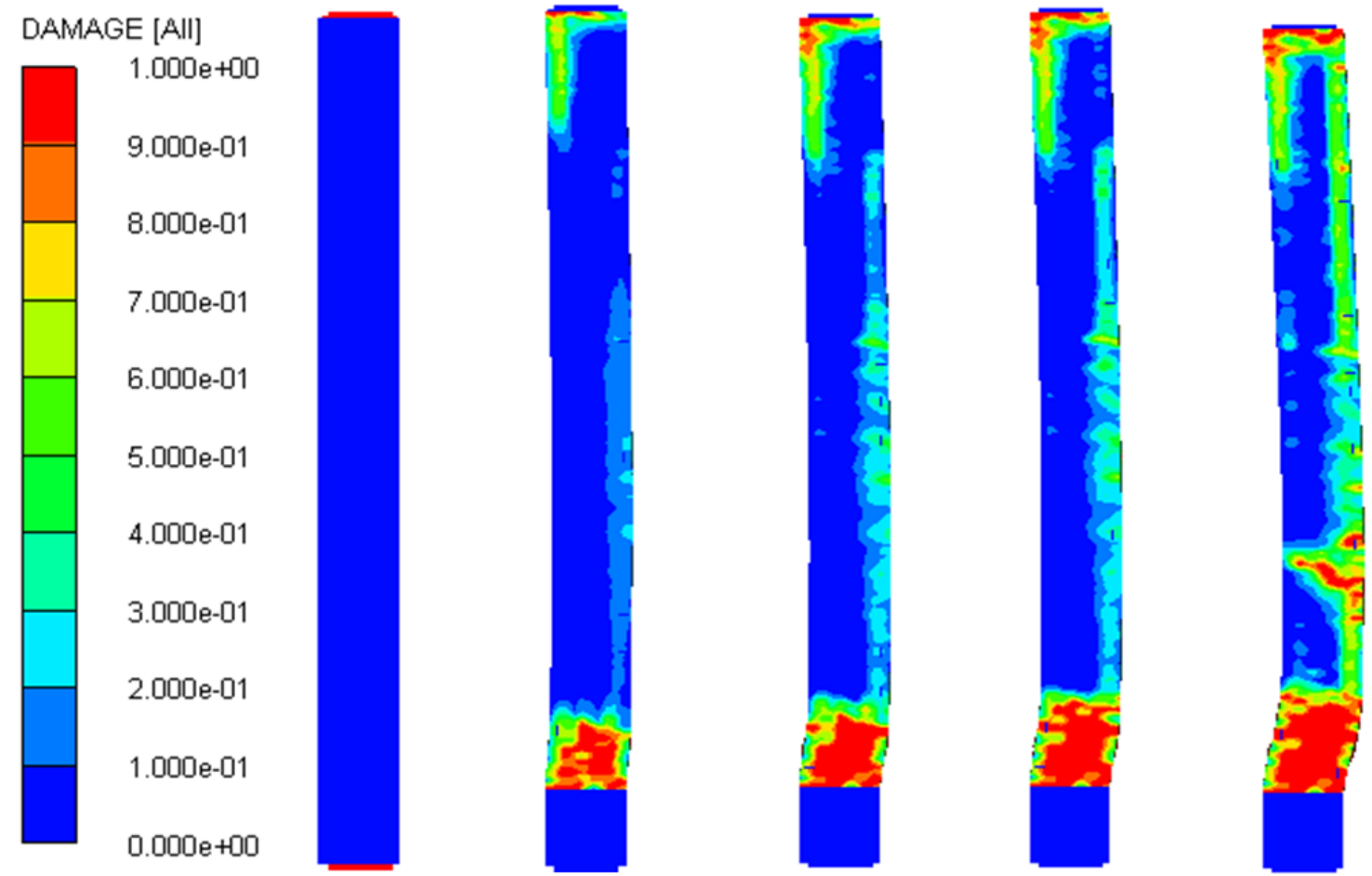

Figure 4-19: Shear failure along a 75-mm tie spacing RC column for $100 \mathrm{~kg}$ 

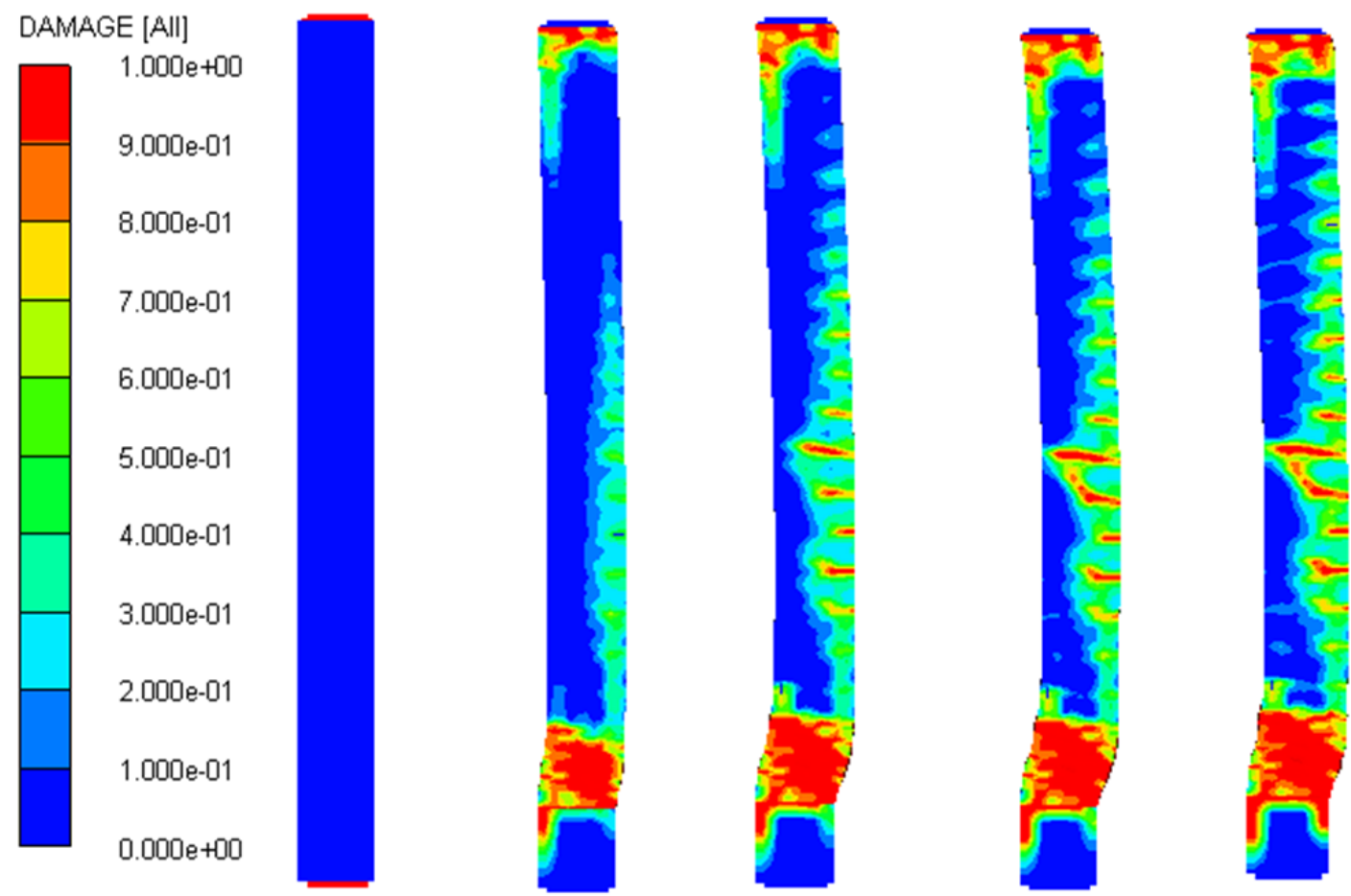

Figure 4-20: Shear failure along a 150-mm tie spacing RC column for $100 \mathrm{~kg}$
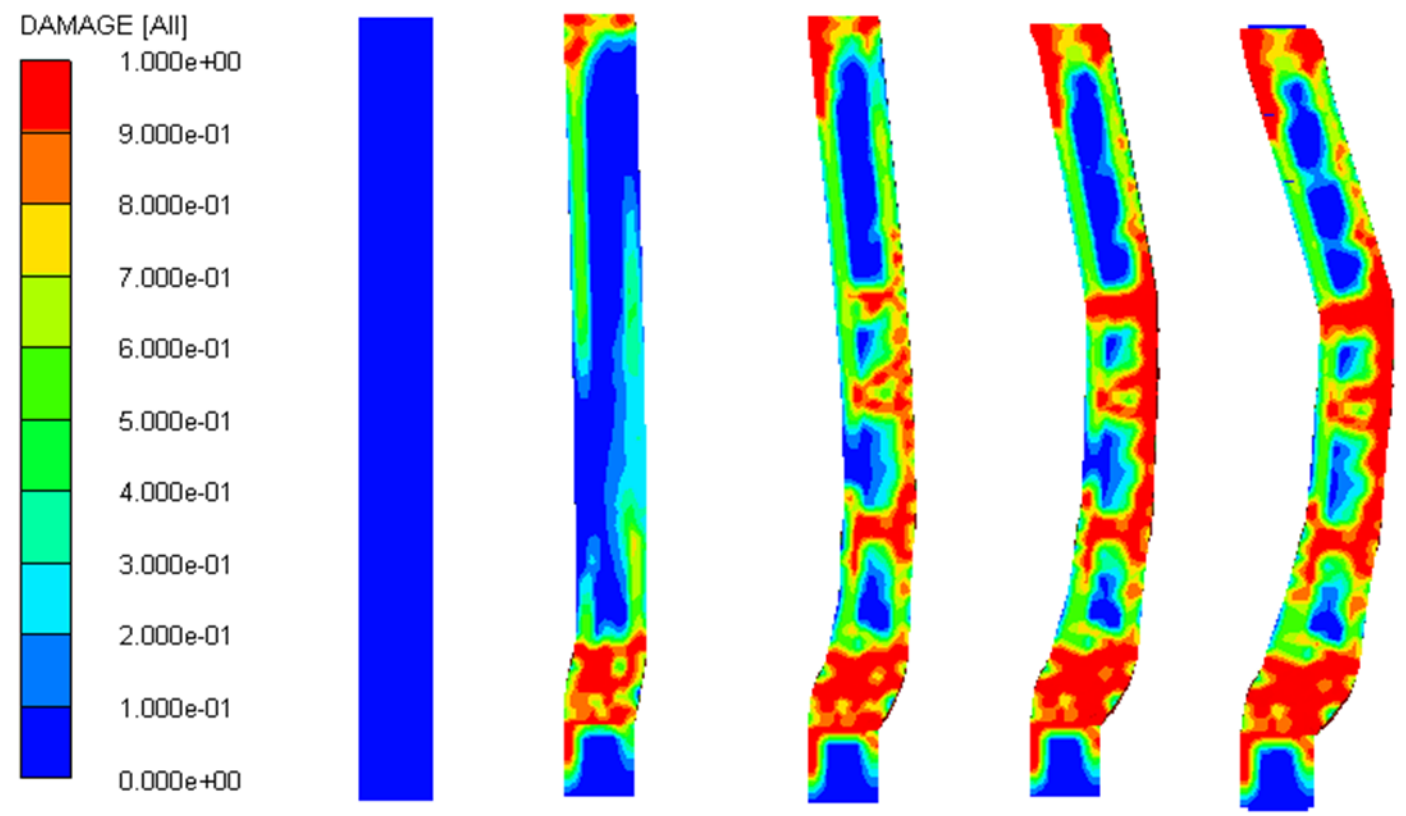

Figure 4-21: Shear failure along a 300-mm tie spacing RC column for $100 \mathrm{~kg}$ 


\subsection{Effect of concrete compressive strength}

Different compressive strengths were used for the concrete model to investigate their effect on the response of reinforced concrete columns under blast loading. The compressive strengths used were $35 \mathrm{MPa}$, $40 \mathrm{MPa}$, $60 \mathrm{MPa}$, and $80 \mathrm{MPa}$. Reinforced concrete columns with $300-\mathrm{mm}$ tie spacing were modelled at scaled distances of 0.25 $\mathrm{m} / \mathrm{kg}^{1 / 3}$ and $0.6 \mathrm{~m} / \mathrm{kg}^{1 / 3}$ for a $100 \mathrm{~kg}$ charge mass. For the scaled distances of $0.25 \mathrm{~m} / \mathrm{kg}^{1 / 3}$ and $0.6 \mathrm{~m} / \mathrm{kg}^{1 / 3}$, the maximum mid-height deflections decreased with increased concrete strength as shown in Figure 4-22 and Figure 4-23 respectively. As the concrete strength decreased concrete damage due to crushing and spalling increased, resulting in reduced stiffness of the columns. The reduced stiffness resulted in higher natural periods observed from the columns with the lower compressive strength. Similar trends were also observed for the lower and upper-third points on the columns. Figure 4-24 and Figure 4-25 show the failure modes for RC columns at scaled distance of 0.25 for $100 \mathrm{~kg}$ and $150 \mathrm{~kg}$ charge masses respectively. For Figure 4-24, columns with compressive strength of $35 \mathrm{MPa}$ and $40 \mathrm{MPa}$ failed predominantly in shear. Columns with compressive strength from $60 \mathrm{MPa}$ and $80 \mathrm{MPa}$ show increased resistance to failure with increased compressive strength. Due to the high magnitude of the pressure developed by the $150 \mathrm{~kg}$ charge mass, the columns in Figure 4-25 the degree of failure was also higher. In Figure 4-25, columns with compressive strengths of $35 \mathrm{MPa}, 40 \mathrm{MPa}, 60 \mathrm{MPa}$, and $80 \mathrm{MPa}$ experience extensive failure which was predominately shear failure at the base of the columns. 


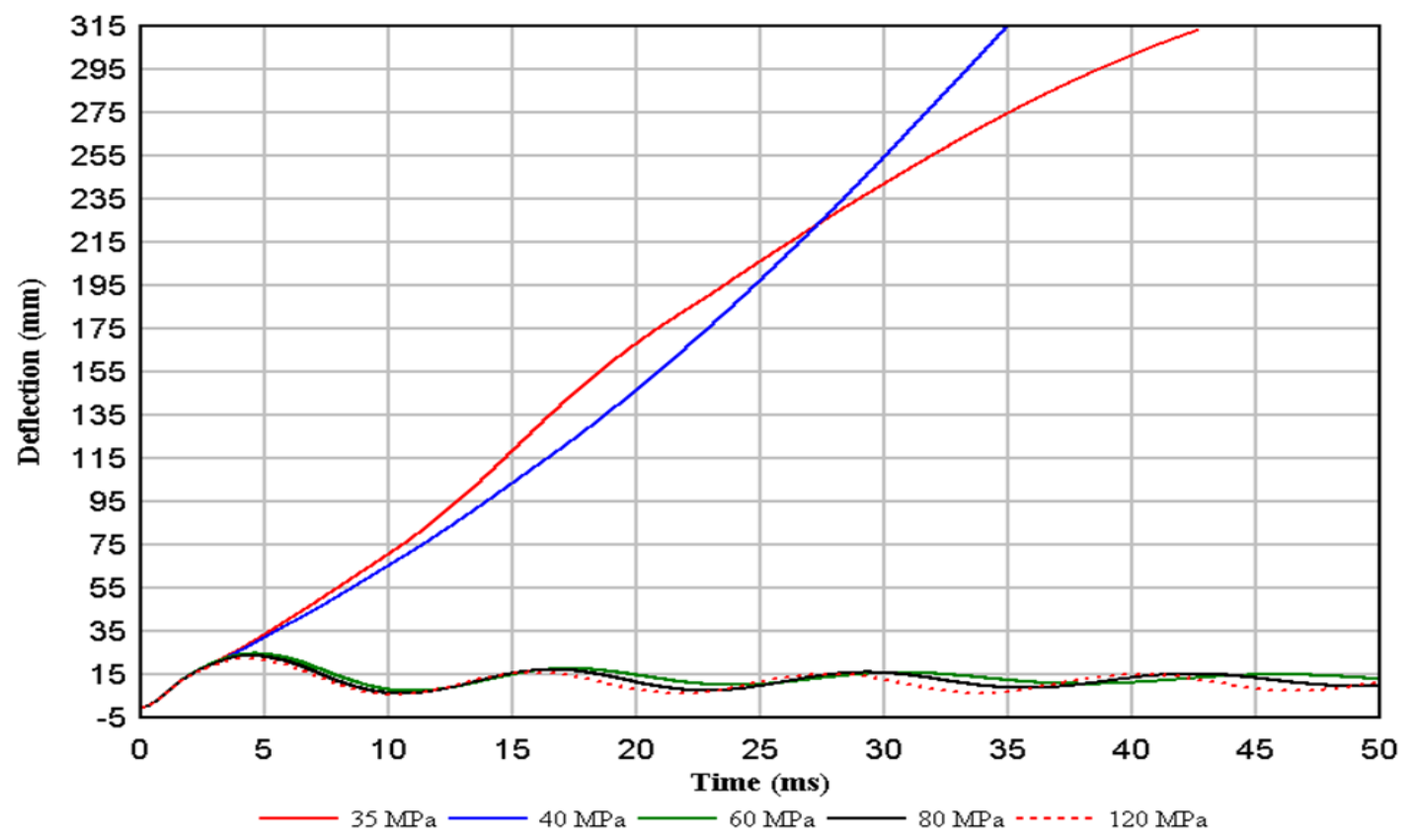

Figure 4-22: Mid-Height Column Deflections at $Z=0.25 \mathrm{~m} / \mathrm{kg}^{1 / 3}$

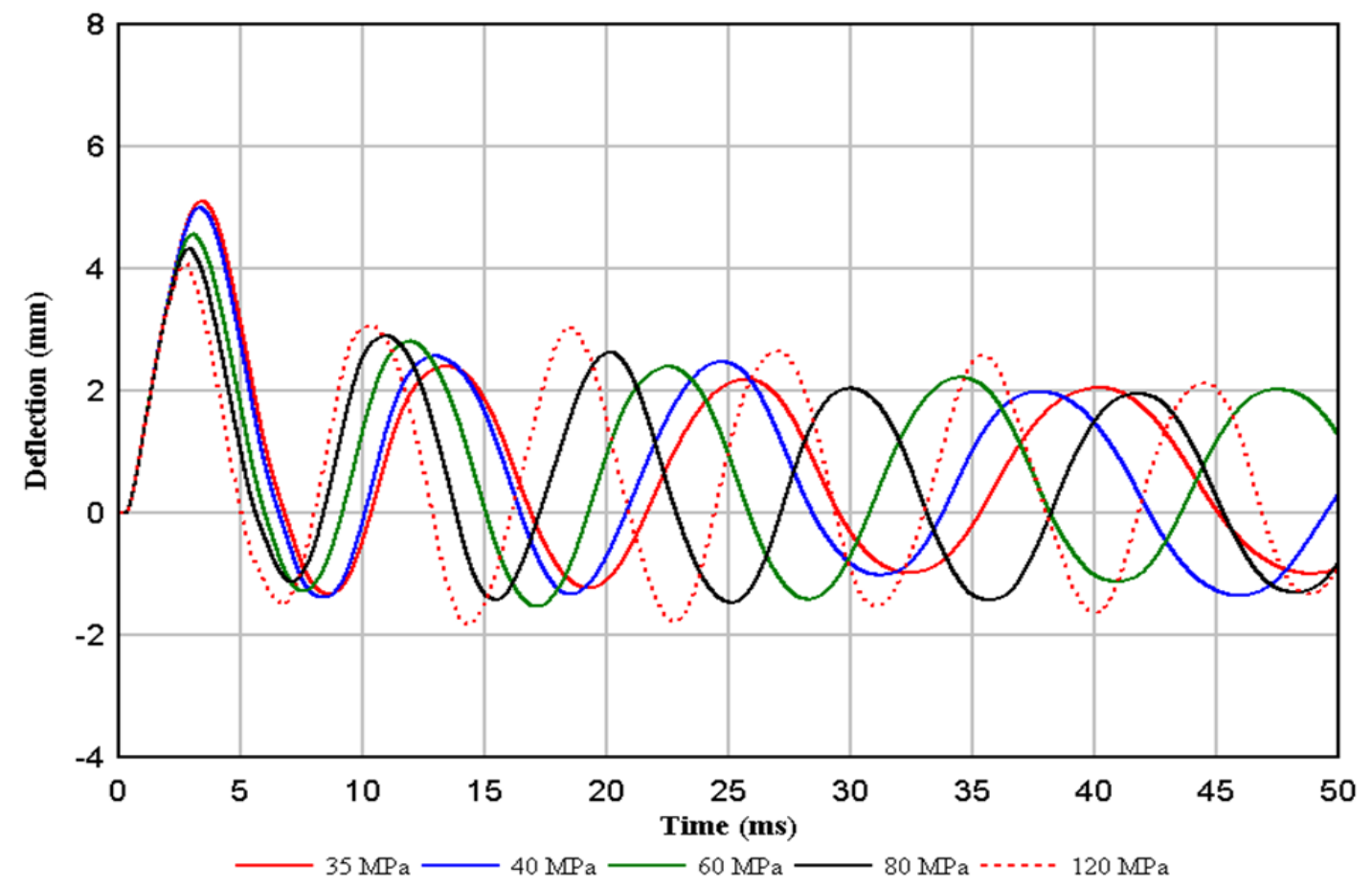

Figure 4-23: Mid-Height Column Deflections at $Z=0.6 \mathrm{~m} / \mathrm{kg}^{1 / 3}$ 


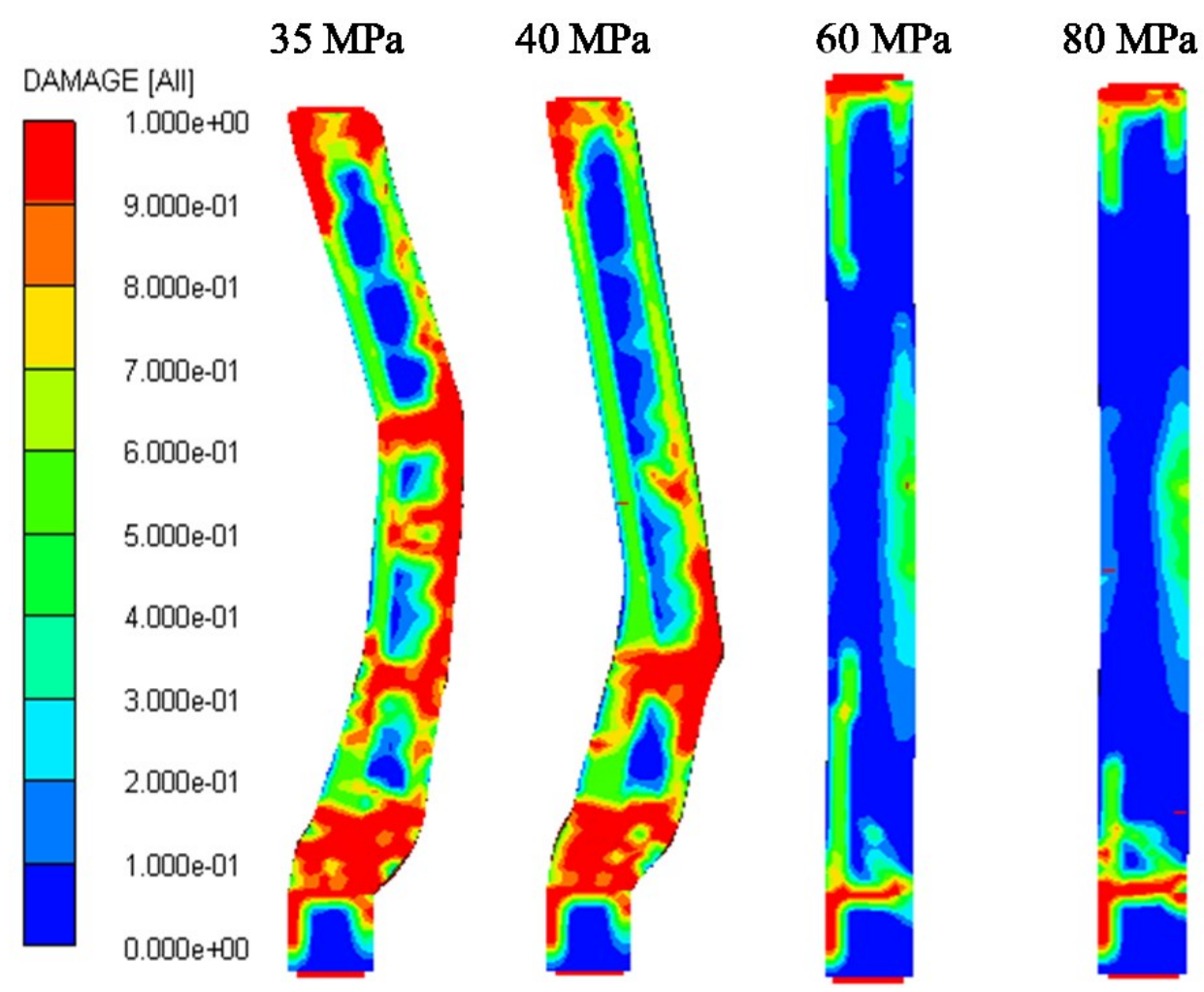

Figure 4-24: Failure modes for each concrete strength at $\mathrm{Z}=0.25 \mathrm{~m} / \mathrm{kg}^{1 / 3}$ for $100 \mathrm{~kg}$

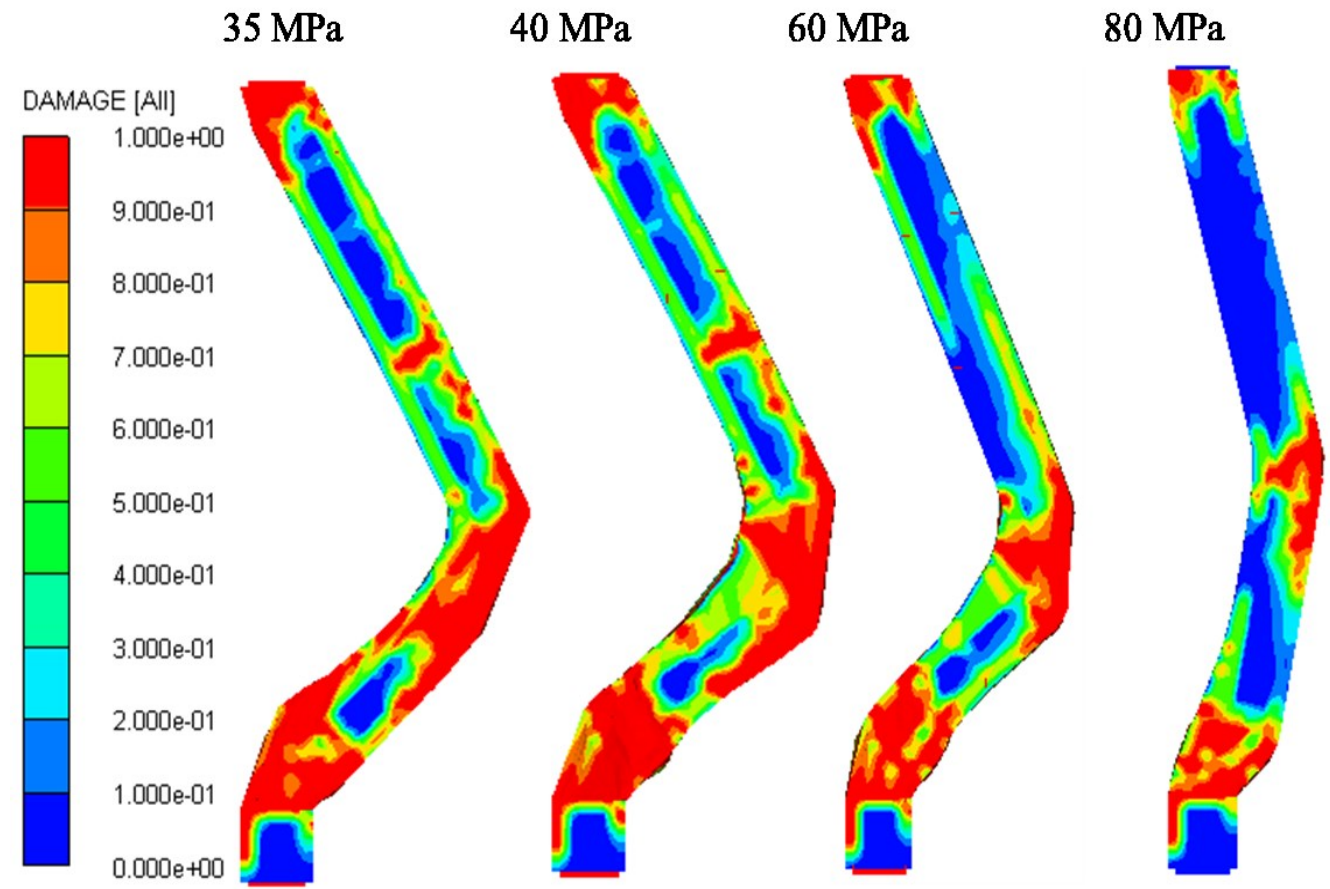

Figure 4-25: Failure modes for each concrete strength at $\mathrm{Z}=0.25 \mathrm{~m} / \mathrm{kg}^{1 / 3}$ for $150 \mathrm{~kg}$ 


\subsection{Strain Development in Reinforcing Bars}

The strains in the reinforcing bars were measured for a reinforced concrete column with a 300-mm tie spacing under blast loading from 50-kg charge mass explosion at a scaled distance of $0.25 \mathrm{~m} / \mathrm{kg}^{1 / 3}$ and $0.6 \mathrm{~m} / \mathrm{kg}^{1 / 3}$. Figure $4-26$ shows the strains in longitudinal reinforcements close to the front face of the column while Figure 4-27 shows the strains in longitudinal reinforcements close to the back face of the column at scaled distances of $0.6 \mathrm{~m} / \mathrm{kg}^{1 / 3}$. Strain gauge S5-S6 (Figure 4-26) at the mid-height of the columns recorded the peak compressive strain which coincided with the peak deflection at mid-height of the column. Also S1-S2 and S10-S11 (Figure 4-26) represent the tensile strain at the supports of the column. For Figure 4-27, reinforcing bars at mid-height of the column experience tensile strain while reinforcing bars near the support are in compression. Strain gauge S16-S17 in Figure 4-27 registered the peak tensile strain at mid-height, occurring at $3 \mathrm{~ms}$ same time as the peak mid-height deflection. Figure 4-28 and Figure 4-29 show that higher strains occur at the supports than at the mid-height of the reinforced columns. The increased nonlinearity of the waves due to the closer scaled distance of $0.25 \mathrm{~m} / \mathrm{kg}^{1 / 3}$ resulted in higher strains in the columns in comparison to columns at scaled distance of $0.6 \mathrm{~m} / \mathrm{kg}^{1 / 3}$. The support strain gauges $\mathrm{S} 1-\mathrm{S} 2$ and $\mathrm{S} 12-\mathrm{S} 13$ at the front face and back face of the column respectively were compared for a scaled distance of $0.25 \mathrm{~m} / \mathrm{kg}^{1 / 3}$ (Figure 4-28 and Figure 4-29). Strain gauge S1-S2 was in compression while S12-S13 was in tension with strain gauge S1-S2 registering a peak strain value of $-4309.3 \times 10^{6}$ and strain gauge S12-S13 registering a value of $3140.3 \times 10^{6}$.

Table 4-7 and Table 4-8 show the peak strains for a scaled distance of $0.6 \mathrm{~m} / \mathrm{kg}^{1 / 3}$ for reinforcing bars at the front and back of the column respectively. Table 4-9 and Table 
4-10 also show the peak strains for a scaled distance of $0.25 \mathrm{~m} / \mathrm{kg}^{1 / 3}$ for reinforcing bars at the front and back of the column respectively. Comparing the front peak strains in Table 4-7 and Table 4-9, the strains increased with decreasing scaled standoff distance. The same increasing trend was also observed when the back face strains were compared in Table 4-8 and Table 4-10. Table 4-7 shows that peak compressive strains occur around the mid-height of the column. However, in Table 4-9 the peak compressive strains occurred at the base of the column confirming that shear failure occurs at that point for closer scaled distances.

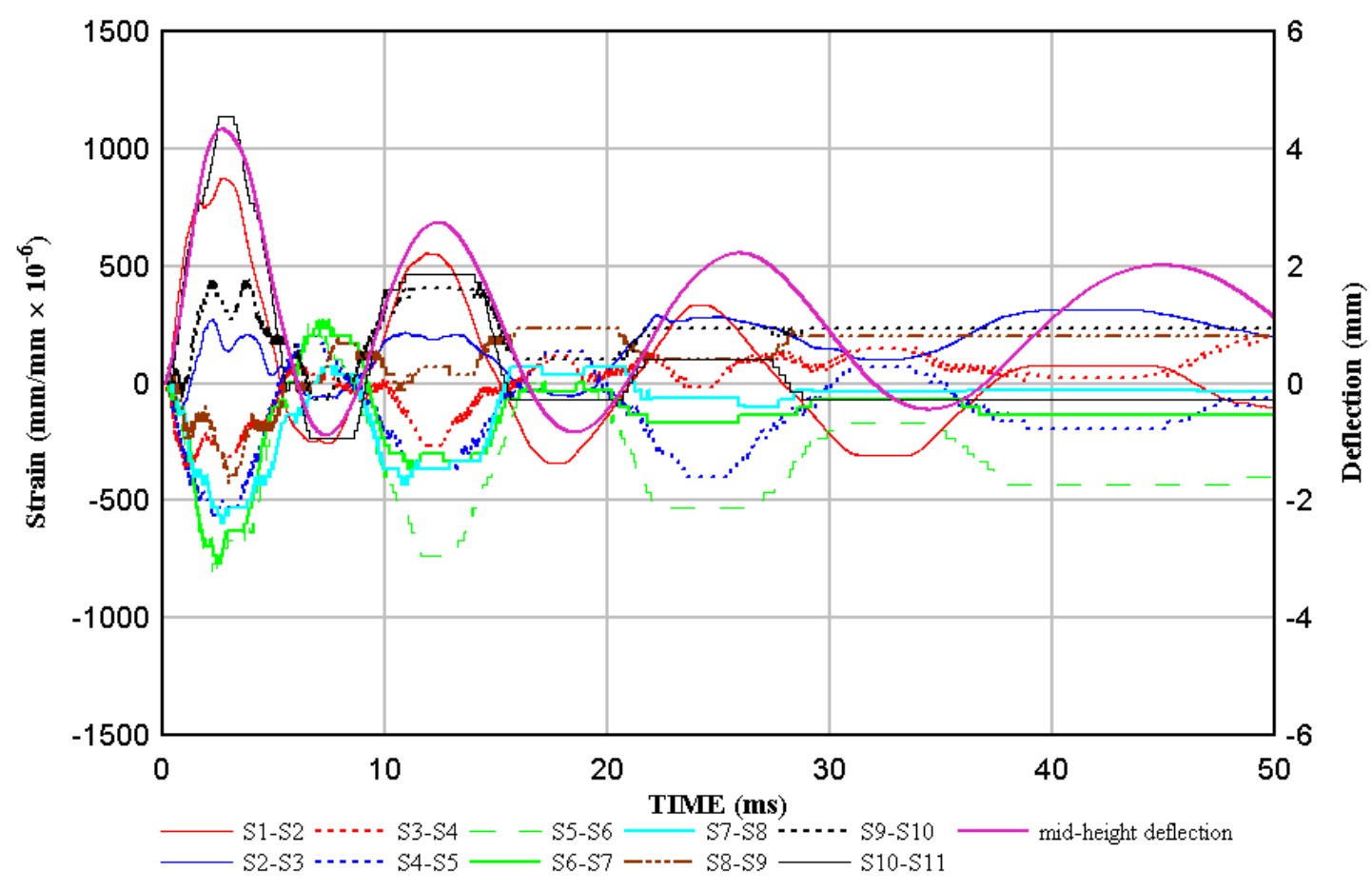

Figure 4-26: Steel reinforcement strains on front face at $Z=0.6 \mathrm{~m} / \mathrm{kg}^{1 / 3}$ for $50 \mathrm{~kg}$ 


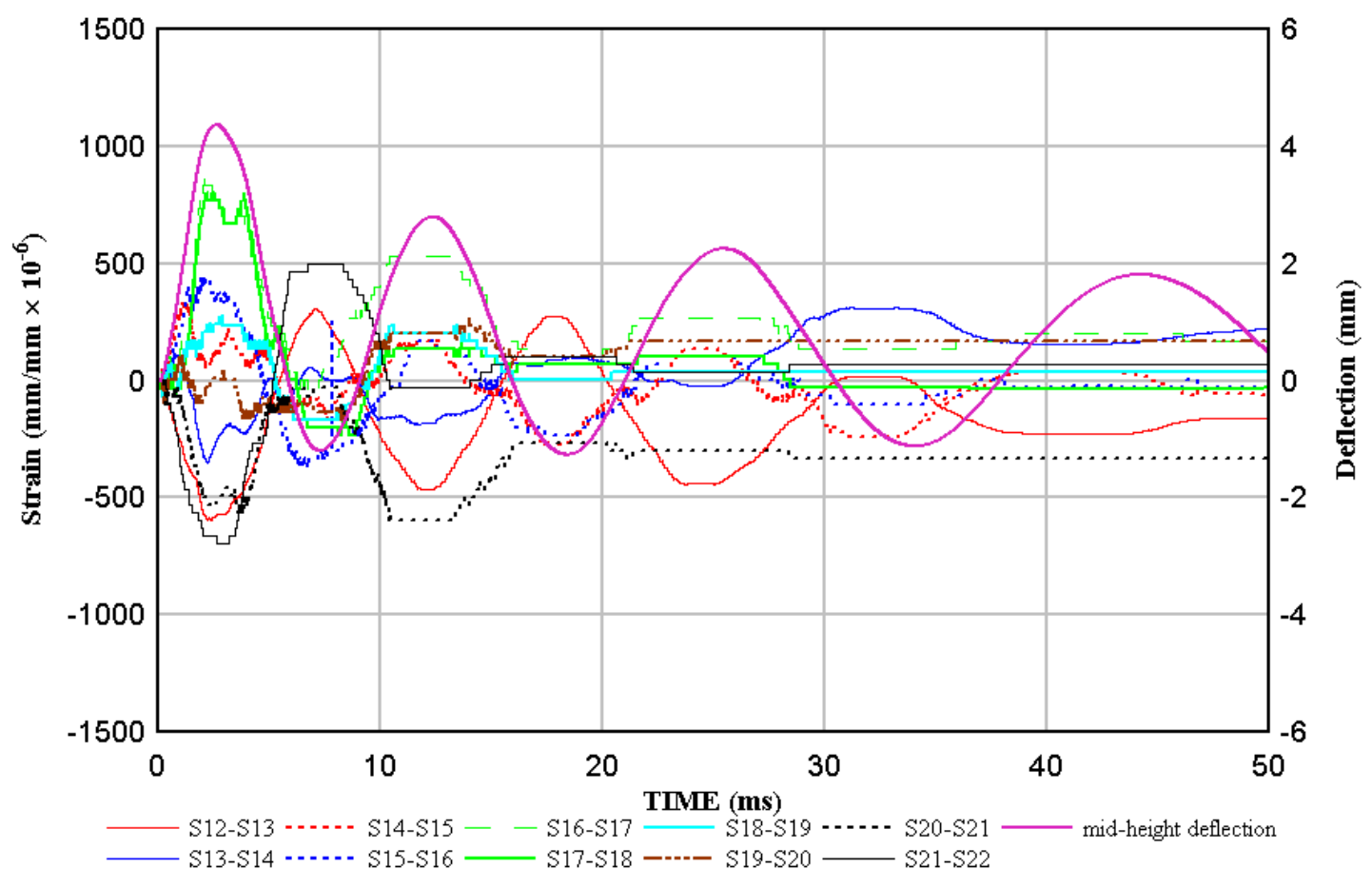

Figure 4-27: Steel reinforcement strains on back face at $Z=0.6 \mathrm{~m} / \mathrm{kg}^{1 / 3}$ for $50 \mathrm{~kg}$

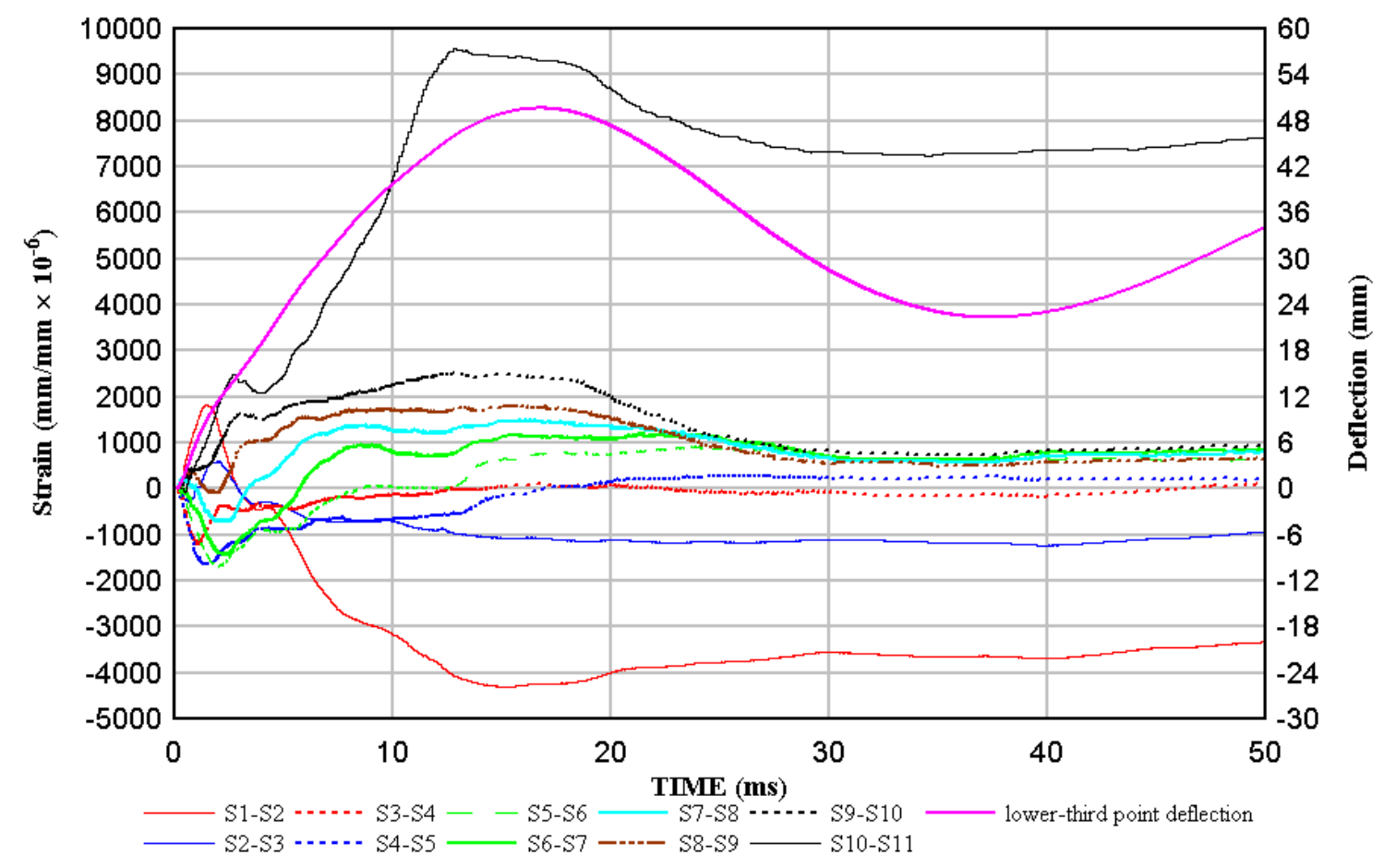

Figure 4-28: Steel reinforcement strains on front face at $Z=0.25 \mathrm{~m} / \mathrm{kg}^{1 / 3}$ for $50 \mathrm{~kg}$ 
e

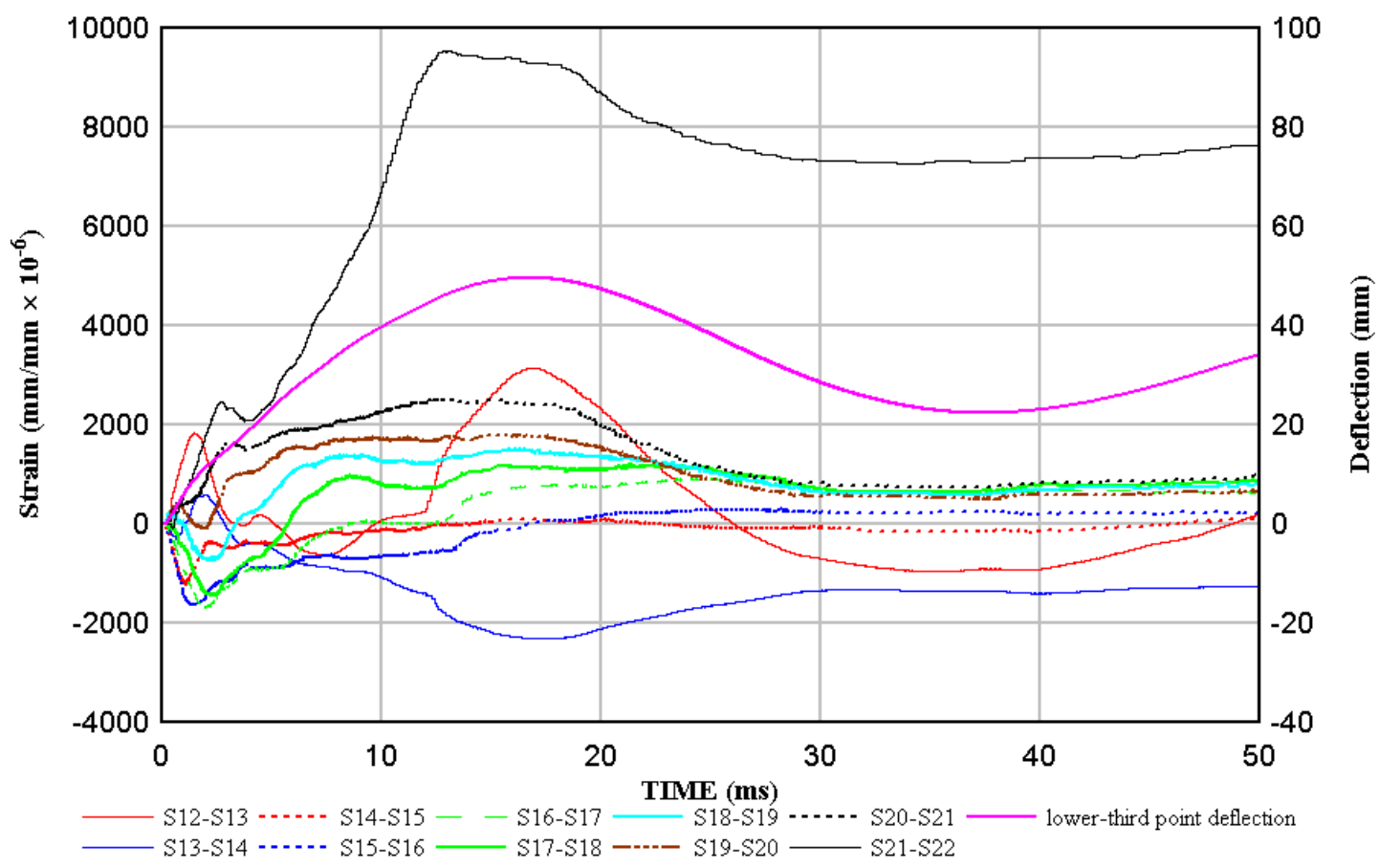

Figure 4-29: Steel reinforcement strains on back face at $Z=0.25 \mathrm{~m} / \mathrm{kg}^{1 / 3}$ for $50 \mathrm{~kg}$

Table 4-7: Steel reinforcement strains on front face at $Z=0.6 \mathrm{~m} / \mathrm{kg}^{1 / 3}$ for $50 \mathrm{~kg}$

\begin{tabular}{|c|c|c|}
\hline strain gauges & peak strains $\left(\mathbf{1 0}^{-6}\right)$ & strain rates (1/s) \\
\hline S1-S2 & 876.6 & 0.3139 \\
\hline S2-S3 & 273.6 & 0.1218 \\
\hline S3-S4 & -369.2 & 0.3529 \\
\hline S4-S5 & -562.7 & 0.2556 \\
\hline S5-S6 & -799.6 & 0.3568 \\
\hline S6-S7 & -765.6 & 0.2895 \\
\hline S7-S8 & -596.0 & 0.2136 \\
\hline S8-S9 & -427.3 & 0.1443 \\
\hline S9-S10 & 437.9 & 0.1206 \\
\hline S10-S11 & 1138.6 & 0.3695 \\
\hline
\end{tabular}


Table 4-8: Steel reinforcement strains on back face at $Z=0.6 \mathrm{~m} / \mathrm{kg}^{1 / 3}$ for $50 \mathrm{~kg}$

\begin{tabular}{|l|l|l|}
\hline strain gauges & peak strains $\left.\mathbf{( 1 0}^{-6}\right)$ & strain rates (1/s) \\
\hline S12-S13 & -595.2 & 0.268 \\
\hline S13-S14 & -349.7 & 0.159 \\
\hline S14-S15 & 331.8 & 0.261 \\
\hline S15-S16 & 437.3 & 0.195 \\
\hline S16-S17 & 866.9 & 0.413 \\
\hline S17-S18 & 801.4 & 0.368 \\
\hline S18-S19 & 271.3 & 0.099 \\
\hline S19-S20 & -164.2 & 0.039 \\
\hline S20-S21 & -563.0 & 0.146 \\
\hline S21-S22 & -696.3 & 0.262 \\
\hline
\end{tabular}

Table 4-9: Steel reinforcement strains on front face at $Z=0.25 \mathrm{~m} / \mathrm{kg}^{1 / 3}$ for $50 \mathrm{~kg}$

\begin{tabular}{|l|l|l|}
\hline strain gauges & peak strains $\left.\mathbf{( 1 0}^{-\mathbf{6}}\right)$ & strain rates $\mathbf{( 1 / s )}$ \\
\hline S1-S2 & -4309.3 & 0.2835 \\
\hline S2-S3 & -1141.5 & 0.0604 \\
\hline S3-S4 & -1219.1 & 1.1184 \\
\hline S4-S5 & -1633.2 & 1.2563 \\
\hline S5-S6 & -1697.0 & 0.8359 \\
\hline S6-S7 & -1444.7 & 0.5825 \\
\hline S7-S8 & 1498.0 & 0.0908 \\
\hline S8-S9 & 1811.9 & 0.1154 \\
\hline S9-S10 & 2527.3 & 0.1915 \\
\hline S10-S11 & 9559.9 & 0.7411 \\
\hline
\end{tabular}


Table 4-10: Steel reinforcement strains on back face at $Z=0.25 \mathrm{~m} / \mathrm{kg}^{1 / 3}$ for $50 \mathrm{~kg}$

\begin{tabular}{|l|l|l|}
\hline strain gauges & peak strains $\left(\mathbf{1 0}^{-6}\right)$ & strain rates $\mathbf{( 1 / s )}$ \\
\hline S12-S13 & 3140.9 & 0.185 \\
\hline S13-S14 & -2316.8 & 0.133 \\
\hline S14-S15 & -1220.5 & 1.120 \\
\hline S15-S16 & -1633.3 & 1.256 \\
\hline S16-S17 & -1696.5 & 0.840 \\
\hline S17-S18 & 1207.2 & 0.055 \\
\hline S18-S19 & 1501.9 & 0.093 \\
\hline S19-S20 & 1811.2 & 0.115 \\
\hline S20-S21 & 2533.2 & 0.192 \\
\hline S21-S22 & 9549.0 & 0.746 \\
\hline
\end{tabular}




\section{Chapter: Conclusions}

The following conclusion was drawn from the parametric study from the numerical simulations:

- The natural period of vibration of reinforced concrete columns increased with increasing charge mass at constant scaled distances. This was largely attributed to cracking and spalling resulting in a reduction in column stiffness.

- Although charge mass and standoff distance combination can have the same scaled distance and thus same peak reflected pressure, their effect on reinforced concrete columns is markedly different. This was due to different impulses of the blast waves at different scaled distances.

- The effect of tie spacing was much more pronounced at lower scaled distances as compared to higher scaled distances for similar charge masses. This observation was largely due to the fact that at higher scaled distances, the columns experienced less failure.

- Peak column deflections at higher scaled distances occurred mid-height while peak column deflections at lower scaled distances occurred closer to the column supports. Peak mid-height deflections for higher scaled was also confirmed by the strains developed in the reinforcing bars. High compressive and tensile strains were measured for both the front and back face of the reinforcing bars respectively. 


\section{Chapter: Recommendation and Future Research}

Recommendations for future research are as follows:

- Investigate the effects of height of charge mass on the response behaviour of reinforced concrete columns. This can be achieved by varying the height of the charge mass above the ground.

- While only scaled distances of $0.25 \mathrm{~m} / \mathrm{kg}^{1 / 3}$ and $0.6 \mathrm{~m} / \mathrm{kg}^{1 / 3}$ were studied for this research, other research could include more scaled distances upto $1.2 \mathrm{~m} / \mathrm{kg}^{1 / 3}$ to further confirm the observations. Investigate the effect of tie spacing on circular columns. For rectangular columns most of the blast loading occurs on the front face. However to the shape of circular columns, the blasting will be different leading to different responses.

- Investigate the effects of Axial Load Ratios on the Response of reinforced concrete columns to blast loading. This can be achieved by axially loading the top of the columns prior to the blast loading. 


\section{References}

Anderson, J. D. (2001). Fundamentals of aerodynamics. McGraw-Hill New York.

ASCE. (2010). Design of Blast-resistant Buildings in Petrochemical Facilities Task Committee on Blast Resistant Design. ASCE Publications.

Asprone, D., Cadoni, E., and Prota, A. (2009). "Tensile high strain-rate behavior of reinforcing steel from an existing bridge." ACI Struct.J., 106(4), 523.

AUTODYN, A. (2009). "Interactive Non-Linear Dynamic Analysis Software, Version 12, User's Manual." SAS IP Inc .

Baker, W. E., Cox, P., Kulesz, J., Strehlow, R., and Westine, P. (1983). Explosion hazards and evaluation. Access Online via Elsevier.

Bangash, M., and Bangash, T. (2006). Explosion-resistant buildings: design, analysis, and case studies. Springer.

Beshara, F. B. A. (1994). "Modelling of blast loading on aboveground structures-II. Internal blast and ground shock." Computers Structures, 51(5), 597-606.

Birkimer, D. L., and Lindemann, R. (1971). "Dynamic tensile strength of concrete materials." ACI Journal Proceedings, 68(1).

Birnbaum, N. K., Cowler, M., and Hayhurst, C. (1996). "Numerical Simulation of Impact Using AUTODYN." Proceedings.

Birnbaum, N. K., Francis, N. J., and Gerber, B. I. (1999). "Coupled techniques for the simulation of fluid-structure and impact problems." Comput.Assis.Mech.Eng.Sci., 6(3/4), 295-312.

Bischoff, P. H., and Perry, S. H. (1991). "Compressive behaviour of concrete at high strain rates." Matériaux Et Constructions, 24(6), 425-450.

Blatchford, A. (2013). "Lac-Megantic Explosions And Fire Sparked By Train Derailment, 5 Confirmed Dead (PHOTOS, VIDEO)." http://www.huffingtonpost.ca/2013/07/06/lac-megantic-explosionsfire_n_3553810.html?utm_hp_ref=lac-megantic-explosion (November 18, 2013).

Braimah, A., and Contestabile, E. (2007). "Blast Vulnerability Assessment: Challenges and Myths, Structures under Extreme Loading." Proceedings of First International Workshop on Performance, Protection, and Strengthening of Structures Under Extreme Loading, Whistler, British Columbia, Canada. 
Brannon, R. M., and Leelavanichkul, S. (2009). "Survey of Four Damage Models for Concrete." (No. SAND2009-5544).

Comité Euro-International du Béton. (1993). CEB-FIP model code 1990: design code. Telford.

Cormie, D., Mays, G., and Smith, P. (2009). Blast effects on buildings. Thomas Telford Services Ltd.

Drury, J., Cocking, C., and Reicher, S. (2009). "The nature of collective resilience: Survivor reactions to the 2005 London bombings." International Journal of Mass Emergencies and Disasters, 27(1), 66-95.

Fairlie, G. E. (1997). "Efficient analysis of high explosive air blast in complex urban geometries using the AUTODYN-2D \& 3D hydrocodes, analytical and experimental methods, 15th Int." Symposium on the Military Aspects of Blast and Shock, 14-19.

Fairlie, G. (1998). "The Numerical Simulation of High Explosives using AUTODYN-2D \& 3D." Institute of Explosive Engineers 4th Biannual Symposium.

Flathau, W. J. (1971). "Dynamic tests of large reinforcing bar splices." (No. AEWES-TRN-71-2.).

Fu, H., Erki, M., and Seckin, M. (1991). "Review of effects of loading rate on reinforced concrete." J.Struct.Eng., 117(12), 3660-3679.

Fujikura, S. (2011). "Experimental investigation of seismically resistant bridge piers under blast loading." J.Bridge Eng., 16(1), 63-71.

Gama, B. A., and Gama, B. (2004). "Hopkinson bar experimental technique: A critical review." Appl.Mech.Rev., 57(1), 223-250.

Gebbeken, N., Greulich, S., and Pietzsch, A. (2001). "Performance of Concrete Based Building Materials Against Blast and Impact." Proceedings of the fib-Symposium on Concrete and Environment, Berlin.

Gebbeken, N., Greulich, S., Pietzsch, A., and Doege, T. (2003). "Interaction of Local and Global Structural Behavior of Buildings under Catastrophic Loadings." Response of Structures to Extreme Loading. Toronto, (2).

Gebbeken, N., and Ruppert, M. (2000). "A new material model for concrete in highdynamic hydrocode simulations." Arch Appl Mech, 70(7), 463-478. 
Gunaratna, R. (2008). "The Islamabad Marriott in Flames: The Attack on the World's Most Protected Hotel." Journal of Policing, Intelligence and Counter Terrorism, 3(2), 99-116.

Hayhurst, C. J., Clegg, R. A., Livingstone, I. H., and Francis, N. J. (1996). "The Application of SPH techniques in AUTODYN-2DTM to Ballistic Impact Problems." 16th International Symposium on Ballistics.

Herrmann, W. (1969). "Constitutive equation for the dynamic compaction of ductile porous materials." J.Appl.Phys., 40(6), 2490-2499.

Hughes, R., (2013). "Attempted Terrorist Attack at BC's Victoria Legislative Buildings Foiled." http://richardhughes.ca/cowichan-conversations/attempted-terrorist-attack-atbcs-victoria-legislative-buildings-foiled/ (November/18, 2013).

Johnson, G. R., and Holmquist, T. J. (1994). "An improved computational constitutive model for brittle materials." AIP Conference Proceedings, 981.

Johnson, G. R., and Cook, W. H. (1985). "Fracture characteristics of three metals subjected to various strains, strain rates, temperatures and pressures." Eng.Fract.Mech., 21(1), 31 .

Katayama, M., Itoh, M., Tamura, S., Beppu, M., and Ohno, T. (2007). "Numerical analysis method for the RC and geological structures subjected to extreme loading by energetic materials." Int.J.Impact Eng., 34(9), 1546-1561.

Kraus, D., Roetzer, J., and Thoma, K. (1994). "Effect of high explosive detonations on concrete structures." Nucl.Eng.Des., 150(2-3), 309-314.

Krauthammer, T. (1994). "Response of structural concrete elements to severe impulsive loads." Computers Structures, 53(1), 119-130.

Le Nard, H., and Bailly, P. (2000). "Dynamic behaviour of concrete: the structural effects on compressive strength increase." Mechanics of Cohesive-Frictional Materials, 5(6), 491.

Lee, O. S. (2003). "Dynamic material property characterization by using split Hopkinson pressure bar (SHPB) technique." Nucl.Eng.Des., 226(2), 119-125.

Leppänen, J. (2006). "Concrete subjected to projectile and fragment impacts: Modelling of crack softening and strain rate dependency in tension." Int.J.Impact Eng., 32(11), $1828-1841$.

Low, H. Y., and Hao, H. (2002). "Reliability analysis of direct shear and flexural failure modes of RC slabs under explosive loading." Eng.Struct., 24(2), 189-198. 
Low, H. Y., and Hao, H. (2001). "Reliability analysis of reinforced concrete slabs under explosive loading." Struct.Saf., 23(2), 157-178.

Lu, Y., and Xu, K. (2004). "Modelling of dynamic behaviour of concrete materials under blast loading." Int.J.Solids Structures, 41(1), 131-143.

Luccioni, B., Ambrosini, R., and Danesi, R. (2004). "Analysis of building collapse under blast loads." Eng.Struct., 26(1), 63-71.

Malvar, L. J., and Ross, C. A. (1998). "Review of strain rate effects for concrete in tension." ACI Mater.J., 95(6).

McVay, M. K. (1988). "Spall damage of concrete structures." No. WES/TR/SL-88-22. ARMY ENGINEER WATERWAYS EXPERIMENT STATION VICKSBURG MS STRUCTURES LAB.

Meyers, S., and Shanley, E. S. (1990). "Industrial explosives - a brief history of their development and use." J.Hazard.Mater., 23(2), 183-201.

Mungin, L. (2013). "Explosion hits fertilizer plant north of Waco, Texas." http://www.cnn.com/2013/04/17/us/texas-explosion/index.html (November 18, 2013).

Nash, P., Vallabhan, C. V. G., and Knight, T. C. (1995). "Spall damage to concrete walls from near-field cased and uncased explosions in air." ACI Struct.J., 92(6), 680-688.

O'Grady, H., Hayhurst, C., and Fairlie, G. (1996). "The Numerical Simulation of Warheads, Impact and Blast Phenomena using AUTODYN-2D and AUTODYN-3D." South African Ballistics Synposium, Stellenbosch, South Africa.

Ohtsu, M., Uddin, F. A., Tong, W., and Murakami, K. (2007). "Dynamics of spall failure in fiber reinforced concrete due to blasting." Construction and Building Materials, 21(3), 511-518.

Ožbolt, J., and Sharma, A. (2011). "Numerical simulation of reinforced concrete beams with different shear reinforcements under dynamic impact loads." Int.J.Impact Eng., 38(12), 940-950.

Quan, X., Birnbaum, N., Cowler, M., Gerber, B., Clegg, R., and Hayhurst, C. (2003). "Numerical simulation of structural deformation under shock and impact loads using a coupled multi-solver approach." Proceedings of 5th Asia-Pacific Conference on Shock and Impact Loads on Structures, 12-14.

Razaqpur, G., Mekky, W., and Foo, S. (2009). "Fundamental concepts in blast resistance evaluation of structures ." Canadian Journal of Civil Engineering, 36(8), 1292-1304. 
Riedel, W., Thoma, K., Hiermaier, S., and Schmolinske, E. (1999). "Penetration of reinforced concrete by BETA-B-500 numerical analysis using a new macroscopic concrete model for hydrocodes." 9th Int Symp Interaction of the Effects of Munitions with Structures.

Riedel, W., Kawai, N., and Kondo, K. (2009). "Numerical assessment for impact strength measurements in concrete materials." Int.J.Impact Eng., 36(2), 283-293.

Robertson, N., Hayhurst, C., and Fairlie, G. (1994). "Numerical simulation of impact and fast transient phenomena using AUTODYNTM-2D and 3D." Nucl.Eng.Des., 150(2), 235241.

Rule, W. K., and Jones, S. E. (1998). "A REVISED FORM FOR THE JOHNSONCOOK STRENGTH MODEL." Int.J.Impact Eng., 21(8), 609-624.

Sadee, C., Samuels, D. E., and O'Brien, T. P. (1977). "The characteristics of the explosion of cyclohexane at the Nypro (UK) Flixborough plant on 1st June 1974." J.Occup.Accid., 1(3), 203-235.

Schuler, H., Mayrhofer, C., and Thoma, K. (2006). "Spall experiments for the measurement of the tensile strength and fracture energy of concrete at high strain rates." Int.J.Impact Eng., 32(10), 1635-1650.

Smith, P. D., Hetherington, J. G., Smith, P., and Hetherington. (1994). Blast and ballistic loading of structures. Butterworth-Heinemann Oxford.

Sorensen, A., and McGill, W. L. (2011). "What to look for in the aftermath of an explosion? A review of blast scene damage observables." Eng.Failure Anal., 18(3), 836845.

Soroushian, P., and Choi, K. (1987). "Steel mechanical properties at different strain rates." J.Struct.Eng., 113(4), 663-672.

Stephens, H. W. (1997). The Texas city disaster 1947. U of Texas Press.

Tai, Y. S., Chu, T. L., Hu, H. T., and Wu, J. Y. (2011). "Dynamic response of a reinforced concrete slab subjected to air blast load." Theor.Appl.Fract.Mech., 56(3), 140147.

Tanapornraweekit, G., Haritos, N., and Mendis, P. (2011). "Behavior of FRP-RC Slabs under Multiple Independent Air Blasts." J.Perform.Constr.Facil., 25(5), 433-440.

Tham, C. (2005). "Reinforced concrete perforation and penetration simulation using AUTODYN-3D." Finite Elements Anal.Des., 41(14), 1401-1410. 
Tu, Z., and Lu, Y. (2009). "Evaluation of typical concrete material models used in hydrocodes for high dynamic response simulations." Int.J.Impact Eng., 36(1), 132-146.

Van Amelsfort, R., and Weerheijm, J. (1988). "The Failure Mode of Concrete Slabs Due to Contact Charges." PRINS MAURITS LABORATORIUM TNO RIJSWIJK (NETHERLANDS).

Watstein, D. (1953). "Effect of straining rate on the compressive strength and elastic properties of concrete." ACI Journal Proceedings, ACI.

Weerheijm, J., Karthaus, W., and Opschoor, G. (1984). "The Failure Mode of Layered Concrete Constructions due to Contact Charges." PRINS MAURITS LABORATORIUM TNO RIJSWIJK (NETHERLANDS).

Weston, G. (2013). "Alleged 'al-Qaeda-supported' plot against Via train thwarted." http://www.cbc.ca/news/politics/alleged-al-qaeda-supported-plot-against-via-trainthwarted-1.1377031 (November 18, 2013).

Wu, K., Li, B., and Tsai, K. (2011). "Residual axial compression capacity of localized blast-damaged RC columns." Int.J.Impact Eng., 38(1), 29-40.

$\mathrm{Xu}, \mathrm{K}$, and $\mathrm{Lu}, \mathrm{Y}$. (2006). "Numerical simulation study of spallation in reinforced concrete plates subjected to blast loading." Computers Structures, 84(5), 431-438.

Yamaguchi, M., Murakami, K., Takeda, K., and Mitsui, Y. (2011). "Blast resistance of polyethylene fiber reinforced concrete to contact detonation." Journal of Advanced Concrete Technology, 9(1), 63-71.

Yan, D., and Lin, G. (2006). "Dynamic properties of concrete in direct tension." Cem.Concr.Res., 36(7), 1371-1378.

Yuan, L., Gong, S., and Jin, W. (2008). "Spallation mechanism of RC slabs under contact detonation." Trans.Tianjin Univ., 14 464-469.

Yusof, M. A., Norazman, N., Ariffin, A., Mohd Zain, F., Risby, R., and Ng, C. P. (2011). "Normal Strength Steel Fiber Reinforced Concrete Subjected to Explosive Loading." International Journal of Sustainable Construction Engineering and Technology, 1(2), 127.

Zech, B., and Wittmann, F. (1980). "Variablility and Mean Value of Strength of Concrete as Function of Load." ACI Journal Proceedings, ACI.

Zhao, C. F., Chen, J. Y., Wang, Y., and Lu, S. J. (2012). "Damage mechanism and response of reinforced concrete containment structure under internal blast loading." Theor.Appl.Fract.Mech., 61(0), 12-20. 
Zhou, X., Kuznetsov, V., Hao, H., and Waschl, J. (2008). "Numerical prediction of concrete slab response to blast loading." Int.J.Impact Eng., 35(10), 1186-1200.

Zielinski, A. J., and Reinhardt, H. W. (1982). "Stress-strain behaviour of concrete and mortar at high rates of tensile loading." Cem.Concr.Res., 12(3), 309-319.

Zineddin, M., and Krauthammer, T. (2007). "Dynamic response and behavior of reinforced concrete slabs under impact loading." Int.J.Impact Eng., 34(9), 1517-1534. 


\section{Appendix A Graph plots}

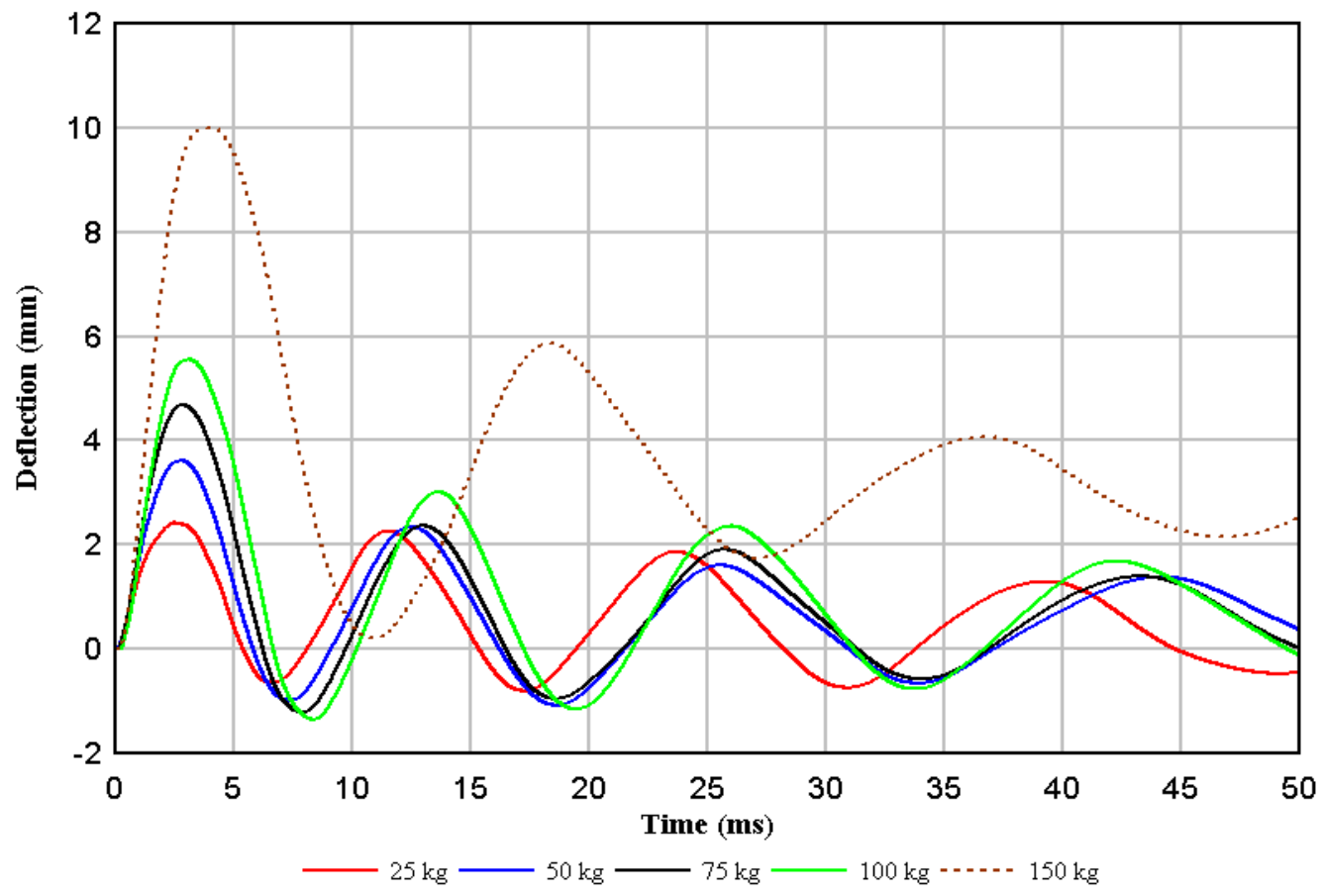

Figure 6-1: Column deflections at height $1 \mathrm{~m}$ for $75-\mathrm{mm}$ tie spacing at $\mathrm{Z}=0.6 \mathrm{~m} / \mathrm{kg}^{1 / 3}$

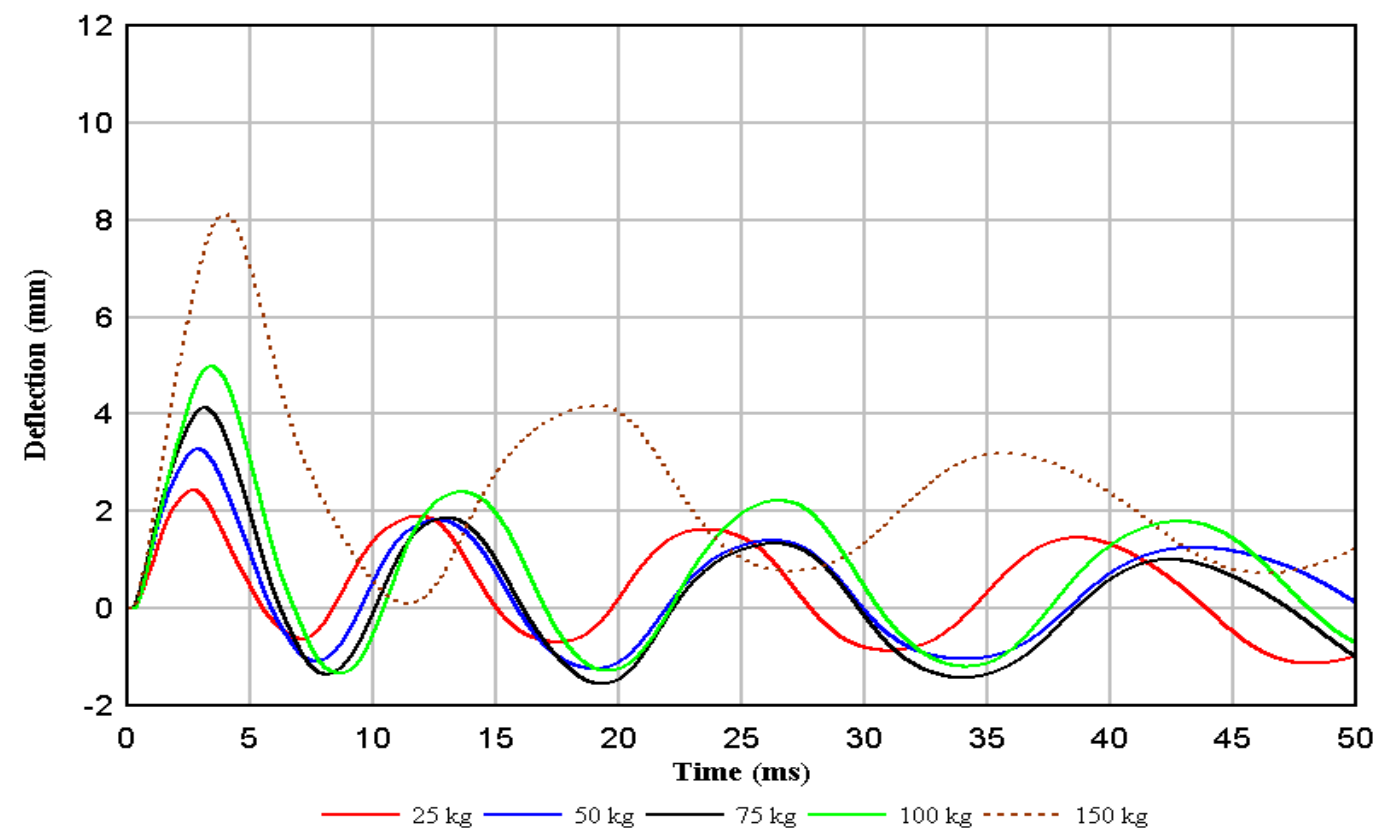

Figure 6-2: Column deflections at height $2 \mathrm{~m}$ for $75-\mathrm{mm}$ tie spacing at $\mathrm{Z}=0.6 \mathrm{~m} / \mathrm{kg}^{1 / 3}$ 


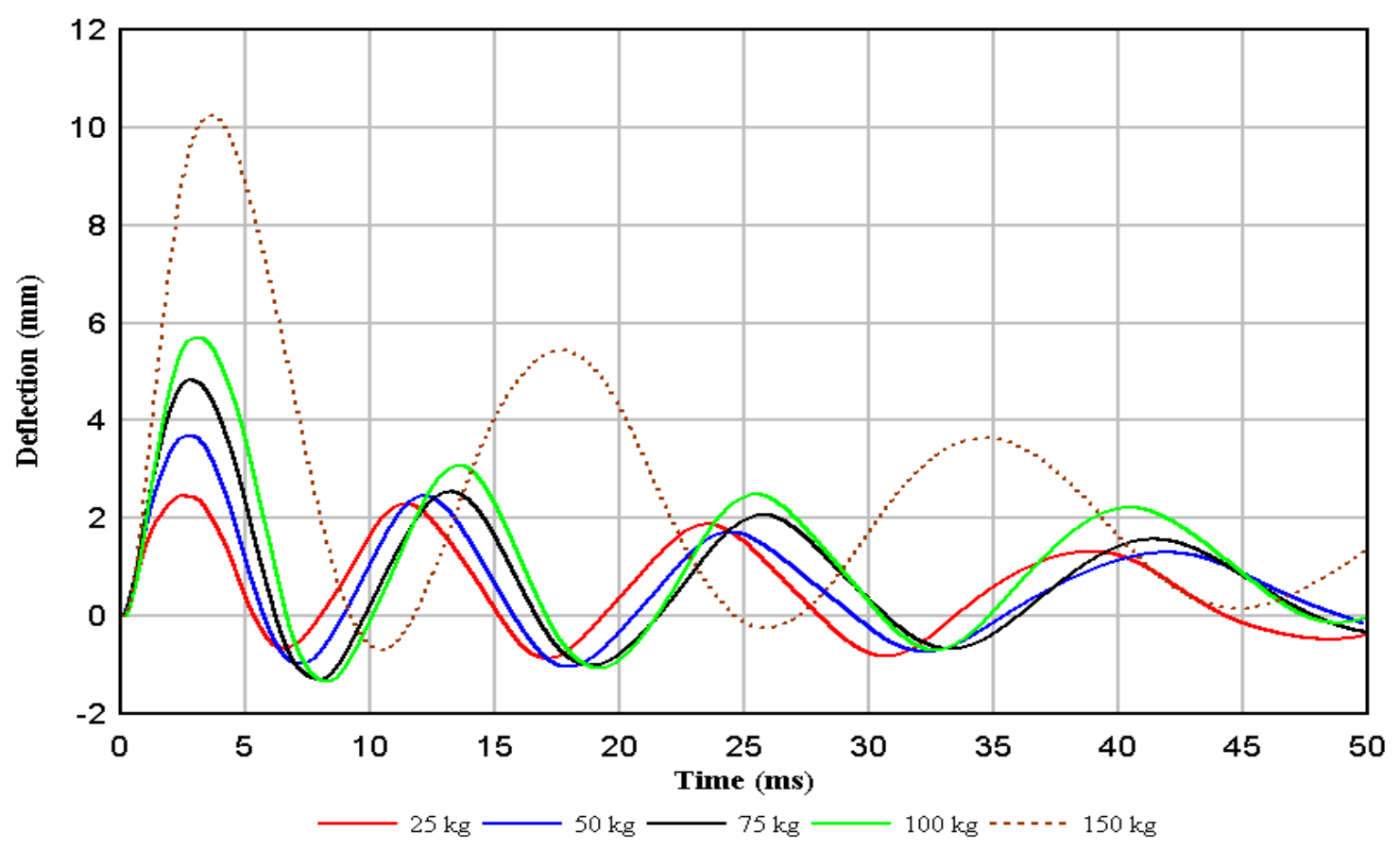

Figure 6-3: Column deflections at height $1 \mathrm{~m}$ for $150-\mathrm{mm}$ tie spacing at $Z=0.6 \mathrm{~m} / \mathrm{kg}^{1 / 3}$

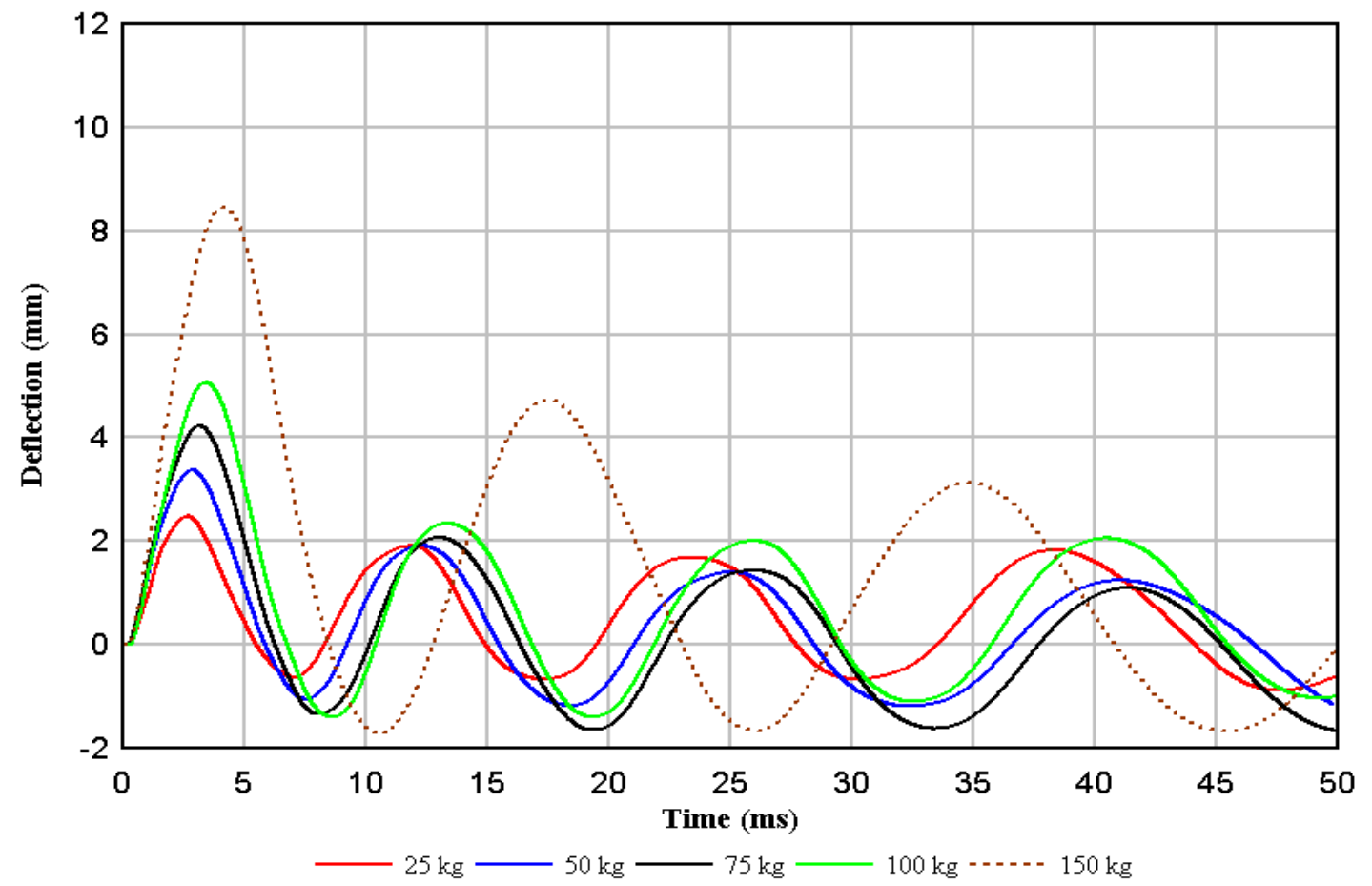

Figure 6-4: Column deflections at height $2 \mathrm{~m}$ for $150-\mathrm{mm}$ tie spacing at $Z=0.6 \mathrm{~m} / \mathrm{kg}^{1 / 3}$ 


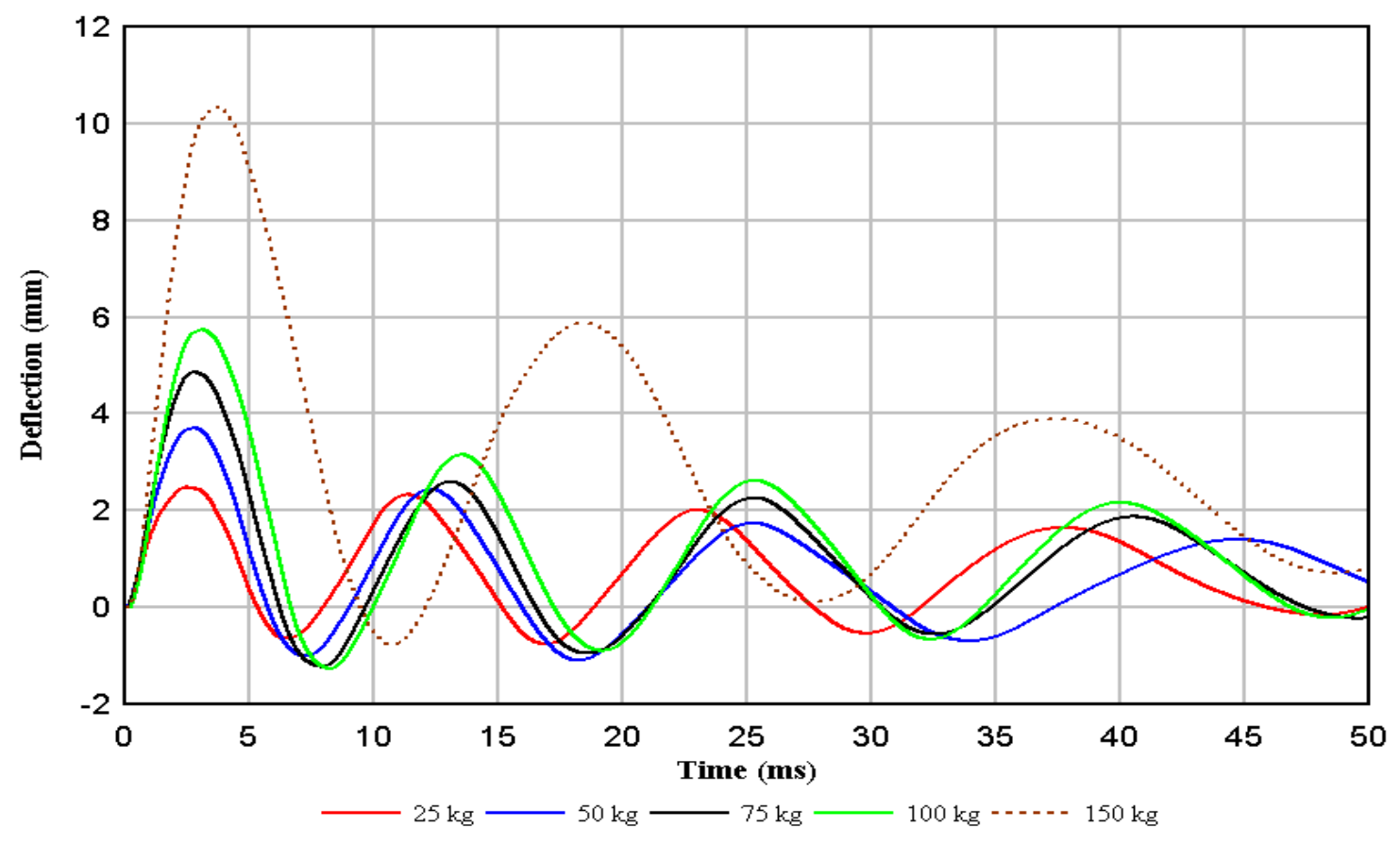

Figure 6-5: Column deflections at height $1 \mathrm{~m}$ for $300-\mathrm{mm}$ tie spacing at $\mathrm{Z}=0.6 \mathrm{~m} / \mathrm{kg}^{1 / 3}$

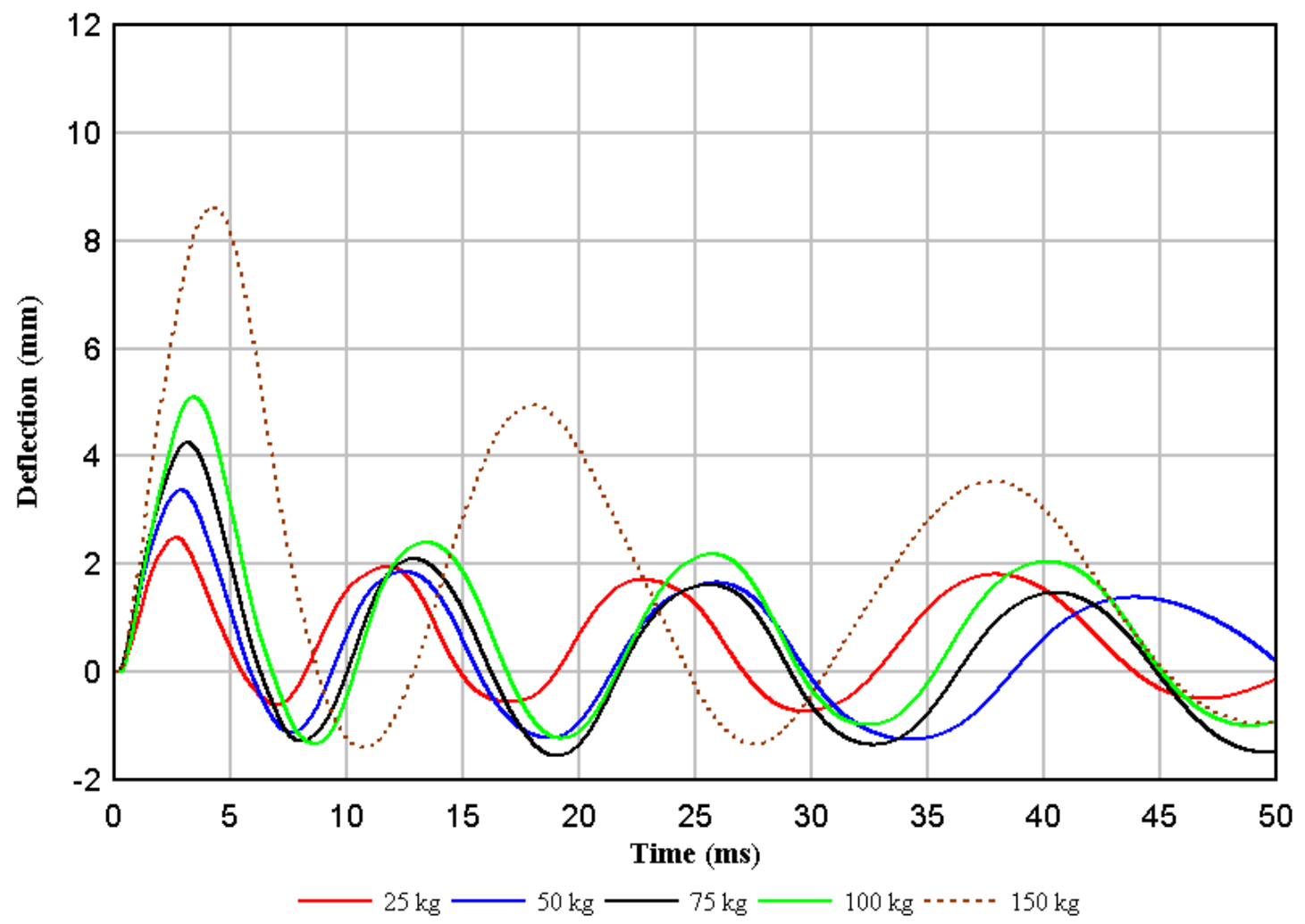

Figure 6-6: Column deflections at height $2 \mathrm{~m}$ for $300-\mathrm{mm}$ tie spacing at $Z=0.6 \mathrm{~m} / \mathrm{kg}^{1 / 3}$ 


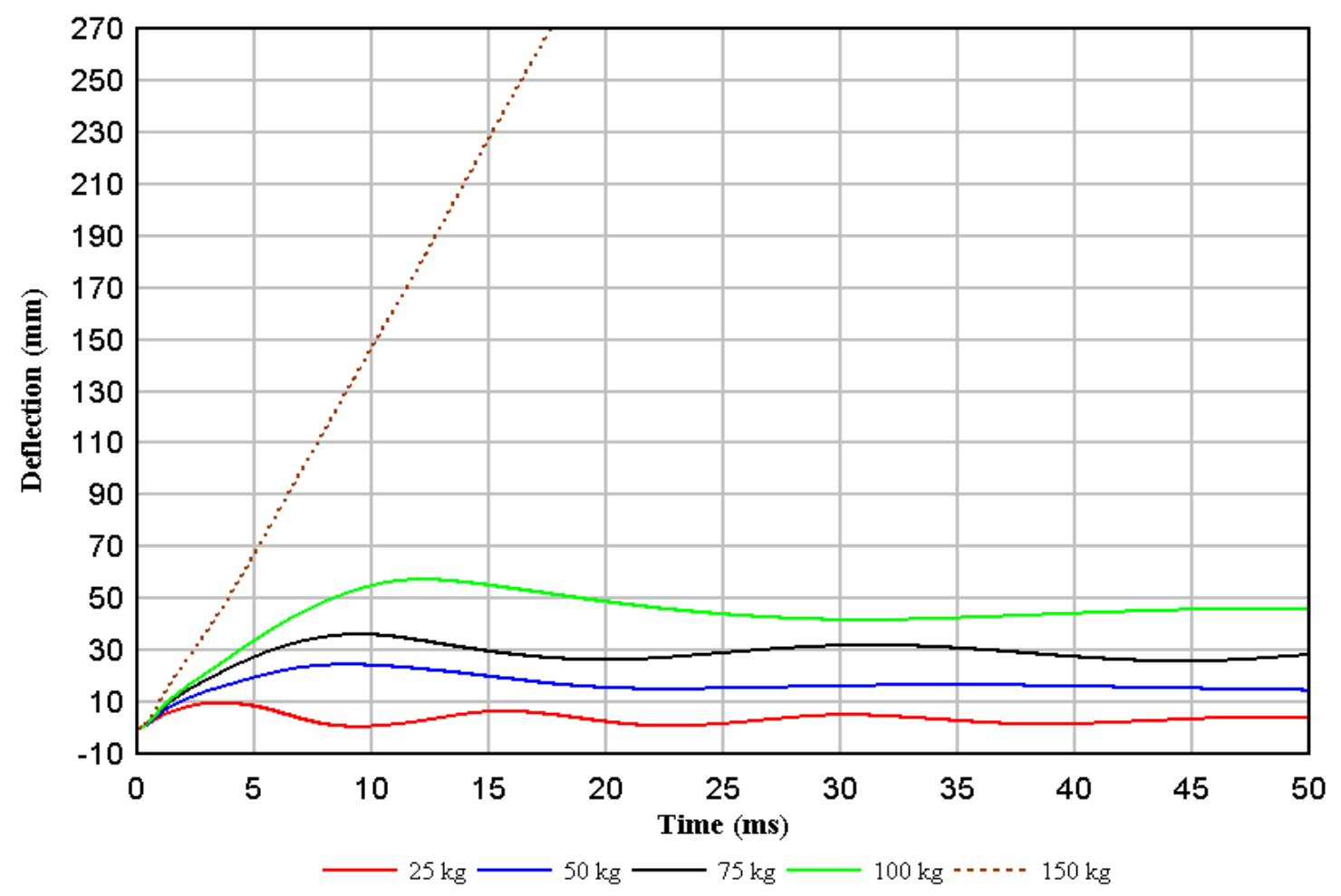

Figure 6-7: Column deflections at height $1 \mathrm{~m}$ for $75-\mathrm{mm}$ tie spacing at $\mathrm{Z}=0.25 \mathrm{~m} / \mathrm{kg}^{1 / 3}$

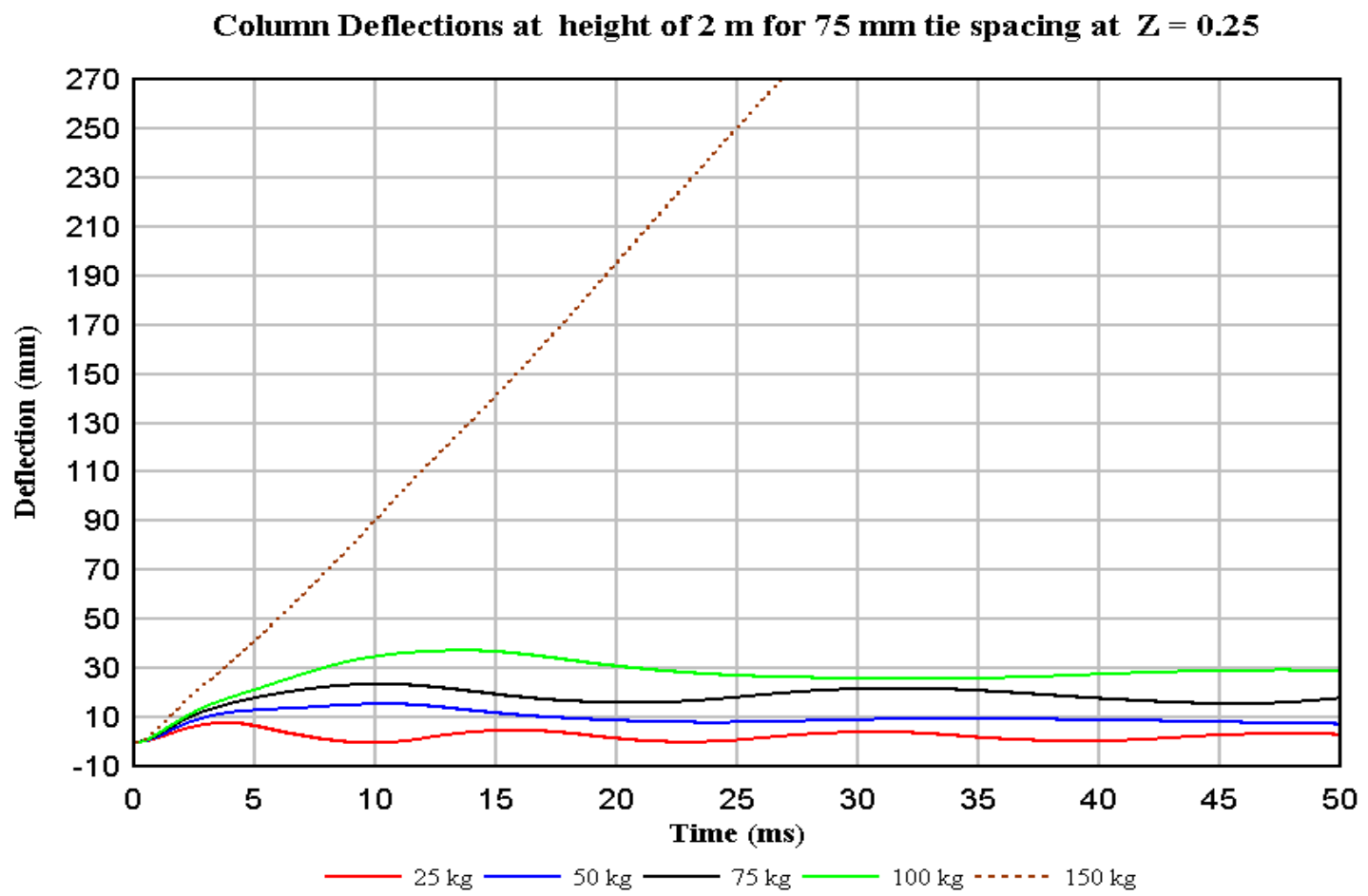

Figure 6-8: Column deflections at height $2 \mathrm{~m}$ for $75-\mathrm{mm}$ tie spacing at $Z=0.25 \mathrm{~m} / \mathrm{kg}^{1 / 3}$ 


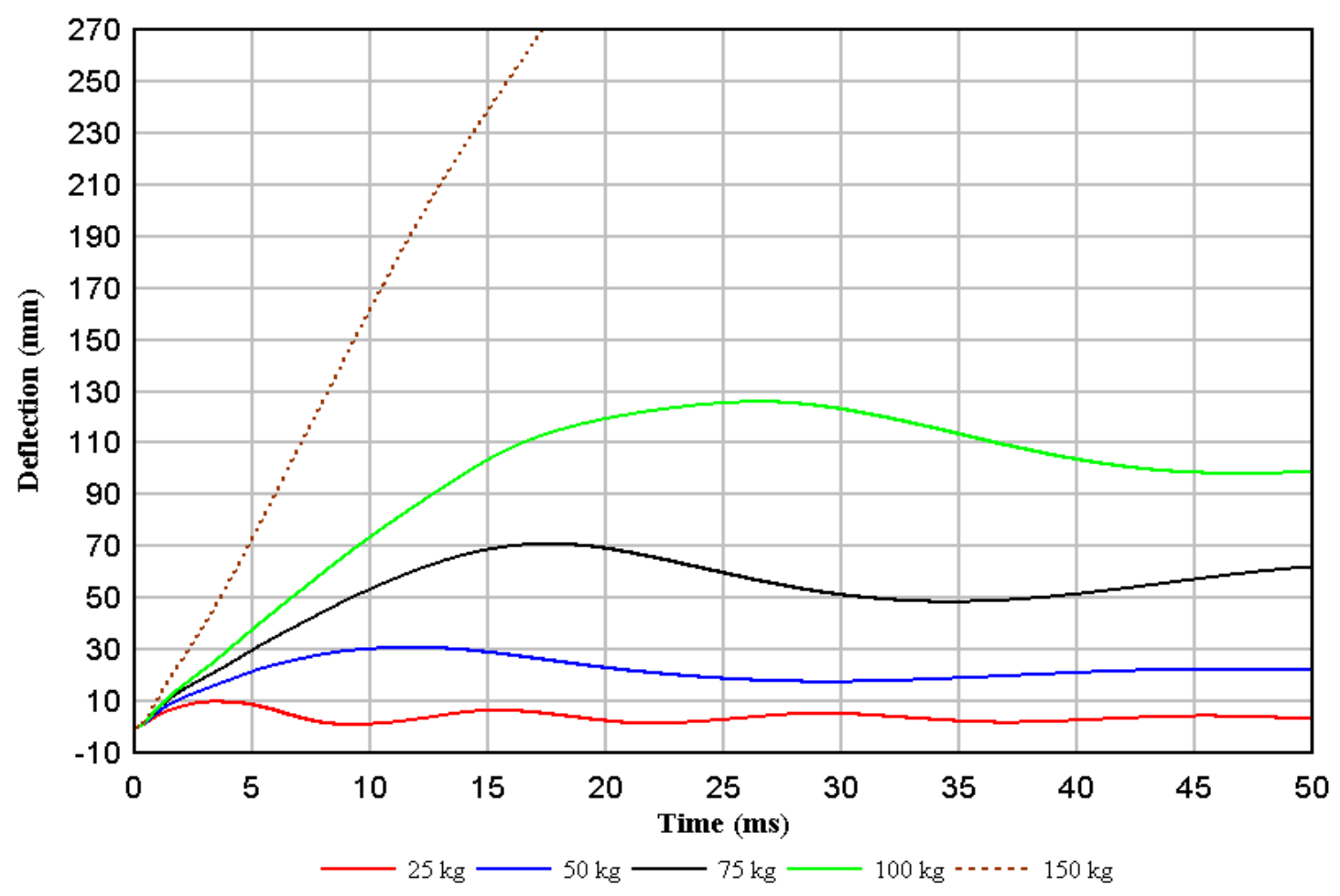

Figure 6-9: Column deflections at height $1 \mathrm{~m}$ for $150-\mathrm{mm}$ tie spacing at $Z=0.25 \mathrm{~m} / \mathrm{kg}^{1 / 3}$

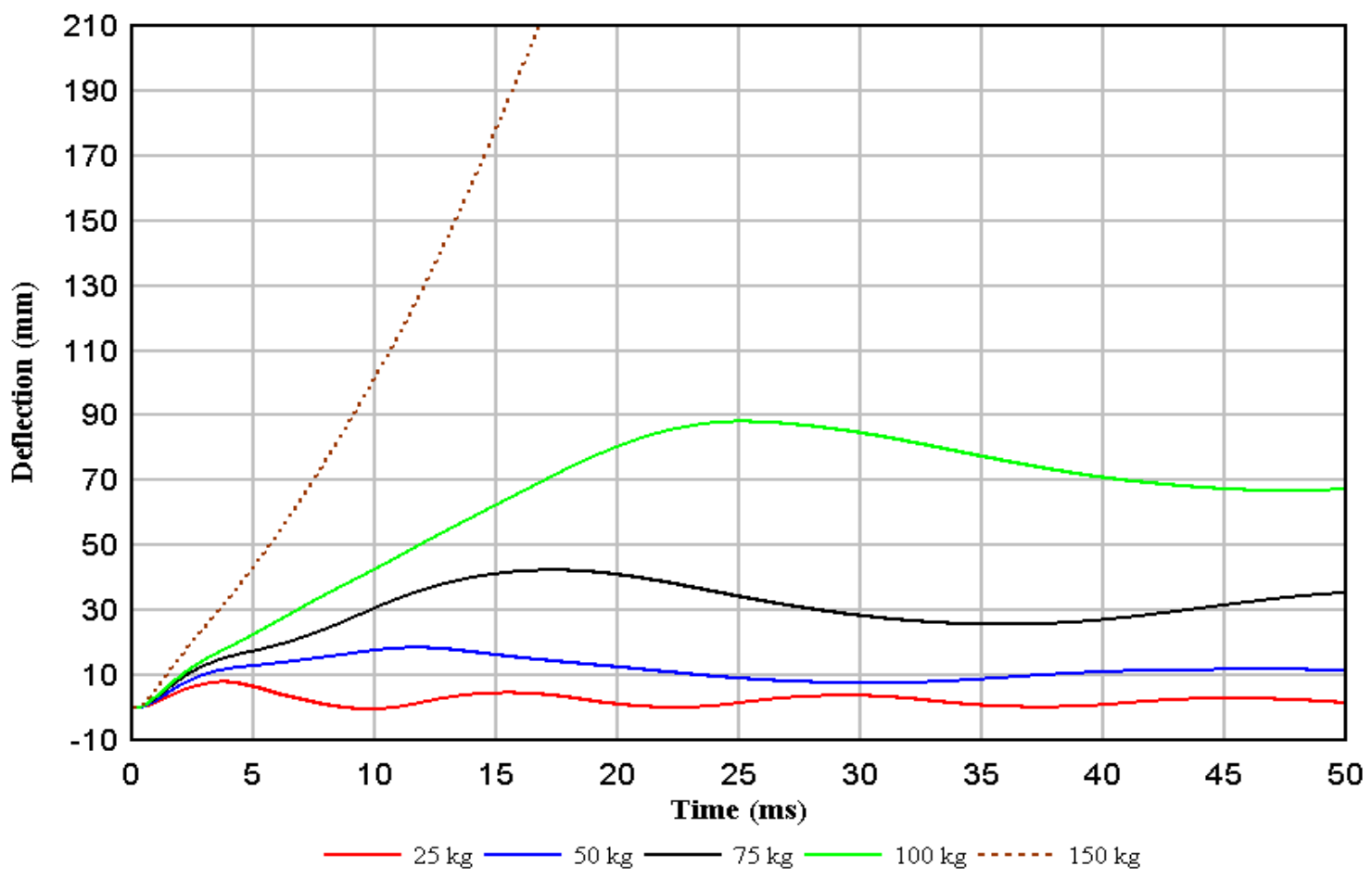

Figure 6-10: Column deflections at height $2 \mathrm{~m}$ for $150-\mathrm{mm}$ tie spacing at $\mathrm{Z}=0.25 \mathrm{~m} / \mathrm{kg}^{1 / 3}$ 


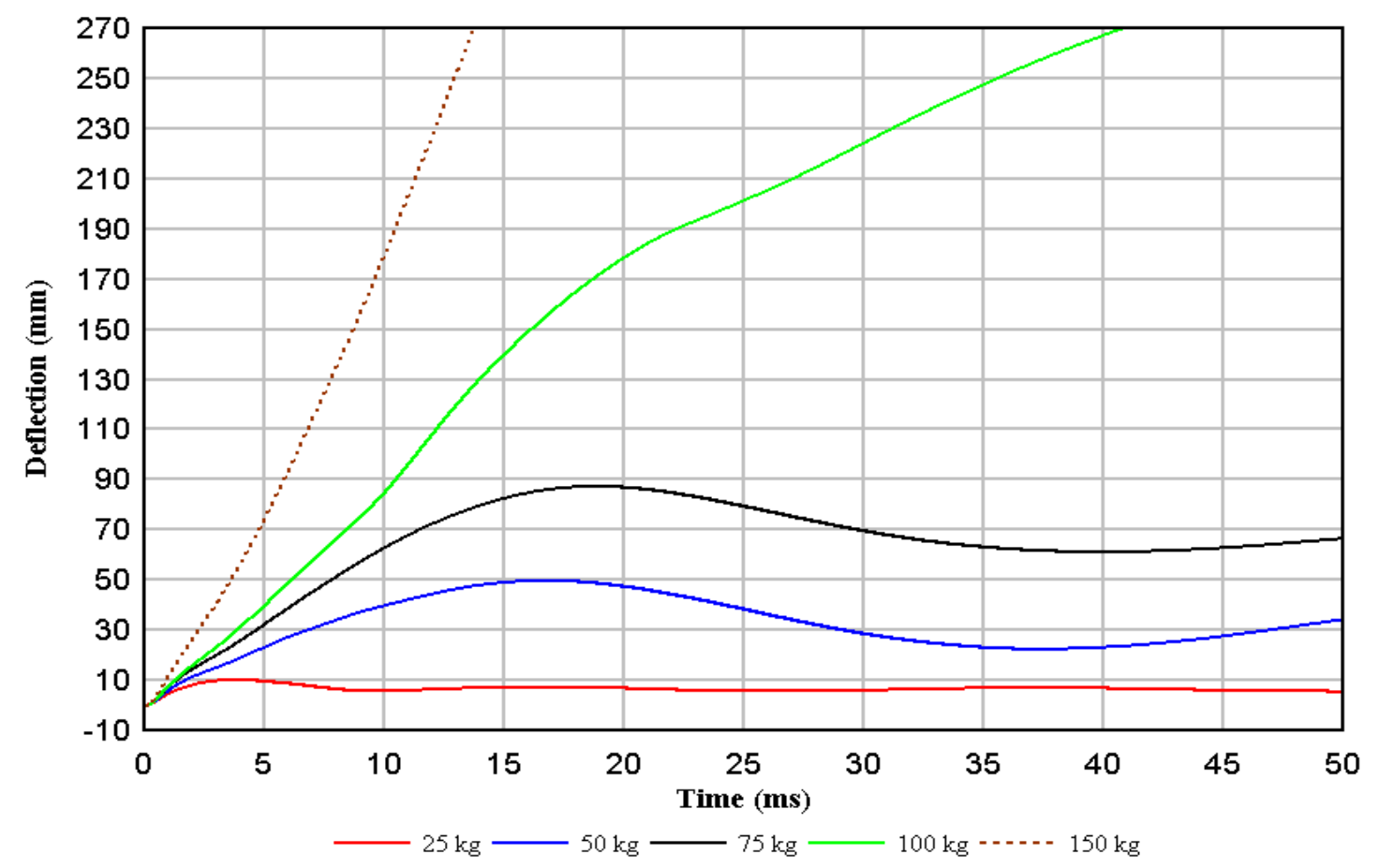

Figure 6-11: Column deflections at height $1 \mathrm{~m}$ for $300-\mathrm{mm}$ tie spacing at $Z=0.25 \mathrm{~m} / \mathrm{kg}^{1 / 3}$

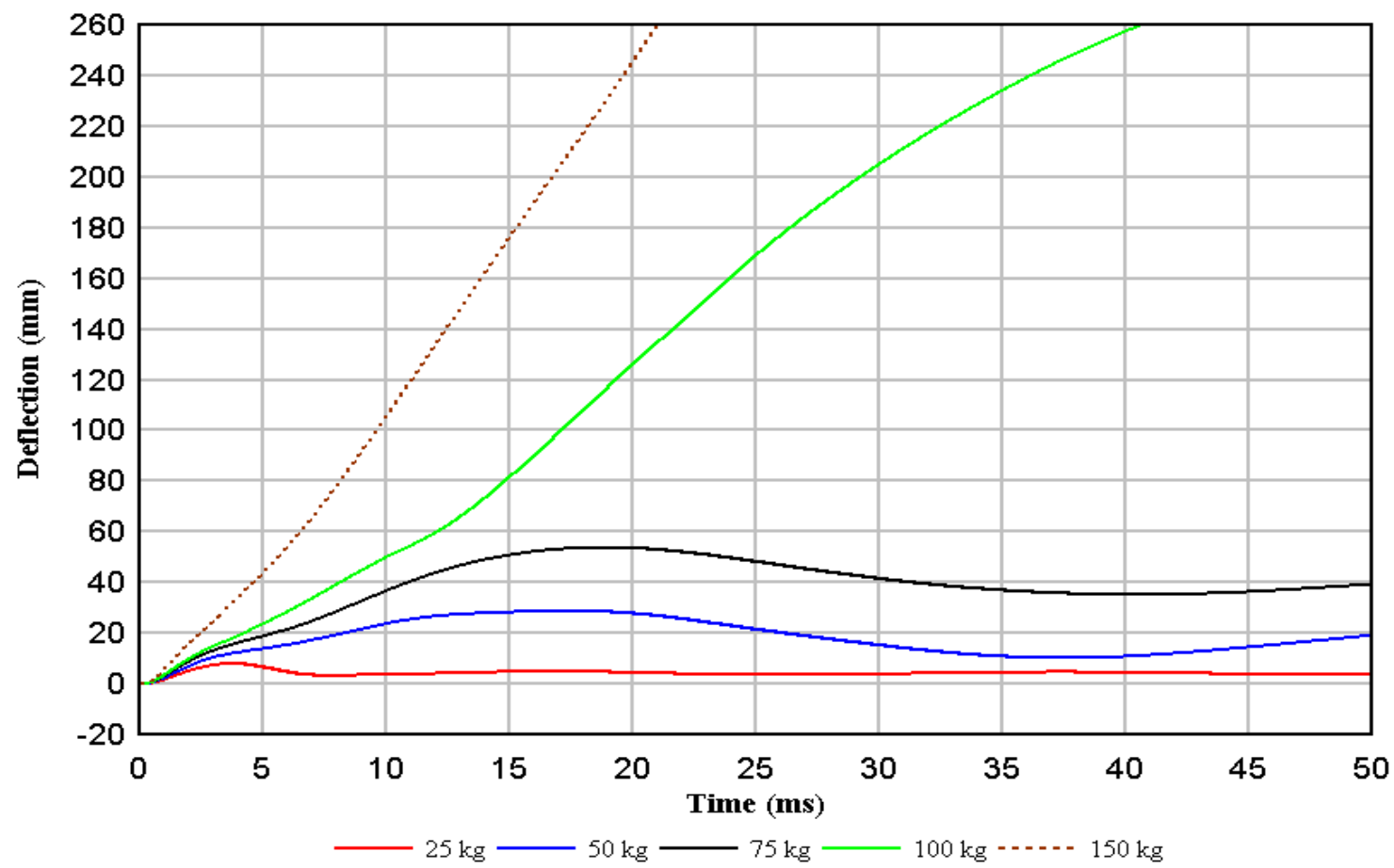

Figure 6-12: Column deflections at height $2 \mathrm{~m}$ for $300-\mathrm{mm}$ tie spacing at $\mathrm{Z}=0.25 \mathrm{~m} / \mathrm{kg}^{1 / 3}$ 


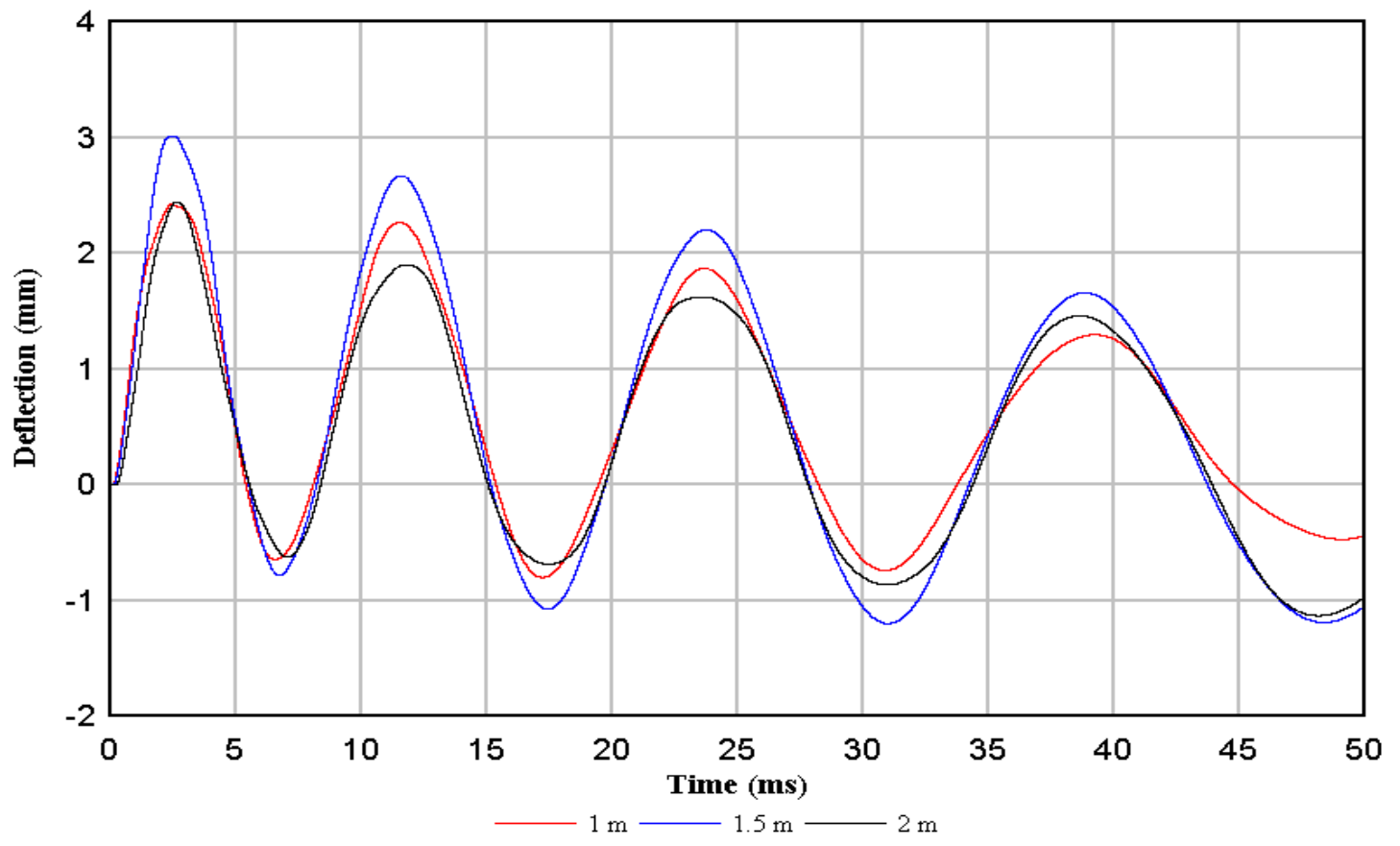

Figure 6-13: Column deflections for $75-\mathrm{mm}$ tie spacing at $Z=0.6 \mathrm{~m} / \mathrm{kg}^{1 / 3}$ for $50 \mathrm{~kg}$ charge mass

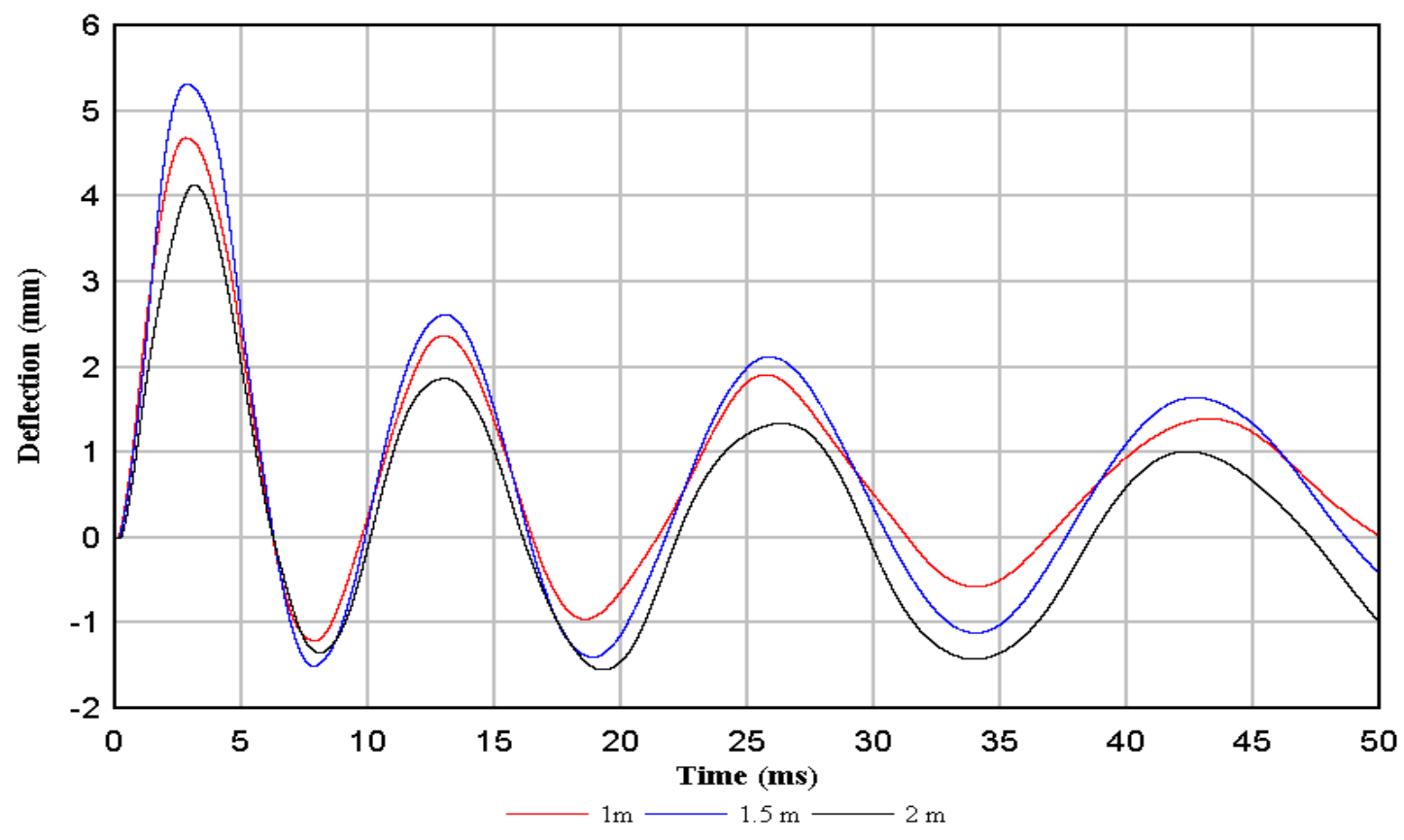

Figure 6-14: Column deflections for $75-\mathrm{mm}$ tie spacing at $Z=0.6 \mathrm{~m} / \mathrm{kg}^{1 / 3}$ for $75 \mathrm{~kg}$ charge mass 


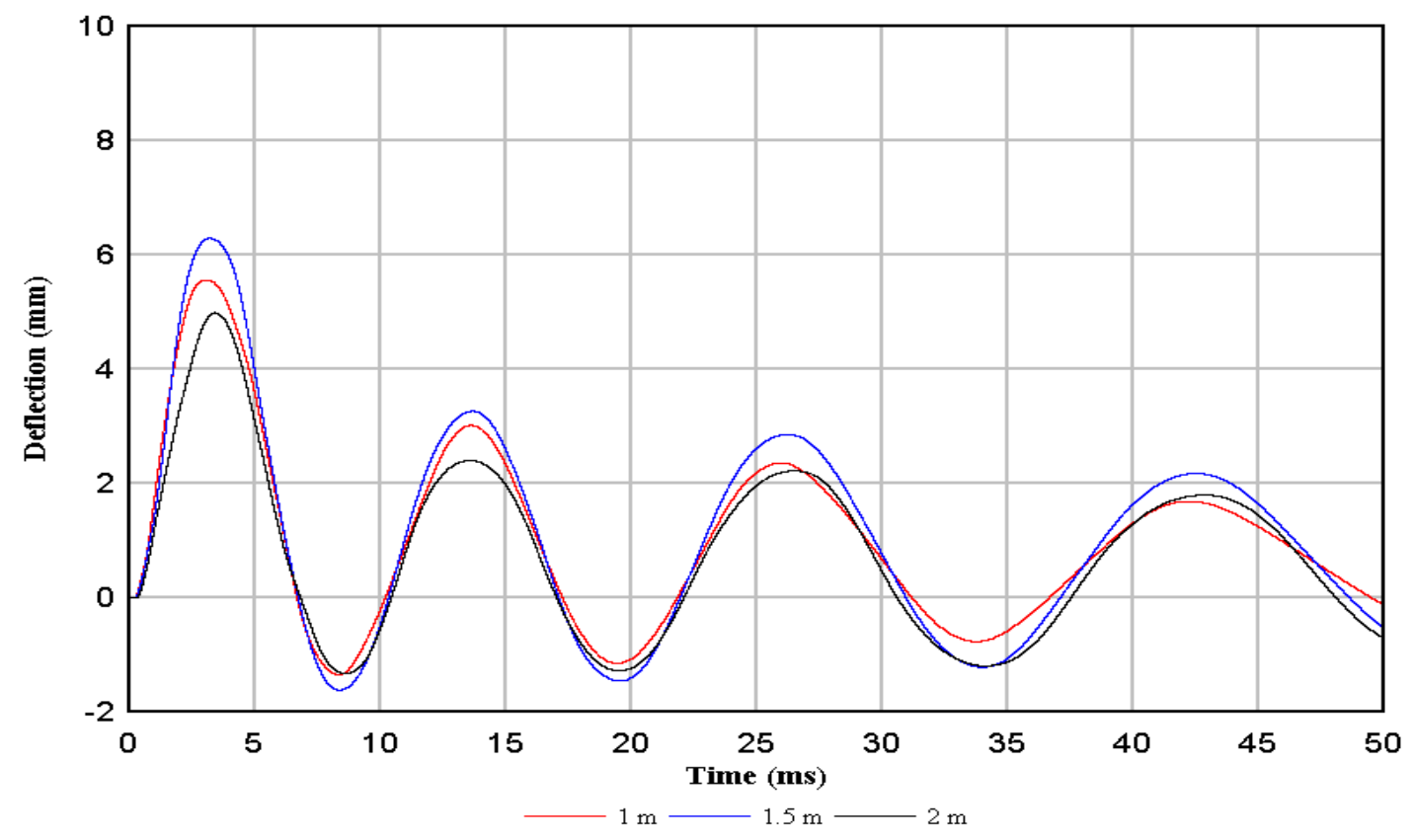

Figure 6-15: Column deflections for $75-\mathrm{mm}$ tie spacing at $\mathrm{Z}=0.6$ for $\mathrm{m} / \mathrm{kg}^{1 / 3} 100 \mathrm{~kg}$ charge mass

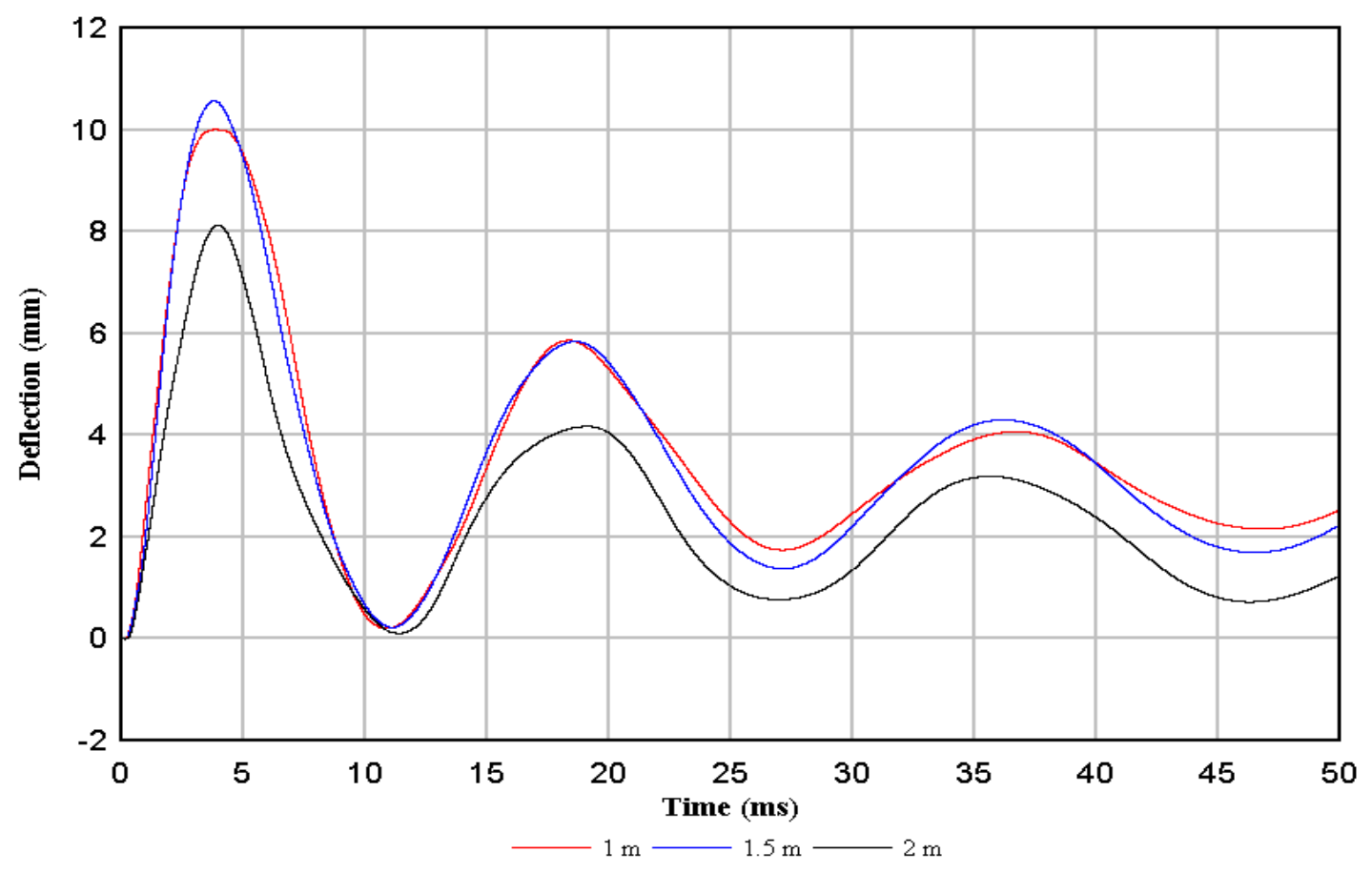

Figure 6-16: Column deflections for $75-\mathrm{mm}$ tie spacing at $Z=0.6 \mathrm{~m} / \mathrm{kg}^{1 / 3}$ for $150 \mathrm{~kg}$ charge mass 


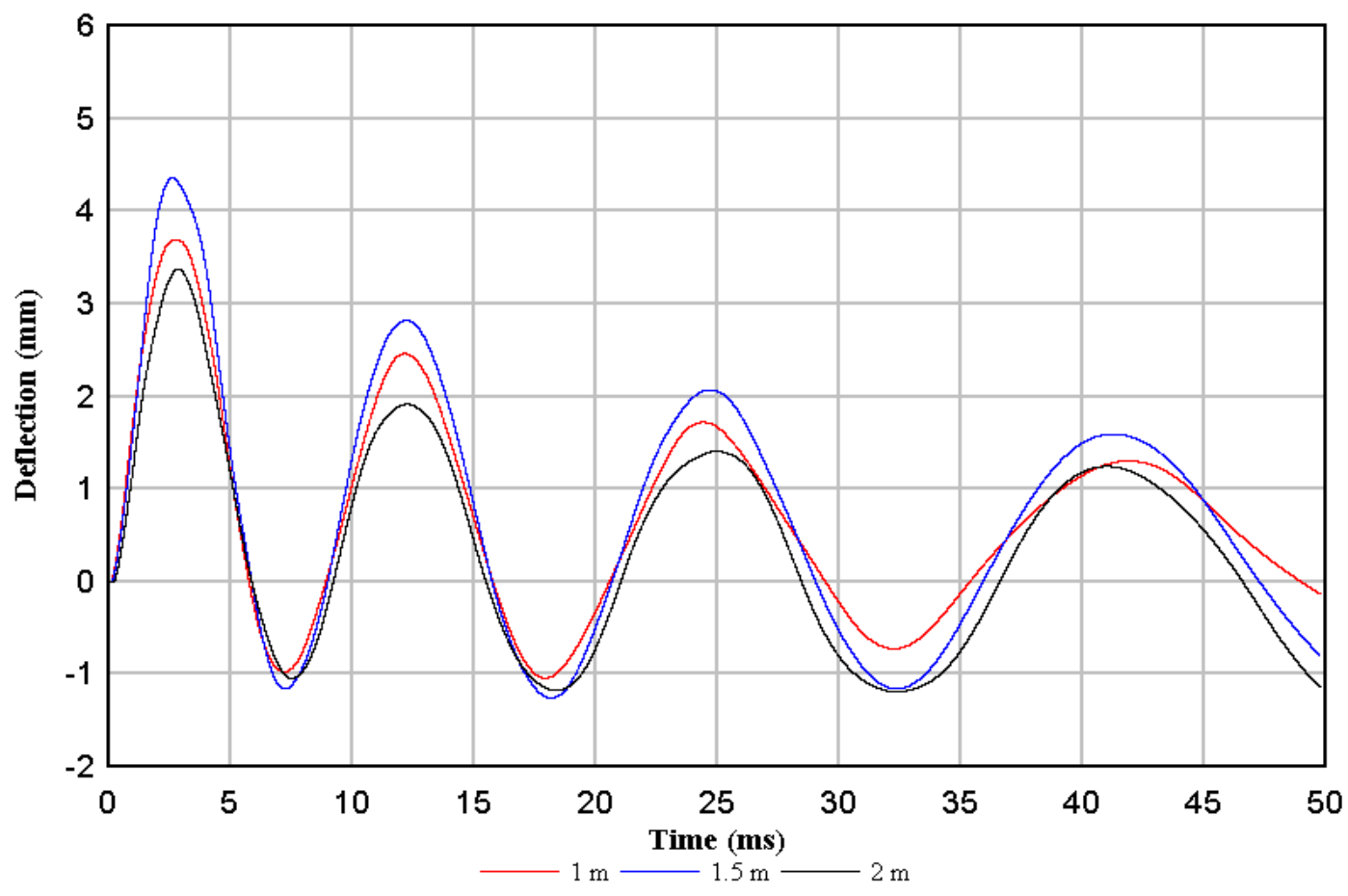

Figure 6-17: Column deflections for $150-\mathrm{mm}$ tie spacing at $\mathrm{Z}=0.6 \mathrm{~m} / \mathrm{kg}^{1 / 3}$ for $50 \mathrm{~kg}$ charge mass

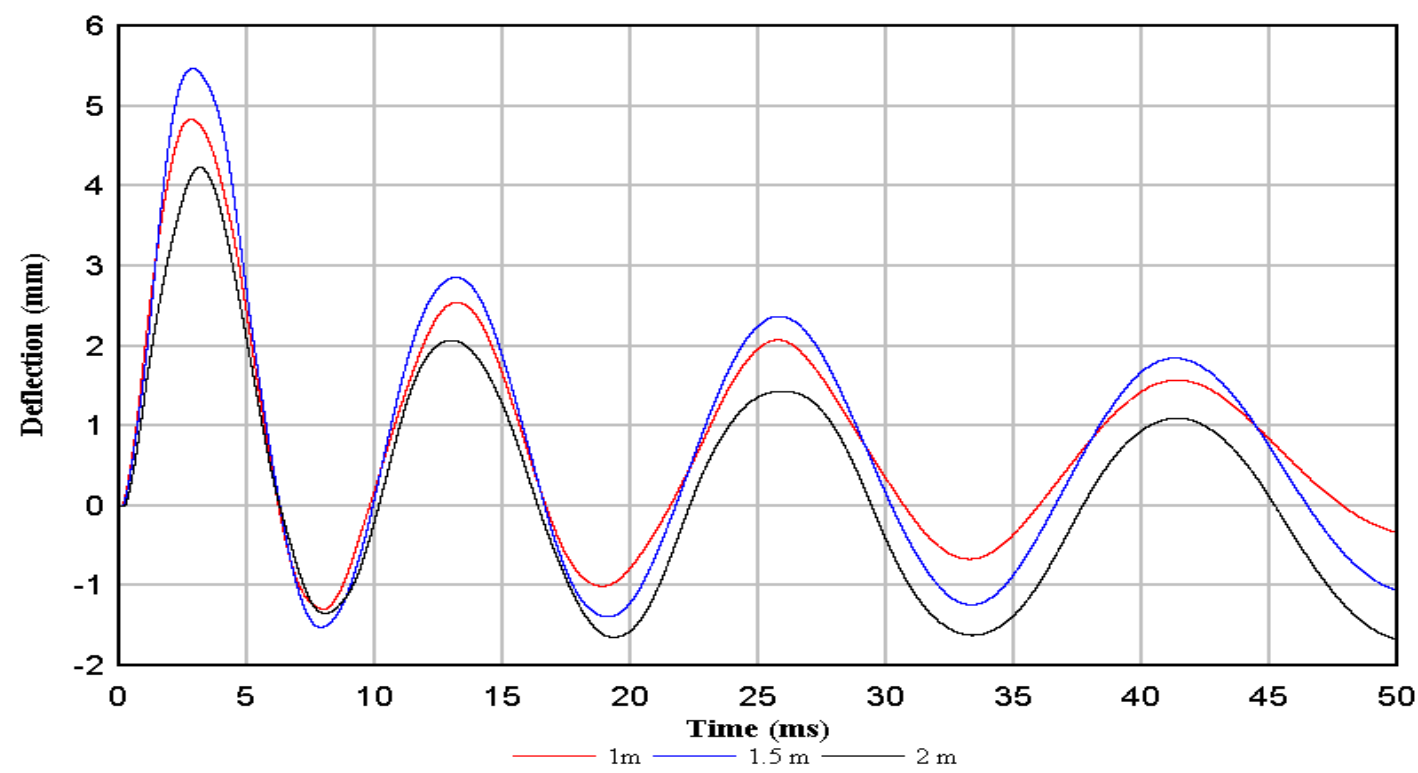

Figure 6-18 Column deflections for 150 - $\mathrm{mm}$ tie spacing at $Z=0.6 \mathrm{~m} / \mathrm{kg}^{1 / 3}$ for $75 \mathrm{~kg}$ charge mass 


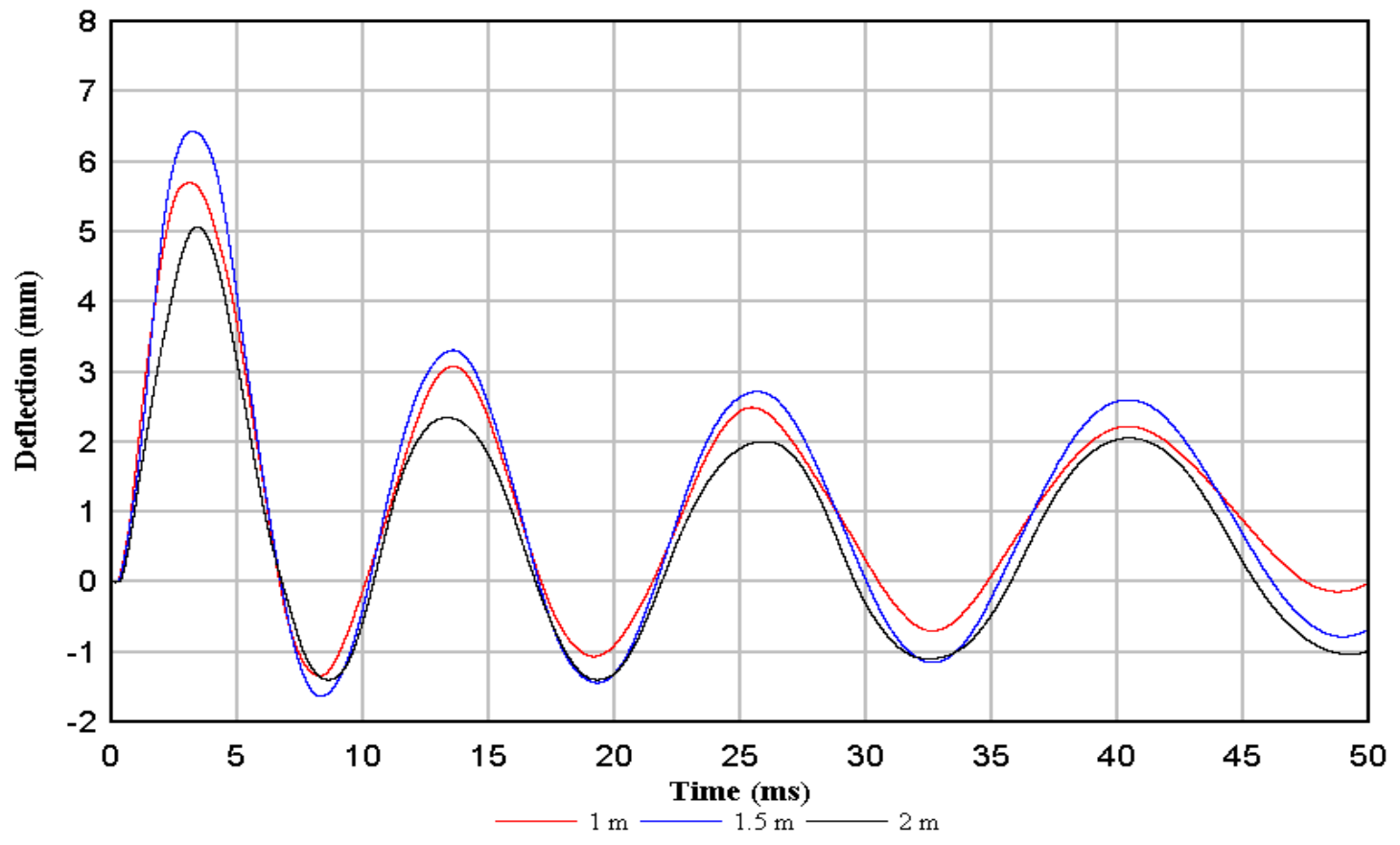

Figure 6-19: Column deflections for $150-\mathrm{mm}$ tie spacing at $Z=0.6 \mathrm{~m} / \mathrm{kg}^{1 / 3}$ for $100 \mathrm{~kg}$ charge mass

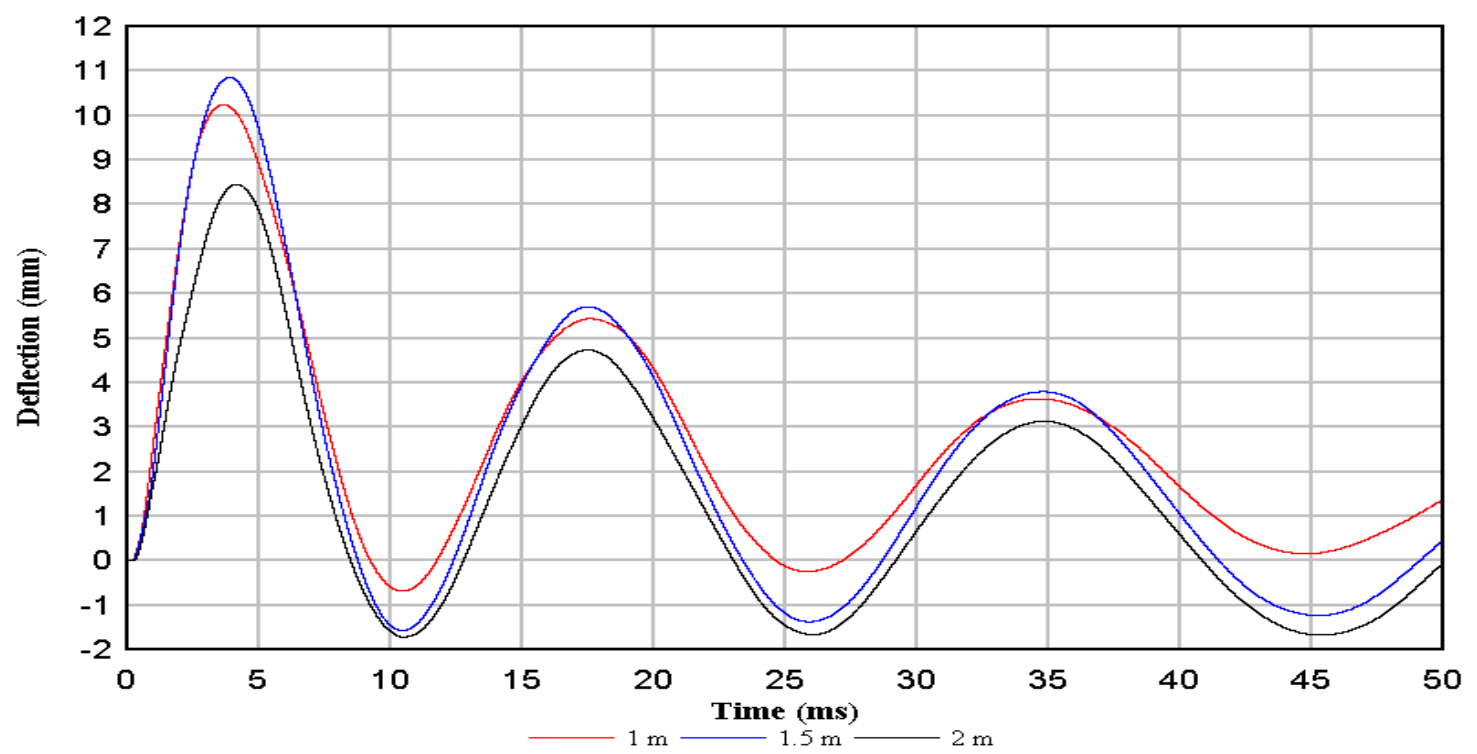

Figure 6-20: Column deflections for $150-\mathrm{mm}$ tie spacing at $Z=0.6 \mathrm{~m} / \mathrm{kg}^{1 / 3}$ for $150 \mathrm{~kg}$ charge mass 


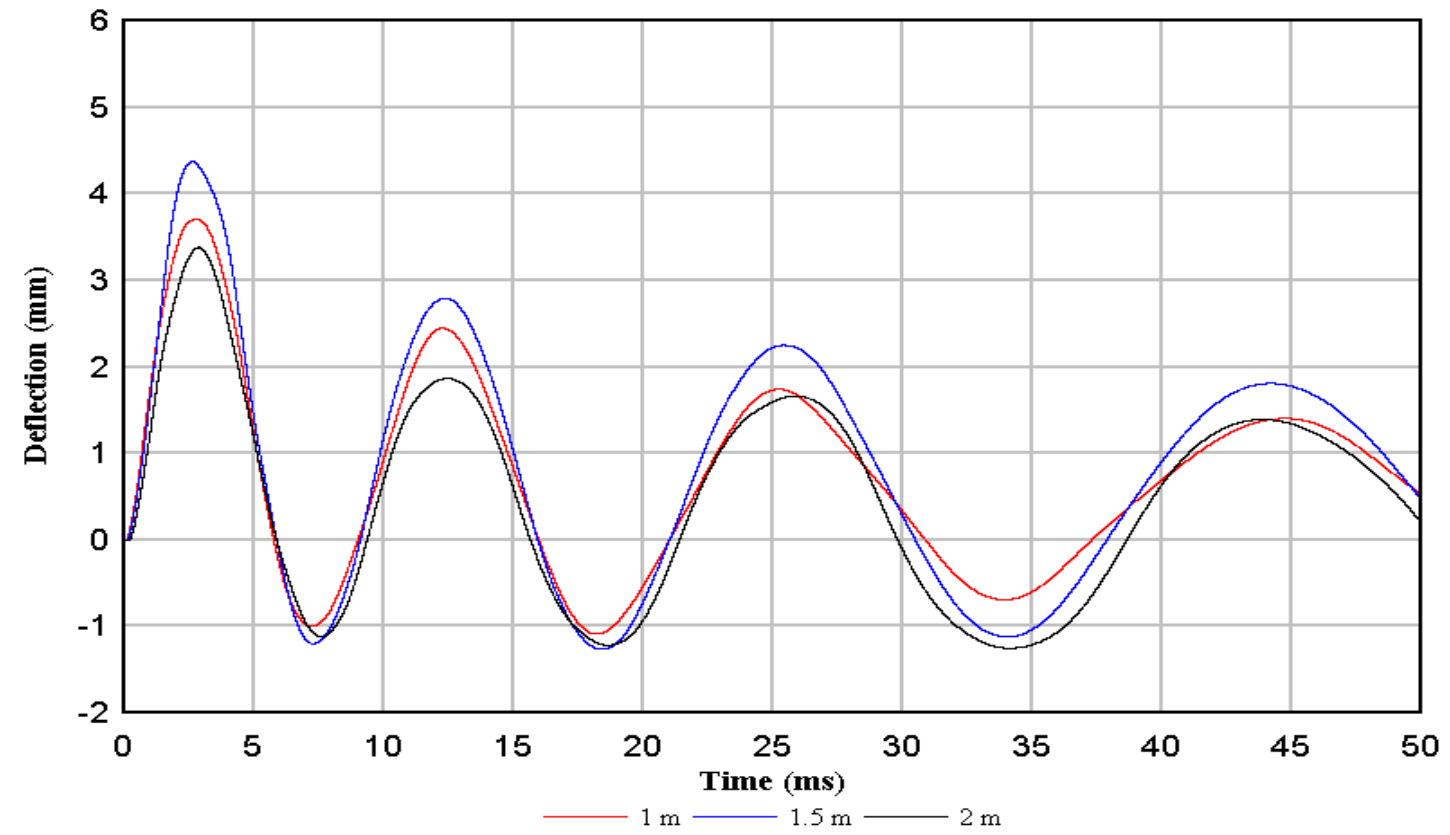

Figure 6-21: Column deflections for $300-\mathrm{mm}$ tie spacing at $\mathrm{Z}=0.6 \mathrm{~m} / \mathrm{kg}^{1 / 3}$ for $50 \mathrm{~kg}$ charge mass

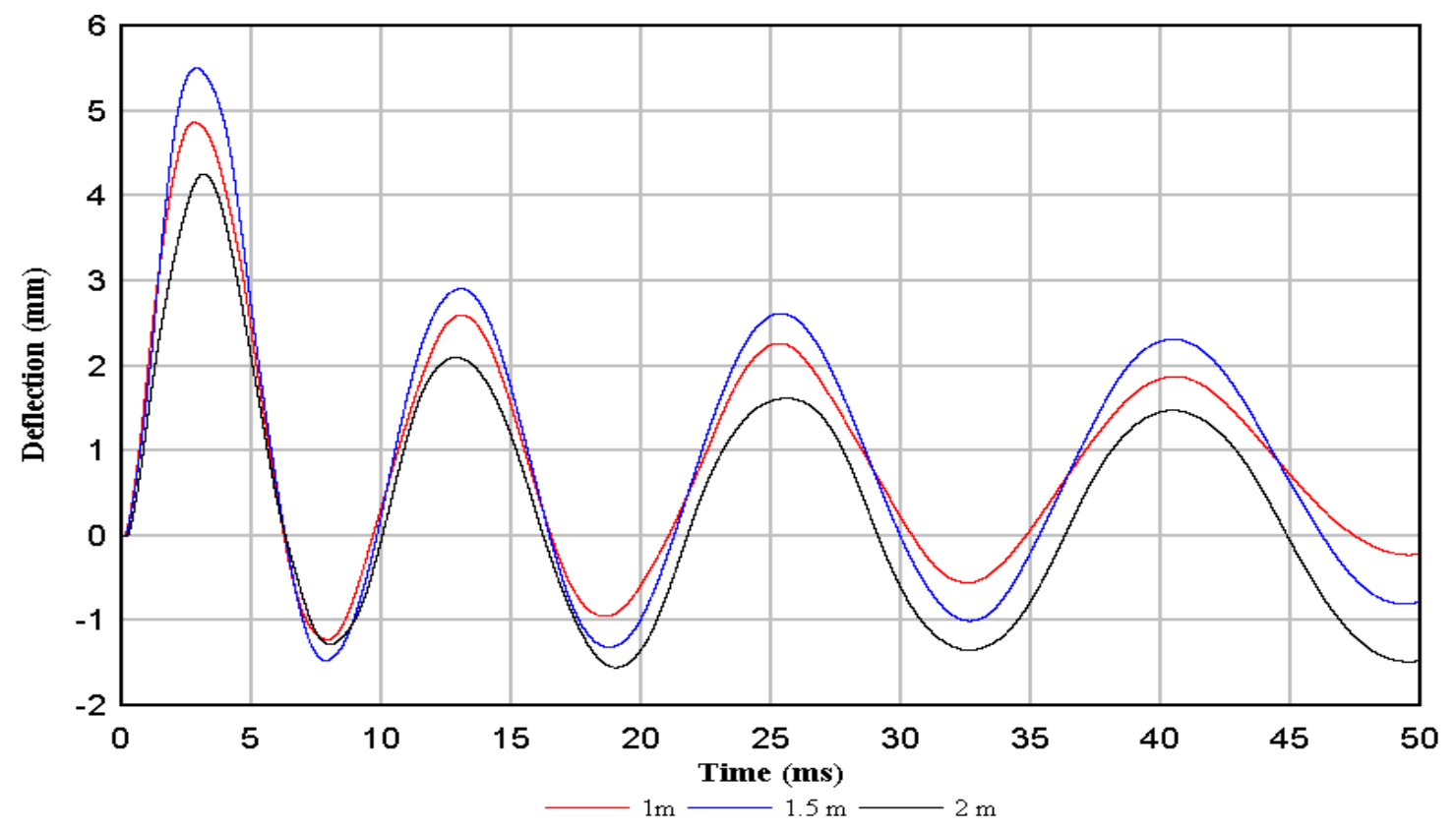

Figure 6-22: Column deflections for $300-\mathrm{mm}$ tie spacing at $Z=0.6 \mathrm{~m} / \mathrm{kg}^{1 / 3}$ for $75 \mathrm{~kg}$ charge mass 


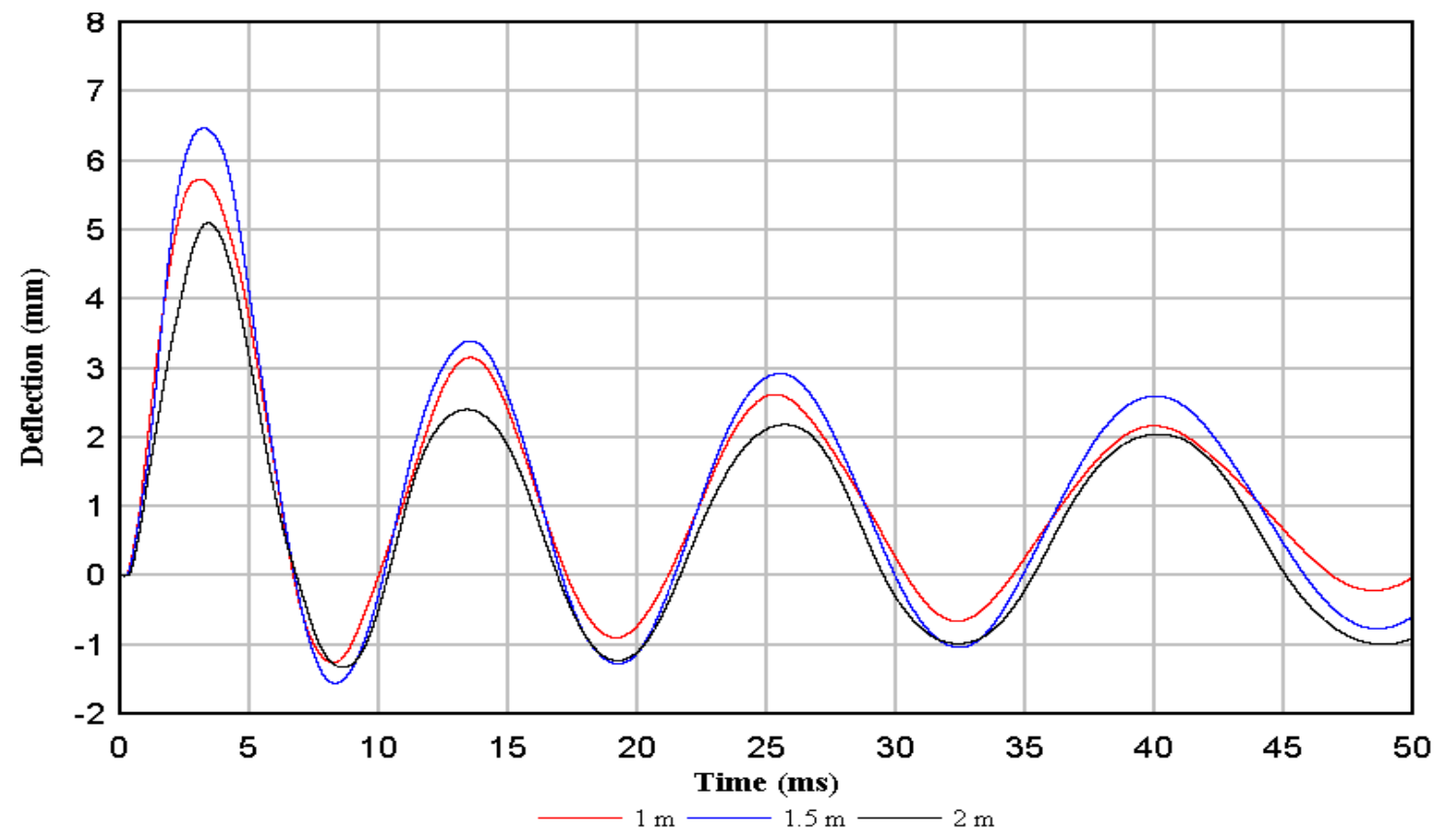

Figure 6-23: Column deflections for 300-mm tie spacing at $Z=0.6 \mathrm{~m} / \mathrm{kg}^{1 / 3}$ for $100 \mathrm{~kg}$ charge mass

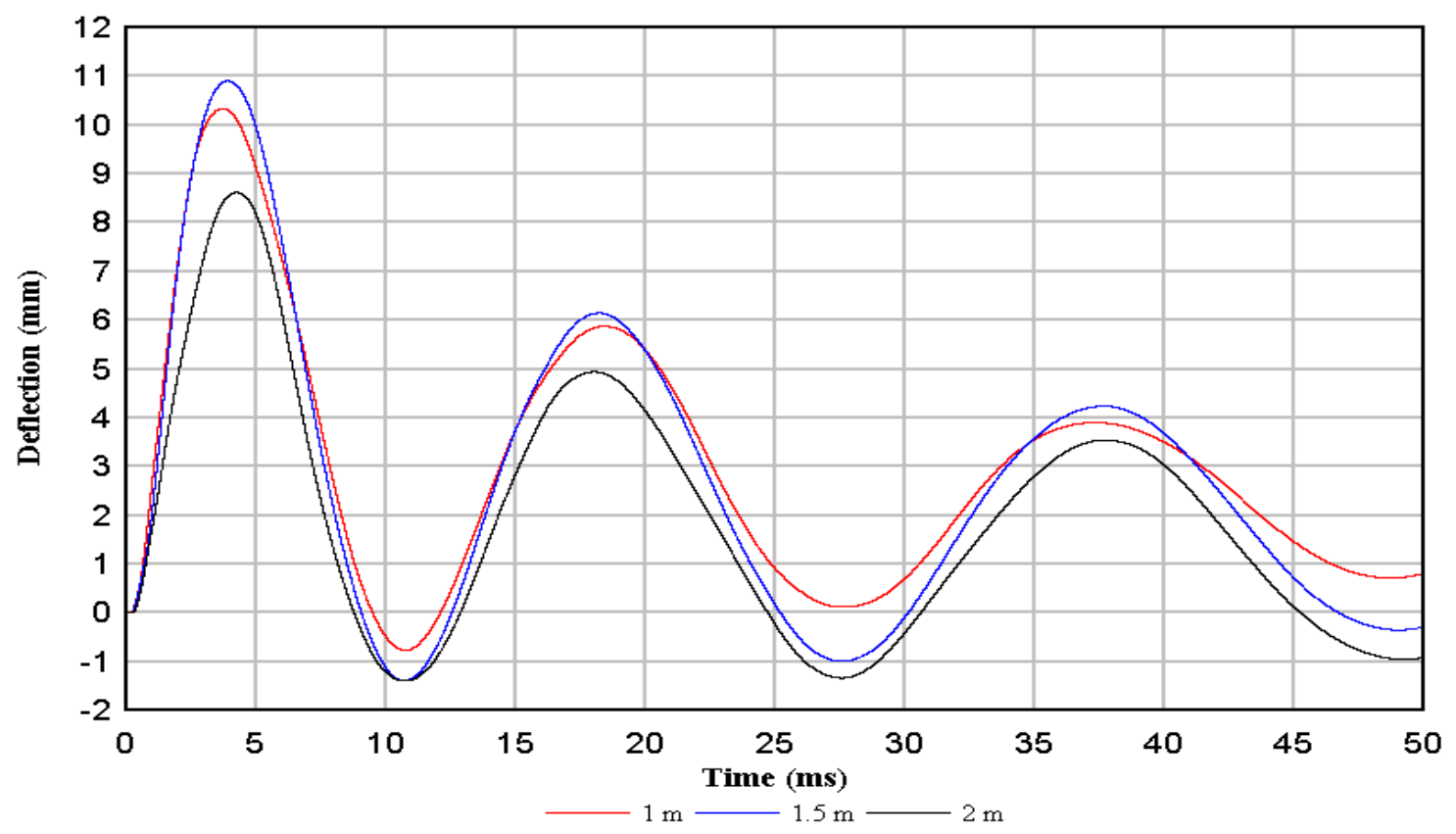

Figure 6-24: Column deflections for 300-mm tie spacing at $Z=0.6 \mathrm{~m} / \mathrm{kg}^{1 / 3}$ for $150 \mathrm{~kg}$ charge mass 


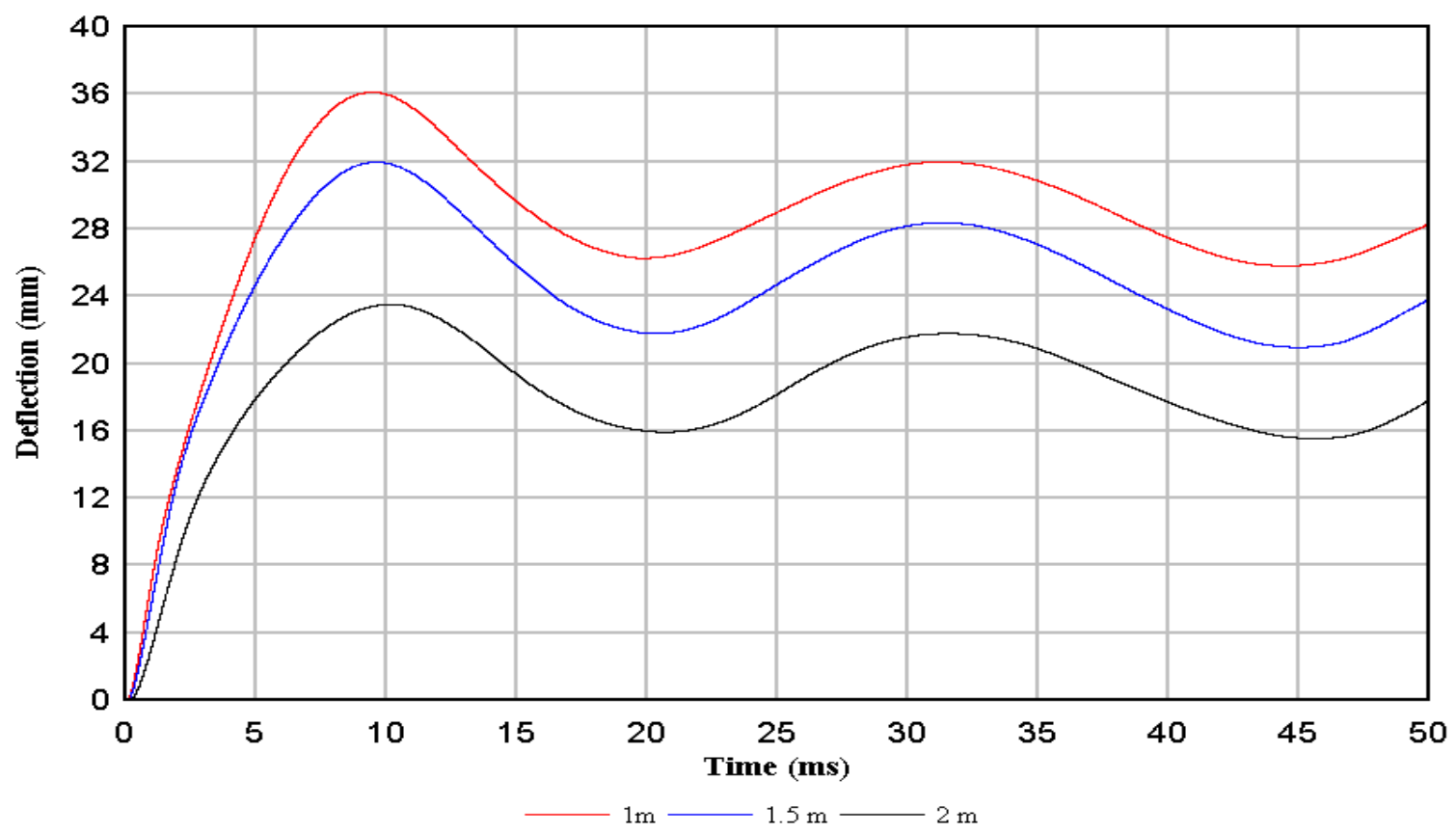

Figure 6-25: Column deflections for $75-\mathrm{mm}$ tie spacing at $Z=0.25 \mathrm{~m} / \mathrm{kg}^{1 / 3}$ for $75 \mathrm{~kg}$ charge mass

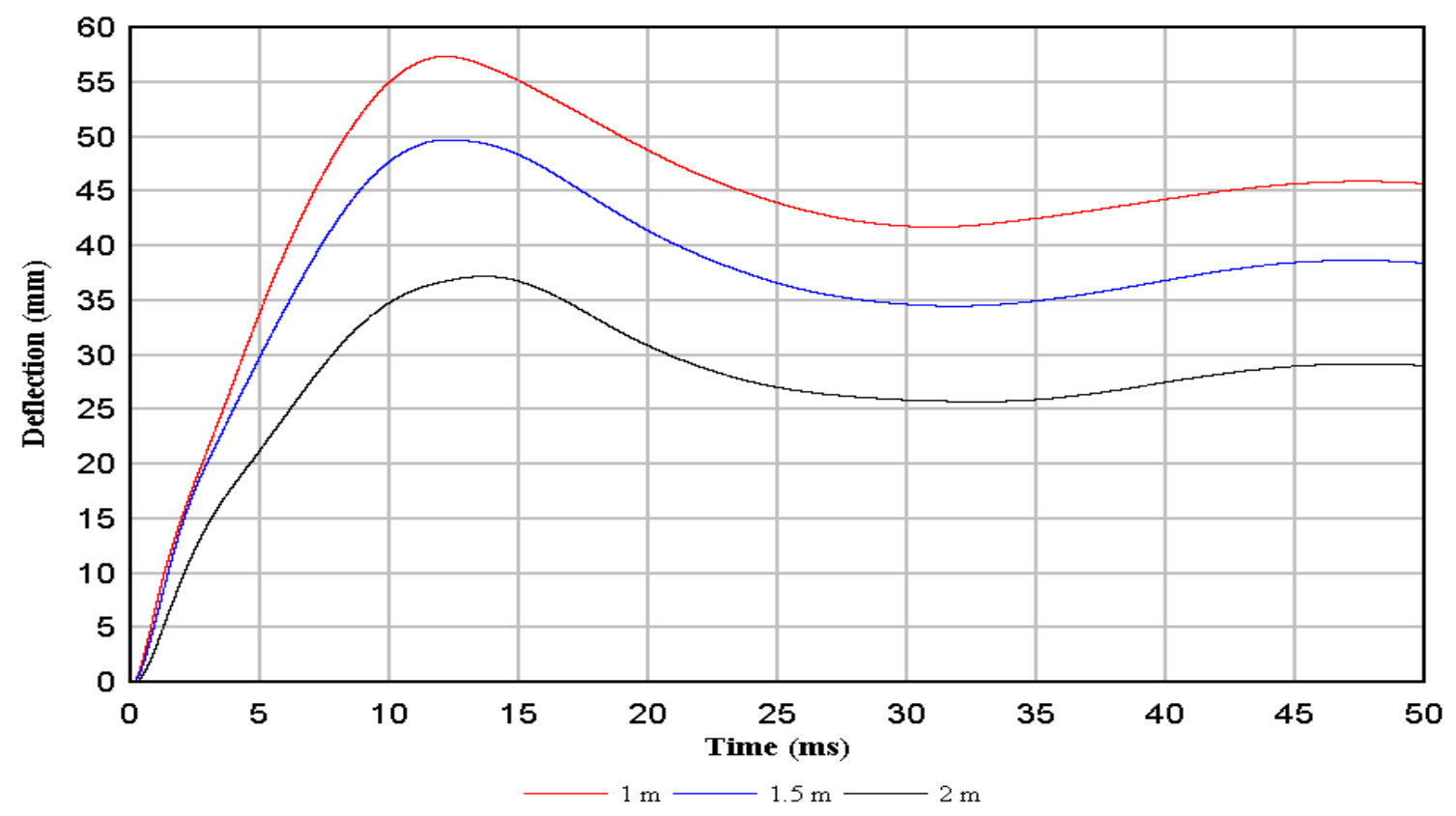

Figure 6-26: Column deflections for $75-\mathrm{mm}$ tie spacing at $Z=0.25 \mathrm{~m} / \mathrm{kg}^{1 / 3}$ for $100 \mathrm{~kg}$ charge mass 


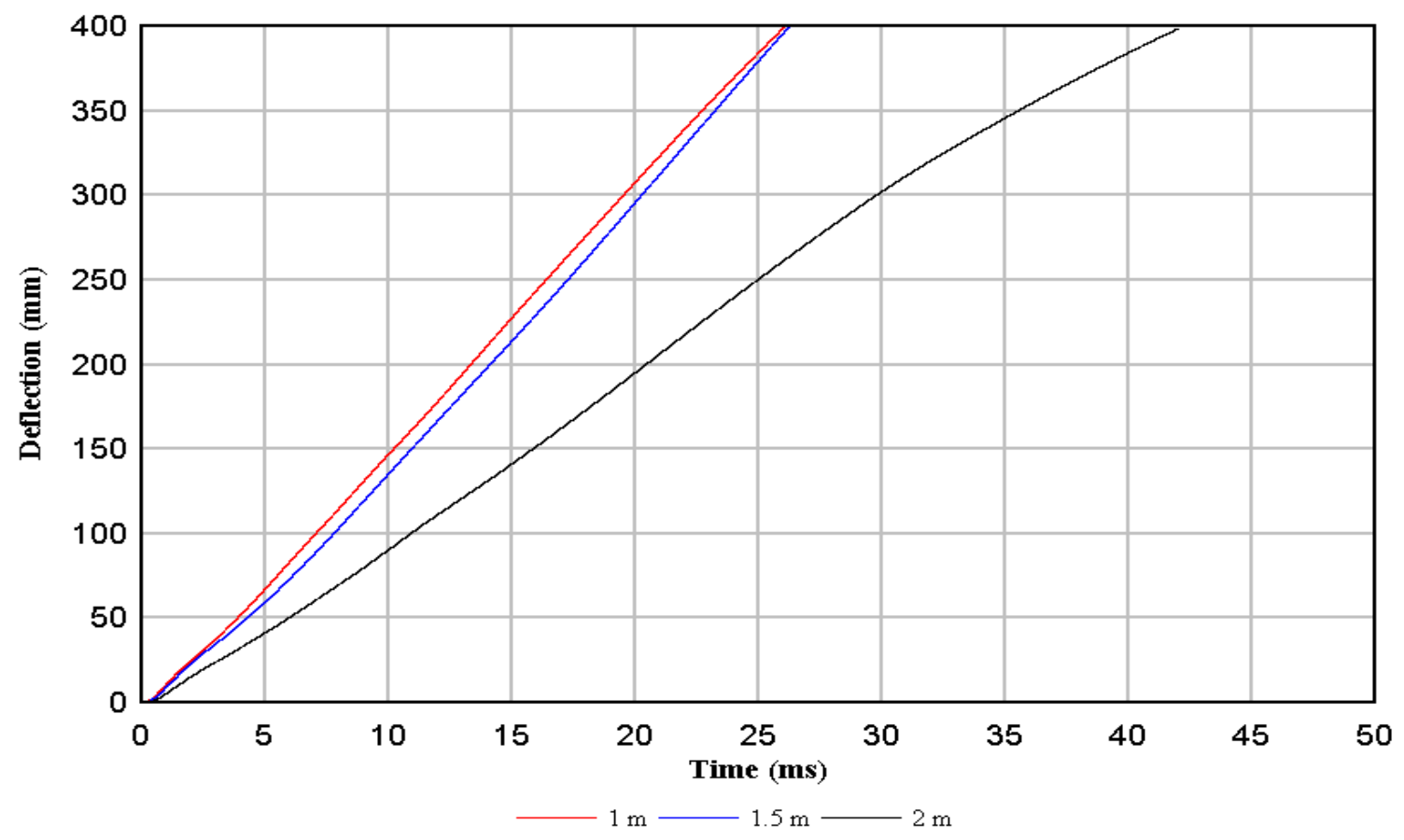

Figure 6-27: Column deflections for $75-\mathrm{mm}$ tie spacing at $\mathrm{Z}=0.25 \mathrm{~m} / \mathrm{kg}^{1 / 3}$ for $150 \mathrm{~kg}$ charge mass

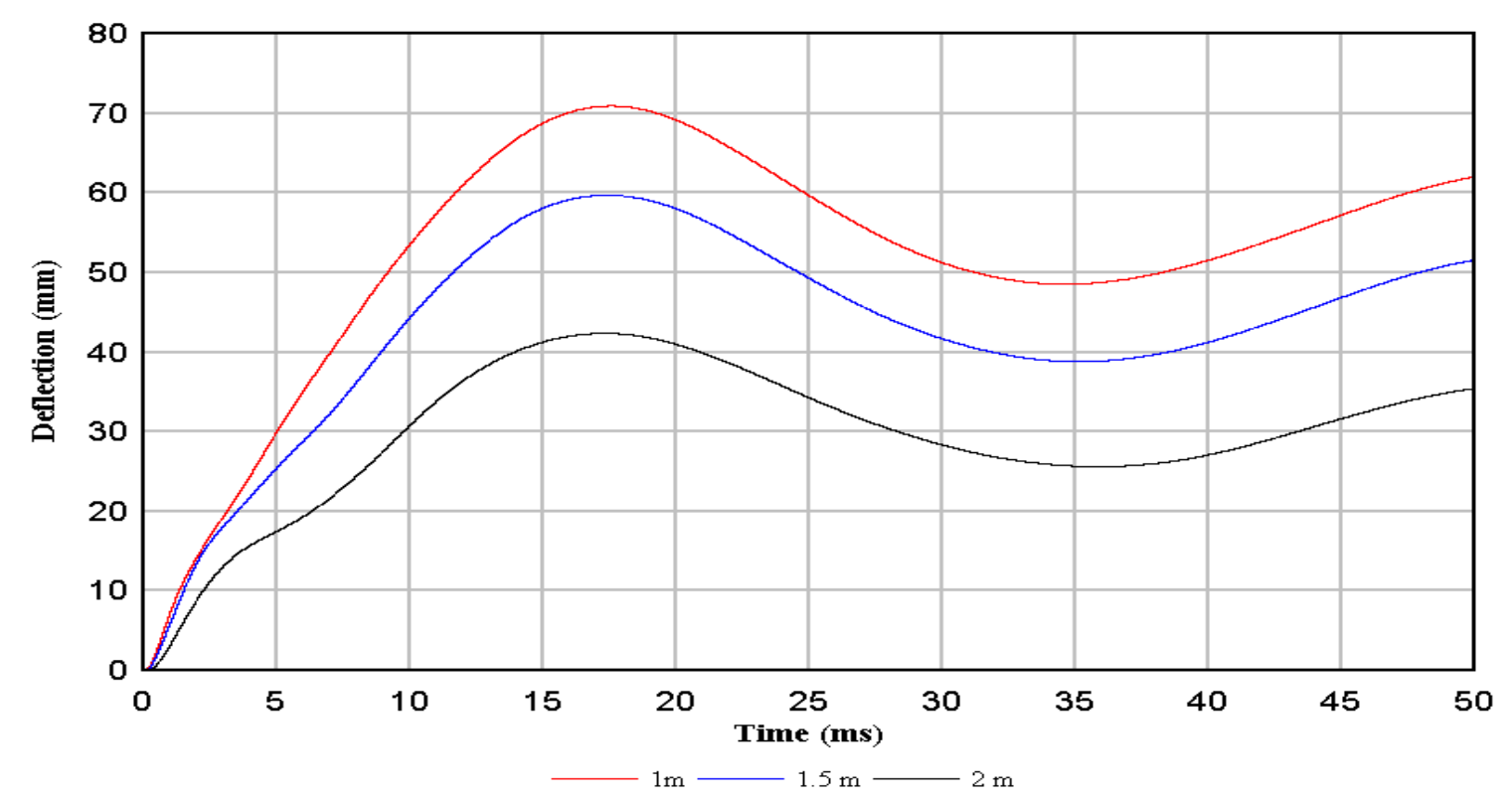

Figure 6-28: Column deflections for $150-\mathrm{mm}$ tie spacing at $\mathrm{Z}=0.25 \mathrm{~m} / \mathrm{kg}^{1 / 3}$ for $75 \mathrm{~kg}$ charge mass 


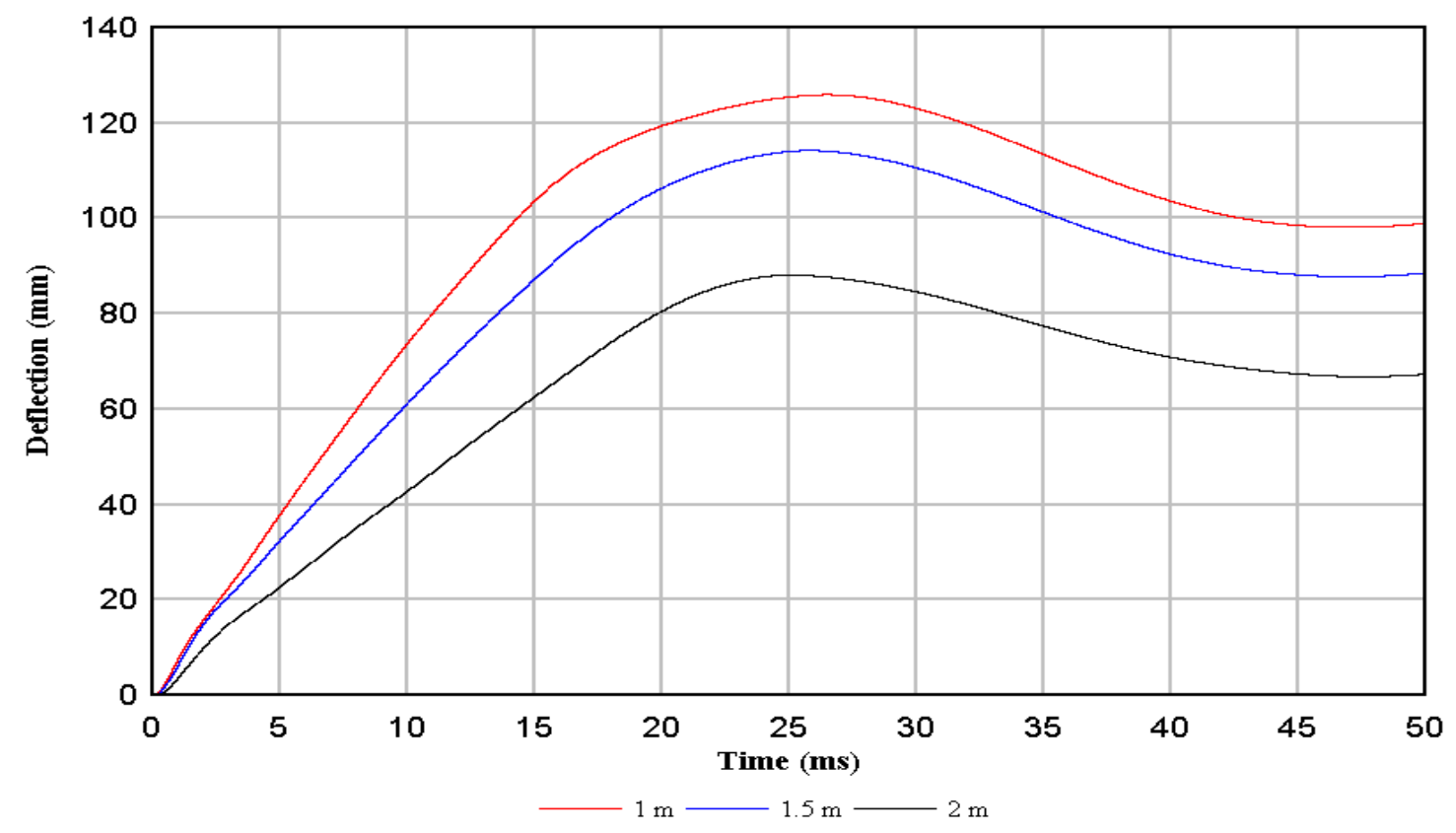

Figure 6-29: Column deflections for $150-\mathrm{mm}$ tie spacing at $Z=0.25 \mathrm{~m} / \mathrm{kg}^{1 / 3}$ for $100 \mathrm{~kg}$ charge mass

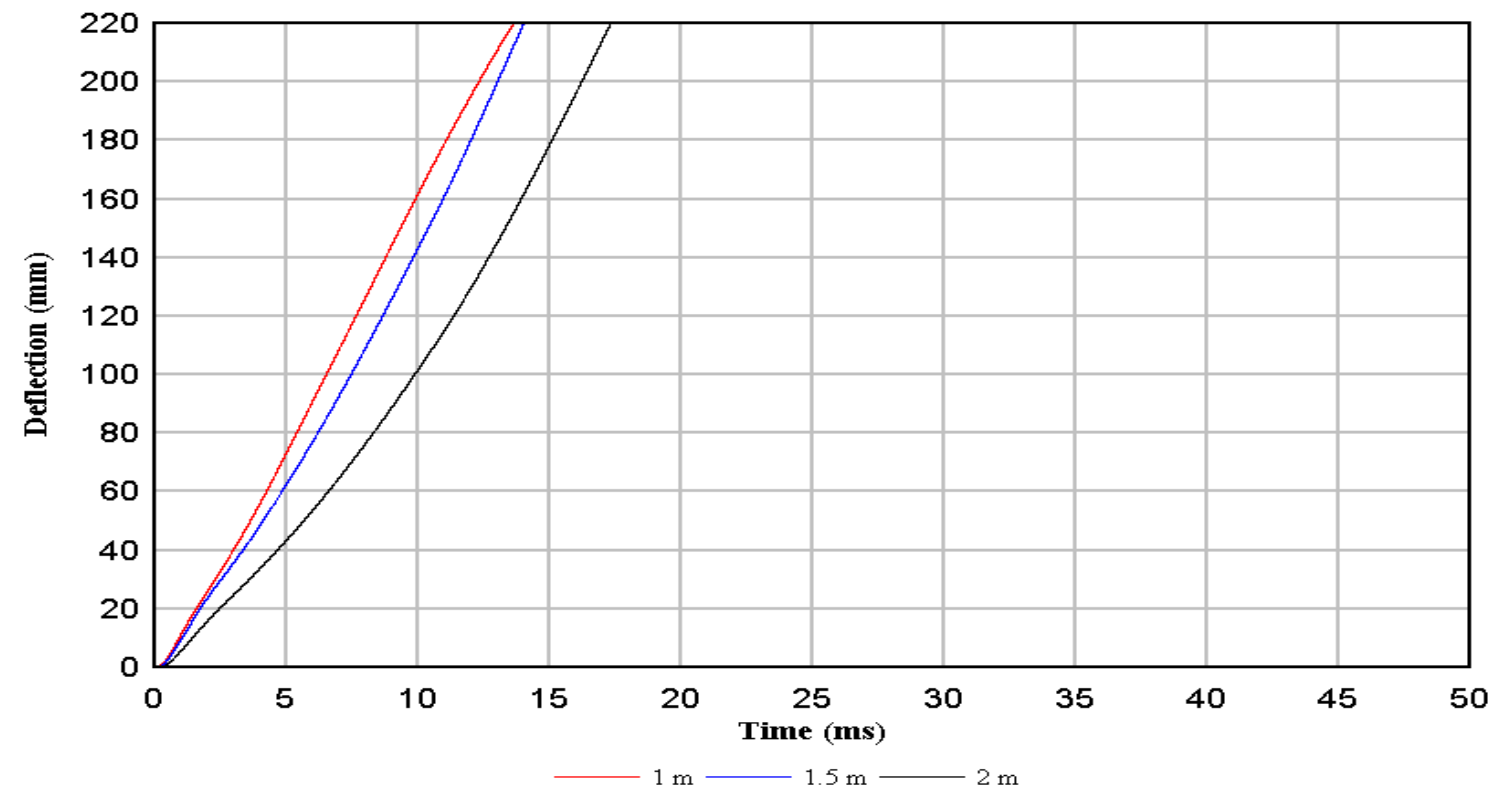

Figure 6-30: Column deflections for $150-\mathrm{mm}$ tie spacing at $\mathrm{Z}=0.25 \mathrm{~m} / \mathrm{kg}^{1 / 3}$ for $150 \mathrm{~kg}$ charge mass 


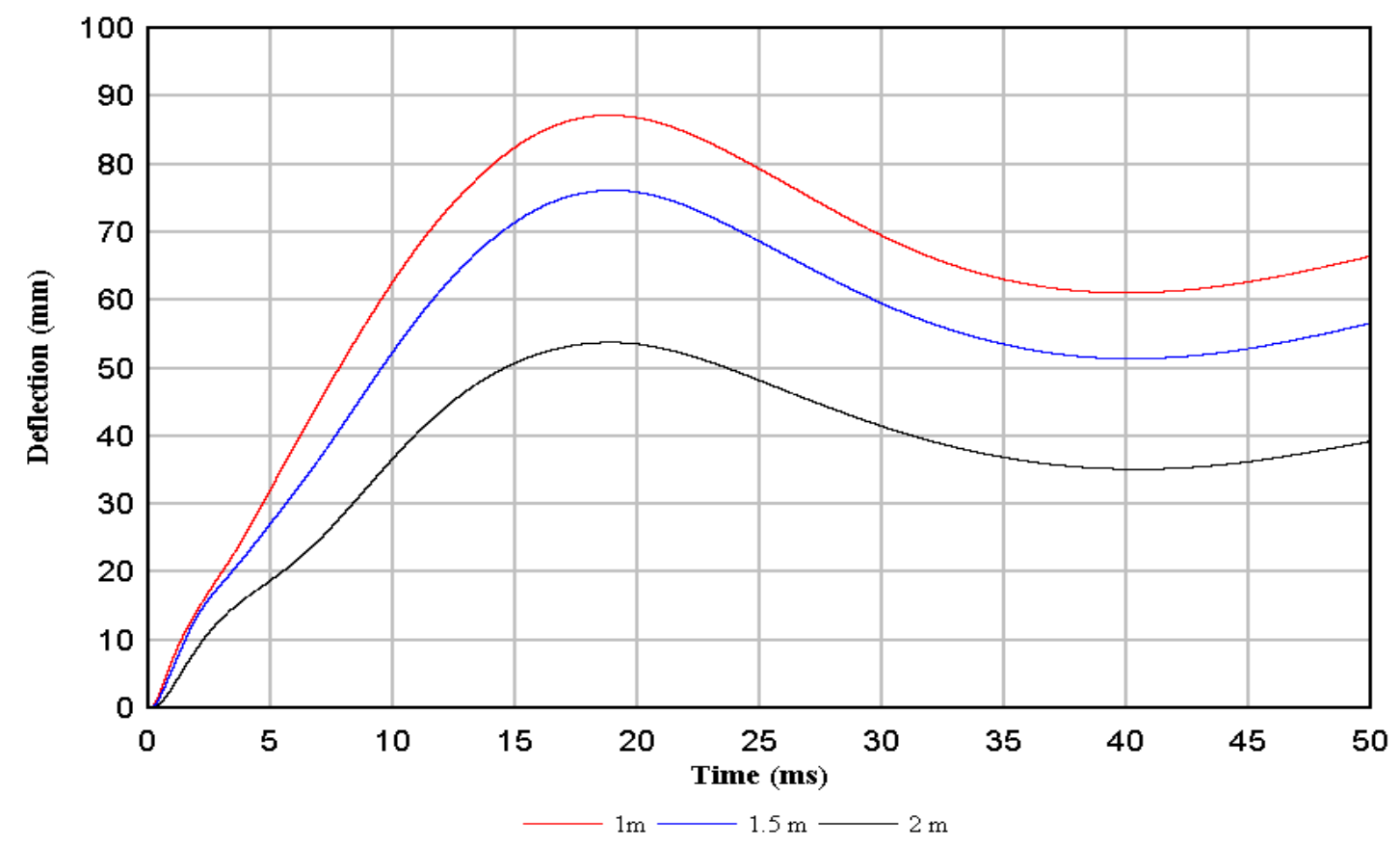

Figure 6-31: Column deflections for 300-mm tie spacing at $Z=0.25 \mathrm{~m} / \mathrm{kg}^{1 / 3}$ for $75 \mathrm{~kg}$ charge mass

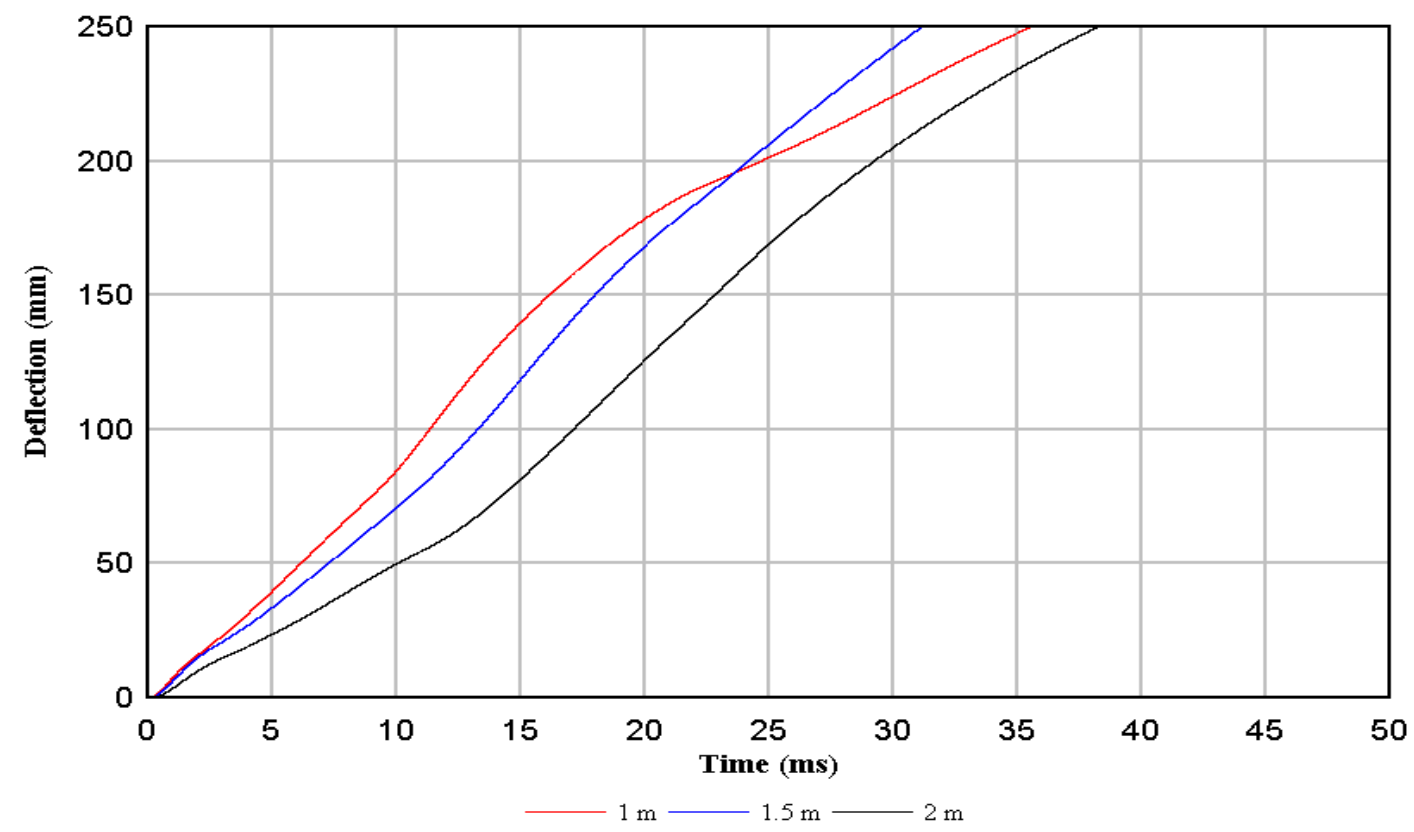

Figure 6-32: Column deflections for 300-mm tie spacing at $Z=0.25 \mathrm{~m} / \mathrm{kg}^{1 / 3}$ for $100 \mathrm{~kg}$ charge mass 


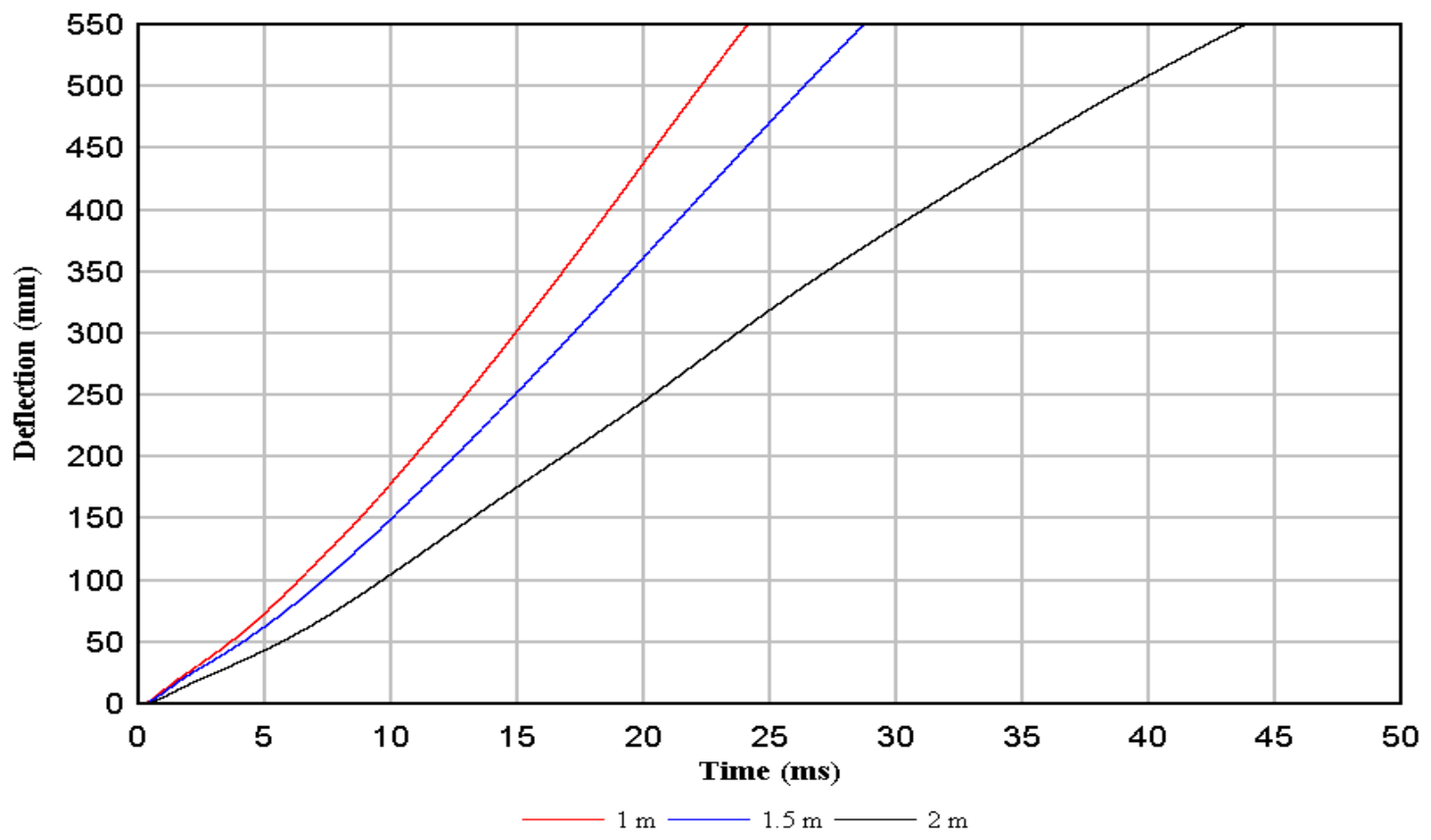

Figure 6-33: Column deflections for $300-\mathrm{mm}$ tie spacing at $Z=0.25 \mathrm{~m} / \mathrm{kg}^{1 / 3}$ for $150 \mathrm{~kg}$ charge mass 